\title{
A functional m 6 A- RNA methylation pathway in the oyster Crassostrea gigas assumes epitranscriptomic regulation of lophotrochozoan development
}

\author{
Le Franc Lorane 1,2, Bernay Benoit ${ }^{3}$, Petton Bruno ${ }^{4}$, Since Marc ${ }^{5}$, Favrel Pascal 1,2, \\ Rivière Guillaume ${ }^{1,2,{ }^{*}}$
}

1 UNICAEN CNRS BOREA Normandie Univ Caen, France

2 Laboratoire Biologie des organismes et Ecosystèmes aquatiques (BOREA) Muséum d'Histoire naturelle CNRS IRD Sorbonne Université, Université de Caen NormandieUniversité des Antilles Caen ,France

3 UNICAEN, ICOREPROTEOGEN Core Facility Caen SF ,France

4 Ifremer, Laboratoire des Sciences de l'Environnement Marin UMR 6539 CNRS/UBO/IRD/Ifremer

Centre Bretagne Normandie Univ Plouzané, France

5 UNICAEN ,Comprehensive Cancer Center F. Baclesse, SF ICORE PRISMM Core Facility Normandie Univ Caen ,France

* Corresponding author : Guillaume Rivière, email address : guillaume.riviere@unicaen.fr

\begin{abstract}
:
N6-methyladenosine (m6A) is a prevalent epitranscriptomic mark in eukaryotic RNA, with crucial roles for mammalian and ecdysozoan development. Indeed, m6A-RNA and the related protein machinery are important for splicing, translation, maternal-to-zygotic transition and cell differentiation. However, to date, the presence of an m6A-RNA pathway remains unknown in more distant animals, questioning the evolution and significance of the epitranscriptomic regulation. Therefore, we investigated the m6A-RNA pathway in the oyster Crassostrea gigas, a lophotrochozoan model whose development was demonstrated under strong epigenetic influence. Using mass spectrometry and dot blot assays, we demonstrated that m6A-RNA is actually present in the oyster and displays variations throughout early oyster development, with the lowest levels at the end of cleavage. In parallel, by in silico analyses, we were able to characterize at the molecular level a complete and conserved putative m6A machinery. The expression levels of the identified putative $\mathrm{m} 6 \mathrm{~A}$ writers, erasers and readers were strongly regulated across oyster development. Finally, RNA pull-down coupled to LC-MS/MS allowed us to prove the actual presence of readers able to bind $\mathrm{m} 6 \mathrm{~A}-\mathrm{RNA}$ and exhibiting specific developmental patterns. Altogether, our results demonstrate the conservation of a complete m6A-RNA pathway in the oyster and strongly suggest its implication in early developmental processes including MZT. This first demonstration and characterization of an epitranscriptomic regulation in a lophotrochozoan model, potentially involved in the embryogenesis, bring new insights into our understanding of developmental epigenetic processes and their evolution.
\end{abstract}


Keywords : development, epitranscriptomics, methylation, oyster, RNA 


\section{Abbreviations}

$27 \quad N^{6}$-methyladenosine $\left(\mathrm{m}^{6} \mathrm{~A}\right)$, Methyltransferase like (METTL), Wilms' tumor 1-associated

28 protein (WTAP), RNA-binding motif 15 (RBM15), Ring finger E3 ubiquitin ligase (HAKAI), Zinc

29 finger $\mathrm{CCCH}$-type containing 13 (ZC3H13), AlkB homologue 5 (ALKBH5), Fat mass and

30 obesity associated protein (FTO), YTH domain family protein (YTHDF), YTH domain

31 containing protein (YTHDC), Heterogeneous nuclear ribonucleoproreins A2 B1

32 (HNRNPA2B1), Proline rich coiled-coil 2a (Prrc2a), Eukaryotic initiation factor 3 (elF3), Sterile

33 sea water (SSW), Oocytes (E), Fertilized oocytes (F E), Two to eight cell embryos (2/8 C),

34 Hours post fertilization (hpf), Morula (M), Blastula (B), Gastrula (G), D larvae (D), solid-phase

35 reversible immobilization (SPRI), TPM (Transcripts Per Million), Gene ontology (GO), oyster

$36 \mathrm{~m}^{6} \mathrm{~A}$-interacting protein ( $\left.\mathrm{Cg}-\mathrm{m}^{6} \mathrm{~A}-\mathrm{BPs}\right)$, S-adenosyl-methionine (SAM), maternal-to-zygotic

37 transition $(\mathrm{MZT})$, acetonitrile $(\mathrm{ACN})$ 


\section{Introduction}

The $N^{6}$-methyladenosine $\left(\mathrm{m}^{6} \mathrm{~A}\right)$ is the prevalent chemical RNA modification in all eukaryotic coding and non-coding RNAs [1]. Messenger RNAs are the most heavily $\mathrm{m}^{6} \mathrm{~A}$ methylated RNAs, with $\mathrm{m}^{6} \mathrm{~A}$ bases lying mostly in their $3^{\prime}$ UTRs, at the vicinity of their stop codon [2-4] and also in 5' UTRs and long internal exons [4,5]. $N^{6}$-methylation of RNA adenosines is responsible for RNA processing and, like DNA methylation or histone modifications, contributes to the regulation of gene expression without changing the DNA or mRNA sequence. Therefore $\mathrm{m}^{6} \mathrm{~A}$ constitutes a new layer of post-transcriptional gene regulation, which is emerging or has been proven critical in various biological processes, and referred to as epitranscriptomic [2].

The dynamics and biological outcomes of $\mathrm{m}^{6} \mathrm{~A}$ levels are the results of the activity of a complex protein machinery comprising writers, erasers and readers. The addition of a methyl group to the $6^{\text {th }}$ nitrogen of RNA adenosines is catalysed by $\mathrm{m}^{6} \mathrm{~A}$ writers with distinct properties. Methyltransferase like 16 (METTL16) is a 'stand-alone' class I methyltransferase that recognizes the UACA*GAGAA consensus sequence (with * indicating the target adenosine) [6]. By contrast, METTL3 transfers methyl groups to adenosines within the RRA* $\mathrm{CH}$ motif [2,3,7]. METTL3 is only active within a tripartite 'core complex' [8] comprising METTL3, METTL14 which enhances the methyltransferase activity supported by the MTA-70 domain of METTL3 $[9,10]$ and the regulator protein Wilms' tumor 1-associated protein (WTAP) $[4,9,11]$. 
ligase (HAKAI) [12,13], zinc finger CCCH-type containing 13 (ZC3H13) [12,14], RNA-binding motif 15 (RBM15) and RBM15B [7,15] which are suspected to intervene in the core complex activity and target specificity. The demethylation of adenosines has been demonstrated to be an active process catalysed by eraser enzymes belonging to the $\mathrm{Fe}(\mathrm{II}) / 2$-oxoglutarate dioxygenase family: AlkB homologue 5 (ALKBH5) [16,17] and the fat mass and obesity associated protein (FTO) $[17,18]$.

A growing number of reader proteins which recognize the $\mathrm{m}^{6} \mathrm{~A}-\mathrm{RNA}$ mark is being described. They may be divided into two classes depending on the presence of a YT521 B Homology (YTH) domain in their primary sequence. The YTH protein family includes YTH domain family protein 1-3 (YTHDF1-3) and YTH domain containing protein 2 (YTHDC2), which are cytosolic $\mathrm{m}^{6} \mathrm{~A}$ readers involved in $\mathrm{m}^{6} \mathrm{~A}-\mathrm{RNA}$ stability and translation [19-22]. The fifth $\mathrm{YTH}$ member is YTHDC1, which is present in the nucleus and controls splicing [23] and nuclear export [24] of $\mathrm{m}^{6} \mathrm{~A}-\mathrm{RNA}$. The second class of readers comprises proteins without YTH domain which are involved in several molecular mechanisms. For example, the heterogeneous nuclear ribonucleoprotein A2 B1 (HNRNPA2B1) is important for miRNA processing [25]. Insulin-like growth factor 2 mRNA binding protein 1-3 (IGF2BP 1-3) [26] and proline-rich coiled-coil 2a (Prrc2a) [27] participate in RNA stability while eukaryotic initiation factor 3 (elF3) guides capindependent translation [5].

The $\mathrm{m}^{6} \mathrm{~A}$ epitranscriptomes underlie important biological functions, most of which being related to developmental processes, including the control of cell differentiation [27-32], maternal to zygotic transition (MZT) [33], sex determination [7,34] and gametogenesis [16,21,35,36]. Such 
110 critical epitransriptomic outcomes are conserved in the animal evolution and were

111 characterized in both vertebrates and ecdysozoans, i.e. mammals and drosophila.

112 However, such conserved biological significance originates in diverse epitranscriptomic 113 mechanisms. Indeed, not all ecdysozoans bear a complete $\mathrm{m}^{6} \mathrm{~A}-\mathrm{RNA}$ machinery, such as $C$. 114 elegans whose genome is devoid of the related protein machinery with the exception of a 115 putative orthologue of METTL16 $[37,38]$. In addition, no $\mathrm{m}^{6} \mathrm{~A}$ eraser has been described to 116 date in non-vertebrate models, and especially ecdysozoans such as the drosophila or $C$. 117 elegans [38-40], where it cannot be excluded that $\mathrm{m}^{6} \mathrm{~A}-\mathrm{RNA}$ methylation could be removed by 118 the activity of characterised $6 \mathrm{~mA}-\mathrm{DNA}$ demethylases $[41,42]$. This situation may illustrate a 119 growing complexity of epitranscriptomic mechanisms during the animal phylogeny and raises 120 fundamental questions about its evolution and its presence in organisms distant from 121 mammals and ecdysozoans. However, to date, no data about a possible epitranscriptomic 122 regulation is available to our knowledge in lophotrochozoans, the understudied sister group of 123 ecdysozoans within protostomes, although representing an important range of metazoan 124 biodiversity.

125 The Pacific oyster Crassostrea gigas (i.e. Magallana gigas) is a bivalve mollusc whose great 126 ecological an economical significance allowed its emergence as a model species within 127 lophotrochozoan organisms. As such, an important amount of genetic, transcriptomic and 128 epigenetic data have been generated in this model. Interestingly, the embryolarval 129 development of $C$. gigas is described to be under the strong epigenetic influence of DNA 130 methylation [43-47] and histone marks [48-50]. Besides, oyster development occurs exposed 131 to external environmental conditions, and in other models the $\mathrm{m}^{6} \mathrm{~A}$ methylation of RNA and/or 


\section{the expression of its machinery can be induced by heat stress, UV exposure or endocrine}

disruptors $[5,51-54]_{2}$ questioning the presence of an $\mathrm{m}^{6} \mathrm{~A}$ pathway in $C$. gigas and its significance in oyster early development.

To investigate this, we measured $\mathrm{m}^{6} \mathrm{~A}$ levels in RNA across the entire embryolarval life of the oyster using mass spectrometry and dot-blot. We also searched the available in silico resources for putative conserved $\mathrm{m}^{6} \mathrm{~A}$-related proteins in $C$. gigas genomic data as well as their cognate expression kinetics using RNAseq assembly analyses. We also performed RNApulldown with a synthetic $\mathrm{m}^{6} \mathrm{~A}-\mathrm{RNA}$ oligonucleotide coupled to liquid chromatography and mass spectrometry (LC-MS/MS) to characterize potential oyster $\mathrm{m}^{6} \mathrm{~A}$-binding proteins. To our knowledge, this study is the first report unravelling epitranscriptomic mechanisms outside vertebrate and ecdyzosoan animal models.

\section{Results:}

$m^{6} A$ is present in oyster RNA, differentially affects distinct RNA populations and displays variations during embryonic life.

Mass spectrometry measurements revealed that $\mathrm{m}^{6} \mathrm{~A}$ is present in oyster RNA, with global $\mathrm{m}^{6} \mathrm{~A} / \mathrm{A}$ levels of ca. $0.3 \%$, a value comparable to what has been found in the human and the fruit fly (Figure 1A). Immunoblot assays indicate that total and polyA+ RNA present variable amounts of $\mathrm{m}^{6} \mathrm{~A}$ during oyster development and that these variations display distinct profiles suggesting specific methylation patterns between RNA populations. Indeed, $N^{6} \mathrm{~A}$-methylation in total RNA is the highest in the early stages (oocytes and fertilized oocytes) then gradually 
154

decreases until the morula stage before gradually increasing again up to the trochophore stage
when it recovers its maximum (Figure 1B). In contrast, $\mathrm{m}^{6} \mathrm{~A}$ levels in polyA+ RNA are hardly detected in early stages but display a peak in the gastrula and trochophore stages (Figure 1C).

157 the fruit fly. bears the Rho SF domain present in the human, but not in the fruit fly orthologue (Figure 2A). C. gigas also presents a putative $\mathrm{m}^{6} \mathrm{~A}-\mathrm{RNA}$ eraser, $\mathrm{ALKBH} 5$, which is present in the human

174 but has not been characterized in drosophila. The oyster ALKBH5 exhibits a 2OG-Fell_Oxy 175 domain suggestive of a presumably conserved catalytic functionality through fe2+-dependent

All the eight $\mathrm{m}^{6} \mathrm{~A}-\mathrm{RNA}$ writers characterized in the human and/or drosophila at the time of the study, namely METTL3, METTL14, WTAP, Virilizer-like, HAKAI, ZC3H13, RBM15/15B and METTL16, were present in the oyster at the gene level. The encoded protein primary sequences all display the specific domains required for enzymatic activity and/or binding. They include MT-A70 and AdoMetMtases SF domains for METTL3, METTL14 and METTL16, respectively, that bear the methyltransferase activity. Oyster WTAP and Virilizer-like orthologues exhibit WTAP and VIR_N domains, respectively, that are required in their human counterparts to bind and activate the catalytic subunit of the $\mathrm{m}^{6} \mathrm{~A}-\mathrm{RNA}$ methyltransferase complex. Oyster Hakai and RBM15/15B present RHHL, RHF-Zn-BS and specific RRM domains, respectively, similar to human and fruit fly orthologues. Besides, the oyster $\mathrm{ZC} 3 \mathrm{H} 13$

$\mathrm{m}^{6} \mathrm{~A}$ machinery is conserved at the molecular level in the oyster.

In silico analyses led to the identification of oyster sequences encoding putative orthologues of $\mathrm{m}^{6} \mathrm{~A}$ writers, erasers and readers that are present in the human and/or in the human and 
176 oxoglutarate oxidation. Of note, no orthologue of the human FTO eraser could be identified in

177 the oyster genomic or transcriptomic databases available to date (Figure 2B).

178 Many $\mathrm{m}^{6} \mathrm{~A}$ reader orthologues have also been found in the oyster, including proteins containing 179 a YTH domain, such as YTHDF, YTHDC1 and YTHDC2. An oyster Prrc2a-like protein 180 produces homology with the human Prrc2a, especially within the $\mathrm{m}^{6} \mathrm{~A}$-binding GRE-rich 181 domain. Oyster readers also include a heterogeneous nuclear ribonucleoprotein-coding gene, 182 hnRNPA2B1 with greater sequence similarity with the drosophila counterpart than with the 183 human orthologue. Similarly, the IGF2BP-coding sequence has also been found in C. gigas 184 (Figure $2 \mathrm{C}$ ). Five oyster sequences display homologies with elF3a which is able to bind $\mathrm{m}^{6} \mathrm{~A}$ 185 RNA [5] but it was not possible to discriminate whether a unique oyster predicted protein was 186 an elF3a orthologue.

187 Overall, these results indicate the conservation of a complete $\mathrm{m}^{6} \mathrm{~A}-\mathrm{RNA}$ machinery in the 188 oyster. The complete list of the identified genes encoding the conserved $\mathrm{m}^{6} \mathrm{~A}$ machinery actors 189 and their isoforms, as well as the related information is given in the supplementary data (Data 190 S1).

192 Oyster putative $\mathbf{m}^{6} \mathbf{A}$ actors display expression level variations across development.

193 RNAseq data analyses showed that all the oyster $\mathrm{m}^{6} \mathrm{~A}$-related genes were expressed during 194 the early life (Figure 3). Their expression level displayed gene-specific profiles, most of them 195 being variable throughout oyster development.

196 The expression of writers belonging to the core methylation complex is weak overall. METTL3 197 and WTAP share similar profiles with little expression increasing up to the gastrulation and 
198

remaining stable afterwards. In contrast METTL14 displays a weak expression level across the embryo larval life. The expression profile of Virilizer-like resembles WTAP, while HAKAI, RBM15/15B and METTL16 seem to have mRNA levels which decrease after cleavage, whereas those of $\mathrm{ZC} 3 \mathrm{H} 13$ transcript variants seem to drop at the D larva stage. Interestingly, METTL16 mRNA levels display an opposite developmental profile when compared to METTL3 expression; with the highest values during cleavage which decrease later on (Figure $3 \mathrm{~A}$ ).

ALKBH5 transcripts are weakly represented within oyster early embryos and the higher TPM values are found in gastrulas. However, maximum levels are observed after metamorphosis in juveniles (Figure 3B).

Regarding $\mathrm{m}^{6} \mathrm{~A}$ putative readers, the expression of $\mathrm{YTH}$ family genes during development showed different patterns. In fact, YTHDF is the most represented YTH-domain bearing actor and YTHDF TPM values are ca. 5-fold higher than all the other oyster YTH readers. YTHDF is strongly expressed at the beginning of development until a peak at the morula stage. Prrc2a is the most represented reader at the mRNA level in oyster embryos, and the sum of the TPM of the two Prrc2a oyster isoforms are at most ca. 20-fold higher than those of YTH family. However, Prrc2a and YTHDF transcript content profiles are similar across oyster development, and also remind of the IGF2BP mRNA levels.

By contrast, the two isoforms of YTHDC1 identified by in silico analysis, YTHDC1.1 and YTHDC1.2, display similar patterns together with YTHDC2, with a maximum representation in gastrulas. The expression of hnRNPA2B1 isoforms has likewise patterns except for a marked drop at the D larvae stage (Figure $3 \mathrm{C}$ ). 


\section{Oyster orthologues of $\mathrm{m}^{6} \mathrm{~A}-\mathrm{RNA}$ interacting proteins bind $\mathrm{m}^{6} \mathrm{~A}$ RNA in vitro.}

221 To determine whether oyster proteins can bind $\mathrm{m}^{6} \mathrm{~A}-\mathrm{RNA}$, we performed RNA-pulldown of

222 cytoplasmic and nuclear embryonic cell extracts using a methylated versus a non-methylated

223 oligonucleotide, followed by LC/MS-MS characterisation and identification of the captured 224 proteins with the Mascot software.

225 In nuclear extracts, we detected 591 proteins able to bind both the methylated and 226 unmethylated oligos. We identified 43 proteins specific to unmethylated RNA while 131

227 proteins specifically bind the $\mathrm{m}^{6} \mathrm{~A}$-methylated oligo. In cytosolic extracts, there were 228 respectively 646,436 and 36 of such proteins, respectively. Regardless of the methylation 229 status, more proteins in the cytoplasmic extracts can bind to the RNA oligonucleotides than in 230 the nuclear extracts (1118 proteins vs. 765 , respectively). However, more nuclear proteins are 231 found exclusively bound to the $\mathrm{m}^{6} \mathrm{~A}$-containing oligo than cytoplasmic proteins (131 vs. 36 , i.e. $23217 \%$ vs. $3 \%$, respectively). In addition, many nuclear and cytoplasmic proteins can bind both 233 the methylated and the non-methylated oligo (591 vs. 646 , i.e. $77 \%$ vs. $58 \%$ ). An important 234 number of proteins in the cytoplasmic extract were found exclusively bound to the non235 methylated oligo, whereas only a limited number of nuclear proteins display such a specificity 236 (436 vs. 43 , i.e. $39 \%$ vs. $6 \%$ ). Among the $167 \mathrm{~m}^{6} \mathrm{~A}$-specific proteins in oyster extracts, only 5 237 were found in both the nuclear and cytoplasmic extracts. These results show that oyster 238 proteins can directly or indirectly bind $m^{6} A-R N A$, and suggest an important 239 compartmentalization of $\mathrm{m}^{6} \mathrm{~A}$-related processes.

240 Among the identified proteins in this assay, four of the putative oyster $\mathrm{m}^{6} \mathrm{~A}$ readers are found, 241 YTHDC1, hnRNPA2B1, IGF2BP and elF3. In the nuclear extracts YTHDC1 is uncovered as 
$242 \mathrm{~m}^{6} \mathrm{~A}$-specific whereas hnRNPA2B1 and IGF2BP were present complexed with both the $\mathrm{m}^{6} \mathrm{~A}$ -

243 and A-oligos. In the cytoplasmic extracts, YTHDC1 and elF3a are $\mathrm{m}^{6} \mathrm{~A}$-specific while

244 hnRNPA2B1, IGF2BP were pulled down by both methylated and unmethylated oligos (Figure 2454 A).

246 These results demonstrate that some proteins in the oyster can specifically bind $\mathrm{m}^{6} \mathrm{~A}-\mathrm{RNA}$ and 247 that the putative $\mathrm{m}^{6} \mathrm{~A}$ reader orthologues in the oyster are conserved at the protein level and 248 are able to interact with $\mathrm{m}^{6} \mathrm{~A}-\mathrm{RNA}$.

The $\mathrm{m}^{6} \mathrm{~A}$-interacting protein-coding genes display clustered expression regulation and functional annotation during oyster development.

252 The mRNA expression level of the genes encoding the 162 oyster $\mathrm{m}^{6} \mathrm{~A}$-interacting protein (Cg$\left.253 \mathrm{~m}^{6} \mathrm{~A}-\mathrm{BPs}\right)$ was examined using RNAseq databases. Most of them display a specific and 254 regulated expression level across oyster developmental stages. However, three main 255 expression clusters could be distinguished according to their developmental mRNA expression 256 level profile. Cluster 1 includes genes that show high expression at the beginning of the embryo 257 life (i.e. cleavage) and strongly decrease after gastrulation; the second cluster contains weakly 258 expressed genes except in the latest examined larval phases, after gastrulation (i.e. 259 Trochophore and D Larvae); cluster 3 groups genes that show an expression peak during 260 gastrulation (Figure 4B).

261 The Gene Ontology annotation of the $\mathrm{Cg}-\mathrm{m}^{6} \mathrm{~A}-\mathrm{BP}$ genes reveal that the distinct clusters are 262 related to distinct functional pathways as indicated by the little - if any - common GO terms 263 between them (Figure 4C). However, the functional pathways of all three gene clusters point 


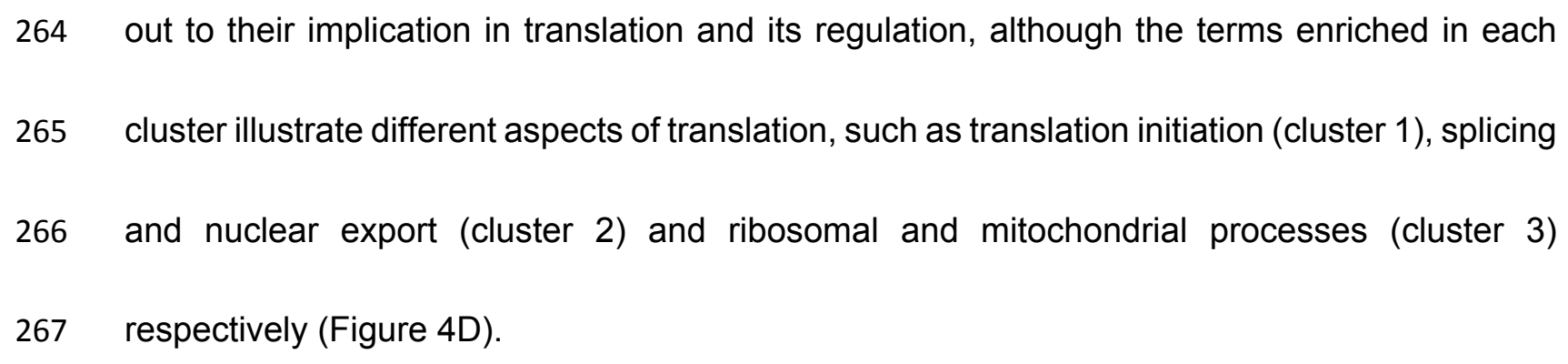

270 This work demonstrates that $\mathrm{m}^{6} \mathrm{~A}-\mathrm{RNA}$ is present and variable during the embryo-larval life of

271 the oyster, and that C. gigas exhibits putative conserved and functional $\mathrm{m}^{6} \mathrm{~A}-\mathrm{RNA}$ writers, 272 eraser and readers. The dynamics of such mark and of its actors strongly suggest a biological 273 significance of the epitranscriptomic pathway in the control of development of a 274 lophotrochozoan species, which has, to date, never been demonstrated to our knowledge.

$275 \quad \mathrm{~m}^{6} \mathrm{~A}-\mathrm{R} N \mathrm{~A}$ levels vary across oyster development.

276 Using mass spectrometry and immunological measurements, we showed that oyster RNA is $277 \mathrm{~m}^{6} \mathrm{~A}$-methylated. The global proportion of $N^{6}$-methyladenosine in RNA in the developing oyster $278(0.28 \%)$ is similar to those observed elsewhere in the animal kingdom, such as in the fruit fly $279(0.24 \%)[34]$ or the human $(0.11-0.23 \%)$ [55] (Figure 1A), despite those values are difficult 280 to compare because they were not measured within the same developmental phase (adult flies 281 and human cell lines vs. oyster embryos). However, the comparable magnitude of $\mathrm{m}^{6} \mathrm{~A}-\mathrm{RNA}$ 282 amounts between taxa, in contrast to DNA methylation [46], may indicate conserved biological 283 significance of epitranscriptomic processes between groups. The amount of $\mathrm{m}^{6} \mathrm{~A}$ in total RNA 284 displays a striking decrease during cleavage and then recovers its maximum levels at the end 285 of the gastrulation (Figure 1B). Therefore, the $\mathrm{m}^{6} \mathrm{~A}$ decrease in total RNA during cleavage, i.e. 
286 before the transcription of the zygotic genome starts, reflects a degradation of maternal $\mathrm{m}^{6} \mathrm{~A}$ -

287 RNAs or their demethylation. However, all RNA populations do not exhibit the same pattern,

288 indeed polyA+ RNAs are $\mathrm{m}^{6} \mathrm{~A}$ methylated only after cleavage. The extent of polyadenylation

289 of oyster maternal messenger RNAs accumulating during vitellogenesis is unknown.

290 Therefore, which maternal RNA population(s) is methylated in oyster oocytes is unclear.

291 Nevertheless, the observation that $\mathrm{m}^{6} \mathrm{~A}-\mathrm{RNA}$ levels are variable and affecting distinct RNA

292 populations across embryonic stages strongly favours an important biological significance of

$293 \mathrm{~m}^{6} \mathrm{~A}-\mathrm{RNA}$ in oyster development. We hypothesize that oyster maternal messenger RNAs are

294 poorly polyadenylated, and that $\mathrm{m}^{6} \mathrm{~A}$, aside polyadenylation, might play a role in the stability of

295 quiescent maternal mRNAs. Alternatively, other maternal RNA populations such as snRNA,

296 miRNA, rRNA or IncRNA might be methylated $[6,15,25,56]$, which become demethylated or

297 degraded up to the morula stage. The later increase in $\mathrm{m}^{6} \mathrm{~A}$ RNA after cleavage could therefore

298 be the result of the methylation of the increasingly transcribed RNAs from the blastula stage,

299 including polyadenylated mRNAs.

300 The $\mathrm{m}^{6} \mathrm{~A}-\mathrm{RNA}$ machinery is conserved in the oyster and regulated during development.

301 The important regulation of $\mathrm{m}^{6} \mathrm{~A}$ levels during oyster development assumes the presence of a

302 related protein machinery. We identified in silico cDNA sequences encoding conserved

303 putatively functional orthologues of $\mathrm{m}^{6} \mathrm{~A}-\mathrm{RNA}$ writers, eraser and readers in the oyster, with

304 great confidence (homologies ranging from ca. 30 to $65 \%$ with their human counterpart, see

305 Data S1). The writers include all the members of the methylation complex (METTL3, METTL14,

306 WTAP, Virilizer-like, Hakai, ZC3H13, RBM15/15B) identified to date in the human and the fruit

307 fly $[7,11,12,14,15,57]$. We also identified an orthologue of the stand-alone METTL16 $\mathrm{m}^{6} \mathrm{~A}$ 
308 methyltransferase. Each orthologue bears the conserved domain(s) demonstrated to be 309 implicated in the catalytic and/or binding activity of their cognate counterpart in other species,

310 such as the MT-A70 domain which transfers methyl groups from the S-adenosyl-methionine 311 (SAM) to the $N^{6}$ nitrogen of RNA adenines [57]. Of the two proteins that can erase RNA 312 methylation, only ALKBH5, which is important for mouse spermatogenesis [16], was identified 313 at the cDNA level in the oyster. Indeed, no C. gigas sequence displayed significant homology 314 with the mammalian FTO protein, whose functional significance remains controversial [17].

315 Most the characterized $\mathrm{m}^{6} \mathrm{~A}-\mathrm{RNA}$ readers are also present at the molecular level in the oyster 316 and are putatively able to bind $\mathrm{m}^{6} \mathrm{~A}$ regarding their primary sequence, such as the YTHDC and 317 YTHDF family members [19,21,23,58], Prrc2A [27], HnRNPA2B1 [25] and IGF2BP [26]. Of 318 note, some of these readers have not been characterized to date in $D$. melanogaster but 319 display strong homologies between humans and oysters. In mammals, elF3a has important 320 functional outcomes in cap-independent translational stress response [5]. However, it was not 321 possible to ascribe a single oyster sequence as a unique elF3a orthologue (Data S1), although 322 its presence was demonstrated by RNA pull down (see below) (see Data S2). Altogether, in silico results show the conservation of a complete $\mathrm{m}^{6} \mathrm{~A}-\mathrm{RNA}$ machinery in the oyster. To date 324 to our knowledge, this is the first demonstration in a lophotrochozoan organism of an 325 epitranscriptomic pathway. Its presence suggests its ancestral origin, and questions its 326 biological significance in oyster development.

327 To investigate this, we analysed the expression level of the $\mathrm{m}^{6} \mathrm{~A}$ machinery genes using RNA328 seq data. Our results indicate that the core methylation complex (METTL3, METTL14 and 329 WTAP) would not be active during cleavage because of the absence of METTL3 and little 
WTAP expression. METTL16 catalyses the downregulation of SAM methyl donor availability in mammals [59]. If METTL16 function is conserved in the oyster as suggested by the high sequence homology, the peak in METTL16 expression, together with the weak expression of the core complex in $2 / 8$ cell embryos is consistent with an absence of $m^{6} A-R N A$ up to the blastula stage. Then, the core complex would likely be active as soon as the end of cleavage (i.e. since the blastula stage), in line with the increase in $\mathrm{m}^{6} \mathrm{~A}$ levels observed at the same time. The correlation between the increasing METTL3 expression and $\mathrm{m}^{6} \mathrm{~A}-\mathrm{RNA}$ levels after cleavage strongly favours the conservation of the methyltransferase activity of the oyster MTA70 domain. Interpreting the regulation of the $\mathrm{m}^{6} \mathrm{~A}$ activity by the other methyltransferase complex members (i.e. Virilizer-like, HAKAI, ZC3H13 and RBM15/15B) is difficult because how - or even if - oyster orthologues act within the complex is not known. Nevertheless, their specific expression profiles may reflect their implication in the regulation of distinct biological contexts. There might be little functional significance of active $m^{6} \mathrm{~A}-\mathrm{RNA}$ erasure during oyster development, consistent with the normal embryonic phenotype of ALKBH5 knockdown mice [16]. Overall, the $\mathrm{m}^{6} \mathrm{~A}$ readers display distinct developmental expression patterns. While YTHDF and Prrc2a peak during cleavage, YTHDC1, YTHDC2, IGF2BP and hnRNPA2B1 mRNA levels gradually increase up to the gastrulation and remain mostly highly expressed afterwards (except for hnRNPA2B1 and IGF2BP). These profiles evoke the mediation of distinct biological functions depending on the reader and the developmental phases. Therefore, we hypothesized that YTHDF and Prrc2a might participate in the blastulean transition in the oyster. Indeed, in the zebrafish, a YTHDF reader triggers the maternal-tozygotic transition through the decay of the maternal $\mathrm{m}^{6} \mathrm{~A}$ RNAs during cleavage [33]. The role 
352 in the axon myelination and specification of mouse oligodendrocytes [27] is unlikely conserved

353 for Prrc2a because the oyster orthologue is expressed before the neurogenesis is detected in

354 trochophore stages [60]. Alternatively, the early expression of Prrc2a suggests that it might

355 rather compete with YTHDF for $\mathrm{m}^{6} \mathrm{~A}-\mathrm{RNA}$ targets [27], thereby possibly acting in oyster MZT,

356 bringing new perspectives into this process which remains poorly understood in

357 lophotrochozoans. In mammals $\mathrm{m}^{6} \mathrm{~A}$ is implicated in the embryonic cell fate $[30,31]$ notably via

358 the regulation of cell differentiation by YTHDC2 [32] or hnRNPA2B1 [29]. In the oyster,

359 YTHDC1, YTHDC2, IGF2BP and hnRNPA2B1 have their maximum expression during

360 gastrulation correlated to the second $\mathrm{m}^{6} \mathrm{~A}$ peak, suggesting similar implications.

$361 \quad$ Putative oyster $\mathrm{m}^{6} \mathrm{~A}$ readers actually bind $\mathrm{m}^{6} \mathrm{~A}-\mathrm{RNA}$ in vitro.

362 To better approach the developmental processes involving $\mathrm{m}^{6} \mathrm{~A}$ in the oyster, we characterized

363 the proteins that can interact with $m^{6} \mathrm{~A}-\mathrm{RNA}$ using a methylated-RNA-pulldown / mass

364 spectrometry assay. We identified 162 proteins able to specifically bind the $\mathrm{m}^{6} \mathrm{~A}-\mathrm{RNA}$ oligo in

365 embryonic cell extracts, demonstrating the actual presence of genuine $\mathrm{m}^{6} \mathrm{~A}$-readers in the

366 oyster. Most (ca. $75 \%$ ) of these proteins were found in nuclear extracts and only 5 were found

367 in both the cytoplasmic and nuclear fractions, showing an important compartmentalization of

368 the epitranscriptomic pathway. Regarding the little number of $\mathrm{m}^{6} \mathrm{~A}$ readers in other animals,

369 and because the assay conditions do not discriminate between direct and indirect interactions,

370 we hypothesize that most these proteins indirectly bind $\mathrm{m}^{6} \mathrm{~A}$ via a limited number of 'scaffold'

$371 \mathrm{~m}^{6} \mathrm{~A}$ readers. Such authentic readers that only bind the $\mathrm{m}^{6} \mathrm{~A}-\mathrm{RNA}$ oligo in our assay likely

372 include YTHDC1 and elF3a, which have been demonstrated to directly bind $\mathrm{m}^{6} \mathrm{~A}$ in other

373 species, demonstrating the conservation of the $\mathrm{m}^{6} \mathrm{~A}$-binding capacity and specificity of the $\mathrm{YTH}$ 
374 domain in the oyster. Besides, YTHDC1 is found in both cell fractions, suggesting its

375 implication in the trafficking of $\mathrm{m}^{6} \mathrm{~A}-\mathrm{RNA}$ across the nuclear envelope [24], and reinforcing the

376 hypothesis that YTH proteins could participate in oyster MZT and cell differentiation. The

377 presence of the oyster eiF3a in the cytoplasm is consistent with a conserved role in $\mathrm{m}^{6} \mathrm{~A}$ -

378 mediated translation processes, such as cap-independent translation [5].

379 Possible functions of $\mathrm{m}^{6} \mathrm{~A}-\mathrm{RNA}$ in oyster development.

380 We investigated the expression level and the functional annotation of the 162 genes encoding

381 the $\mathrm{m}^{6} \mathrm{~A}$-interacting proteins across oyster early life. These genes can be clustered into three

382 successive expression phases corresponding to three distinct functional pathways, which are

383 independent albeit all mostly related to translation regulation. The cluster 1 is mostly expressed

384 during the cleavage and the associated GO terms are related to the initiation of translation,

385 consistent with maternal RNA consumption before MZT is complete and the zygotic genome

386 becomes fully activated. The genes within cluster 3 show an expression peak during

387 gastrulation. Their ontology terms evoke ribosomal and mitochondrial processes, the latter

388 being required for energy supply and signalling integration during gastrulation [61-64]. The

389 cluster 2 contains genes that peak after gastrulation and which are related to splicing and

390 nuclear export. Such functional annotations are in line with a fine regulation of transcript variant

391 translation within the distinct cell lineages in the three cell layers of the late embryos.

393 Taken together, our findings bring to light a possible implication of $\mathrm{m}^{6} \mathrm{~A}$ in oyster development.

394 First, during cleavage the decrease of $\mathrm{m}^{6} \mathrm{~A}-\mathrm{RNA}$, the weak expression of methyltransferase

395 complex genes, the maximum of YTHDF gene expression and the expression of $\mathrm{Cg}$-m ${ }^{6} \mathrm{~A}-\mathrm{BPs}$ 
396 related to the initiation of the translation strongly suggest the implication of $\mathrm{m}^{6} \mathrm{~A}$ in $\mathrm{MZT}$ in $\mathrm{C}$.

397 gigas. Second, the increasing $\mathrm{m}^{6} \mathrm{~A}$ level during gastrula stage is correlated to the increase of 398 methyltransferase complex gene expression. In addition, the increased RNA level of readers 399 putatively related to cell differentiation and the peak of gene expression of $\mathrm{Cg}$-m ${ }^{6} \mathrm{~A}-\mathrm{BPs}$ 400 associated to ribosomal and mitochondrial processes, support the hypothesize of a $\mathrm{m}^{6} \mathrm{~A}$ 401 implication in gastrulation. Finally, the highest $\mathrm{m}^{6} \mathrm{~A}$ level at the trochophore stage, the gene 402 expression of the methyltransferase complex and of readers associated to cell differentiation, 403 as well as high RNA level of $\mathrm{Cg}-\mathrm{m}^{6} \mathrm{~A}-\mathrm{BPs}$ related to splicing and nuclear export is correlated 404 with the fine cell differentiation taking place at this stage. However, inferring the biological 405 significance of $\mathrm{m}^{6} \mathrm{~A}$ in development from the indirect and incomplete functional annotation of 406 the oyster genome is only limited. Characterization of the precise targets of $\mathrm{m}^{6} \mathrm{~A}$ and how their 407 individual methylation is regulated across development, for example using high throughput 408 sequencing of precipitated $\mathrm{m}^{6} \mathrm{~A}-\mathrm{RNA}$ (MeRIP-seq), could be extremely relevant to better 409 understand this issue. In addition, despite sequence conservation and binding ability of oyster 410 actor orthologues strongly suggest functional conservation, future dedicated studies such as

411 biochemical inhibition or gene inactivation could help demonstrate their genuine biological

412 function. Besides, there seems to be an inverse correlation between $\mathrm{m}^{6} \mathrm{~A}-\mathrm{RNA}$ and $5 \mathrm{mC}$-DNA

413 levels during the considered oyster developmental window [46]. This may suggest an interplay 414 between epigenetic and epitranscriptomic marks, possibly reflecting competition for methyl415 donor availability [59] or a link by histone epigenetic pathways [65,66].

416 Regarding the potential influence of the environment on $\mathrm{m}^{6} \mathrm{~A}$ and the accumulation of RNA in 417 oocytes, we are at present investigating our hypothesis that $\mathrm{m}^{6} \mathrm{~A}$ may convey intergenerational 
418

419

420

10

epitranscriptomic inheritance of maternal life traits in the oyster. On an evolutionary

perspective, the presence of a putatively fully conserved epitranscriptomic pathway in the

oyster suggests that it was already present in the bilaterian common ancestor thereby in favour

421 of an important biological significance. Why Drosophila and Caenorhabditis seem to have lost

422 specific $\mathrm{m}^{6} \mathrm{~A}-\mathrm{RNA}$ erasers could be related to a sub-functionalization of the DMAD [41] and

423 NMAD-1 [42] N6-methyladenine DNA demethylase activity broadened towards RNA. However,

424 more work in required to better understand the evo-devo implications of our results.

To conclude, in this work we report the discovery and characterisation of a putatively complete epitranscriptomic pathway in a lophotrochozoan organism, the oyster Crassostrea gigas. This pathway includes the $\mathrm{m}^{6} \mathrm{~A}$ mark in RNA and the actors of all the aspects of its regulation 429 (writers, eraser, readers) which are conserved at the molecular level and putatively functional. 430 We show that $\mathrm{m}^{6} \mathrm{~A}$ levels are variable across oyster development and that $\mathrm{m}^{6} \mathrm{~A}$ differentially 431 affects distinct RNA populations. Expression levels of the related enzymatic machinery is 432 consistent with the observed $\mathrm{m}^{6} \mathrm{~A}$ level variations. We demonstrate the $\mathrm{m}^{6} \mathrm{~A}$ binding capacity 433 and specificity of putative oyster $\mathrm{m}^{6} \mathrm{~A}$ readers in the cytoplasm and nucleus of embryolarval 434 cells. These readers mediate distinct putative biological outcomes depending on the 435 development stage considered. From these results we hypothesize that early decay of 436 maternal $\mathrm{m}^{6} \mathrm{~A}$ RNA participates in maternal-to-zygotic transition during cleavage and that later 437 de novo zygotic m6A methylation contributes to gastrulation and cell differentiation. This first 438 characterisation of an $\mathrm{m}^{6} \mathrm{~A}$-epitranscriptomic pathway in a lophotrochozoan organism, together 439 with its potential implication in development, opens new perspectives on the evolution of 
$\mid \begin{aligned} & 440 \\ & 441\end{aligned}$

epigenetic mechanisms and on the potential epitranscriptomic inheritance of environmentally-

induced life traits.

\section{Methods:}

445 Animals:

446 Broodstock oysters [67] and oyster embryos [46] were obtained at the IFREMER marine

447 facilities (Argenton, France) as previously described. Briefly, gametes of mature broodstock 448 oysters were obtained by stripping the gonads and filtering the recovered material on a $60 \mu \mathrm{m}$ 449 mesh to remove large debris. Oocytes were collected as the remaining fraction on a $20 \mu \mathrm{m}$ 450 mesh and spermatozoa as the passing fraction on a $20 \mu \mathrm{m}$ mesh. Oocytes were pre-incubated 451 in $5 \mathrm{~L}$ of UV-treated and $1 \mu \mathrm{m}$ filtered sterile sea water (SSW) at $21^{\circ} \mathrm{C}$ until germinal vesicle 452 breakdown. Fertilization was triggered by the addition of ca.10 spermatozoids per oocyte. After 453 the expulsion of the second polar body was assessed by light microscopy, embryos were 454 transferred in $150 \mathrm{~L}$ tanks of oxygenated SSW at $21{ }^{\circ} \mathrm{C}$. The development stages were 455 determined by light microscopy observation. The stages collected were oocytes (E, 456 immediately before sperm addition), fertilized oocytes ( $F$ E, immediately before transfer to 457 150L tanks), two to eight cell embryos (2/8 C, ca. 1.5 hours post fertilization (hpf)), morula (M, 458 ca. 4 hpf), blastula (B, ca. 6 hpf), gastrula (G, ca. 10 hpf), trochophore (T, ca 16 hpf) and D 459 larvae (D, ca. 24 hpf). For each development stage, 3 million embryos were collected as the 460 remaining fraction on a $20 \mu \mathrm{m}$ mesh and centrifuged at $123 \mathrm{~g}$ for $5 \mathrm{~min}$ at room temperature. 
461 Supernatant was discarded and samples of 1 million embryos were then snap-frozen in liquid 462 nitrogen directly of after resuspension in Tri-Reagent (Sigma-Aldrich, St Louis, MO, USA) (1 $463 \mathrm{~mL} / 10^{6}$ embryos) and stored at $-80^{\circ} \mathrm{C}$. Three distinct experiments were realized (February to 464 May 2019) using the gametes of 126 to 140 broodstock animals, respectively.

465

466

467

468

469

470

471

472

473

474

475

476

477

478

479

480

481

482

\section{RNA extraction:}

- total RNA extraction

RNA was extracted using phenol-chloroform followed by affinity chromatography as previously described [68]. Briefly, embryos were ground in Tri-Reagent (Sigma-Aldrich) and RNA was purified using affinity chromatography (Nucleospin RNA II kit, Macherey-Nagel, Duren, Germany). Potential contaminating DNA was removed by digestion with rDNase (MachereyNagel) according to the manufacturer's instructions for 15 min at $37^{\circ} \mathrm{C}$ then RNA was purified using Beckman Coulter's solid-phase reversible immobilization (SPRI) paramagnetic beads (AgencourtAMPure XP, Beckman Coulter, Brea, CA, USA) according to the manufacturer's instructions. Briefly, paramagnetic beads and RNAs were mixed slowly and incubated 5 min at room temperature followed by 2 min on a magnetic rack. Cleared supernatant was removed, and beads were washed three times with $70 \%$ ethanol. After 4 min of drying at room temperature, RNAs were mixed slowly with RNase free water and incubated for $1 \mathrm{~min}$ at room temperature on the magnetic rack. Eluted total RNA was stored at $-80^{\circ} \mathrm{C}$.

\section{- PolyA RNA enrichment}

Poly-A RNA was extracted from total RNA by oligo-dT affinity chromatography (NucleoTrap mRNA kit, Macherey-Nagel) according to the manufacturer's instructions. Briefly, up to $130 \mu \mathrm{g}$ 
483 of total RNAs were mixed with oligo-dT latex beads and incubated for 5 min at $68{ }^{\circ} \mathrm{C}$ then 10 $484 \mathrm{~min}$ at room temperature. After centrifugation (2,000 $\mathrm{g}$ then $11,000 \mathrm{~g})$, the pellets were washed 485 three times on the microfilter and dried by centrifugation at $11,000 \mathrm{~g}$ for $1 \mathrm{~min}$. Finally, polyA+ 486 RNA was incubated with RNAse-free water for $7 \mathrm{~min}$ at $68{ }^{\circ} \mathrm{C}$ then centrifuged at $11,000 \mathrm{~g}$ for $4871 \mathrm{~min}$. Eluted polyA+ RNA was stored at $-80{ }^{\circ} \mathrm{C}$ until needed.

488 Total and polyA-enriched RNA purity and concentrations were assayed by spectrophotometry 489 (Nanodrop, Thermo Scientific, Waltham, MA, USA).

490

491

$\mathrm{m}^{6} \mathrm{~A}$ quantification by LC-MS/MS:

492

- RNA hydrolysis

493 To generate nucleosides for quantification against standard curves, $5 \mu \mathrm{g}$ of total RNA were 494 denatured for $10 \mathrm{~min}$ at $70{ }^{\circ} \mathrm{C}$ followed by $10 \mathrm{~min}$ on ice, and hydrolyzed with $100 \mathrm{U}$ Nuclease $495 \mathrm{~S} 1(50 \mathrm{U} / \mu \mathrm{L}$, Promega, Madison, WI, USA) in Nuclease S1 buffer (Promega) in a final reaction 496 volume of $25 \mu \mathrm{L}$ for $2 \mathrm{~h}$ at $37^{\circ} \mathrm{C}$ under gentle shaking. Samples were then incubated with 497 alkaline phosphatase buffer (Promega) for $5 \mathrm{~min}$ at room temperature, before $10 \mathrm{U}$ alkaline 498 phosphatase (Promega) were added and incubated further for $2 \mathrm{~h}$ at $37^{\circ} \mathrm{C}$ under gentle 499 shaking. Ten extra units of alkaline phosphatase were added after 1 hour of incubation to 500 complete the reaction. Finally, samples were centrifuged at $13,000 \mathrm{rpm}$ for $10 \mathrm{~min}$ at $4{ }^{\circ} \mathrm{C}$ and 501 the supernatant containing digested total RNA was collected and kept at $-20{ }^{\circ} \mathrm{C}$ before 502 quantification.

$503-\mathrm{m}^{6} \mathrm{~A}$ quantification: 
504 The apparatus was composed of a NexeraX² UHPLC system coupled with LCMS8030 Plus

505 (Shimadzu, Kyoto, Japan) mass spectrometer using an electrospray interface in positive mode.

506 The column $(1.7 \mu \mathrm{m}, 100 \times 3 \mathrm{~mm})$ was a HILIC Aquity ${ }^{\circledR}$ Amide (Waters, Millford, MA, USA)

507 maintained at $35{ }^{\circ} \mathrm{C}$. The injection volume and run-to-run time were $3 \mu \mathrm{L}$ and $10 \mathrm{~min}$,

508 respectively. The flow rate was set to $1 \mathrm{~mL} / \mathrm{min}$. Mobile phase was initially composed of a

509 mixture of ammonium formate solution $(10 \mathrm{mM})$ containing $0.2 \%(\mathrm{v} / \mathrm{v})$ formic acid and $95 \%$

510 acetonitrile (ACN) and it was maintained for $1 \mathrm{~min}$. Then, a linear gradient was applied to reach

$51183 \%$ ACN for 6 min. The composition returned to the initial conditions and the column was

512 equilibrated for $3 \mathrm{~min}$.

513 The mass spectrometer was running in the Multiple Reaction Monitoring (MRM) acquisition

514 mode. LabSolutions 5.86 SP1 software was used to process the data. The desolvatation

515 temperature was $230{ }^{\circ} \mathrm{C}$, source temperature was $400{ }^{\circ} \mathrm{C}$ and nitrogen flows were $2.5 \mathrm{~L} / \mathrm{min}$

516 for the cone and $15 \mathrm{~L} / \mathrm{min}$ for the desolvatation. The capillary voltage was $+4.5 \mathrm{kV}$. For each

517 compound, two transitions were monitored from the fragmentation of the $[\mathrm{M}+\mathrm{H}]^{+}$ion. The first

518 transition (A in Table S1) was used for quantification and the second one (B in Table S1) for

519 confirmation of the compound according to European Commission Decision 2002/657/EC

520 (Table S1).

521 Blank plasma samples were analysed to check specificity. Calibrators were prepared using

522 diluted solutions of $A$ (Toronto Research Chemical, Toronto, Canada) and $\mathrm{m}^{6} \mathrm{~A}$ (Carbosynth,

523 Berkshire, UK) in water at 1, 2, 5, 10, 20 50, $100 \mathrm{ng} / \mathrm{mL}$ The calibration curves were drawn by

524 plotting the ratio of the peak area of $\mathrm{A}$ and $\mathrm{m}^{6} \mathrm{~A}$. For both nucleosides, a quadratic regression

525 with $1 / C$ weighting resulted in standard curves with $R^{2}>0.998$ and more than $75 \%$ of standards 
526 with back-calculated concentrations within $15 \%$ of their nominal values as recommended for 527 by the European medicines agency for bioanalytical methods [69]. The limits of quantifications 528 for both compounds were considered as the lowest concentrations of the calibration curve.

$529 \mathrm{~m}^{6} \mathrm{~A} / \mathrm{A}$ ratios were calculated for each single sample using the determined concentrations. 530 Final results are the average of three technical replicates.

$\mathrm{m}^{6} \mathrm{~A}$ quantification by immunoblotting:

533 Immunological quantification of $\mathrm{m}^{6} \mathrm{~A}$ was performed by dot-blot using total and polyA+ RNAs.

534 Dogfish total RNA (Dr. A. Gautier, personal communication) and a synthetic unmethylated 535 RNA oligo (Eurogentec, Liege, Belgium) were used as positive and negative controls, 536 respectively. RNA samples were denatured for $15 \mathrm{~min}$ at $55{ }^{\circ} \mathrm{C}$ with gentle shaking in 537 denaturing solution (2.2 M formaldehyde, $50 \%$ formamide, 0.5X MOPS, DEPC water) followed 538 by 2 min on ice. Blotting was performed on a vacuum manifold as follows: a nylon membrane 539 (Amersham Hybond-N+, GE Healthcare life Sciences, Chicago, IL, USA) was pre-hydrated in 540 DEPC water for $5 \mathrm{~min}$, then each well was washed twice with 10X SSC (Sigma-Aldrich) before 541 RNA was spotted onto the membrane and incubated for $15 \mathrm{~min}$ at room temperature. Then, 542 vacuum aspiration was applied and each well was washed twice with 10X SSC. After heat 543 crosslinking for $2 \mathrm{~h}$ at $70^{\circ} \mathrm{C}$, the membrane was rehydrated with DEPC water for $5 \mathrm{~min}$, washed 544 with PBS then PBST (PBS, $0.1 \%$ Tween-20) for 5 min each and blocked with two 5 min 545 incubations with blocking buffer (PBS, $0.1 \%$ Tween-20, $10 \%$ dry milk, $1 \%$ BSA) at room 546 temperature. The blocked membrane was incubated overnight at $4{ }^{\circ} \mathrm{C}$ under gentle shaking 547 with the anti-m ${ }^{6}$ A primary antibody (Total RNA: Millipore (Burlington, MA, USA) ABE572, 1 : 
5481,000 dilution in blocking buffer; polyA+ RNA: Diagenode (Liege, Belgium) C15200082, 1:500

549 dilution in blocking buffer) followed by four washes of PBST for $5 \mathrm{~min}$. The secondary antibody

550 (Total RNA: Dako (Santa Clara, CA, USA) P0447 goat anti-mouse HRP antibody, $1: 10,000$

551 dilution; polyA+ RNA: Invitrogen (Carlsbad, CA, USA) A21202 donkey anti-mouse Alexa 488,

$5521: 250$ dilution) was diluted in PBST supplemented with $5 \%$ dry milk and added onto the

553 membrane for $1 \mathrm{~h} 30$ (total RNA) or $1 \mathrm{~h}$ (polyA+ RNA) at room temperature under gentle

554 shaking. Membranes were extensively washed in PBST (at least 4 washes of 5 min for total

$555 \mathrm{RNA}$ and 5 min then $1 \mathrm{~h}$ for polyA+ RNA) then total and polyA+ RNA immunoblots were

556 visualized using chemiluminescence (ECL kit, Promega) or fluorescence scanning at 480-530

$557 \mathrm{~nm}$ (Pro Xpress, Perkin-Elmer, Waltham, MA, USA), respectively. The amount of $\mathrm{m}^{6} \mathrm{~A}$ was

558 inferred from dot intensity measurements using ImageJ (v.1.49). Signal intensities were

559 determined as 'integrated densities as a percentage of the total' which corresponds to the area

560 under the curve of the signal of each dot after membrane background and negative control

561 signal subtraction.

562

563 In silico analyses:

564 All protein and RNA sequences of the $\mathrm{m}^{6} \mathrm{~A}$ machinery of Homo sapiens and Drosophila 565 melanogaster (Data S1) were recovered by their published designation (i.e., 'METTL3' or 566 'YTHDF' etc.) and their identified protein sequence (ie. RefSeq accession number NP...) 567 collected from $\mathrm{NCBI}$ and used as query sequences to search for putative homologue 568 sequences in Crassostrea gigas databases. The presence of oyster orthologue RNA and 569 protein sequences were investigated by reciprocal 
570 BLAST(https://blast.ncbi.nlm.nih.gov/Blast.cgi) on the Crassostrea gigas GigaTON [70] and

$571 \mathrm{NCBI}$ databases and results were compared between the two oyster databases. Domain

572 prediction was performed with CD-search software

573 (https://www.ncbi.nlm.nih.gov/Structure/cdd/wrpsb.cgi) with default settings on protein

574 sequences of Homo sapiens, Drosophila melanogaster and Crassostrea gigas. The GRE-rich

575 domain identified in vertebrate Prrc2a sequence [27] was performed with ProtParam

576 (https://web.expasy.org/cgi-bin/protparam/protparam).

577

578 Protein machinery mRNA expression analyses:

579 The transcriptome data of the different development stages are available on the GigaTON

580 database $[70,71]$. The correspondence between development stages in our study, and the

581 GigaTON database were assessed using light microscopy based on the morphological

582 description by Zhang et al., 2012 [71] (Table S2). Expression data was expressed in TPM

583 (Transcripts Per Million) [72] to provide a normalized comparison of gene expression between

584 all samples. The actual presence of some transcripts that display unclear or chimeric

585 sequences within available oyster databases was assessed using RT-PCR (Data S1).

586

587 Protein $\mathrm{m}^{6} \mathrm{~A}$ RNA pull down:

588 - Protein extraction and RNA affinity chromatography

589 Protein extraction and RNA affinity chromatography were performed as described previously

590 [27] with some modifications as follows. Equal amounts (1 million individuals) of each

591 developmental stage (oocyte to D larvae) were pooled together then homogenized in 3.5 
592 volumes of buffer $\mathrm{A}(10 \mathrm{mM} \mathrm{KCl}, 1.5 \mathrm{mM} \mathrm{MgCl}$, $10 \mathrm{mM}$ HEPES, pH 7.9, DEPC water, 1X 593 Protease inhibitor cocktail, DTT $0.5 \mathrm{mM}$ ) by extensive pipetting (ca. 30 times) and incubated 59410 min at $4{ }^{\circ} \mathrm{C}$. Embryos were ground with 10 slow $23 \mathrm{G}$-needle syringe strokes and centrifuged 595 at 2,000 rpm for $10 \mathrm{~min}$ at $4{ }^{\circ} \mathrm{C}$. The supernatant was diluted in 0.11 volume of buffer $\mathrm{B}(1.4 \mathrm{M}$ $596 \mathrm{KCl}, 0.03 \mathrm{M} \mathrm{MgCl}$, HEPES 0.3 M, pH 7.9, DEPC water), centrifuged at 10,000 $\mathrm{g}$ for $1 \mathrm{~h}$ at 4 $597{ }^{\circ} \mathrm{C}$ and the supernatant containing cytosolic proteins was stored at $-80{ }^{\circ} \mathrm{C}$. The pellet of the 598 first centrifugation, containing nuclei, was re-suspended in two volumes of buffer $\mathrm{C}(0.42 \mathrm{M}$ $599 \mathrm{NaCl}, 1.5 \mathrm{mM} \mathrm{MgCl}$, $0.2 \mathrm{mM}$ EDTA, $25 \%$ glycerol, 20 mM HEPES, pH 7.9, 0.5 mM PMSF, $600 \quad 0.5 \mathrm{mM}$ DTT, water DEPC). Nuclei were then lysed with a $23 \mathrm{G}$ needle (10 vigorous syringe 601 strokes) followed by centrifugation at $30,000 \mathrm{rpm}$ for $30 \mathrm{~min}$ at $4{ }^{\circ} \mathrm{C}$ and the supernatant 602 containing nuclear proteins was stored at $-80^{\circ} \mathrm{C}$.

603 To identify putative proteins able to bind $\mathrm{m}^{6} \mathrm{~A}-\mathrm{RNA}$, the cytosolic and nuclear fractions were 604 submitted to affinity chromatography using 5'-biotin-labelled RNA oligonucleotides either 605 bearing $N^{6}$-methylated adenosines or not. The methylated adenosines were designed to lie 606 within RRACH motifs, according to the conserved methylated consensus sequence in other 607 organisms $[2,3,7,33,73]$ (oligo-m6A: 5'Biotin-AGAAAAGACAACCAACGAGRR-m6 ${ }^{6}$ 608 CWCAUCAU-3', oligo-A: 5'Biotin-AGAAAAGACAACCAACGAGRRACWCAUCAU-3', R = A or $609 \mathrm{G}, \mathrm{W}=\mathrm{A}$ or U, Eurogentec).

610 For RNA pull down, streptavidin-conjugated magnetic beads (Dynabeads Myone Streptavidin, 611 Invitrogen) were pre-blocked with $0.2 \mathrm{mg} / \mathrm{mL}$ tRNA (Sigma-Aldrich) and $0.2 \mathrm{mg} / \mathrm{mL}$ BSA for 1 $612 \mathrm{~h}$ at $4{ }^{\circ} \mathrm{C}$ under gentle rotation followed by three washes with $0.1 \mathrm{M} \mathrm{NaCl}$. To avoid the 613 identification of non-target proteins, cytosolic and nuclear protein extracts were cleared with 
614 pre-blocked magnetic beads in binding buffer $(50 \mathrm{mM}$ Tris- $\mathrm{HCl}, 250 \mathrm{mM} \mathrm{NaCl}, 0.4 \mathrm{mM}$ EDTA,

$6150.1 \% \mathrm{NP}-40$, DEPC water, $1 \mathrm{mM} \mathrm{DTT}, 0.4 \mathrm{U} / \mu \mathrm{L}$ RNAsin) for $1 \mathrm{~h}$ at $4{ }^{\circ} \mathrm{C}$ under gentle rotation.

616 After incubation on magnetic rack, the supernatants containing putative target proteins were

617 collected and mixed with pre-blocked magnetic beads and oligo-m ${ }^{6} \mathrm{~A}$ or oligo-A for $2 \mathrm{~h}$ at $4{ }^{\circ} \mathrm{C}$

618 under gentle rotation. The beads binding putative target proteins were washed three times with

619 binding buffer and diluted in $50 \mathrm{mM}$ ammonium bicarbonate.

620

- Identification of $\mathrm{m}^{6} \mathrm{~A}-$ binding proteins by LC-MS/MS:

621 Protein samples were first reduced, alkylated and digested with trypsin then desalted and

622 concentrated onto a $\mu \mathrm{C} 18$ Omix (Agilent, Santa Clara, CA, USA) before analysis.

623 The chromatography step was performed on a NanoElute (Bruker Daltonics, Billerica, MA,

624 USA) ultra-high pressure nano flow chromatography system. Peptides were concentrated onto

625 a C18 pepmap $100(5 \mathrm{~mm} \times 300 \mu \mathrm{m}$ i.d.) precolumn (Thermo Scientific) and separated at 50

$626{ }^{\circ} \mathrm{C}$ onto a reversed phase Reprosil column $(25 \mathrm{~cm} \times 75 \mu \mathrm{m}$ i.d. $)$ packed with $1.6 \mu \mathrm{m}$ C18 coated

627 porous silica beads (Ionopticks, Parkville, Victoria, Australia). Mobile phases consisted of 0.1

$628 \%$ formic acid, $99.9 \%$ water (v/v) (A) and $0.1 \%$ formic acid in $99.9 \%$ ACN (v/v) (B). The

629 nanoflow rate was set at $400 \mathrm{~nL} / \mathrm{min}$, and the gradient profile was as follows: from 2 to $15 \% \mathrm{~B}$

630 within 60 min, followed by an increase to $25 \%$ B within 30 min and further to $37 \%$ within 10

631 min, followed by a washing step at $95 \%$ B and re-equilibration.

632 MS experiments were carried out on an TIMS-TOF pro mass spectrometer (Bruker Daltonics)

633 with a modified nano-electrospray ion source (CaptiveSpray, Bruker Daltonics). The system

634 was calibrated each week and mass precision was better than $1 \mathrm{ppm}$. A 1600 spray voltage

635 with a capillary temperature of $180{ }^{\circ} \mathrm{C}$ was typically employed for ionizing. MS spectra were 
636 acquired in the positive mode in the mass range from 100 to $1700 \mathrm{~m} / \mathrm{z}$. In the experiments 637 described here, the mass spectrometer was operated in PASEF mode with exclusion of single 638 charged peptides. A number of 10 PASEF MS/MS scans was performed during 1.16 seconds 639 from charge range 2-5.

640 The fragmentation pattern was used to determine the sequence of the peptide. Database 641 searching was performed using the Mascot 2.6.1 program (Matrix Science) with a Crassostrea 642 gigas Uniprot database (including 25,982 entries). The variable modifications allowed were as 643 follows: C-Carbamidomethyl, K-acetylation, methionine oxidation, and Deamidation (NQ). The 644 'Trypsin' parameter was set to 'Semispecific'. Mass accuracy was set to $30 \mathrm{ppm}$ and $0.05 \mathrm{Da}$ 645 for MS and MS/MS mode respectively. Mascot data were then transferred to Proline validation 646 software (http://www.profiproteomics.fr/proline/) for data filtering according to a significance 647 threshold of $<0.05$ and the elimination of protein redundancy on the basis of proteins being 648 evidenced by the same set or a subset of peptides (Data S2).

- Gene ontology analysis:

650 The mRNA sequences of the characterized $m^{6} A$-binding proteins were identified using tBlastn 651 [74-76] against the GigaTON database [70] with default settings. Gene ontology (GO) 652 analyses were carried out with the GO annotations obtained from GigaTON database gene 653 universe [70]. GO term-enrichment tests were performed using the goseq (V1.22.0) R package 654 [77] with p-values calculated by the Wallenius method and filtered using REVIGO [78]. GO 655 terms with a p-value $<0.05$ were considered significantly enriched (Data S3). 
658 Results are given as the mean \pm SD of three independent experiments unless otherwise stated.

659 They were analysed using one-way ANOVA or Kruskall-wallis tests when required, depending

660 on the normality of result distribution. The normality was tested using the Shapiro-Wilk's test

661 and homoscedasticity of variances with Bartlett's tests. Statistics and graphics were computed 662

with Prism v.6 (Graphpad), R (v.3.6.1) and RStudio (v.1.0.153) softwares. The R packages

663 eulerr [79] and Complexheatmap [80] were used for production of specific figures.

664

665

666

Author contribution

667 Experiment design: GR, LLF.

668 Benchwork and bioinformatics: LLF, GR, BB, BP, MS.

669 Data analysis: LLF, GR, BB, MS.

670 Manuscript writing and editing: LLF, GR, PF, BB, MS, BP.

671

672 Acknowledgements

673 The authors would like to acknowledge PRISMM core facility collaborators R. Delepée and S.

674 Lagadu for their expertise in $\mathrm{m}^{6} \mathrm{~A} / \mathrm{A}$ UHPLC-MS/MS quantification. We also thank J. Pontin for

675 technical assistance and J. Le Grand for help with sampling.

676

677 Funding sources and disclosure of conflicts of interest 
678 This work was supported by the French National program CNRS EC2CO (Ecosphère 679 Continentale et Côtière 'HERITAGe' to G. Rivière) and the council of the Normandy Region 680 (RIN ECUME to P. Favrel). The authors declare they have no conflict of interest.

681 
682

683

684

685

686

687

688

689

690

691

692

693

694

695

696

697

698

699

700

701

702

703

704

705

706

707

708

709

710

711

712

713

714

715

716

717

718

719

720

721

722

723

724

725

726

\section{References:}

1 Saletore Y, Meyer K, Korlach J, Vilfan ID, Jaffrey S \& Mason CE (2012) The birth of the Epitranscriptome: deciphering the function of RNA modifications. Genome Biol. 13, 175.

2 Meyer KD, Saletore Y, Zumbo P, Elemento O, Mason CE \& Jaffrey SR (2012) Comprehensive analysis of mRNA methylation reveals enrichment in 3' UTRs and near stop codons. Cell 149, 1635-1646.

3 Dominissini D, Moshitch-moshkovitz S, Schwartz S, Salmon-Divon M, Ungar L, Osenberg S, Cesarkas K, Jacob-hirsch J, Amariglio N, Kupiee M, Sorek R \& Rechavi G (2012) Topology of the human and mouse $m 6$ A RNAmethylomes revealed bym6A-seq. Nature 485, 201-206.

4 Ke S, Alemu EA, Mertens C, Gantman EC, Fak JJ, Mele A, Haripal B, Zucker-Scharff I, Moore MJ, Park CY, Vågbø CB, Kusśnierczyk A, Klungland A, Darnell JE, Darnell RB, Kuśnierczyk A, Klungland A, Darnell JE, Darnell RB, Kusśnierczyk A, Klungland A, Darnell JE \& Darnell RB (2015) A majority of $m 6$ A residues are in the last exons, allowing the potential for 3' UTR regulation. Genes Dev. 29, 2037-2053.

5 Meyer KD, Patil DP, Zhou J, Zinoviev A, Skabkin MA, Elemento O, Pestova T V., Qian SB \& Jaffrey SR (2015) 5' UTR m6A Promotes Cap-Independent Translation. Cell 163, 999-1010.

6 Pendleton KE, Chen B, Liu K, Hunter O V., Xie Y, Tu BP \& Conrad NK (2017) The U6 snRNA m6A Methyltransferase METTL16 Regulates SAM Synthetase Intron Retention. Cell 169, 824-835.e14.

7 Lence T, Akhtar J, Bayer M, Schmid K, Spindler L, Ho CH, Kreim N, Andrade-Navarro MA, Poeck B, Helm M \& Roignant JY (2016) M6A modulates neuronal functions and sex determination in Drosophila. Nature 540, 242-247.

8 Bokar JA, Shambaugh ME, Polayes D, Matera AG \& Rottman FM (1997) Purification and cDNA cloning of the AdoMet-binding subunit of the human mRNA (N6-adenosine)methyltransferase. RNA 3, 1233-47.

9 Liu J, Yue Y, Han D, Wang X, Fu YY, Zhang L, Jia G, Yu M, Lu Z, Deng X, Dai Q, Chen W \& He C (2013) A METTL3-METTL14 complex mediates mammalian nuclear RNA N6adenosine methylation. Nat. Chem. Biol. 10, 93-95.

10 Wang X, Feng J, Xue Y, Guan Z, Zhang D, Liu Z, Gong Z, Wang Q, Huang J, Tang C, Zou T \& Yin P (2016) Structural basis of N6-adenosine methylation by the METTL3METTL14 complex. Nature 534, 575-578.

11 Ping X-LL, Sun B-FF, Wang L, Xiao W, Yang X, Wang W-JJ, Adhikari S, Shi Y, Lv Y, Chen Y-SS, Zhao X, Li A, Yang YGYY-G, Dahal U, Lou X-MM, Liu X, Huang J, Yuan WPP, Zhu X-FF, Cheng T, Zhao Y-LL, Wang X, Danielsen JMRR, Liu F \& Yang YGYY-G (2014) Mammalian WTAP is a regulatory subunit of the RNA N6-methyladenosine methyltransferase. Cell Res. 24, 177-189.

12 Yue Y, Liu J, Cui X, Cao J, Luo G, Zhang Z, Cheng T, Gao M, Shu X, Ma H, Wang F, Wang X, Shen B, Wang Y, Feng X, He C \& Liu J (2018) VIRMA mediates preferential m6A mRNA methylation in 3'UTR and near stop codon and associates with alternative polyadenylation. Cell Discov. 4, 10.

13 Růžička K, Zhang M, Campilho A, Bodi Z, Kashif M, Saleh M, Eeckhout D, El-Showk S, Li H, Zhong S, Jaeger G De, Mongan NP, Hejátko J, Helariutta Y \& Fray RG (2017) Identification of factors required for m6A mRNA methylation in Arabidopsis reveals a 
role for the conserved E3 ubiquitin ligase HAKAI. New Phytol. 215, 157-172.

14 Knuckles P, Lence T, Haussmann IU, Jacob D, Kreim N, Carl SH, Masiello I, Hares T, Villaseñor R, Hess D, Andrade-Navarro MA, Biggiogera M, Helm M, Soller M, Bühler M \& Roignant J-YY (2018) Zc3h13/Flacc is required for adenosine methylation by bridging the mRNA-binding factor Rbm15/Spenito to the $\mathrm{m} 6 \mathrm{~A}$ machinery component Wtap/FI(2)d. Genes Dev. 32, 1-15.

15 Patil DP, Chen CK, Pickering BF, Chow A, Jackson C, Guttman M \& Jaffrey SR (2016) m6A RNA methylation promotes XIST-mediated transcriptional repression. Nature $\mathbf{5 3 7}$, 369-373.

16 Zheng G, Dahl JA, Niu Y, Fedorcsak P, Huang CM, Li CJ, Vågbø CB, Shi Y, Wang WL, Song SH, Lu Z, Bosmans RPG, Dai Q, Hao YJ, Yang X, Zhao WM, Tong WM, Wang XJ, Bogdan F, Furu K, Fu Y, Jia G, Zhao X, Liu J, Krokan HE, Klungland A, Yang YG \& He C (2013) ALKBH5 Is a Mammalian RNA Demethylase that Impacts RNA Metabolism and Mouse Fertility. Mol. Cell 49, 18-29.

17 Mauer J, Luo X, Blanjoie A, Jiao X, Grozhik A V, Patil DP, Linder B, Pickering BF, Vasseur J-J, Chen Q, Gross SS, Elemento O, Debart F, Kiledjian M \& Jaffrey SR (2017) Reversible methylation of m6Am in the $5^{\prime}$ cap controls mRNA stability. Nature 541, 371375.

18 Jia G, Fu Y, Zhao X, Dai Q, Zheng G, Yang YGYY-GGYY-G, Yi C, Lindahl T, Pan T, Yang YGYY-GGYY-G \& He C (2011) N6-Methyladenosine in nuclear RNA is a major substrate of the obesity-associated FTO. Nat. Chem. Biol. 7, 885-887.

19 Wang X, Lu Z, Gomez A, Hon GC, Yue Y, Han D, Fu Y, Parisien M, Dai Q, Jia G, Ren B, Pan T, He C, Zhike L, Gomez A, Hon GC, Yue Y, Han D, Fu Y, Ärisien M, Dai Q, Jia G, Ren B, Pan T \& He C (2014) N6-methyladenosine-dependent regulation of messenger RNA stability. Nature 505, 117-120.

20 Wang X, Zhao BS, Roundtree IA, Lu Z, Han D, Ma H, Weng X, Chen K, Shi H \& He C (2015) N6-methyladenosine modulates messenger RNA translation efficiency. Cell 161, 1388-1399.

21 Hsu PJ, Zhu Y, Ma H, Guo Y, Shi X, Liu Y, Qi M, Lu Z, Shi H, Wang J, Cheng Y, Luo G, Dai Q, Liu M, Guo X, Sha J, Shen B \& He C (2017) Ythdc2 is an N6-methyladenosine binding protein that regulates mammalian spermatogenesis. Cell Res. 27, 1115-1127.

22 Shi H, Wang X, Lu Z, Zhao BS, Ma H, Hsu PJ, Liu C \& He C (2017) YTHDF3 facilitates translation and decay of N 6-methyladenosine-modified RNA. Cell Res. 27, 315-328.

23 Xiao W, Adhikari S, Dahal U, Chen Y-S, Hao Y-J, Sun B-F, Sun H-Y, Li A, Ping X-L, Lai W-Y, Wang XX-J, Ma H-L, Huang C-M, Yang YY-G, Huang N, Jiang G-B, Wang H-L, Zhou Q, Wang XX-J, Zhao Y-L \& Yang YY-G (2016) Nuclear $m 6$ A Reader YTHDC1 Regulates mRNA Splicing. Mol. Cell 61, 507-519.

24 Roundtree IA, Luo G-ZZ, Zhang Z, Wang X, Zhou T, Cui Y, Sha J, Huang X, Guerrero L, Xie P, He E, Shen B \& He C (2017) YTHDC1 mediates nuclear export of N6methyladenosine methylated mRNAs. Elife 6, 1-28.

25 Alarcón CR, Goodarzi H, Lee H, Liu X, Tavazoie SFSSF \& Tavazoie SFSSF (2015) HNRNPA2B1 Is a Mediator of m6A-Dependent Nuclear RNA Processing Events. Cell 162, 1299-1308.

26 Huang $H$, Weng $H$, Sun W, Qin X, Shi H, Wu H, Zhao BS, Mesquita A, Liu C, Yuan CL, Hu YC, Hüttelmaier S, Skibbe JR, Su R, Deng X, Dong L, Sun M, Li C, Nachtergaele S, 
Wang Y, Hu C, Ferchen K, Greis KD, Jiang X, Wei M, Qu L, Guan JL, He C, Yang J \& Chen J (2018) Recognition of RNA N6-methyladenosine by IGF2BP proteins enhances mRNA stability and translation. Nat. Cell Biol. 20, 285-295.

27 Wu R, Li A, Sun B, Sun J-GG, Zhang J, Zhang T, Chen Y, Xiao Y, Gao Y, Zhang Q, Ma J, Yang X, Liao Y, Lai W-YY, Qi X, Wang S, Shu Y, Wang H-LL, Wang F, Yang Y-GG \& Yuan Z (2018) A novel m6A reader Prrc2a controls oligodendroglial specification and myelination. Cell Res. 29, 23-41.

28 Bertero A, Brown S, Madrigal P, Osnato A, Ortmann D, Yiangou L, Kadiwala J, Hubner NC, De Los Mozos IR, Sadee C, Lenaerts A-SS, Nakanoh S, Grandy R, Farnell E, Ule J, Stunnenberg HG, Mendjan S, Vallier L, Sadée C, Lenaerts A-SS, Nakanoh S, Grandy R, Farnell E, Ule J, Stunnenberg HG, Mendjan S \& Vallier L (2018) The SMAD2/3 interactome reveals that TGF $\beta$ controls $\mathrm{m} 6 \mathrm{~A}$ mRNA methylation in pluripotency. Nature 555, 256-259.

29 Kwon J, Jo YJ, Namgoong S \& Kim NH (2019) Functional roles of hnRNPA2/B1 regulated by METTL3 in mammalian embryonic development. Sci. Rep. 9, 8640.

30 Geula S, Moshitch-Moshkovitz S, Dominissini D, Mansour AAF, Kol N, Salmon-Divon M, Hershkovitz V, Peer E, Mor N, Manor YS, Ben-Haim MS, Eyal E, Yunger S, Pinto Y, Jaitin DA, Viukov S, Rais Y, Krupalnik V, Chomsky E, Zerbib M, Maza I, Rechavi Y, Massarwa R, Hanna S, Amit I, Levanon EY, Amariglio N, Stern-Ginossar N, Novershtern N, Rechavi G \& Hanna JH (2015) m6A mRNA methylation facilitates resolution of naïve pluripotency toward differentiation. Science (80-. ). 347, 1002-1006.

31 Batista PJ, Molinie B, Wang J, Qu K, Zhang J, Li L, Bouley DM, Lujan E, Haddad B, Daneshvar K, Carter AC, Flynn RA, Zhou C, Lim KS, Dedon P, Wernig M, Mullen AC, Xing Y, Giallourakis CC, Chang HY, Howard Y, Batista PJ, Molinie B, Wang J, Qu K, Zhang J, Li L, Bouley DM, Dedon P, Wernig M, Mullen AC, Xing Y, Giallourakis CC \& Chang HY (2014) M ${ }^{6}$ A RNA modification controls cell fate transition in mammalian embryonic stem cells. Cell Stem Cell 15, 707-719.

32 Wojtas MN, Pandey RR, Mendel M, Homolka D, Sachidanandam R \& Pillai RS (2017) Regulation of m6A Transcripts by the $3^{\prime} \rightarrow 5^{\prime}$ RNA Helicase YTHDC2 Is Essential for a Successful Meiotic Program in the Mammalian Germline. Mol. Cell 68, 374-387.e12.

33 Zhao BS, Wang X, Beadell A V., Lu Z, Shi H, Kuuspalu A, Ho RK \& He C (2017) M6Adependent maternal mRNA clearance facilitates zebrafish maternal-to-zygotic transition. Nature 542, 475-478.

34 Kan L, Grozhik A V., Vedanayagam J, Patil DP, Pang N, Lim K-S, Huang Y-C, Joseph B, Lin C-J, Despic V, Guo J, Yan D, Kondo S, Deng W-M, Dedon PC, Jaffrey SR \& Lai EC (2017) The m6A pathway facilitates sex determination in Drosophila. Nat. Commun. 8, 15737.

35 Kasowitz SD, Ma J, Anderson SJ, Leu NA, Xu Y, Gregory BD, Schultz RM \& Wang PJ (2018) Nuclear $m 6$ A reader YTHDC1 regulates alternative polyadenylation and splicing during mouse oocyte development. PLoS Genet. 14, 1-28.

36 Ivanova I, Much C, Di Giacomo M, Azzi C, Morgan M, Moreira PN, Monahan J, Carrieri C, Enright AJ, O'Carroll D, Giacomo M Di, Azzi C, Morgan M, Moreira PN, Monahan J, Carrieri C, Enright AJ, O'carroll D, Di Giacomo M, Azzi C, Morgan M, Moreira PN, Monahan J, Carrieri C, Enright AJ \& O'carroll D (2017) The RNA m 6 A Reader YTHDF2 Is Essential for the Post-transcriptional Regulation of the Maternal Transcriptome and Oocyte Competence. Mol. Cell 67, 1059-1067.e4. 
37 Lence T, Paolantoni C, Worpenberg L \& Roignant JY (2019) Mechanistic insights into m 6 A RNA enzymes. Biochim. Biophys. Acta - Gene Regul. Mech. 1862, 222-229.

38 Balacco DL \& Soller M (2018) The $\mathrm{m}^{6} \mathrm{~A}$ writer: Rise of a machine for growing tasks. Biochemistry 58, acs.biochem.8b01166.

39 Lence T, Soller M \& Roignant JY (2017) A fly view on the roles and mechanisms of the m6A mRNA modification and its players. RNA Biol. 14, 1232-1240.

40 Robbens S, Rouzé P, Cock JM, Spring J, Worden AZ \& Van De Peer Y (2008) The FTO gene, implicated in human obesity, is found only in vertebrates and marine algae. $J$. Mol. Evol. 66, 80-84.

41 Zhang G, Huang H, Liu D, Cheng Y, Liu X, Zhang W, Yin R, Zhang D, Zhang P, Liu J, Li C, Liu B, Luo Y, Zhu Y, Zhang N, He S, He C, Wang H \& Chen D (2015) N6methyladenine DNA modification in Drosophila. Cell 161, 893-906.

42 Greer EL, Blanco MA, Gu L, Sendinc E, Liu J, Aristizábal-Corrales D, Hsu CH, Aravind L, He C \& Shi Y (2015) DNA methylation on N6-adenine in C. elegans. Cell 161, 868-878.

43 Riviere G, He Y, Tecchio S, Crowell E, Sourdaine P, Guo X \& Favrel P (2017) Dynamics of DNA methylomes underlie oyster development. PLOS Genet. 13, 1-16.

44 Sussarellu R, Lebreton M, Rouxel J, Akcha F, Riviere G \& Rivière G (2018) Copper induces expression and methylation changes of early development genes in Crassostrea gigas embryos. Aquat. Toxicol. 196, submitted.

45 Rondon R, Grunau C, Fallet M, Charlemagne N, Sussarellu R, Chaparro C, Montagnani C, Mitta G, Bachère E, Akcha F \& Cosseau C (2017) Effects of a parental exposure to diuron on Pacific oyster spat methylome. Environ. Epigenetics 3, 1-13.

46 Riviere G, Wu G-CC, Fellous A, Goux D, Sourdaine P \& Favrel P (2013) DNA Methylation Is Crucial for the Early Development in the Oyster C . gigas. Mar. Biotechnol. 15, 1-15.

47 Saint-Carlier E \& Riviere G (2015) Regulation of Hox orthologues in the oyster Crassostrea gigas evidences a functional role for promoter DNA methylation in an invertebrate. FEBS Lett. 589, 1459-1466.

48 Fellous A, Favrel P \& Riviere G (2015) Temperature influences histone methylation and mRNA expression of the Jmj-C histone-demethylase orthologues during the early development of the oyster Crassostrea gigas. Mar. Genomics 19, 23-30.

49 Fellous A, Favrel P, Guo X \& Riviere G (2014) The Jumonji gene family in Crassostrea gigas suggests evolutionary conservation of $\mathrm{Jmj}-\mathrm{C}$ histone demethylases orthologues in the oyster gametogenesis and development. Gene 538, 164-175.

50 Fellous A, Le Franc L, Jouaux A, Goux D, Favrel P \& Rivière G (2019) Histone Methylation Participates in Gene Expression Control during the Early Development of the Pacific Oyster Crassostrea gigas. Genes (Basel). 10, 695.

51 Zhou J, Wan J, Gao X, Zhang X, Jaffrey SR \& Qian S-B (2015) Dynamic m6A mRNA methylation directs translational control of heat shock response. Nature 526, 591-594.

52 Lu Z, Ma Y, Li Q, Liu E, Jin M, Zhang L \& Wei C (2019) The role of N6-methyladenosine RNA methylation in the heat stress response of sheep (Ovis aries). Cell Stress Chaperones 24, 333-342.

53 Xiang Y, Laurent B, Hsu C, Nachtergaele S, Lu Z, Sheng W, Xu C, Chen H, Ouyang J, 
Wang S, Ling D, Hsu P, Zou L, Jambhekar A \& He C (2017) m6A RNA methylation regulates the UV-induced DNA damage response. Nature 543, 573-576.

54 Cayir A, Barrow TM, Guo L \& Byun HM (2019) Exposure to environmental toxicants reduces global N6-methyladenosine RNA methylation and alters expression of RNA methylation modulator genes. Environ. Res. 175, 228-234.

55 Liu J, Li K, Cai J, Zhang M, Zhang X, Xiong X, Meng H, Xu X, Huang Z, Fan J \& Yi C (2019) Landscape and Regulation of $M^{6} A$ and $M{ }^{6} A m$ Methylome Across Human and Mouse Tissues. SSRN Electron. J., 1-56.

56 Ren W, Lu J, Huang M, Gao L, Li D, Greg Wang G \& Song J (2019) Structure and regulation of ZCCHC4 in m6A-methylation of 28S rRNA. Nat. Commun. 10, 5042.

57 Bokar JA, Shambaugh ME, Polayes D, Matera AG \& Rottman FM (1997) Purification and cDNA cloning of the AdoMet-binding subunit of the human mRNA (N6-adenosine)methyltransferase. RNA 3, 1233-1247.

58 Theler D, Dominguez C, Blatter M, Boudet J \& Allain FHT (2014) Solution structure of the YTH domain in complex with N6-methyladenosine RNA: A reader of methylated RNA. Nucleic Acids Res. 42, 13911-13919.

59 Shima H, Matsumoto M, Ishigami Y, Ebina M, Muto A, Sato Y, Kumagai S, Ochiai K, Suzuki T \& Igarashi K (2017) S-Adenosylmethionine Synthesis Is Regulated by Selective N6-Adenosine Methylation and mRNA Degradation Involving METTL16 and YTHDC1. Cell Rep. 21, 3354-3363.

60 Yurchenko O V., Skiteva OI, Voronezhskaya EE \& Dyachuk VA (2018) Nervous system development in the Pacific oyster, Crassostrea gigas ( Mollusca : Bivalvia ). Front. Zool. $15,1-21$.

61 Ratnaparkhi A (2013) Signaling by folded gastrulation is modulated by mitochondrial fusion and fission. J. Cell Sci. 126, 5369-5376.

62 Ren L, Zhang C, Tao L, Hao J, Tan K, Miao K, Yu Y, Sui L, Wu Z, Tian J \& An L (2017) High-resolution profiles of gene expression and DNA methylation highlight mitochondrial modifications during early embryonic development. J. Reprod. Dev. 63, 247-261.

63 Prudent J, Popgeorgiev N, Bonneau B, Thibaut J, Gadet R, Lopez J, Gonzalo P, Rimokh R, Manon S, Houart C, Herbomel P, Aouacheria A \& Gillet G (2013) Bcl-wav and the mitochondrial calcium uniporter drive gastrula morphogenesis in zebrafish. Nat. Commun. 4.

64 Dumollard R, Duchen M \& Carroll J (2007) The Role of Mitochondrial Function in the Oocyte and Embryo. Curr. Top. Dev. Biol. 77, 21-49.

65 Huang $\mathrm{H}$, Weng $\mathrm{H}$, Zhou K, Wu T, Zhao BS, Sun MM, Chen Z, Deng X, Xiao G, Auer F, Klemm L, Wu H, Zuo Z, Qin X, Dong Y, Zhou Y, Qin H, Tao S, Du J, Liu J, Lu Z, Yin H, Mesquita A, Yuan CL, Hu Y-CC, Sun W, Su R, Dong L, Shen C, Li C, Qing Y, Jiang X, Wu X, Sun MM, Guan J-LL, Qu L, Wei M, Müschen M, Huang G, He C, Yang J \& Chen $\mathrm{J}(2019)$ Histone $\mathrm{H} 3$ trimethylation at lysine 36 guides m6A RNA modification cotranscriptionally. Nature 567, 414-419.

66 Wang Y, Li Y, Yue M, Wang J, Kumar S, Wechsler-Reya RJ, Zhang Z, Ogawa Y, Kellis M, Duester G \& Zhao JC (2018) N 6-methyladenosine RNA modification regulates embryonic neural stem cell self-renewal through histone modifications. Nat. Neurosci. 21, 195-206. 
67 Petton B, Pernet F, Robert R \& Boudry P (2013) Temperature influence on pathogen transmission and subsequent mortalities in juvenile pacific oysters Crassostrea gigas. Aquac. Environ. Interact. 3, 257-273.

68 Riviere G, Fellous A, Franco A, Bernay B \& Favrel P (2011) A crucial role in fertility for the oyster angiotensin-converting enzyme orthologue CgACE. PLoS One 6.

69 EMA (2011) Guideline on bioanalytical method validation. EMEA/CHMP/EWP/192217/2009.

70 Riviere G, Klopp C, Ibouniyamine N, Huvet A, Boudry P \& Favrel P (2015) GigaTON: An extensive publicly searchable database providing a new reference transcriptome in the pacific oyster Crassostrea gigas. BMC Bioinformatics 16, 1-12.

71 Zhang G, Fang X, Guo X, Li L, Luo R, Xu F, Yang P, Zhang L, Wu F, Chen Y, Wang J, Peng C, Meng J, Yang L, Liu J, Wen B, Zhang N \& Huang Z (2012) The oyster genome reveals stress adaptation and complexity of shell formation. Nature 490, 49-54.

72 Li B, Ruotti V, Stewart RM, Thomson JA \& Dewey CN (2010) RNA-Seq gene expression estimation with read mapping uncertainty. Bioinformatics 26, 493-500.

73 Qi ST, Ma JY, Wang ZB, Guo L, Hou Y \& Sun QY (2016) N6 -methyladenosine sequencing highlights the involvement of mRNA methylation in oocyte meiotic maturation and embryo development by regulating translation in xenopus laevis. J. Biol. Chem. 291, 23020-23026.

74 Altschul SF, Madden TL, Schäffer AA, Zhang J, Zhang Z, Miller W \& Lipman DJ (1997) Gapped BLAST and PSI-BLAST: a new generation of protein database search programs. Nucleic Acids Res. 25, 3389-3402.

75 Cock PJA, Chilton JM, Grüning B, Johnson JE \& Soranzo N (2015) NCBI BLAST+ integrated into Galaxy. Gigascience 4, 0-6.

76 Camacho C, Coulouris G, Avagyan V, Ma N, Papadopoulos J, Bealer K \& Madden TL (2009) BLAST+: Architecture and applications. BMC Bioinformatics 10, 1-9.

77 Young MD, Wakefield MJ, Smyth GK \& Oshlack A (2010) Gene ontology analysis for RNA-seq: accounting for selection bias. Genome Biol. 11, R14.

78 Supek F, Bošnjak M, Škunca N \& Šmuc T (2011) Revigo summarizes and visualizes long lists of gene ontology terms. PLoS One 6.

79 Larsson J (2019) eulerr: Area-Proportional Euler and Venn Diagrams with Ellipses. .

$80 \mathrm{Gu} Z$, Eils R \& Schlesner M (2016) Complex heatmaps reveal patterns and correlations in multidimensional genomic data. Bioinformatics 32, 2847-2849. 
939

940

941

942

943

944

945

946

947

948

949

950

951

952

953

954

955

one isoform is represented for each protein and each species for clarity (see supplementary

956 figure S2 for other isoforms).

957

958 Figure 3: Gene expression of the putative $\mathrm{m}^{6} \mathrm{~A}$ machinery throughout oyster development

\section{Figure legends}

\section{Figure 1: $\mathrm{m}^{6} \mathrm{~A}$ levels across oyster development.}

A. $\mathrm{m}^{6} \mathrm{~A}$ level quantified by LC-MS/MS in Crassostrea gigas embryo-larval stages pooled from oocytes to D-larvae $(n=3)$ is compared to the $m^{6} \mathrm{~A}$ level in Homo sapiens and Drosophila melanogaster; B. Dot blot quantification of $\mathrm{m}^{6} \mathrm{~A}$ in total RNA throughout oyster development $(n=3)$; C. Dot blot quantification of $m^{6} A$ in polyA+ RNAs throughout oyster development $(n=3)$

Kruskal-Wallis test, $\alpha<0,05$. E: Egg, F E: fertilized egg, 2/8C: two to eight cell embryos, M: Morula, B: Blastula, G: Gastrula, T: Trochophore, D: D larvae. Chemiluminescence (B) and fluorescence $(C)$ are measured as a ratio between dot intensity of development stages and their respective controls for each amount of RNA (120ng, 60ng and 30ng).

\section{Figure 2: The putative conserved $\mathrm{m}^{6} \mathrm{~A}$ machinery in Crassostrea gigas.}

Domain architecture of actors of the $\mathrm{m}^{6} \mathrm{~A}$ machinery identified by in silico analyses in the oyster compared to the fruit fly and human, A. Writer proteins; B. Eraser protein; C. Reader proteins. Putative domains involved in $\mathrm{m}^{6} \mathrm{~A}$ processes are coloured (writers, green; eraser, red; readers, blue). Other domains identified but not involved in $\mathrm{m}^{6} \mathrm{~A}$ processes are indicated in grey. Only 
959 Expression levels of writers (A), eraser (B) and readers (C) identified by in silico analysis at 960 each development stage were inferred from the GigaTON database. Expression levels are 961 given in Transcripts Per kilobases per Million Reads (TPM) as the mean of the GigaTON values 962 according to the table S2. E: Egg, 2/8C: two to eight cell, M: Morula, B: Blastula, G: Gastrula, 963 T: Trochophore, D: D larvae, S: Spat, J: Juvenile.

964

965 Figure 4: Characterization of $\mathrm{m}^{6} \mathrm{~A}-\mathrm{RNA}$ binding proteins in oyster development.

966 A. Venn diagrams representation of proteins bound to the A- and/or $\mathrm{m}^{6} \mathrm{~A}$ - oligos in nuclear and 967 cytosolic fractions of oyster embryo-larval stages. The number of proteins identified is 968 indicated. Some actors characterized in this study are highlighted: elF3, YTHC1, hnRNPA2B1 969 and IGF2BP. B. Heatmap of gene expression levels of the proteins that bind specifically to the $970 \mathrm{~m}^{6} \mathrm{~A}$-oligo throughout oyster development. The expression level is normalized regarding the 971 maximum value for each gene according to the GigaTON database. C. GO term distribution 972 among the three expression clusters in B. D. Examples of GO term enrichment within the 973 expression clusters of the $\mathrm{m}^{6} \mathrm{~A}$-bound proteins. The -log10(p-value) associated to each term 974 is given. E: Egg, 2/8C: two to eight cells, M: Morula, B: Blastula, G: Gastrula, T: Trochophore, 975 D: D larvae, S: Spat, J: Juvenile. 


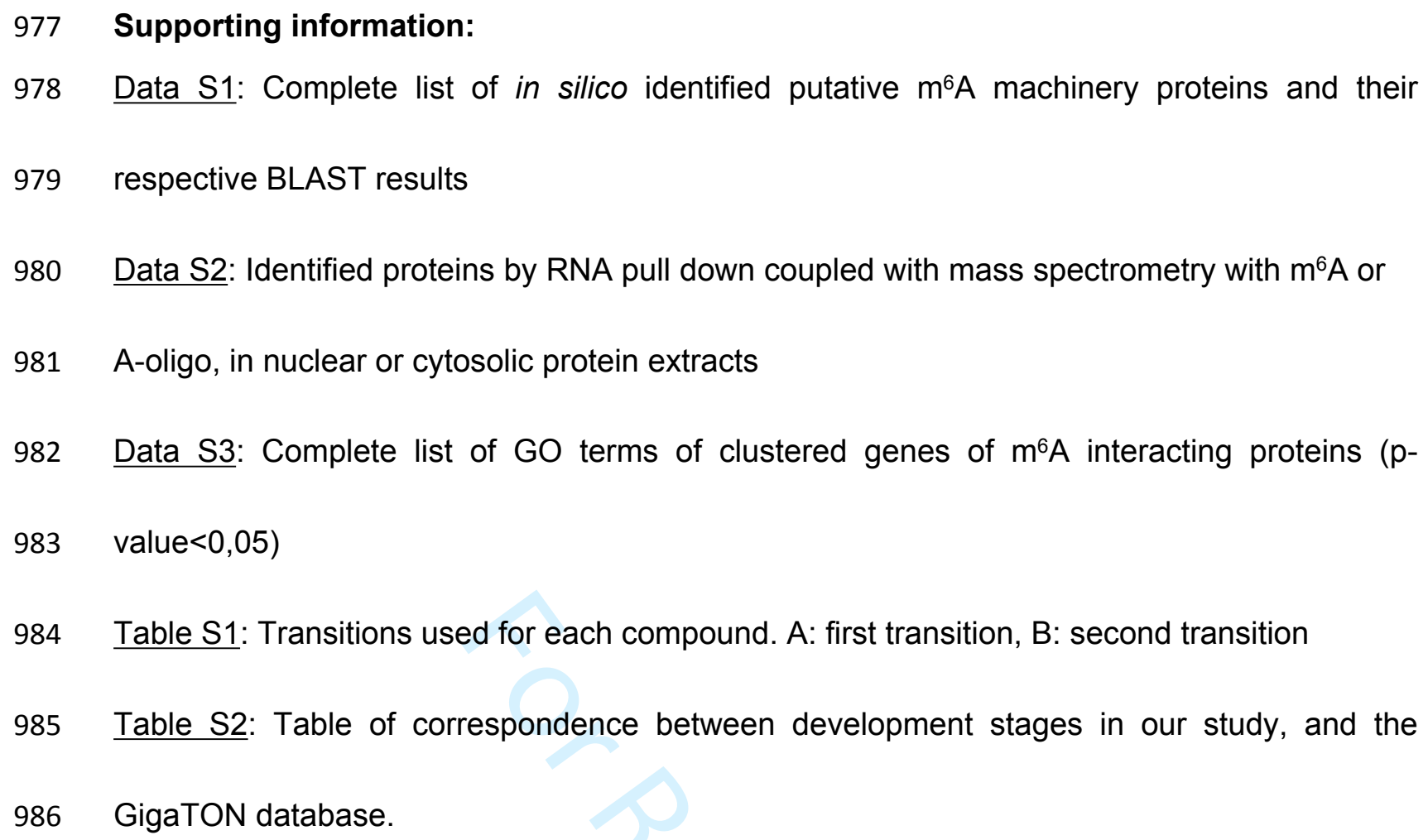


1 A functional $\mathrm{m}^{6} \mathrm{~A}-\mathrm{RNA}$ methylation pathway in the oyster Crassostrea gigas

2 assumes epitranscriptomic regulation of lophotrochozoan development

3

4 6 Guillaume RIVIERE1

7

8

10

\section{Authors}

\section{Addresses}

\section{Corresponding author}

Lorane LE FRANC ${ }^{1}$, Benoit BERNAY ${ }^{2}$, Bruno PETTON ${ }^{3}$, Marc SINCE ${ }^{4}$, Pascal FAVREL ${ }^{1}$ and

${ }^{1}$ Normandie Univ, UNICAEN, CNRS, BOREA, 14000 Caen, France.

Laboratoire Biologie des organismes et Ecosystèmes aquatiques (BOREA), Muséum d'Histoire naturelle, Sorbonne Université, Université de Caen Normandie, Université des Antilles, CNRS, IRD, Esplanade de la paix, 14032 Caen, France.

${ }^{2}$ Normandie Univ, UNICAEN, SF ICORE, PROTEOGEN core facility, 14000 Caen, France

3lfremer, Laboratoire des Sciences de l'Environnement Marin, UMR 6539 CNRS/UBO/IRD/Ifremer, Centre Bretagne, 29280, Plouzané, France

${ }^{4}$ Normandie Univ, UNICAEN, Comprehensive Cancer Center F. Baclesse, SF ICORE, PRISMM core facility, 14000 Caen, France.

Guillaume Rivière (0033231565113; guillaume.riviere@unicaen.fr) , Normandie Univ, UNICAEN, CNRS, BOREA, 14000 Caen, France (https://borea.mnhn.fr/ ). Tel : 


\section{Running title}

$\mathrm{m}^{6} \mathrm{~A}-\mathrm{RNA}$ methylation pathway in oyster development

\section{Abbreviations}

$N^{6}$-methyladenosine $\left(\mathrm{m}^{6} \mathrm{~A}\right)$, Methyltransferase like (METTL), Wilms' tumor 1-associated protein (WTAP), RNA-binding motif 15 (RBM15), Ring finger E3 ubiquitin ligase (HAKAI), Zinc finger $\mathrm{CCCH}$-type containing $13(\mathrm{ZC} 3 \mathrm{H} 13)$, AlkB homologue $5(\mathrm{ALKBH} 5)$, Fat mass and obesity associated protein (FTO), YTH domain family protein (YTHDF), YTH domain containing protein (YTHDC), Heterogeneous nuclear ribonucleoproreins A2 B1 (HNRNPA2B1), Proline rich coiled-coil 2a (Prrc2a), Eukaryotic initiation factor 3 (elF3), Sterile sea water (SSW), Oocytes (E), Fertilized oocytes (F E), Two to eight cell embryos (2/8 C), Hours post fertilization (hpf), Morula (M), Blastula (B), Gastrula (G), D larvae (D), solid-phase reversible immobilization (SPRI), TPM (Transcripts Per Million), Gene ontology (GO), oyster $\mathrm{m}^{6} \mathrm{~A}$-interacting protein $\left(\mathrm{Cg}-\mathrm{m}^{6} \mathrm{~A}-\mathrm{BPs}\right)$, S-adenosyl-methionine (SAM), maternal-to-zygotic transition $(\mathrm{MZT})$, acetonitrile $(\mathrm{ACN})$

\section{Keywords}

RNA, methylation, epitranscriptomics, oyster, development.

\section{Conflicts of interest}

The authors declare they have no competing conflict of interest 
44

45

46

47

48

49

50

51

52

53

54

55

\section{Abstract}

$N^{6}$-methyladenosine $\left(\mathrm{m}^{6} \mathrm{~A}\right)$ is a prevalent epitranscriptomic mark in eukaryotic RNA, with crucial roles for mammalian and ecdysozoan development. Indeed, $\mathrm{m}^{6} \mathrm{~A}-\mathrm{RNA}$ and the related protein machinery are important for splicing, translation, maternal-to-zygotic transition and cell differentiation. However, to date, the presence of an $m^{6} A-R N A$ pathway remains unknown in more distant animals, questioning the evolution and significance of the epitranscriptomic regulation. Therefore, we investigated the $\mathrm{m}^{6} \mathrm{~A}-\mathrm{RNA}$ pathway in the oyster Crassostrea gigas, a lophotrochozoan model whose development was demonstrated under strong epigenetic influence.

Using mass spectrometry and dot blot assays, we demonstrated that $m^{6} A-R N A$ is actually present in the oyster and displays variations throughout early oyster development, with the lowest levels at the end of cleavage. In parallel, by in silico analyses, we were able to characterize at the molecular level a complete and conserved putative $\mathrm{m}^{6} \mathrm{~A}$-machinery. The expression levels of the identified putative $\mathrm{m}^{6} \mathrm{~A}$ writers, erasers and readers were strongly regulated across oyster development. Finally, RNA pull-down coupled to LC-MS/MS allowed us to prove the actual presence of readers able to bind $m^{6} \mathrm{~A}-\mathrm{RNA}$ and exhibiting specific developmental patterns.

Altogether, our results demonstrate the conservation of a complete $\mathrm{m}^{6} \mathrm{~A}-\mathrm{RNA}$ pathway in the oyster and strongly suggest its implication in early developmental processes including MZT. This first demonstration and characterization of an epitranscriptomic regulation in a lophotrochozoan model, potentially involved in the embryogenesis, brings new insights into our understanding of developmental epigenetic processes and their evolution. 


\section{Introduction}

The $N^{6}$-methyladenosine $\left(\mathrm{m}^{6} \mathrm{~A}\right)$ is the prevalent chemical RNA modification in all eukaryotic coding and non-coding RNAs [1]. Messenger RNAs are the most heavily $\mathrm{m}^{6} \mathrm{~A}$ methylated RNAs, with $\mathrm{m}^{6} \mathrm{~A}$ bases lying mostly in their $3^{\prime}$ UTRs, at the vicinity of their stop codon [2-4] and also in 5' UTRs and long internal exons [4,5]. $N^{6}$-methylation of RNA adenosines is responsible for RNA processing and, like DNA methylation or histone modifications, contributes to the regulation of gene expression without changing the DNA or mRNA sequence. Therefore $\mathrm{m}^{6} \mathrm{~A}$ constitutes a new layer of post-transcriptional gene regulation, which is emerging or has been proven critical in various biological processes, and referred to as epitranscriptomic [2].

The dynamics and biological outcomes of $\mathrm{m}^{6} \mathrm{~A}$ levels are the results of the activity of a complex protein machinery comprising writers, erasers and readers. The addition of a methyl group to the $6^{\text {th }}$ nitrogen of RNA adenosines is catalysed by $\mathrm{m}^{6} \mathrm{~A}$ writers with distinct properties. Methyltransferase like 16 (METTL16) is a 'stand-alone' class I methyltransferase that recognizes the UACA*GAGAA consensus sequence (with * indicating the target adenosine) [6]. By contrast, METTL3 transfers methyl groups to adenosines within the RRA*CH motif [2,3,7]. METTL3 is only active within a tripartite 'core complex' [8] comprising METTL3, METTL14 which enhances the methyltransferase activity supported by the MTA-70 domain of METTL3 $[9,10]$ and the regulator protein Wilms' tumor 1-associated protein (WTAP) $[4,9,11]$. 
ligase (HAKAI) [12,13], zinc finger $\mathrm{CCCH}$-type containing 13 (ZC3H13) [12,14], RNA-binding motif 15 (RBM15) and RBM15B $[7,15]$ which are suspected to intervene in the core complex activity and target specificity. The demethylation of adenosines has been demonstrated to be an active process catalysed by eraser enzymes belonging to the $\mathrm{Fe}(\mathrm{II}) / 2$-oxoglutarate dioxygenase family: AlkB homologue 5 (ALKBH5) [16,17] and the fat mass and obesity associated protein (FTO) $[17,18]$.

A growing number of reader proteins which recognize the $\mathrm{m}^{6} \mathrm{~A}-\mathrm{RNA}$ mark is being described. They may be divided into two classes depending on the presence of a YT521 B Homology (YTH) domain in their primary sequence. The YTH protein family includes YTH domain family protein 1-3 (YTHDF1-3) and YTH domain containing protein 2 (YTHDC2), which are cytosolic $\mathrm{m}^{6} \mathrm{~A}$ readers involved in $\mathrm{m}^{6} \mathrm{~A}-\mathrm{RNA}$ stability and translation [19-22]. The fifth $\mathrm{YTH}$ member is YTHDC1, which is present in the nucleus and controls splicing [23] and nuclear export [24] of $\mathrm{m}^{6} \mathrm{~A}-\mathrm{RNA}$. The second class of readers comprises proteins without YTH domain which are involved in several molecular mechanisms. For example, the heterogeneous nuclear ribonucleoprotein A2 B1 (HNRNPA2B1) is important for miRNA processing [25]. Insulin-like growth factor 2 mRNA binding protein 1-3 (IGF2BP 1-3) [26] and proline-rich coiled-coil 2a (Prrc2a) [27] participate in RNA stability while eukaryotic initiation factor 3 (elF3) guides capindependent translation [5].

The $\mathrm{m}^{6} \mathrm{~A}$ epitranscriptomes underlie important biological functions, most of which being related to developmental processes, including the control of cell differentiation [27-32], maternal to zygotic transition (MZT) [33], sex determination [7,34] and gametogenesis [16,21,35,36]. Such 
110 critical epitransriptomic outcomes are conserved in the animal evolution and were

111 characterized in both vertebrates and ecdysozoans, i.e. mammals and drosophila.

112 However, such conserved biological significance originates in diverse epitranscriptomic 113 mechanisms. Indeed, not all ecdysozoans bear a complete $\mathrm{m}^{6} \mathrm{~A}-\mathrm{RNA}$ machinery, such as $C$. 114 elegans whose genome is devoid of the related protein machinery with the exception of a 115 putative orthologue of METTL16 $[37,38]$. In addition, no $\mathrm{m}^{6} \mathrm{~A}$ eraser has been described to 116 date in non-vertebrate models, and especially ecdysozoans such as the drosophila or C. 117 elegans [38-40], where it cannot be excluded that $\mathrm{m}^{6} \mathrm{~A}-\mathrm{RNA}$ methylation could be removed by 118 the activity of characterised $6 \mathrm{~mA}-\mathrm{DNA}$ demethylases $[41,42]$. This situation may illustrate a 119 growing complexity of epitranscriptomic mechanisms during the animal phylogeny and raises 120 fundamental questions about its evolution and its presence in organisms distant from 121 mammals and ecdysozoans. However, to date, no data about a possible epitranscriptomic 122 regulation is available to our knowledge in lophotrochozoans, the understudied sister group of 123 ecdysozoans within protostomes, although representing an important range of metazoan 124 biodiversity.

125 The Pacific oyster Crassostrea gigas (i.e. Magallana gigas) is a bivalve mollusc whose great 126 ecological an economical significance allowed its emergence as a model species within 127 lophotrochozoan organisms. As such, an important amount of genetic, transcriptomic and 128 epigenetic data have been generated in this model. Interestingly, the embryolarval 129 development of $C$. gigas is described to be under the strong epigenetic influence of DNA 130 methylation [43-47] and histone marks [48-50]. Besides, oyster development occurs exposed 131 to external environmental conditions, and in other models the $\mathrm{m}^{6} \mathrm{~A}$ methylation of RNA and/or 
132 the expression of its machinery can be induced by heat stress, UV exposure or endocrine

133 disruptors [5,51-54], questioning the presence of an $\mathrm{m}^{6} \mathrm{~A}$ pathway in $C$. gigas and its 134 significance in oyster early development.

135 To investigate this, we measured $\mathrm{m}^{6} \mathrm{~A}$ levels in RNA across the entire embryolarval life of the oyster using mass spectrometry and dot-blot. We also searched the available in silico

137 resources for putative conserved $\mathrm{m}^{6} \mathrm{~A}$-related proteins in $C$. gigas genomic data as well as

138 their cognate expression kinetics using RNAseq assembly analyses. We also performed RNA-

139 pulldown with a synthetic $\mathrm{m}^{6} \mathrm{~A}-\mathrm{RNA}$ oligonucleotide coupled to liquid chromatography and 140 mass spectrometry (LC-MS/MS) to characterize potential oyster $\mathrm{m}^{6} \mathrm{~A}$-binding proteins. To our 141 knowledge, this study is the first report unravelling epitranscriptomic mechanisms outside 142 vertebrate and ecdyzosoan animal models.

144 Results:

$\mathrm{m}^{6} \mathrm{~A}$ is present in oyster RNA, differentially affects distinct RNA populations and displays variations during embryonic life.

148 Mass spectrometry measurements revealed that $m^{6} A$ is present in oyster RNA, with global $149 \mathrm{~m}^{6} \mathrm{~A} / \mathrm{A}$ levels of ca. $0.3 \%$, a value comparable to what has been found in the human and the 150 fruit fly (Figure 1A). Immunoblot assays indicate that total and polyA+ RNA present variable 151 amounts of $\mathrm{m}^{6} \mathrm{~A}$ during oyster development and that these variations display distinct profiles 152 suggesting specific methylation patterns between RNA populations. Indeed, $N^{6} \mathrm{~A}-$ methylation in total RNA is the highest in the early stages (oocytes and fertilized oocytes) then gradually 
154 decreases until the morula stage before gradually increasing again up to the trochophore stage

155 when it recovers its maximum (Figure 1B). In contrast, $\mathrm{m}^{6} \mathrm{~A}$ levels in polyA+ RNA are hardly 156 detected in early stages but display a peak in the gastrula and trochophore stages (Figure 1C).

$\mathrm{m}^{6} \mathrm{~A}$ machinery is conserved at the molecular level in the oyster.

159 In silico analyses led to the identification of oyster sequences encoding putative orthologues 160 of $\mathrm{m}^{6} \mathrm{~A}$ writers, erasers and readers that are present in the human and/or in the human and 161 the fruit fly.

162 All the eight $\mathrm{m}^{6} \mathrm{~A}-\mathrm{RNA}$ writers characterized in the human and/or drosophila at the time of the 163 study, namely METTL3, METTL14, WTAP, Virilizer-like, HAKAI, ZC3H13, RBM15/15B and 164 METTL16, were present in the oyster at the gene level. The encoded protein primary 165 sequences all display the specific domains required for enzymatic activity and/or binding. They 166 include MT-A70 and AdoMetMtases SF domains for METTL3, METTL14 and METTL16, 167 respectively, that bear the methyltransferase activity. Oyster WTAP and Virilizer-like 168 orthologues exhibit WTAP and VIR_N domains, respectively, that are required in their human 169 counterparts to bind and activate the catalytic subunit of the $m^{6} \mathrm{~A}-\mathrm{RNA}$ methyltransferase 170 complex. Oyster Hakai and RBM15/15B present RHHL, RHF-Zn-BS and specific RRM 171 domains, respectively, similar to human and fruit fly orthologues. Besides, the oyster $\mathrm{ZC} 3 \mathrm{H} 13$ 172 bears the Rho SF domain present in the human, but not in the fruit fly orthologue (Figure 2A). 173 C. gigas also presents a putative $\mathrm{m}^{6} \mathrm{~A}-\mathrm{RNA}$ eraser, ALKBH5, which is present in the human 174 but has not been characterized in drosophila. The oyster ALKBH5 exhibits a 2OG-Fell_Oxy 175 domain suggestive of a presumably conserved catalytic functionality through fe2+-dependent 
176 oxoglutarate oxidation. Of note, no orthologue of the human FTO eraser could be identified in

177 the oyster genomic or transcriptomic databases available to date (Figure 2B).

178 Many $\mathrm{m}^{6} \mathrm{~A}$ reader orthologues have also been found in the oyster, including proteins containing 179 a YTH domain, such as YTHDF, YTHDC1 and YTHDC2. An oyster Prrc2a-like protein 180 produces homology with the human Prrc2a, especially within the $\mathrm{m}^{6} \mathrm{~A}$-binding GRE-rich 181 domain. Oyster readers also include a heterogeneous nuclear ribonucleoprotein-coding gene, 182 hnRNPA2B1 with greater sequence similarity with the drosophila counterpart than with the 183 human orthologue. Similarly, the IGF2BP-coding sequence has also been found in C. gigas 184 (Figure $2 \mathrm{C}$ ). Five oyster sequences display homologies with elF3a which is able to bind $\mathrm{m}^{6} \mathrm{~A}$ 185 RNA [5] but it was not possible to discriminate whether a unique oyster predicted protein was 186 an elF3a orthologue.

187 Overall, these results indicate the conservation of a complete $\mathrm{m}^{6} \mathrm{~A}-\mathrm{RNA}$ machinery in the 188 oyster. The complete list of the identified genes encoding the conserved $\mathrm{m}^{6} \mathrm{~A}$ machinery actors 189 and their isoforms, as well as the related information is given in the supplementary data (Data 190 S1).

192 Oyster putative $\mathbf{m}^{6} \mathbf{A}$ actors display expression level variations across development.

193 RNAseq data analyses showed that all the oyster $\mathrm{m}^{6} \mathrm{~A}$-related genes were expressed during 194 the early life (Figure 3). Their expression level displayed gene-specific profiles, most of them 195 being variable throughout oyster development.

196 The expression of writers belonging to the core methylation complex is weak overall. METTL3 197 and WTAP share similar profiles with little expression increasing up to the gastrulation and 
198

remaining stable afterwards. In contrast METTL14 displays a weak expression level across the embryo larval life. The expression profile of Virilizer-like resembles WTAP, while HAKAI, RBM15/15B and METTL16 seem to have mRNA levels which decrease after cleavage, whereas those of $\mathrm{ZC} 3 \mathrm{H} 13$ transcript variants seem to drop at the D larva stage. Interestingly, METTL16 mRNA levels display an opposite developmental profile when compared to METTL3 expression; with the highest values during cleavage which decrease later on (Figure $3 \mathrm{~A}$ ).

ALKBH5 transcripts are weakly represented within oyster early embryos and the higher TPM values are found in gastrulas. However, maximum levels are observed after metamorphosis in juveniles (Figure 3B).

Regarding $\mathrm{m}^{6} \mathrm{~A}$ putative readers, the expression of $\mathrm{YTH}$ family genes during development showed different patterns. In fact, YTHDF is the most represented YTH-domain bearing actor and YTHDF TPM values are ca. 5-fold higher than all the other oyster YTH readers. YTHDF is strongly expressed at the beginning of development until a peak at the morula stage. Prrc2a is the most represented reader at the mRNA level in oyster embryos, and the sum of the TPM of the two Prrc2a oyster isoforms are at most ca. 20-fold higher than those of YTH family. However, Prrc2a and YTHDF transcript content profiles are similar across oyster development, and also remind of the IGF2BP mRNA levels.

By contrast, the two isoforms of YTHDC1 identified by in silico analysis, YTHDC1.1 and YTHDC1.2, display similar patterns together with YTHDC2, with a maximum representation in gastrulas. The expression of hnRNPA2B1 isoforms has likewise patterns except for a marked drop at the D larvae stage (Figure $3 \mathrm{C}$ ). 


\section{Oyster orthologues of $\mathrm{m}^{6} \mathrm{~A}-\mathrm{RNA}$ interacting proteins bind $\mathrm{m}^{6} \mathrm{~A}$ RNA in vitro.}

To determine whether oyster proteins can bind $\mathrm{m}^{6} \mathrm{~A}-\mathrm{RNA}$, we performed RNA-pulldown of cytoplasmic and nuclear embryonic cell extracts using a methylated versus a non-methylated oligonucleotide, followed by LC/MS-MS characterisation and identification of the captured proteins with the Mascot software.

In nuclear extracts, we detected 591 proteins able to bind both the methylated and unmethylated oligos. We identified 43 proteins specific to unmethylated RNA while 131 proteins specifically bind the $\mathrm{m}^{6} \mathrm{~A}$-methylated oligo. In cytosolic extracts, there were respectively 646,436 and 36 of such proteins, respectively. Regardless of the methylation status, more proteins in the cytoplasmic extracts can bind to the RNA oligonucleotides than in the nuclear extracts (1118 proteins vs. 765 , respectively). However, more nuclear proteins are found exclusively bound to the $\mathrm{m}^{6} \mathrm{~A}$-containing oligo than cytoplasmic proteins (131 vs. 36 , i.e. $17 \%$ vs. $3 \%$, respectively). In addition, many nuclear and cytoplasmic proteins can bind both the methylated and the non-methylated oligo (591 vs. 646 , i.e. $77 \%$ vs. $58 \%$ ). An important number of proteins in the cytoplasmic extract were found exclusively bound to the nonmethylated oligo, whereas only a limited number of nuclear proteins display such a specificity (436 vs. 43 , i.e. $39 \%$ vs. $6 \%$ ). Among the $167 \mathrm{~m}^{6} \mathrm{~A}$-specific proteins in oyster extracts, only 5 were found in both the nuclear and cytoplasmic extracts. These results show that oyster proteins can directly or indirectly bind $m^{6} \mathrm{~A}-\mathrm{RNA}$, and suggest an important compartmentalization of $\mathrm{m}^{6} \mathrm{~A}$-related processes.

Among the identified proteins in this assay, four of the putative oyster $\mathrm{m}^{6} \mathrm{~A}$ readers are found, YTHDC1, hnRNPA2B1, IGF2BP and elF3. In the nuclear extracts YTHDC1 is uncovered as 
$242 \mathrm{~m}^{6} \mathrm{~A}$-specific whereas hnRNPA2B1 and IGF2BP were present complexed with both the $\mathrm{m}^{6} \mathrm{~A}$ 243 and A-oligos. In the cytoplasmic extracts, YTHDC1 and elF3a are $\mathrm{m}^{6} \mathrm{~A}$-specific while 244 hnRNPA2B1, IGF2BP were pulled down by both methylated and unmethylated oligos (Figure 2454 A).

246 These results demonstrate that some proteins in the oyster can specifically bind $\mathrm{m}^{6} \mathrm{~A}-\mathrm{RNA}$ and 247 that the putative $\mathrm{m}^{6} \mathrm{~A}$ reader orthologues in the oyster are conserved at the protein level and 248 are able to interact with $\mathrm{m}^{6} \mathrm{~A}-\mathrm{RNA}$.

The $\mathrm{m}^{6} \mathrm{~A}$-interacting protein-coding genes display clustered expression regulation and functional annotation during oyster development.

252 The mRNA expression level of the genes encoding the 162 oyster $\mathrm{m}^{6} \mathrm{~A}$-interacting protein (Cg$\left.253 \mathrm{~m}^{6} \mathrm{~A}-\mathrm{BPs}\right)$ was examined using RNAseq databases. Most of them display a specific and 254 regulated expression level across oyster developmental stages. However, three main 255 expression clusters could be distinguished according to their developmental mRNA expression 256 level profile. Cluster 1 includes genes that show high expression at the beginning of the embryo 257 life (i.e. cleavage) and strongly decrease after gastrulation; the second cluster contains weakly 258 expressed genes except in the latest examined larval phases, after gastrulation (i.e. 259 Trochophore and D Larvae); cluster 3 groups genes that show an expression peak during 260 gastrulation (Figure 4B).

261 The Gene Ontology annotation of the $\mathrm{Cg}-\mathrm{m}^{6} \mathrm{~A}-\mathrm{BP}$ genes reveal that the distinct clusters are 262 related to distinct functional pathways as indicated by the little - if any - common GO terms 263 between them (Figure 4C). However, the functional pathways of all three gene clusters point 
264 out to their implication in translation and its regulation, although the terms enriched in each 265 cluster illustrate different aspects of translation, such as translation initiation (cluster 1), splicing

266 and nuclear export (cluster 2) and ribosomal and mitochondrial processes (cluster 3) 267 respectively (Figure 4D).

269 Discussion

270 This work demonstrates that $\mathrm{m}^{6} \mathrm{~A}-\mathrm{RNA}$ is present and variable during the embryo-larval life of

271 the oyster, and that C. gigas exhibits putative conserved and functional $\mathrm{m}^{6} \mathrm{~A}-\mathrm{RNA}$ writers, 272 eraser and readers. The dynamics of such mark and of its actors strongly suggest a biological 273 significance of the epitranscriptomic pathway in the control of development of a 274 lophotrochozoan species, which has, to date, never been demonstrated to our knowledge.

\section{5 m6-RNA levels vary across oyster development.}

276 Using mass spectrometry and immunological measurements, we showed that oyster RNA is $277 \mathrm{~m}^{6} \mathrm{~A}$-methylated. The global proportion of $N^{6}$-methyladenosine in RNA in the developing oyster $278(0.28 \%)$ is similar to those observed elsewhere in the animal kingdom, such as in the fruit fly $279(0.24 \%)[34]$ or the human $(0.11-0.23 \%)$ [55] (Figure 1A), despite those values are difficult 280 to compare because they were not measured within the same developmental phase (adult flies 281 and human cell lines vs. oyster embryos). However, the comparable magnitude of $\mathrm{m}^{6} \mathrm{~A}-\mathrm{RNA}$ 282 amounts between taxa, in contrast to DNA methylation [46], may indicate conserved biological 283 significance of epitranscriptomic processes between groups. The amount of $\mathrm{m}^{6} \mathrm{~A}$ in total RNA 284 displays a striking decrease during cleavage and then recovers its maximum levels at the end 285 of the gastrulation (Figure 1B). Therefore, the $\mathrm{m}^{6} \mathrm{~A}$ decrease in total RNA during cleavage, i.e. 
286 before the transcription of the zygotic genome starts, reflects a degradation of maternal $\mathrm{m}^{6} \mathrm{~A}$ -

287 RNAs or their demethylation. However, all RNA populations do not exhibit the same pattern,

288 indeed polyA+ RNAs are $\mathrm{m}^{6} \mathrm{~A}$ methylated only after cleavage. The extent of polyadenylation

289 of oyster maternal messenger RNAs accumulating during vitellogenesis is unknown.

290 Therefore, which maternal RNA population(s) is methylated in oyster oocytes is unclear.

291 Nevertheless, the observation that $\mathrm{m}^{6} \mathrm{~A}-\mathrm{RNA}$ levels are variable and affecting distinct RNA

292 populations across embryonic stages strongly favours an important biological significance of

$293 \mathrm{~m}^{6} \mathrm{~A}-\mathrm{RNA}$ in oyster development. We hypothesize that oyster maternal messenger RNAs are

294 poorly polyadenylated, and that $\mathrm{m}^{6} \mathrm{~A}$, aside polyadenylation, might play a role in the stability of

295 quiescent maternal mRNAs. Alternatively, other maternal RNA populations such as snRNA,

296 miRNA, rRNA or IncRNA might be methylated $[6,15,25,56]$, which become demethylated or

297 degraded up to the morula stage. The later increase in $\mathrm{m}^{6} \mathrm{~A}$ RNA after cleavage could therefore

298 be the result of the methylation of the increasingly transcribed RNAs from the blastula stage,

299 including polyadenylated mRNAs.

300 The $\mathrm{m}^{6} \mathrm{~A}-\mathrm{RNA}$ machinery is conserved in the oyster and regulated during development.

301 The important regulation of $\mathrm{m}^{6} \mathrm{~A}$ levels during oyster development assumes the presence of a

302 related protein machinery. We identified in silico cDNA sequences encoding conserved

303 putatively functional orthologues of $\mathrm{m}^{6} \mathrm{~A}-\mathrm{RNA}$ writers, eraser and readers in the oyster, with

304 great confidence (homologies ranging from ca. 30 to $65 \%$ with their human counterpart, see

305 Data S1). The writers include all the members of the methylation complex (METTL3, METTL14,

306 WTAP, Virilizer-like, Hakai, ZC3H13, RBM15/15B) identified to date in the human and the fruit

307 fly $[7,11,12,14,15,57]$. We also identified an orthologue of the stand-alone METTL16 $\mathrm{m}^{6} \mathrm{~A}$ 
308 methyltransferase. Each orthologue bears the conserved domain(s) demonstrated to be

309 implicated in the catalytic and/or binding activity of their cognate counterpart in other species,

310 such as the MT-A70 domain which transfers methyl groups from the S-adenosyl-methionine

311 (SAM) to the $N^{6}$ nitrogen of RNA adenines [57]. Of the two proteins that can erase RNA

312 methylation, only ALKBH5, which is important for mouse spermatogenesis [16], was identified

313 at the cDNA level in the oyster. Indeed, no C. gigas sequence displayed significant homology

314 with the mammalian FTO protein, whose functional significance remains controversial [17].

315 Most the characterized $\mathrm{m}^{6} \mathrm{~A}-\mathrm{RNA}$ readers are also present at the molecular level in the oyster

316 and are putatively able to bind $\mathrm{m}^{6} \mathrm{~A}$ regarding their primary sequence, such as the YTHDC and

317 YTHDF family members [19,21,23,58], Prrc2A [27], HnRNPA2B1 [25] and IGF2BP [26]. Of

318 note, some of these readers have not been characterized to date in $D$. melanogaster but

319 display strong homologies between humans and oysters. In mammals, elF3a has important

320 functional outcomes in cap-independent translational stress response [5]. However, it was not

321 possible to ascribe a single oyster sequence as a unique elF3a orthologue (Data S1), although

322 its presence was demonstrated by RNA pull down (see below) (see Data S2). Altogether, in 323 silico results show the conservation of a complete $\mathrm{m}^{6} \mathrm{~A}-\mathrm{RNA}$ machinery in the oyster. To date

324 to our knowledge, this is the first demonstration in a lophotrochozoan organism of an 325 epitranscriptomic pathway. Its presence suggests its ancestral origin, and questions its 326 biological significance in oyster development.

327 To investigate this, we analysed the expression level of the $\mathrm{m}^{6} \mathrm{~A}$ machinery genes using RNA-

328 seq data. Our results indicate that the core methylation complex (METTL3, METTL14 and 329 WTAP) would not be active during cleavage because of the absence of METTL3 and little 
330

331

332

333

334

335

336

337

338

339

340

341

342

343

344

345

346

347

348

349

350

351

WTAP expression. METTL16 catalyses the downregulation of SAM methyl donor availability in mammals [59]. If METTL16 function is conserved in the oyster as suggested by the high sequence homology, the peak in METTL16 expression, together with the weak expression of the core complex in $2 / 8$ cell embryos is consistent with an absence of $m^{6} A-R N A$ up to the blastula stage. Then, the core complex would likely be active as soon as the end of cleavage (i.e. since the blastula stage), in line with the increase in $\mathrm{m}^{6} \mathrm{~A}$ levels observed at the same time.

The correlation between the increasing METTL3 expression and $\mathrm{m}^{6} \mathrm{~A}-\mathrm{RNA}$ levels after cleavage strongly favours the conservation of the methyltransferase activity of the oyster MTA70 domain. Interpreting the regulation of the $\mathrm{m}^{6} \mathrm{~A}$ activity by the other methyltransferase complex members (i.e. Virilizer-like, HAKAI, ZC3H13 and RBM15/15B) is difficult because how - or even if - oyster orthologues act within the complex is not known. Nevertheless, their specific expression profiles may reflect their implication in the regulation of distinct biological contexts. There might be little functional significance of active $m^{6} \mathrm{~A}-\mathrm{RNA}$ erasure during oyster development, consistent with the normal embryonic phenotype of ALKBH5 knockdown mice [16]. Overall, the $\mathrm{m}^{6} \mathrm{~A}$ readers display distinct developmental expression patterns. While YTHDF and Prrc2a peak during cleavage, YTHDC1, YTHDC2, IGF2BP and hnRNPA2B1 mRNA levels gradually increase up to the gastrulation and remain mostly highly expressed afterwards (except for hnRNPA2B1 and IGF2BP). These profiles evoke the mediation of distinct biological functions depending on the reader and the developmental phases. Therefore, we hypothesized that YTHDF and Prrc2a might participate in the blastulean transition in the oyster. Indeed, in the zebrafish, a YTHDF reader triggers the maternal-tozygotic transition through the decay of the maternal $\mathrm{m}^{6} \mathrm{~A}$ RNAs during cleavage [33]. The role 
352 in the axon myelination and specification of mouse oligodendrocytes [27] is unlikely conserved

353 for Prrc2a because the oyster orthologue is expressed before the neurogenesis is detected in

354 trochophore stages [60]. Alternatively, the early expression of Prrc2a suggests that it might

355 rather compete with YTHDF for $\mathrm{m}^{6} \mathrm{~A}-\mathrm{RNA}$ targets [27], thereby possibly acting in oyster MZT,

356 bringing new perspectives into this process which remains poorly understood in

357 lophotrochozoans. In mammals $\mathrm{m}^{6} \mathrm{~A}$ is implicated in the embryonic cell fate $[30,31]$ notably via

358 the regulation of cell differentiation by YTHDC2 [32] or hnRNPA2B1 [29]. In the oyster,

359 YTHDC1, YTHDC2, IGF2BP and hnRNPA2B1 have their maximum expression during

360 gastrulation correlated to the second $\mathrm{m}^{6} \mathrm{~A}$ peak, suggesting similar implications.

361 Putative oyster $\mathrm{m}^{6} \mathrm{~A}$ readers actually bind $\mathrm{m}^{6} \mathrm{~A}-\mathrm{RNA}$ in vitro.

362 To better approach the developmental processes involving $\mathrm{m}^{6} \mathrm{~A}$ in the oyster, we characterized

363 the proteins that can interact with $\mathrm{m}^{6} \mathrm{~A}-\mathrm{RNA}$ using a methylated-RNA-pulldown / mass

364 spectrometry assay. We identified 162 proteins able to specifically bind the $\mathrm{m}^{6} \mathrm{~A}-\mathrm{RNA}$ oligo in

365 embryonic cell extracts, demonstrating the actual presence of genuine $\mathrm{m}^{6} \mathrm{~A}$-readers in the

366 oyster. Most (ca. $75 \%$ ) of these proteins were found in nuclear extracts and only 5 were found

367 in both the cytoplasmic and nuclear fractions, showing an important compartmentalization of

368 the epitranscriptomic pathway. Regarding the little number of $\mathrm{m}^{6} \mathrm{~A}$ readers in other animals,

369 and because the assay conditions do not discriminate between direct and indirect interactions,

370 we hypothesize that most these proteins indirectly bind $\mathrm{m}^{6} \mathrm{~A}$ via a limited number of 'scaffold'

$371 \mathrm{~m}^{6} \mathrm{~A}$ readers. Such authentic readers that only bind the $\mathrm{m}^{6} \mathrm{~A}-\mathrm{R} N \mathrm{~A}$ oligo in our assay likely

372 include YTHDC1 and elF3a, which have been demonstrated to directly bind $\mathrm{m}^{6} \mathrm{~A}$ in other

373 species, demonstrating the conservation of the $\mathrm{m}^{6} \mathrm{~A}$-binding capacity and specificity of the YTH 
374 domain in the oyster. Besides, YTHDC1 is found in both cell fractions, suggesting its 375 implication in the trafficking of $\mathrm{m}^{6} \mathrm{~A}-\mathrm{RNA}$ across the nuclear envelope [24], and reinforcing the 376 hypothesis that YTH proteins could participate in oyster MZT and cell differentiation. The 377 presence of the oyster eiF $3 a$ in the cytoplasm is consistent with a conserved role in $\mathrm{m}^{6} \mathrm{~A}$ 378 mediated translation processes, such as cap-independent translation [5].

379 Possible functions of $\mathbf{m}^{6} \mathrm{~A}-\mathrm{RNA}$ in oyster development.

380 We investigated the expression level and the functional annotation of the 162 genes encoding

381 the $\mathrm{m}^{6} \mathrm{~A}$-interacting proteins across oyster early life. These genes can be clustered into three 382 successive expression phases corresponding to three distinct functional pathways, which are 383 independent albeit all mostly related to translation regulation. The cluster 1 is mostly expressed 384 during the cleavage and the associated GO terms are related to the initiation of translation, 385 consistent with maternal RNA consumption before MZT is complete and the zygotic genome 386 becomes fully activated. The genes within cluster 3 show an expression peak during 387 gastrulation. Their ontology terms evoke ribosomal and mitochondrial processes, the latter 388 being required for energy supply and signalling integration during gastrulation [61-64]. The 389 cluster 2 contains genes that peak after gastrulation and which are related to splicing and 390 nuclear export. Such functional annotations are in line with a fine regulation of transcript variant 391 translation within the distinct cell lineages in the three cell layers of the late embryos.

393 Taken together, our findings bring to light a possible implication of $\mathrm{m}^{6} \mathrm{~A}$ in oyster development.

394 First, during cleavage the decrease of $\mathrm{m}^{6} \mathrm{~A}-\mathrm{RNA}$, the weak expression of methyltransferase 395 complex genes, the maximum of YTHDF gene expression and the expression of $\mathrm{Cg}$-m ${ }^{6} \mathrm{~A}-\mathrm{BPs}$ 
related to the initiation of the translation strongly suggest the implication of $\mathrm{m}^{6} \mathrm{~A}$ in MZT in $\mathrm{C}$. gigas. Second, the increasing $\mathrm{m}^{6} \mathrm{~A}$ level during gastrula stage is correlated to the increase of methyltransferase complex gene expression. In addition, the increased RNA level of readers putatively related to cell differentiation and the peak of gene expression of $\mathrm{Cg}^{-\mathrm{m}^{6} \mathrm{~A}-\mathrm{BPs}}$ associated to ribosomal and mitochondrial processes, support the hypothesize of a $\mathrm{m}^{6} \mathrm{~A}$ implication in gastrulation. Finally, the highest $\mathrm{m}^{6} \mathrm{~A}$ level at the trochophore stage, the gene expression of the methyltransferase complex and of readers associated to cell differentiation, as well as high RNA level of $\mathrm{Cg}-\mathrm{m}^{6} \mathrm{~A}-\mathrm{BPs}$ related to splicing and nuclear export is correlated with the fine cell differentiation taking place at this stage. However, inferring the biological significance of $\mathrm{m}^{6} \mathrm{~A}$ in development from the indirect and incomplete functional annotation of the oyster genome is only limited. Characterization of the precise targets of $\mathrm{m}^{6} \mathrm{~A}$ and how their individual methylation is regulated across development, for example using high throughput sequencing of precipitated $\mathrm{m}^{6} \mathrm{~A}-\mathrm{RNA}$ (MeRIP-seq), could be extremely relevant to better understand this issue. In addition, despite sequence conservation and binding ability of oyster actor orthologues strongly suggest functional conservation, future dedicated studies such as biochemical inhibition or gene inactivation could help demonstrate their genuine biological function. Besides, there seems to be an inverse correlation between $\mathrm{m}^{6} \mathrm{~A}-\mathrm{RNA}$ and $5 \mathrm{mC}$-DNA levels during the considered oyster developmental window [46]. This may suggest an interplay between epigenetic and epitranscriptomic marks, possibly reflecting competition for methyldonor availability [59] or a link by histone epigenetic pathways $[65,66]$.

Regarding the potential influence of the environment on $\mathrm{m}^{6} \mathrm{~A}$ and the accumulation of RNA in oocytes, we are at present investigating our hypothesis that $\mathrm{m}^{6} \mathrm{~A}$ may convey intergenerational 
418 epitranscriptomic inheritance of maternal life traits in the oyster. On an evolutionary 419 perspective, the presence of a putatively fully conserved epitranscriptomic pathway in the 420 oyster suggests that it was already present in the bilaterian common ancestor thereby in favour 421 of an important biological significance. Why Drosophila and Caenorhabditis seem to have lost 422 specific $\mathrm{m}^{6} \mathrm{~A}-\mathrm{RNA}$ erasers could be related to a sub-functionalization of the DMAD [41] and 423 NMAD-1 [42] $N^{6}$-methyladenine DNA demethylase activity broadened towards RNA. However, 424 more work in required to better understand the evo-devo implications of our results.

To conclude, in this work we report the discovery and characterisation of a putatively complete epitranscriptomic pathway in a lophotrochozoan organism, the oyster Crassostrea gigas. This pathway includes the $\mathrm{m}^{6} \mathrm{~A}$ mark in RNA and the actors of all the aspects of its regulation 429 (writers, eraser, readers) which are conserved at the molecular level and putatively functional. We show that $\mathrm{m}^{6} \mathrm{~A}$ levels are variable across oyster development and that $\mathrm{m}^{6} \mathrm{~A}$ differentially 431 affects distinct RNA populations. Expression levels of the related enzymatic machinery is 432 consistent with the observed $\mathrm{m}^{6} \mathrm{~A}$ level variations. We demonstrate the $\mathrm{m}^{6} \mathrm{~A}$ binding capacity 433 and specificity of putative oyster $\mathrm{m}^{6} \mathrm{~A}$ readers in the cytoplasm and nucleus of embryolarval 434 cells. These readers mediate distinct putative biological outcomes depending on the 435 development stage considered. From these results we hypothesize that early decay of 436 maternal $\mathrm{m}^{6} \mathrm{~A}$ RNA participates in maternal-to-zygotic transition during cleavage and that later 437 de novo zygotic m6A methylation contributes to gastrulation and cell differentiation. This first 438 characterisation of an $\mathrm{m}^{6} \mathrm{~A}$-epitranscriptomic pathway in a lophotrochozoan organism, together 439 with its potential implication in development, opens new perspectives on the evolution of 
440

441 induced life traits.

\section{Methods:}

444

445 Animals:

446 Broodstock oysters [67] and oyster embryos [46] were obtained at the IFREMER marine 447 facilities (Argenton, France) as previously described. Briefly, gametes of mature broodstock 448 oysters were obtained by stripping the gonads and filtering the recovered material on a $60 \mu \mathrm{m}$ 449 mesh to remove large debris. Oocytes were collected as the remaining fraction on a $20 \mu \mathrm{m}$ 450 mesh and spermatozoa as the passing fraction on a $20 \mu \mathrm{m}$ mesh. Oocytes were pre-incubated 451 in $5 \mathrm{~L}$ of UV-treated and $1 \mu \mathrm{m}$ filtered sterile sea water (SSW) at $21^{\circ} \mathrm{C}$ until germinal vesicle 452 breakdown. Fertilization was triggered by the addition of ca.10 spermatozoids per oocyte. After 453 the expulsion of the second polar body was assessed by light microscopy, embryos were 454 transferred in $150 \mathrm{~L}$ tanks of oxygenated SSW at $21^{\circ} \mathrm{C}$. The development stages were 455 determined by light microscopy observation. The stages collected were oocytes (E, 456 immediately before sperm addition), fertilized oocytes ( $F$ E, immediately before transfer to 457 150L tanks), two to eight cell embryos (2/8 C, ca. 1.5 hours post fertilization (hpf)), morula (M, 458 ca. 4 hpf), blastula (B, ca. 6 hpf), gastrula (G, ca. $10 \mathrm{hpf})$, trochophore (T, ca $16 \mathrm{hpf}$ ) and D 459 larvae (D, ca. $24 \mathrm{hpf})$. For each development stage, 3 million embryos were collected as the 460 remaining fraction on a $20 \mu \mathrm{m}$ mesh and centrifuged at $123 \mathrm{~g}$ for $5 \mathrm{~min}$ at room temperature. 
461 Supernatant was discarded and samples of 1 million embryos were then snap-frozen in liquid 462 nitrogen directly of after resuspension in Tri-Reagent (Sigma-Aldrich, St Louis, MO, USA) (1 $463 \mathrm{~mL} / 10^{6}$ embryos) and stored at $-80^{\circ} \mathrm{C}$. Three distinct experiments were realized (February to 464 May 2019) using the gametes of 126 to 140 broodstock animals, respectively.

465

466 RNA extraction:

467 - total RNA extraction

468 RNA was extracted using phenol-chloroform followed by affinity chromatography as previously 469 described [68]. Briefly, embryos were ground in Tri-Reagent (Sigma-Aldrich) and RNA was 470 purified using affinity chromatography (Nucleospin RNA II kit, Macherey-Nagel, Duren, 471 Germany). Potential contaminating DNA was removed by digestion with rDNase (Macherey472 Nagel) according to the manufacturer's instructions for 15 min at $37^{\circ} \mathrm{C}$ then RNA was purified 473 using Beckman Coulter's solid-phase reversible immobilization (SPRI) paramagnetic beads 474 (AgencourtAMPure XP, Beckman Coulter, Brea, CA, USA) according to the manufacturer's 475 instructions. Briefly, paramagnetic beads and RNAs were mixed slowly and incubated 5 min 476 at room temperature followed by 2 min on a magnetic rack. Cleared supernatant was removed, 477 and beads were washed three times with $70 \%$ ethanol. After 4 min of drying at room 478 temperature, RNAs were mixed slowly with RNase free water and incubated for 1 min at room 479 temperature on the magnetic rack. Eluted total RNA was stored at $-80^{\circ} \mathrm{C}$.

- PolyA RNA enrichment

481 Poly-A RNA was extracted from total RNA by oligo-dT affinity chromatography (NucleoTrap 482 mRNA kit, Macherey-Nagel) according to the manufacturer's instructions. Briefly, up to $130 \mu \mathrm{g}$ 
483 of total RNAs were mixed with oligo-dT latex beads and incubated for 5 min at $68{ }^{\circ} \mathrm{C}$ then 10 $484 \mathrm{~min}$ at room temperature. After centrifugation (2,000 $\mathrm{g}$ then $11,000 \mathrm{~g})$, the pellets were washed 485 three times on the microfilter and dried by centrifugation at $11,000 \mathrm{~g}$ for $1 \mathrm{~min}$. Finally, polyA+ 486 RNA was incubated with RNAse-free water for $7 \mathrm{~min}$ at $68{ }^{\circ} \mathrm{C}$ then centrifuged at $11,000 \mathrm{~g}$ for 487 1 min. Eluted polyA+ RNA was stored at $-80^{\circ} \mathrm{C}$ until needed.

488 Total and polyA-enriched RNA purity and concentrations were assayed by spectrophotometry 489 (Nanodrop, Thermo Scientific, Waltham, MA, USA).

$\mathrm{m}^{6} \mathrm{~A}$ quantification by LC-MS/MS:

- RNA hydrolysis

493 To generate nucleosides for quantification against standard curves, $5 \mu \mathrm{g}$ of total RNA were 494 denatured for $10 \mathrm{~min}$ at $70{ }^{\circ} \mathrm{C}$ followed by $10 \mathrm{~min}$ on ice, and hydrolyzed with $100 \mathrm{U}$ Nuclease $495 \mathrm{~S} 1(50 \mathrm{U} / \mu \mathrm{L}$, Promega, Madison, WI, USA) in Nuclease S1 buffer (Promega) in a final reaction 496 volume of $25 \mu \mathrm{L}$ for $2 \mathrm{~h}$ at $37^{\circ} \mathrm{C}$ under gentle shaking. Samples were then incubated with 497 alkaline phosphatase buffer (Promega) for $5 \mathrm{~min}$ at room temperature, before $10 \mathrm{U}$ alkaline 498 phosphatase (Promega) were added and incubated further for $2 \mathrm{~h}$ at $37^{\circ} \mathrm{C}$ under gentle 499 shaking. Ten extra units of alkaline phosphatase were added after 1 hour of incubation to 500 complete the reaction. Finally, samples were centrifuged at $13,000 \mathrm{rpm}$ for $10 \mathrm{~min}$ at $4{ }^{\circ} \mathrm{C}$ and 501 the supernatant containing digested total RNA was collected and kept at $-20{ }^{\circ} \mathrm{C}$ before 502 quantification.

$503-\mathrm{m}^{6} \mathrm{~A}$ quantification: 
504 The apparatus was composed of a NexeraX² UHPLC system coupled with LCMS8030 Plus

505 (Shimadzu, Kyoto, Japan) mass spectrometer using an electrospray interface in positive mode.

506 The column $(1.7 \mu \mathrm{m}, 100 \times 3 \mathrm{~mm})$ was a HILIC Aquity ${ }^{\circledR}$ Amide (Waters, Millford, MA, USA)

507 maintained at $35{ }^{\circ} \mathrm{C}$. The injection volume and run-to-run time were $3 \mu \mathrm{L}$ and $10 \mathrm{~min}$,

508 respectively. The flow rate was set to $1 \mathrm{~mL} / \mathrm{min}$. Mobile phase was initially composed of a

509 mixture of ammonium formate solution $(10 \mathrm{mM})$ containing $0.2 \%(\mathrm{v} / \mathrm{v})$ formic acid and $95 \%$

510 acetonitrile (ACN) and it was maintained for $1 \mathrm{~min}$. Then, a linear gradient was applied to reach

$51183 \% \mathrm{ACN}$ for $6 \mathrm{~min}$. The composition returned to the initial conditions and the column was

512 equilibrated for $3 \mathrm{~min}$.

513 The mass spectrometer was running in the Multiple Reaction Monitoring (MRM) acquisition

514 mode. LabSolutions 5.86 SP1 software was used to process the data. The desolvatation

515 temperature was $230{ }^{\circ} \mathrm{C}$, source temperature was $400{ }^{\circ} \mathrm{C}$ and nitrogen flows were $2.5 \mathrm{~L} / \mathrm{min}$

516 for the cone and $15 \mathrm{~L} / \mathrm{min}$ for the desolvatation. The capillary voltage was $+4.5 \mathrm{kV}$. For each

517 compound, two transitions were monitored from the fragmentation of the $[\mathrm{M}+\mathrm{H}]^{+}$ion. The first

518 transition (A in Table S1) was used for quantification and the second one (B in Table S1) for

519 confirmation of the compound according to European Commission Decision 2002/657/EC

520 (Table S1).

521 Blank plasma samples were analysed to check specificity. Calibrators were prepared using

522 diluted solutions of $A$ (Toronto Research Chemical, Toronto, Canada) and $\mathrm{m}^{6} \mathrm{~A}$ (Carbosynth,

523 Berkshire, UK) in water at 1, 2, 5, 10, 20 50, $100 \mathrm{ng} / \mathrm{mL}$ The calibration curves were drawn by

524 plotting the ratio of the peak area of $\mathrm{A}$ and $\mathrm{m}^{6} \mathrm{~A}$. For both nucleosides, a quadratic regression

525 with $1 / C$ weighting resulted in standard curves with $R^{2}>0.998$ and more than $75 \%$ of standards 
526 with back-calculated concentrations within $15 \%$ of their nominal values as recommended for

527 by the European medicines agency for bioanalytical methods [69]. The limits of quantifications

528 for both compounds were considered as the lowest concentrations of the calibration curve.

$529 \mathrm{~m}^{6} \mathrm{~A} / \mathrm{A}$ ratios were calculated for each single sample using the determined concentrations.

530 Final results are the average of three technical replicates.

531

532

$\mathrm{m}^{6} \mathrm{~A}$ quantification by immunoblotting:

533 Immunological quantification of $\mathrm{m}^{6} \mathrm{~A}$ was performed by dot-blot using total and polyA+ RNAs.

534 Dogfish total RNA (Dr. A. Gautier, personal communication) and a synthetic unmethylated

535 RNA oligo (Eurogentec, Liege, Belgium) were used as positive and negative controls,

536 respectively. RNA samples were denatured for $15 \mathrm{~min}$ at $55{ }^{\circ} \mathrm{C}$ with gentle shaking in

537 denaturing solution (2.2 M formaldehyde, $50 \%$ formamide, 0.5X MOPS, DEPC water) followed

538 by 2 min on ice. Blotting was performed on a vacuum manifold as follows: a nylon membrane

539 (Amersham Hybond-N+, GE Healthcare life Sciences, Chicago, IL, USA) was pre-hydrated in

540 DEPC water for $5 \mathrm{~min}$, then each well was washed twice with 10X SSC (Sigma-Aldrich) before

541 RNA was spotted onto the membrane and incubated for $15 \mathrm{~min}$ at room temperature. Then,

542 vacuum aspiration was applied and each well was washed twice with 10X SSC. After heat

543 crosslinking for $2 \mathrm{~h}$ at $70^{\circ} \mathrm{C}$, the membrane was rehydrated with DEPC water for $5 \mathrm{~min}$, washed

544 with PBS then PBST (PBS, $0.1 \%$ Tween-20) for 5 min each and blocked with two 5 min

545 incubations with blocking buffer (PBS, $0.1 \%$ Tween-20, $10 \%$ dry milk, $1 \%$ BSA) at room

546 temperature. The blocked membrane was incubated overnight at $4{ }^{\circ} \mathrm{C}$ under gentle shaking

547 with the anti-m ${ }^{6}$ A primary antibody (Total RNA: Millipore (Burlington, MA, USA) ABE572, 1 : 
5481,000 dilution in blocking buffer; polyA+ RNA: Diagenode (Liege, Belgium) C15200082, 1:500

549 dilution in blocking buffer) followed by four washes of PBST for $5 \mathrm{~min}$. The secondary antibody

550 (Total RNA: Dako (Santa Clara, CA, USA) P0447 goat anti-mouse HRP antibody, $1: 10,000$

551 dilution; polyA+ RNA: Invitrogen (Carlsbad, CA, USA) A21202 donkey anti-mouse Alexa 488,

$5521: 250$ dilution) was diluted in PBST supplemented with $5 \%$ dry milk and added onto the

553 membrane for $1 \mathrm{~h} 30$ (total RNA) or $1 \mathrm{~h}$ (polyA+ RNA) at room temperature under gentle

554 shaking. Membranes were extensively washed in PBST (at least 4 washes of 5 min for total

$555 \mathrm{RNA}$ and 5 min then $1 \mathrm{~h}$ for polyA+ RNA) then total and polyA+ RNA immunoblots were

556 visualized using chemiluminescence (ECL kit, Promega) or fluorescence scanning at 480-530

$557 \mathrm{~nm}$ (Pro Xpress, Perkin-Elmer, Waltham, MA, USA), respectively. The amount of $\mathrm{m}^{6} \mathrm{~A}$ was

558 inferred from dot intensity measurements using ImageJ (v.1.49). Signal intensities were

559 determined as 'integrated densities as a percentage of the total' which corresponds to the area

560 under the curve of the signal of each dot after membrane background and negative control

561 signal subtraction.

562

563 In silico analyses:

564 All protein and RNA sequences of the $\mathrm{m}^{6} \mathrm{~A}$ machinery of Homo sapiens and Drosophila 565 melanogaster (Data S1) were recovered by their published designation (i.e., 'METTL3' or 566 'YTHDF' etc.) and their identified protein sequence (ie. RefSeq accession number NP...) 567 collected from $\mathrm{NCBI}$ and used as query sequences to search for putative homologue 568 sequences in Crassostrea gigas databases. The presence of oyster orthologue RNA and 569 protein sequences were investigated by reciprocal 
570 BLAST(https://blast.ncbi.nlm.nih.gov/Blast.cgi) on the Crassostrea gigas GigaTON [70] and

$571 \mathrm{NCBI}$ databases and results were compared between the two oyster databases. Domain

572 prediction was performed with CD-search software

573 (https://www.ncbi.nlm.nih.gov/Structure/cdd/wrpsb.cgi) with default settings on protein

574 sequences of Homo sapiens, Drosophila melanogaster and Crassostrea gigas. The GRE-rich

575 domain identified in vertebrate Prrc2a sequence [27] was performed with ProtParam

576 (https://web.expasy.org/cgi-bin/protparam/protparam).

577

578 Protein machinery mRNA expression analyses:

579 The transcriptome data of the different development stages are available on the GigaTON

580 database $[70,71]$. The correspondence between development stages in our study, and the

581 GigaTON database were assessed using light microscopy based on the morphological

582 description by Zhang et al., 2012 [71] (Table S2). Expression data was expressed in TPM

583 (Transcripts Per Million) [72] to provide a normalized comparison of gene expression between

584 all samples. The actual presence of some transcripts that display unclear or chimeric

585 sequences within available oyster databases was assessed using RT-PCR (Data S1).

586

587 Protein $\mathrm{m}^{6} \mathrm{~A}$ RNA pull down:

588 - Protein extraction and RNA affinity chromatography

589 Protein extraction and RNA affinity chromatography were performed as described previously

590 [27] with some modifications as follows. Equal amounts (1 million individuals) of each

591 developmental stage (oocyte to D larvae) were pooled together then homogenized in 3.5 
592 volumes of buffer $\mathrm{A}(10 \mathrm{mM} \mathrm{KCl}, 1.5 \mathrm{mM} \mathrm{MgCl}$, $10 \mathrm{mM}$ HEPES, pH 7.9, DEPC water, 1X 593 Protease inhibitor cocktail, DTT $0.5 \mathrm{mM}$ ) by extensive pipetting (ca. 30 times) and incubated 59410 min at $4{ }^{\circ} \mathrm{C}$. Embryos were ground with 10 slow $23 \mathrm{G}$-needle syringe strokes and centrifuged 595 at $2,000 \mathrm{rpm}$ for $10 \mathrm{~min}$ at $4{ }^{\circ} \mathrm{C}$. The supernatant was diluted in 0.11 volume of buffer $\mathrm{B}(1.4 \mathrm{M}$ $596 \mathrm{KCl}, 0.03 \mathrm{M} \mathrm{MgCl}$, HEPES 0.3 M, pH 7.9, DEPC water), centrifuged at 10,000 $\mathrm{g}$ for $1 \mathrm{~h}$ at 4 $597{ }^{\circ} \mathrm{C}$ and the supernatant containing cytosolic proteins was stored at $-80{ }^{\circ} \mathrm{C}$. The pellet of the 598 first centrifugation, containing nuclei, was re-suspended in two volumes of buffer C (0.42 M $599 \mathrm{NaCl}, 1.5 \mathrm{mM} \mathrm{MgCl}$, 0.2 mM EDTA, 25 \% glycerol, 20 mM HEPES, pH 7.9, 0.5 mM PMSF, $600 \quad 0.5 \mathrm{mM}$ DTT, water DEPC). Nuclei were then lysed with a $23 \mathrm{G}$ needle (10 vigorous syringe 601 strokes) followed by centrifugation at $30,000 \mathrm{rpm}$ for $30 \mathrm{~min}$ at $4{ }^{\circ} \mathrm{C}$ and the supernatant 602 containing nuclear proteins was stored at $-80^{\circ} \mathrm{C}$.

603 To identify putative proteins able to bind $\mathrm{m}^{6} \mathrm{~A}-\mathrm{RNA}$, the cytosolic and nuclear fractions were 604 submitted to affinity chromatography using 5'-biotin-labelled RNA oligonucleotides either 605 bearing $N^{6}$-methylated adenosines or not. The methylated adenosines were designed to lie 606 within RRACH motifs, according to the conserved methylated consensus sequence in other 607 organisms $[2,3,7,33,73]$ (oligo- ${ }^{6}{ }^{6} \mathrm{~A}: \quad$ 5'Biotin-AGAAAAGACAACCAACGAGRR-m ${ }^{6}$ A608 CWCAUCAU-3', oligo-A: 5'Biotin-AGAAAAGACAACCAACGAGRRACWCAUCAU-3', R = A or $609 \mathrm{G}, \mathrm{W}=\mathrm{A}$ or U, Eurogentec).

610 For RNA pull down, streptavidin-conjugated magnetic beads (Dynabeads Myone Streptavidin, 611 Invitrogen) were pre-blocked with $0.2 \mathrm{mg} / \mathrm{mL}$ tRNA (Sigma-Aldrich) and $0.2 \mathrm{mg} / \mathrm{mL}$ BSA for 1 $612 \mathrm{~h}$ at $4{ }^{\circ} \mathrm{C}$ under gentle rotation followed by three washes with $0.1 \mathrm{M} \mathrm{NaCl}$. To avoid the 613 identification of non-target proteins, cytosolic and nuclear protein extracts were cleared with 
614 pre-blocked magnetic beads in binding buffer (50 mM Tris- $\mathrm{HCl}, 250 \mathrm{mM} \mathrm{NaCl}, 0.4 \mathrm{mM}$ EDTA,

$6150.1 \%$ NP-40, DEPC water, $1 \mathrm{mM} \mathrm{DTT}, 0.4 \mathrm{U} / \mu \mathrm{L}$ RNAsin) for $1 \mathrm{~h}$ at $4{ }^{\circ} \mathrm{C}$ under gentle rotation.

616 After incubation on magnetic rack, the supernatants containing putative target proteins were

617 collected and mixed with pre-blocked magnetic beads and oligo-m ${ }^{6} \mathrm{~A}$ or oligo-A for $2 \mathrm{~h}$ at $4{ }^{\circ} \mathrm{C}$

618 under gentle rotation. The beads binding putative target proteins were washed three times with

619 binding buffer and diluted in $50 \mathrm{mM}$ ammonium bicarbonate.

620

- Identification of $\mathrm{m}^{6} \mathrm{~A}-$ binding proteins by LC-MS/MS:

621 Protein samples were first reduced, alkylated and digested with trypsin then desalted and

622 concentrated onto a $\mu \mathrm{C} 18$ Omix (Agilent, Santa Clara, CA, USA) before analysis.

623 The chromatography step was performed on a NanoElute (Bruker Daltonics, Billerica, MA,

624 USA) ultra-high pressure nano flow chromatography system. Peptides were concentrated onto

625 a C18 pepmap $100(5 \mathrm{~mm} \times 300 \mu \mathrm{m}$ i.d.) precolumn (Thermo Scientific) and separated at 50

$626{ }^{\circ} \mathrm{C}$ onto a reversed phase Reprosil column $(25 \mathrm{~cm} \times 75 \mu \mathrm{m}$ i.d. $)$ packed with $1.6 \mu \mathrm{m} \mathrm{C} 18$ coated

627 porous silica beads (Ionopticks, Parkville, Victoria, Australia). Mobile phases consisted of 0.1

$628 \%$ formic acid, $99.9 \%$ water (v/v) (A) and $0.1 \%$ formic acid in $99.9 \%$ ACN (v/v) (B). The

629 nanoflow rate was set at $400 \mathrm{~nL} / \mathrm{min}$, and the gradient profile was as follows: from 2 to $15 \% \mathrm{~B}$

630 within 60 min, followed by an increase to $25 \%$ B within 30 min and further to $37 \%$ within 10

631 min, followed by a washing step at $95 \%$ B and re-equilibration.

632 MS experiments were carried out on an TIMS-TOF pro mass spectrometer (Bruker Daltonics)

633 with a modified nano-electrospray ion source (CaptiveSpray, Bruker Daltonics). The system

634 was calibrated each week and mass precision was better than $1 \mathrm{ppm}$. A 1600 spray voltage

635 with a capillary temperature of $180{ }^{\circ} \mathrm{C}$ was typically employed for ionizing. MS spectra were 
636 acquired in the positive mode in the mass range from 100 to $1700 \mathrm{~m} / \mathrm{z}$. In the experiments 637 described here, the mass spectrometer was operated in PASEF mode with exclusion of single 638 charged peptides. A number of 10 PASEF MS/MS scans was performed during 1.16 seconds 639 from charge range $2-5$.

640 The fragmentation pattern was used to determine the sequence of the peptide. Database 641 searching was performed using the Mascot 2.6.1 program (Matrix Science) with a Crassostrea 642 gigas Uniprot database (including 25,982 entries). The variable modifications allowed were as 643 follows: C-Carbamidomethyl, K-acetylation, methionine oxidation, and Deamidation (NQ). The 644 'Trypsin' parameter was set to 'Semispecific'. Mass accuracy was set to $30 \mathrm{ppm}$ and $0.05 \mathrm{Da}$ 645 for MS and MS/MS mode respectively. Mascot data were then transferred to Proline validation 646 software (http://www.profiproteomics.fr/proline/) for data filtering according to a significance 647 threshold of $<0.05$ and the elimination of protein redundancy on the basis of proteins being 648 evidenced by the same set or a subset of peptides (Data S2).

- Gene ontology analysis:

650 The mRNA sequences of the characterized $\mathrm{m}^{6} \mathrm{~A}$-binding proteins were identified using tBlastn 651 [74-76] against the GigaTON database [70] with default settings. Gene ontology (GO) 652 analyses were carried out with the GO annotations obtained from GigaTON database gene 653 universe [70]. GO term-enrichment tests were performed using the goseq (V1.22.0) R package 654 [77] with p-values calculated by the Wallenius method and filtered using REVIGO [78]. GO 655 terms with a p-value $<0.05$ were considered significantly enriched (Data S3). 
658 Results are given as the mean \pm SD of three independent experiments unless otherwise stated.

659 They were analysed using one-way ANOVA or Kruskall-wallis tests when required, depending

660 on the normality of result distribution. The normality was tested using the Shapiro-Wilk's test

661 and homoscedasticity of variances with Bartlett's tests. Statistics and graphics were computed 662

with Prism v.6 (Graphpad), R (v.3.6.1) and RStudio (v.1.0.153) softwares. The R packages

663 eulerr [79] and Complexheatmap [80] were used for production of specific figures.

664

665

666

Author contribution

667 Experiment design: GR, LLF.

668 Benchwork and bioinformatics: LLF, GR, BB, BP, MS.

669 Data analysis: LLF, GR, BB, MS.

670 Manuscript writing and editing: LLF, GR, PF, BB, MS, BP.

671

672 Acknowledgements

673 The authors would like to acknowledge PRISMM core facility collaborators R. Delepée and S.

674 Lagadu for their expertise in $\mathrm{m}^{6} \mathrm{~A} / \mathrm{A}$ UHPLC-MS/MS quantification. We also thank J. Pontin for

675 technical assistance and J. Le Grand for help with sampling.

676

677 Funding sources and disclosure of conflicts of interest 
678 This work was supported by the French National program CNRS EC2CO (Ecosphère 679 Continentale et Côtière 'HERITAGe' to G. Rivière) and the council of the Normandy Region 680 (RIN ECUME to P. Favrel). The authors declare they have no conflict of interest.

681 


\section{References:}

1 Saletore Y, Meyer K, Korlach J, Vilfan ID, Jaffrey S \& Mason CE (2012) The birth of the Epitranscriptome: deciphering the function of RNA modifications. Genome Biol. 13, 175.

2 Meyer KD, Saletore Y, Zumbo P, Elemento O, Mason CE \& Jaffrey SR (2012) Comprehensive analysis of mRNA methylation reveals enrichment in 3' UTRs and near stop codons. Cell 149, 1635-1646.

3 Dominissini D, Moshitch-moshkovitz S, Schwartz S, Salmon-Divon M, Ungar L, Osenberg S, Cesarkas K, Jacob-hirsch J, Amariglio N, Kupiee M, Sorek R \& Rechavi G (2012) Topology of the human and mouse $\mathrm{m} 6 \mathrm{~A}$ RNAmethylomes revealed bym6A-seq. Nature 485, 201-206.

4 Ke S, Alemu EA, Mertens C, Gantman EC, Fak JJ, Mele A, Haripal B, Zucker-Scharff I, Moore MJ, Park CY, Vågbø CB, Kusśnierczyk A, Klungland A, Darnell JE, Darnell RB, Kuśnierczyk A, Klungland A, Darnell JE, Darnell RB, Kusśnierczyk A, Klungland A, Darnell JE \& Darnell RB (2015) A majority of $m 6$ A residues are in the last exons, allowing the potential for 3' UTR regulation. Genes Dev. 29, 2037-2053.

5 Meyer KD, Patil DP, Zhou J, Zinoviev A, Skabkin MA, Elemento O, Pestova T V., Qian SB \& Jaffrey SR (2015) 5' UTR m6A Promotes Cap-Independent Translation. Cell 163, 999-1010.

6 Pendleton KE, Chen B, Liu K, Hunter O V., Xie Y, Tu BP \& Conrad NK (2017) The U6 snRNA m6A Methyltransferase METTL16 Regulates SAM Synthetase Intron Retention. Cell 169, 824-835.e14.

7 Lence T, Akhtar J, Bayer M, Schmid K, Spindler L, Ho CH, Kreim N, Andrade-Navarro MA, Poeck B, Helm M \& Roignant JY (2016) M6A modulates neuronal functions and sex determination in Drosophila. Nature 540, 242-247.

8 Bokar JA, Shambaugh ME, Polayes D, Matera AG \& Rottman FM (1997) Purification and cDNA cloning of the AdoMet-binding subunit of the human mRNA (N6-adenosine)methyltransferase. RNA 3, 1233-47.

9 Liu J, Yue Y, Han D, Wang X, Fu YY, Zhang L, Jia G, Yu M, Lu Z, Deng X, Dai Q, Chen W \& He C (2013) A METTL3-METTL14 complex mediates mammalian nuclear RNA N6adenosine methylation. Nat. Chem. Biol. 10, 93-95.

10 Wang X, Feng J, Xue Y, Guan Z, Zhang D, Liu Z, Gong Z, Wang Q, Huang J, Tang C, Zou T \& Yin P (2016) Structural basis of N6-adenosine methylation by the METTL3METTL14 complex. Nature 534, 575-578.

11 Ping X-LL, Sun B-FF, Wang L, Xiao W, Yang X, Wang W-JJ, Adhikari S, Shi Y, Lv Y, Chen Y-SS, Zhao X, Li A, Yang YGYY-G, Dahal U, Lou X-MM, Liu X, Huang J, Yuan WPP, Zhu X-FF, Cheng T, Zhao Y-LL, Wang X, Danielsen JMRR, Liu F \& Yang YGYY-G (2014) Mammalian WTAP is a regulatory subunit of the RNA N6-methyladenosine methyltransferase. Cell Res. 24, 177-189.

12 Yue Y, Liu J, Cui X, Cao J, Luo G, Zhang Z, Cheng T, Gao M, Shu X, Ma H, Wang F, Wang X, Shen B, Wang Y, Feng X, He C \& Liu J (2018) VIRMA mediates preferential m6A mRNA methylation in 3'UTR and near stop codon and associates with alternative polyadenylation. Cell Discov. 4, 10.

13 Růžička K, Zhang M, Campilho A, Bodi Z, Kashif M, Saleh M, Eeckhout D, El-Showk S, Li H, Zhong S, Jaeger G De, Mongan NP, Hejátko J, Helariutta Y \& Fray RG (2017) Identification of factors required for m6A mRNA methylation in Arabidopsis reveals a 
role for the conserved E3 ubiquitin ligase HAKAI. New Phytol. 215, 157-172.

14 Knuckles P, Lence T, Haussmann IU, Jacob D, Kreim N, Carl SH, Masiello I, Hares T, Villaseñor R, Hess D, Andrade-Navarro MA, Biggiogera M, Helm M, Soller M, Bühler M \& Roignant J-YY (2018) Zc3h13/Flacc is required for adenosine methylation by bridging the mRNA-binding factor Rbm15/Spenito to the $\mathrm{m} 6 \mathrm{~A}$ machinery component Wtap/FI(2)d. Genes Dev. 32, 1-15.

15 Patil DP, Chen CK, Pickering BF, Chow A, Jackson C, Guttman M \& Jaffrey SR (2016) m6A RNA methylation promotes XIST-mediated transcriptional repression. Nature $\mathbf{5 3 7}$, 369-373.

16 Zheng G, Dahl JA, Niu Y, Fedorcsak P, Huang CM, Li CJ, Vågbø CB, Shi Y, Wang WL, Song SH, Lu Z, Bosmans RPG, Dai Q, Hao YJ, Yang X, Zhao WM, Tong WM, Wang XJ, Bogdan F, Furu K, Fu Y, Jia G, Zhao X, Liu J, Krokan HE, Klungland A, Yang YG \& He C (2013) ALKBH5 Is a Mammalian RNA Demethylase that Impacts RNA Metabolism and Mouse Fertility. Mol. Cell 49, 18-29.

17 Mauer J, Luo X, Blanjoie A, Jiao X, Grozhik A V, Patil DP, Linder B, Pickering BF, Vasseur J-J, Chen Q, Gross SS, Elemento O, Debart F, Kiledjian M \& Jaffrey SR (2017) Reversible methylation of m6Am in the $5^{\prime}$ cap controls mRNA stability. Nature 541, 371375.

18 Jia G, Fu Y, Zhao X, Dai Q, Zheng G, Yang YGYY-GGYY-G, Yi C, Lindahl T, Pan T, Yang YGYY-GGYY-G \& He C (2011) N6-Methyladenosine in nuclear RNA is a major substrate of the obesity-associated FTO. Nat. Chem. Biol. 7, 885-887.

19 Wang X, Lu Z, Gomez A, Hon GC, Yue Y, Han D, Fu Y, Parisien M, Dai Q, Jia G, Ren B, Pan T, He C, Zhike L, Gomez A, Hon GC, Yue Y, Han D, Fu Y, Ärisien M, Dai Q, Jia G, Ren B, Pan T \& He C (2014) N6-methyladenosine-dependent regulation of messenger RNA stability. Nature 505, 117-120.

20 Wang X, Zhao BS, Roundtree IA, Lu Z, Han D, Ma H, Weng X, Chen K, Shi H \& He C (2015) N6-methyladenosine modulates messenger RNA translation efficiency. Cell 161, 1388-1399.

21 Hsu PJ, Zhu Y, Ma H, Guo Y, Shi X, Liu Y, Qi M, Lu Z, Shi H, Wang J, Cheng Y, Luo G, Dai Q, Liu M, Guo X, Sha J, Shen B \& He C (2017) Ythdc2 is an N6-methyladenosine binding protein that regulates mammalian spermatogenesis. Cell Res. 27, 1115-1127.

22 Shi H, Wang X, Lu Z, Zhao BS, Ma H, Hsu PJ, Liu C \& He C (2017) YTHDF3 facilitates translation and decay of N 6-methyladenosine-modified RNA. Cell Res. 27, 315-328.

23 Xiao W, Adhikari S, Dahal U, Chen Y-S, Hao Y-J, Sun B-F, Sun H-Y, Li A, Ping X-L, Lai W-Y, Wang XX-J, Ma H-L, Huang C-M, Yang YY-G, Huang N, Jiang G-B, Wang H-L, Zhou Q, Wang XX-J, Zhao Y-L \& Yang YY-G (2016) Nuclear $m 6$ A Reader YTHDC1 Regulates mRNA Splicing. Mol. Cell 61, 507-519.

24 Roundtree IA, Luo G-ZZ, Zhang Z, Wang X, Zhou T, Cui Y, Sha J, Huang X, Guerrero L, Xie P, He E, Shen B \& He C (2017) YTHDC1 mediates nuclear export of N6methyladenosine methylated mRNAs. Elife 6, 1-28.

25 Alarcón CR, Goodarzi H, Lee H, Liu X, Tavazoie SFSSF \& Tavazoie SFSSF (2015) HNRNPA2B1 Is a Mediator of m6A-Dependent Nuclear RNA Processing Events. Cell 162, 1299-1308.

26 Huang $H$, Weng $H$, Sun W, Qin X, Shi H, Wu H, Zhao BS, Mesquita A, Liu C, Yuan CL, Hu YC, Hüttelmaier S, Skibbe JR, Su R, Deng X, Dong L, Sun M, Li C, Nachtergaele S, 
Wang Y, Hu C, Ferchen K, Greis KD, Jiang X, Wei M, Qu L, Guan JL, He C, Yang J \& Chen J (2018) Recognition of RNA N6-methyladenosine by IGF2BP proteins enhances mRNA stability and translation. Nat. Cell Biol. 20, 285-295.

27 Wu R, Li A, Sun B, Sun J-GG, Zhang J, Zhang T, Chen Y, Xiao Y, Gao Y, Zhang Q, Ma J, Yang X, Liao Y, Lai W-YY, Qi X, Wang S, Shu Y, Wang H-LL, Wang F, Yang Y-GG \& Yuan $Z$ (2018) A novel m6A reader Prrc2a controls oligodendroglial specification and myelination. Cell Res. 29, 23-41.

28 Bertero A, Brown S, Madrigal P, Osnato A, Ortmann D, Yiangou L, Kadiwala J, Hubner NC, De Los Mozos IR, Sadee C, Lenaerts A-SS, Nakanoh S, Grandy R, Farnell E, Ule J, Stunnenberg HG, Mendjan S, Vallier L, Sadée C, Lenaerts A-SS, Nakanoh S, Grandy R, Farnell E, Ule J, Stunnenberg HG, Mendjan S \& Vallier L (2018) The SMAD2/3 interactome reveals that TGF $\beta$ controls $\mathrm{m} 6 \mathrm{~A}$ mRNA methylation in pluripotency. Nature 555, 256-259.

29 Kwon J, Jo YJ, Namgoong S \& Kim NH (2019) Functional roles of hnRNPA2/B1 regulated by METTL3 in mammalian embryonic development. Sci. Rep. 9, 8640.

30 Geula S, Moshitch-Moshkovitz S, Dominissini D, Mansour AAF, Kol N, Salmon-Divon M, Hershkovitz V, Peer E, Mor N, Manor YS, Ben-Haim MS, Eyal E, Yunger S, Pinto Y, Jaitin DA, Viukov S, Rais Y, Krupalnik V, Chomsky E, Zerbib M, Maza I, Rechavi Y, Massarwa R, Hanna S, Amit I, Levanon EY, Amariglio N, Stern-Ginossar N, Novershtern N, Rechavi G \& Hanna JH (2015) m6A mRNA methylation facilitates resolution of naïve pluripotency toward differentiation. Science (80-. ). 347, 1002-1006.

31 Batista PJ, Molinie B, Wang J, Qu K, Zhang J, Li L, Bouley DM, Lujan E, Haddad B, Daneshvar K, Carter AC, Flynn RA, Zhou C, Lim KS, Dedon P, Wernig M, Mullen AC, Xing Y, Giallourakis CC, Chang HY, Howard Y, Batista PJ, Molinie B, Wang J, Qu K, Zhang J, Li L, Bouley DM, Dedon P, Wernig M, Mullen AC, Xing Y, Giallourakis CC \& Chang HY (2014) $\mathrm{M}^{6} \mathrm{~A}$ RNA modification controls cell fate transition in mammalian embryonic stem cells. Cell Stem Cell 15, 707-719.

32 Wojtas MN, Pandey RR, Mendel M, Homolka D, Sachidanandam R \& Pillai RS (2017) Regulation of m6A Transcripts by the $3^{\prime} \rightarrow 5^{\prime}$ RNA Helicase YTHDC2 Is Essential for a Successful Meiotic Program in the Mammalian Germline. Mol. Cell 68, 374-387.e12.

33 Zhao BS, Wang X, Beadell A V., Lu Z, Shi H, Kuuspalu A, Ho RK \& He C (2017) M6Adependent maternal mRNA clearance facilitates zebrafish maternal-to-zygotic transition. Nature 542, 475-478.

34 Kan L, Grozhik A V., Vedanayagam J, Patil DP, Pang N, Lim K-S, Huang Y-C, Joseph B, Lin C-J, Despic V, Guo J, Yan D, Kondo S, Deng W-M, Dedon PC, Jaffrey SR \& Lai EC (2017) The m6A pathway facilitates sex determination in Drosophila. Nat. Commun. 8, 15737.

35 Kasowitz SD, Ma J, Anderson SJ, Leu NA, Xu Y, Gregory BD, Schultz RM \& Wang PJ (2018) Nuclear $m 6$ A reader YTHDC1 regulates alternative polyadenylation and splicing during mouse oocyte development. PLoS Genet. 14, 1-28.

36 Ivanova I, Much C, Di Giacomo M, Azzi C, Morgan M, Moreira PN, Monahan J, Carrieri C, Enright AJ, O'Carroll D, Giacomo M Di, Azzi C, Morgan M, Moreira PN, Monahan J, Carrieri C, Enright AJ, O'carroll D, Di Giacomo M, Azzi C, Morgan M, Moreira PN, Monahan J, Carrieri C, Enright AJ \& O'carroll D (2017) The RNA m 6 A Reader YTHDF2 Is Essential for the Post-transcriptional Regulation of the Maternal Transcriptome and Oocyte Competence. Mol. Cell 67, 1059-1067.e4. 
37 Lence T, Paolantoni C, Worpenberg L \& Roignant JY (2019) Mechanistic insights into m 6 A RNA enzymes. Biochim. Biophys. Acta - Gene Regul. Mech. 1862, 222-229.

38 Balacco DL \& Soller M (2018) The $\mathrm{m}^{6} \mathrm{~A}$ writer: Rise of a machine for growing tasks. Biochemistry 58, acs.biochem.8b01166.

39 Lence T, Soller M \& Roignant JY (2017) A fly view on the roles and mechanisms of the m6A mRNA modification and its players. RNA Biol. 14, 1232-1240.

40 Robbens S, Rouzé P, Cock JM, Spring J, Worden AZ \& Van De Peer Y (2008) The FTO gene, implicated in human obesity, is found only in vertebrates and marine algae. $J$. Mol. Evol. 66, 80-84.

41 Zhang G, Huang H, Liu D, Cheng Y, Liu X, Zhang W, Yin R, Zhang D, Zhang P, Liu J, Li C, Liu B, Luo Y, Zhu Y, Zhang N, He S, He C, Wang H \& Chen D (2015) N6methyladenine DNA modification in Drosophila. Cell 161, 893-906.

42 Greer EL, Blanco MA, Gu L, Sendinc E, Liu J, Aristizábal-Corrales D, Hsu CH, Aravind L, He C \& Shi Y (2015) DNA methylation on N6-adenine in C. elegans. Cell 161, 868-878.

43 Riviere G, He Y, Tecchio S, Crowell E, Sourdaine P, Guo X \& Favrel P (2017) Dynamics of DNA methylomes underlie oyster development. PLOS Genet. 13, 1-16.

44 Sussarellu R, Lebreton M, Rouxel J, Akcha F, Riviere G \& Rivière G (2018) Copper induces expression and methylation changes of early development genes in Crassostrea gigas embryos. Aquat. Toxicol. 196, submitted.

45 Rondon R, Grunau C, Fallet M, Charlemagne N, Sussarellu R, Chaparro C, Montagnani C, Mitta G, Bachère E, Akcha F \& Cosseau C (2017) Effects of a parental exposure to diuron on Pacific oyster spat methylome. Environ. Epigenetics 3, 1-13.

46 Riviere G, Wu G-CC, Fellous A, Goux D, Sourdaine P \& Favrel P (2013) DNA Methylation Is Crucial for the Early Development in the Oyster C . gigas. Mar. Biotechnol. 15, 1-15.

47 Saint-Carlier E \& Riviere G (2015) Regulation of Hox orthologues in the oyster Crassostrea gigas evidences a functional role for promoter DNA methylation in an invertebrate. FEBS Lett. 589, 1459-1466.

48 Fellous A, Favrel P \& Riviere G (2015) Temperature influences histone methylation and mRNA expression of the Jmj-C histone-demethylase orthologues during the early development of the oyster Crassostrea gigas. Mar. Genomics 19, 23-30.

49 Fellous A, Favrel P, Guo X \& Riviere G (2014) The Jumonji gene family in Crassostrea gigas suggests evolutionary conservation of $\mathrm{Jmj}-\mathrm{C}$ histone demethylases orthologues in the oyster gametogenesis and development. Gene 538, 164-175.

50 Fellous A, Le Franc L, Jouaux A, Goux D, Favrel P \& Rivière G (2019) Histone Methylation Participates in Gene Expression Control during the Early Development of the Pacific Oyster Crassostrea gigas. Genes (Basel). 10, 695.

51 Zhou J, Wan J, Gao X, Zhang X, Jaffrey SR \& Qian S-B (2015) Dynamic m6A mRNA methylation directs translational control of heat shock response. Nature 526, 591-594.

52 Lu Z, Ma Y, Li Q, Liu E, Jin M, Zhang L \& Wei C (2019) The role of N6-methyladenosine RNA methylation in the heat stress response of sheep (Ovis aries). Cell Stress Chaperones 24, 333-342.

53 Xiang Y, Laurent B, Hsu C, Nachtergaele S, Lu Z, Sheng W, Xu C, Chen H, Ouyang J, 
Wang S, Ling D, Hsu P, Zou L, Jambhekar A \& He C (2017) m6A RNA methylation regulates the UV-induced DNA damage response. Nature 543, 573-576.

54 Cayir A, Barrow TM, Guo L \& Byun HM (2019) Exposure to environmental toxicants reduces global N6-methyladenosine RNA methylation and alters expression of RNA methylation modulator genes. Environ. Res. 175, 228-234.

55 Liu J, Li K, Cai J, Zhang M, Zhang X, Xiong X, Meng H, Xu X, Huang Z, Fan J \& Yi C (2019) Landscape and Regulation of $M^{6} A$ and $M{ }^{6} A m$ Methylome Across Human and Mouse Tissues. SSRN Electron. J., 1-56.

56 Ren W, Lu J, Huang M, Gao L, Li D, Greg Wang G \& Song J (2019) Structure and regulation of ZCCHC4 in m6A-methylation of 28S rRNA. Nat. Commun. 10, 5042.

57 Bokar JA, Shambaugh ME, Polayes D, Matera AG \& Rottman FM (1997) Purification and cDNA cloning of the AdoMet-binding subunit of the human mRNA (N6-adenosine)methyltransferase. RNA 3, 1233-1247.

58 Theler D, Dominguez C, Blatter M, Boudet J \& Allain FHT (2014) Solution structure of the YTH domain in complex with N6-methyladenosine RNA: A reader of methylated RNA. Nucleic Acids Res. 42, 13911-13919.

59 Shima H, Matsumoto M, Ishigami Y, Ebina M, Muto A, Sato Y, Kumagai S, Ochiai K, Suzuki T \& Igarashi K (2017) S-Adenosylmethionine Synthesis Is Regulated by Selective N6-Adenosine Methylation and mRNA Degradation Involving METTL16 and YTHDC1. Cell Rep. 21, 3354-3363.

60 Yurchenko O V., Skiteva OI, Voronezhskaya EE \& Dyachuk VA (2018) Nervous system development in the Pacific oyster, Crassostrea gigas ( Mollusca : Bivalvia ). Front. Zool. $15,1-21$.

61 Ratnaparkhi A (2013) Signaling by folded gastrulation is modulated by mitochondrial fusion and fission. J. Cell Sci. 126, 5369-5376.

62 Ren L, Zhang C, Tao L, Hao J, Tan K, Miao K, Yu Y, Sui L, Wu Z, Tian J \& An L (2017) High-resolution profiles of gene expression and DNA methylation highlight mitochondrial modifications during early embryonic development. J. Reprod. Dev. 63, 247-261.

63 Prudent J, Popgeorgiev N, Bonneau B, Thibaut J, Gadet R, Lopez J, Gonzalo P, Rimokh R, Manon S, Houart C, Herbomel P, Aouacheria A \& Gillet G (2013) Bcl-wav and the mitochondrial calcium uniporter drive gastrula morphogenesis in zebrafish. Nat. Commun. 4.

64 Dumollard R, Duchen M \& Carroll J (2007) The Role of Mitochondrial Function in the Oocyte and Embryo. Curr. Top. Dev. Biol. 77, 21-49.

65 Huang $\mathrm{H}$, Weng $\mathrm{H}$, Zhou K, Wu T, Zhao BS, Sun MM, Chen Z, Deng X, Xiao G, Auer F, Klemm L, Wu H, Zuo Z, Qin X, Dong Y, Zhou Y, Qin H, Tao S, Du J, Liu J, Lu Z, Yin H, Mesquita A, Yuan CL, Hu Y-CC, Sun W, Su R, Dong L, Shen C, Li C, Qing Y, Jiang X, Wu X, Sun MM, Guan J-LL, Qu L, Wei M, Müschen M, Huang G, He C, Yang J \& Chen $\mathrm{J}(2019)$ Histone $\mathrm{H} 3$ trimethylation at lysine 36 guides m6A RNA modification cotranscriptionally. Nature 567, 414-419.

66 Wang Y, Li Y, Yue M, Wang J, Kumar S, Wechsler-Reya RJ, Zhang Z, Ogawa Y, Kellis M, Duester G \& Zhao JC (2018) N 6-methyladenosine RNA modification regulates embryonic neural stem cell self-renewal through histone modifications. Nat. Neurosci. 21, 195-206. 
904

905

906

907

908

909

910

911

912

913

914

915

916

917

918

919

920

921

922

923

924

925

926

927

928

929

930

931

932

933

934

935

936

937

938
67 Petton B, Pernet F, Robert R \& Boudry P (2013) Temperature influence on pathogen transmission and subsequent mortalities in juvenile pacific oysters Crassostrea gigas. Aquac. Environ. Interact. 3, 257-273.

68 Riviere G, Fellous A, Franco A, Bernay B \& Favrel P (2011) A crucial role in fertility for the oyster angiotensin-converting enzyme orthologue CgACE. PLoS One 6.

69 EMA (2011) Guideline on bioanalytical method validation. EMEA/CHMP/EWP/192217/2009.

70 Riviere G, Klopp C, Ibouniyamine N, Huvet A, Boudry P \& Favrel P (2015) GigaTON: An extensive publicly searchable database providing a new reference transcriptome in the pacific oyster Crassostrea gigas. BMC Bioinformatics 16, 1-12.

71 Zhang G, Fang X, Guo X, Li L, Luo R, Xu F, Yang P, Zhang L, Wu F, Chen Y, Wang J, Peng C, Meng J, Yang L, Liu J, Wen B, Zhang N \& Huang Z (2012) The oyster genome reveals stress adaptation and complexity of shell formation. Nature 490, 49-54.

72 Li B, Ruotti V, Stewart RM, Thomson JA \& Dewey CN (2010) RNA-Seq gene expression estimation with read mapping uncertainty. Bioinformatics 26, 493-500.

73 Qi ST, Ma JY, Wang ZB, Guo L, Hou Y \& Sun QY (2016) N6 -methyladenosine sequencing highlights the involvement of mRNA methylation in oocyte meiotic maturation and embryo development by regulating translation in xenopus laevis. J. Biol. Chem. 291, 23020-23026.

74 Altschul SF, Madden TL, Schäffer AA, Zhang J, Zhang Z, Miller W \& Lipman DJ (1997) Gapped BLAST and PSI-BLAST: a new generation of protein database search programs. Nucleic Acids Res. 25, 3389-3402.

75 Cock PJA, Chilton JM, Grüning B, Johnson JE \& Soranzo N (2015) NCBI BLAST+ integrated into Galaxy. Gigascience 4, 0-6.

76 Camacho C, Coulouris G, Avagyan V, Ma N, Papadopoulos J, Bealer K \& Madden TL (2009) BLAST+: Architecture and applications. BMC Bioinformatics 10, 1-9.

77 Young MD, Wakefield MJ, Smyth GK \& Oshlack A (2010) Gene ontology analysis for RNA-seq: accounting for selection bias. Genome Biol. 11, R14.

78 Supek F, Bošnjak M, Škunca N \& Šmuc T (2011) Revigo summarizes and visualizes long lists of gene ontology terms. PLoS One 6.

79 Larsson J (2019) eulerr: Area-Proportional Euler and Venn Diagrams with Ellipses. .

$80 \mathrm{Gu} Z$, Eils R \& Schlesner M (2016) Complex heatmaps reveal patterns and correlations in multidimensional genomic data. Bioinformatics 32, 2847-2849. 
939

940

941

942

943

944

945

946

947

\section{Figure legends}

\section{Figure 1: $\mathrm{m}^{6} \mathrm{~A}$ levels across oyster development.}

A. $\mathrm{m}^{6} \mathrm{~A}$ level quantified by LC-MS/MS in Crassostrea gigas embryo-larval stages pooled from oocytes to D-larvae $(n=3)$ is compared to the $\mathrm{m}^{6} \mathrm{~A}$ level in Homo sapiens and Drosophila melanogaster; B. Dot blot quantification of $\mathrm{m}^{6} \mathrm{~A}$ in total RNA throughout oyster development $(n=3)$; C. Dot blot quantification of $m^{6} A$ in polyA+RNAs throughout oyster development $(n=3)$ Kruskal-Wallis test, $\alpha<0,05$. E: Egg, F E: fertilized egg, 2/8C: two to eight cell embryos, M: Morula, B: Blastula, G: Gastrula, T: Trochophore, D: D larvae. Chemiluminescence (B) and fluorescence $(C)$ are measured as a ratio between dot intensity of development stages and their respective controls for each amount of RNA (120ng, 60ng and 30ng).

Figure 2: The putative conserved $\mathrm{m}^{6} \mathrm{~A}$ machinery in Crassostrea gigas.

Domain architecture of actors of the $\mathrm{m}^{6} \mathrm{~A}$ machinery identified by in silico analyses in the oyster compared to the fruit fly and human, A. Writer proteins; B. Eraser protein; C. Reader proteins. Putative domains involved in $\mathrm{m}^{6} \mathrm{~A}$ processes are coloured (writers, green; eraser, red; readers, blue). Other domains identified but not involved in $\mathrm{m}^{6} \mathrm{~A}$ processes are indicated in grey. Only one isoform is represented for each protein and each species for clarity (see supplementary figure $\mathrm{S} 2$ for other isoforms). 
959 Expression levels of writers (A), eraser (B) and readers (C) identified by in silico analysis at 960 each development stage were inferred from the GigaTON database. Expression levels are 961 given in Transcripts Per kilobases per Million Reads (TPM) as the mean of the GigaTON values 962 according to the table S2. E: Egg, 2/8C: two to eight cell, M: Morula, B: Blastula, G: Gastrula, 963 T: Trochophore, D: D larvae, S: Spat, J: Juvenile.

965 Figure 4: Characterization of $\mathrm{m}^{6} \mathrm{~A}-\mathrm{RNA}$ binding proteins in oyster development.

966 A. Venn diagrams representation of proteins bound to the $\mathrm{A}$ - and/or $\mathrm{m}^{6} \mathrm{~A}$ - oligos in nuclear and 967 cytosolic fractions of oyster embryo-larval stages. The number of proteins identified is 968 indicated. Some actors characterized in this study are highlighted: elF3, YTHC1, hnRNPA2B1

969 and IGF2BP. B. Heatmap of gene expression levels of the proteins that bind specifically to the $970 \mathrm{~m}^{6} \mathrm{~A}$-oligo throughout oyster development. The expression level is normalized regarding the 971 maximum value for each gene according to the GigaTON database. C. GO term distribution 972 among the three expression clusters in B. D. Examples of GO term enrichment within the 973 expression clusters of the $\mathrm{m}^{6} \mathrm{~A}$-bound proteins. The -log10(p-value) associated to each term 974 is given. E: Egg, 2/8C: two to eight cells, M: Morula, B: Blastula, G: Gastrula, T: Trochophore, 975 D: D larvae, S: Spat, J: Juvenile.

\section{Supporting information:}

977 Data S1: Complete list of in silico identified putative $\mathrm{m}^{6} \mathrm{~A}$ machinery proteins and their 978 respective BLAST results

979 Data S2: Identified proteins by RNA pull down coupled with mass spectrometry with $\mathrm{m}^{6} \mathrm{~A}$ or 980 A-oligo, in nuclear or cytosolic protein extracts 
981 Data S3: Complete list of GO terms of clustered genes of $m^{6} \mathrm{~A}$ interacting proteins ( $p$ 982 value $<0,05)$

983 Table S1: Transitions used for each compound. A: first transition, B: second transition

984 Table S2: Table of correspondence between development stages in our study, and the 985 GigaTON database. 
A

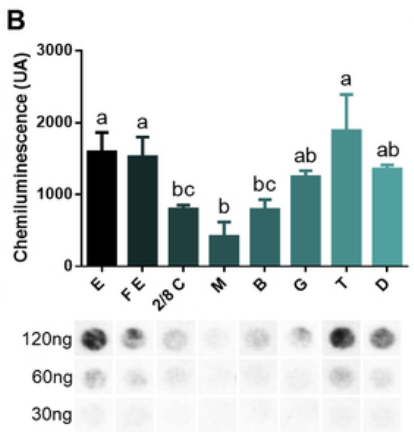

C
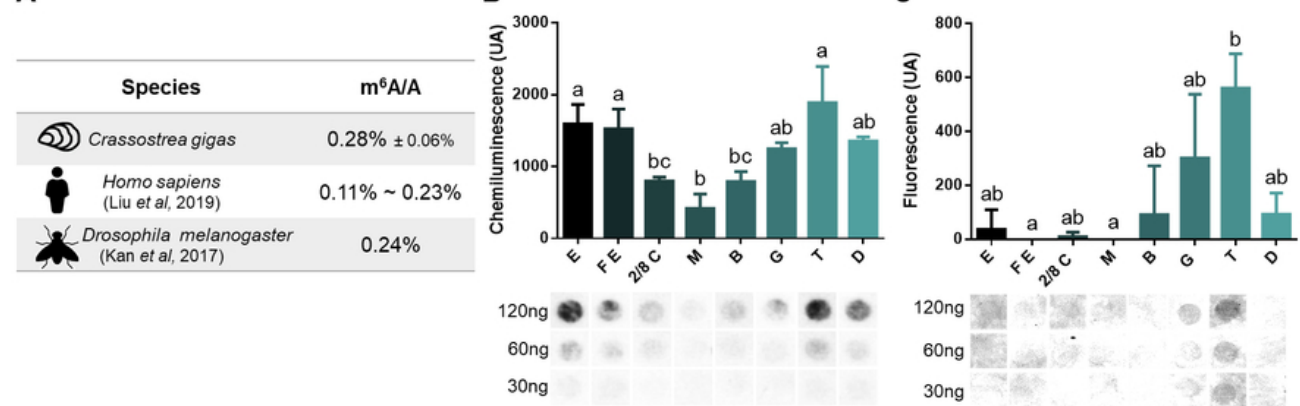

Figure 1: m6A levels across oyster development.

A. m6A level quantified by LC-MS/MS in Crassostrea gigas embryo-larval stages pooled from oocytes to Dlarvae $(n=3)$ is compared to the m6A level in Homo sapiens and Drosophila melanogaster; B. Dot blot quantification of m6A in total RNA throughout oyster development $(n=3) ; C$. Dot blot quantification of m6A in polyA+ RNAs throughout oyster development $(n=3)$ Kruskal-Wallis test, $a<0,05$. E: Egg, F E: fertilized egg, 2/8C: two to eight cell embryos, M: Morula, B: Blastula, G: Gastrula, T: Trochophore, D: D larvae. Chemiluminescence $(B)$ and fluorescence $(C)$ are measured as a ratio between dot intensity of development stages and their respective controls for each amount of RNA (120ng, 60ng and 30ng). 

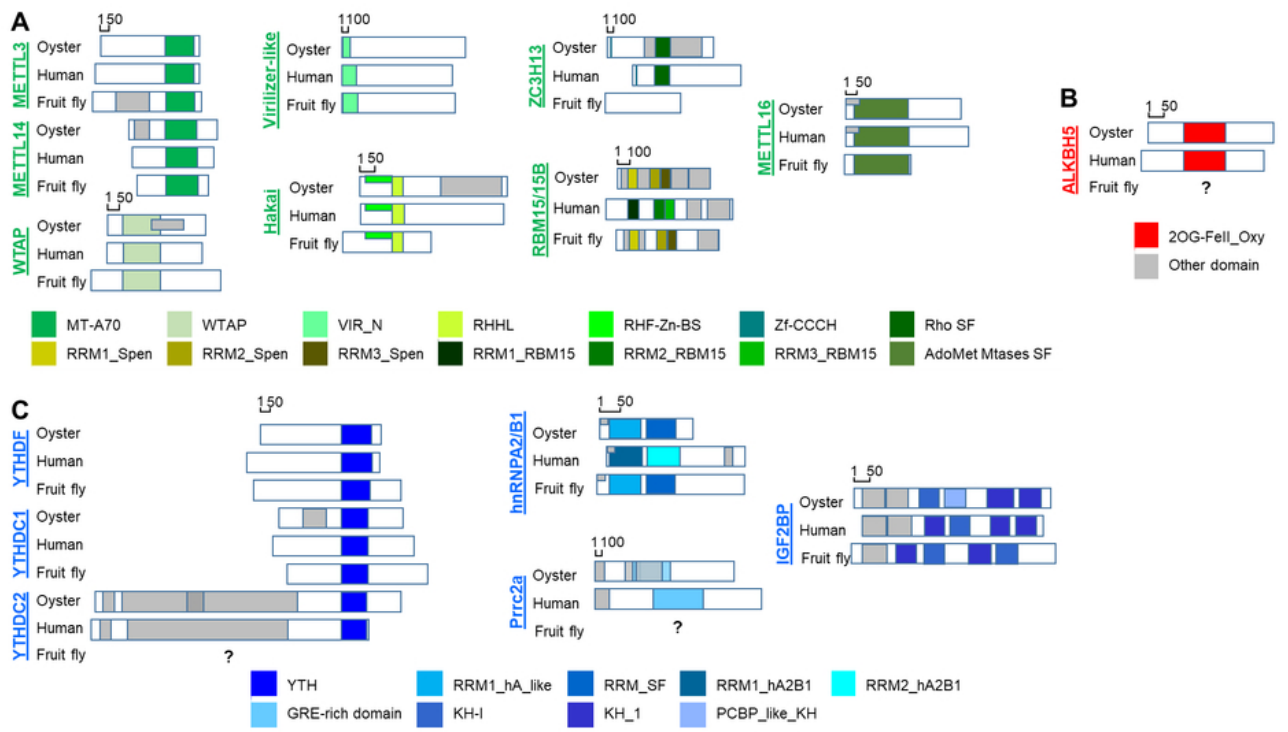

Figure 2: The putative conserved m6A machinery in Crassostrea gigas.

Domain architecture of actors of the $\mathrm{m6A}$ machinery identified by in silico analyses in the oyster compared to the fruit fly and human, A. Writer proteins; B. Eraser protein; C. Reader proteins. Putative domains involved in $\mathrm{m6 \textrm {A }}$ processes are coloured (writers, green; eraser, red; readers, blue). Other domains identified but not involved in m6A processes are indicated in grey. Only one isoform is represented for each protein and each species for clarity (see supplementary figure S2 for other isoforms).

$80 \times 47 m m(300 \times 300$ DPI) 

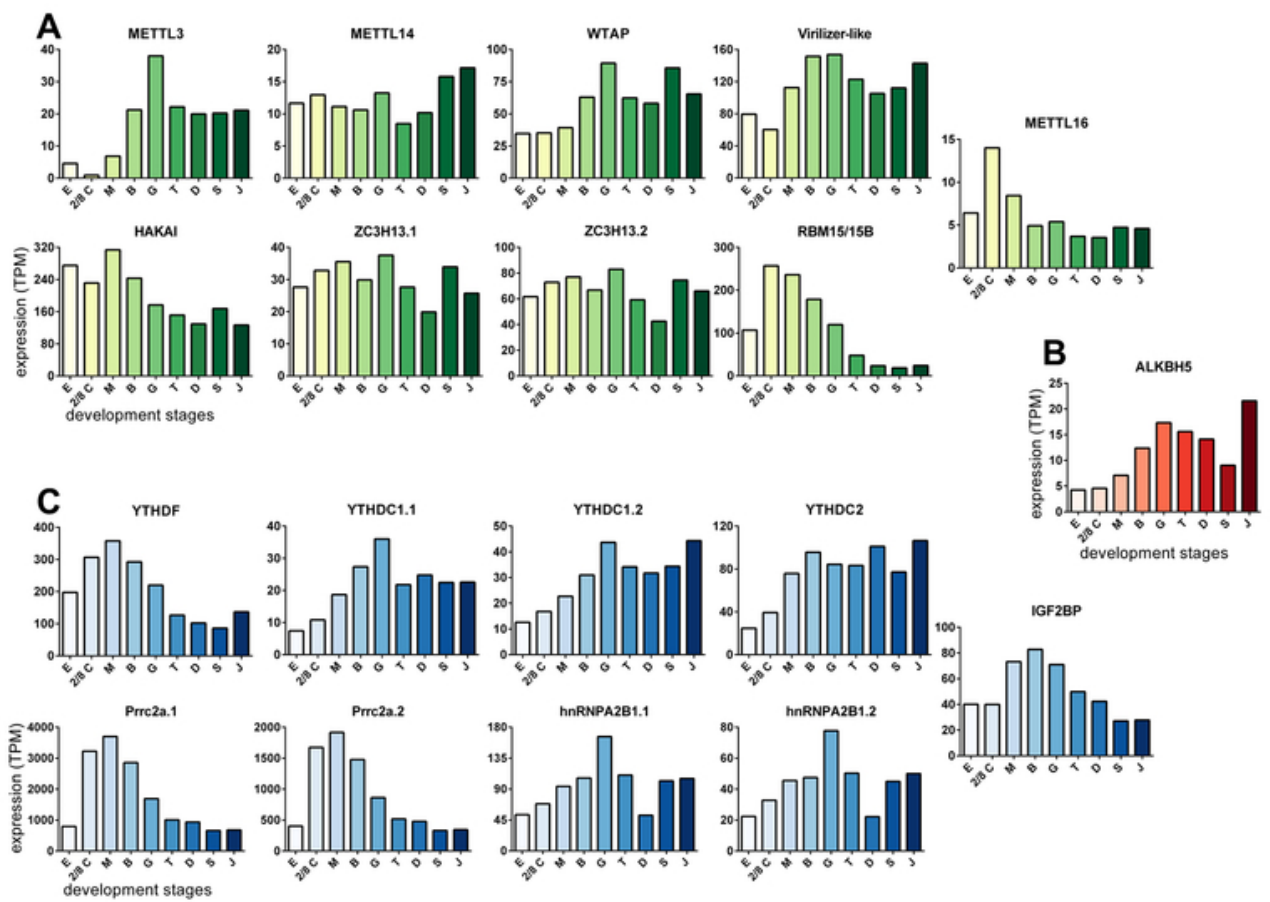

Figure 3: Gene expression of the putative m6A machinery throughout oyster development Expression levels of writers (A), eraser (B) and readers (C) identified by in silico analysis at each development stage were inferred from the GigaTON database. Expression levels are given in Transcripts Per kilobases per Million Reads (TPM) as the mean of the GigaTON values according to the table S2. E: Egg, 2/8C: two to eight cell, M: Morula, B: Blastula, G: Gastrula, T: Trochophore, D: D larvae, S: Spat, J: Juvenile. 
A
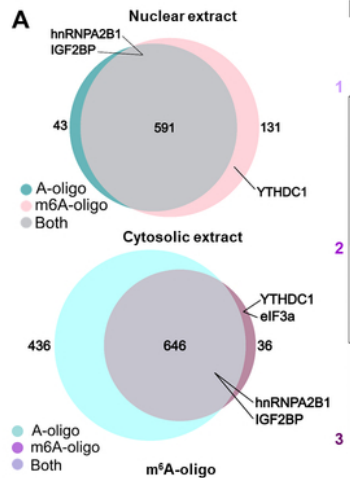
- m6A-oligo

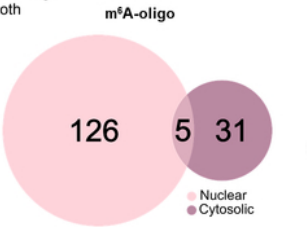

B

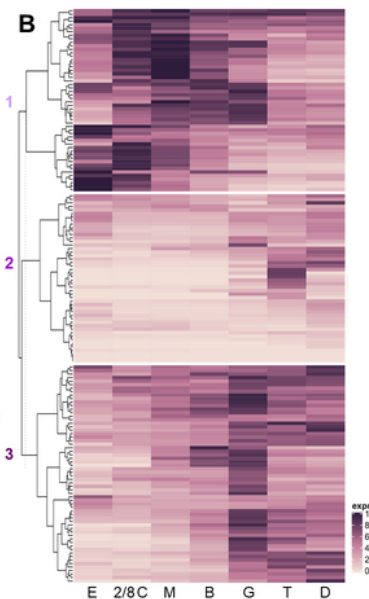

C

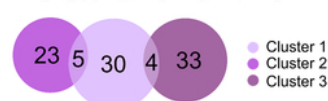

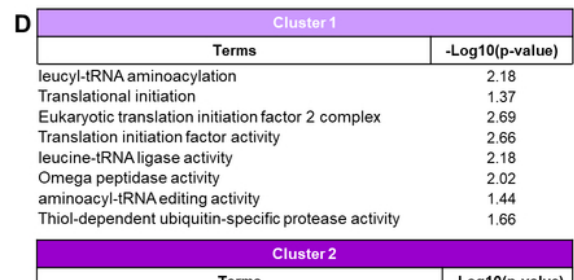

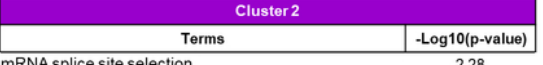

mRNA splice site selection

Protein import into nucleus U1 snRNP

Nuclear pore

Structural constituent of nuclear pore

mRNA binding

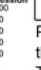

\begin{tabular}{|c|l|}
\hline \multicolumn{1}{|c|}{ Terms } & -Log10(p-value) \\
\hline Protein polymerization &
\end{tabular}

Protein polymerization $\quad 2.68$

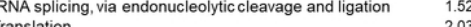
Eukaryotic translation initiation factor 3 complex Ribosome

Ribosome

Succinate-clex ligase (adp-forming) activity

Structural constituent of ribosome

Figure 4: Characterization of m6A-RNA binding proteins in oyster development.

A. Venn diagrams representation of proteins bound to the A- and/or m6A- oligos in nuclear and cytosolic fractions of oyster embryo-larval stages. The number of proteins identified is indicated. Some actors characterized in this study are highlighted: eIF3, YTHC1, hnRNPA2B1 and IGF2BP. B. Heatmap of gene expression levels of the proteins that bind specifically to the m6A-oligo throughout oyster development. The expression level is normalized regarding the maximum value for each gene according to the GigaTON database. C. GO term distribution among the three expression clusters in B. D. Examples of GO term enrichment within the expression clusters of the m6A-bound proteins. The $-\log 10(\mathrm{p}$-value) associated to each term is given. E: Egg, 2/8C: two to eight cells, M: Morula, B: Blastula, G: Gastrula, T: Trochophore, D: D larvae, S: Spat, J: Juvenile.

$85 \times 49 \mathrm{~mm}(300 \times 300 \mathrm{DPI})$ 
Data S1: Complete list of in silico identified putative m6A machinery proteins and their respective BLAST results Probable assembly artefact highlighted in grey

\begin{tabular}{|c|c|c|c|c|c|}
\hline Specie & database & sequence accession number & length & & conserved domain \\
\hline \multicolumn{6}{|c|}{$\underline{\text { METTL3 }}$} \\
\hline Homo sapiens & NCBI & gi|21361827 (NP_062826.2) & 580 & MT-A70 & \\
\hline Drosophila melanogaster (IME4) & NCBI & gi|21355141 (NP_651204.1) & 608 & MT-A70 & MDN1 \\
\hline \multirow{2}{*}{ Crassostrea gigas } & GIGATON & CHOYP_PHUM_PHUM423190.1.1 & 554 & MT-A70 & \\
\hline & $\mathrm{NCBI}$ & gi|762092209 (XP_011428532.1) & 555 & MT-A70 & \\
\hline \multicolumn{6}{|c|}{ METTL14 } \\
\hline Homo sapiens & $\mathrm{NCBI}$ & gi|24308265 (NP_066012.1) & 456 & MT-A70 & \\
\hline Drosophila melanogaster (CG7818) & $\mathrm{NCBI}$ & gi|19920926 (NP_609205.1) & 397 & MT-A70 & \\
\hline \multirow{3}{*}{ Crassostrea gigas } & \multirow{2}{*}{ GIGATON } & CHOYP_MET14.1.1 & 495 & MT-A70 & MttA_Hfc106 \\
\hline & & CHOYP_LOC100743733.1.1 & 723 & MT-A70 & 7tmA_NPR-like_invertebrate \\
\hline & $\mathrm{NCBI}$ & gi|762082967 (XP_011424173.1) & 470 & MT-A70 & MttA_Hfc106 \\
\hline \multicolumn{6}{|c|}{ WTAP } \\
\hline \multirow{3}{*}{ Homo sapiens } & \multirow{3}{*}{ NCBI } & gi||395455090 (NP_001257460.1) & 396 & WTAP & \\
\hline & & gi|23199974 (NP_690596.1) & 151 & WTAP & \\
\hline & & gi|395455092 (NP_001257461.1) & 170 & WTAP & \\
\hline \multirow{2}{*}{ Drosophila melanogaster $(\mathrm{FL}(2) \mathrm{D})$} & \multirow{2}{*}{ NCBI } & gi|24653459 (NP_523732.2) & 536 & WTAP & \\
\hline & & gi|24653461 (NP_725327.1) & 412 & WTAP & \\
\hline \multirow{4}{*}{ Crassostrea gigas } & \multirow{3}{*}{ GIGATON } & CHOYP_FL2D.1.1 & 406 & WTAP & IncA \\
\hline & & CHOYP_SODM.1.2 & 252 & WTAP & IncA \\
\hline & & CHOYP_LOC100121674.1.1 & 290 & WTAP & $\operatorname{Inc} A$ \\
\hline & NCBI & gi|762078268 (XP_011453082.1) & 406 & WTAP & $\operatorname{Inc} A$ \\
\hline
\end{tabular}


YTHDF

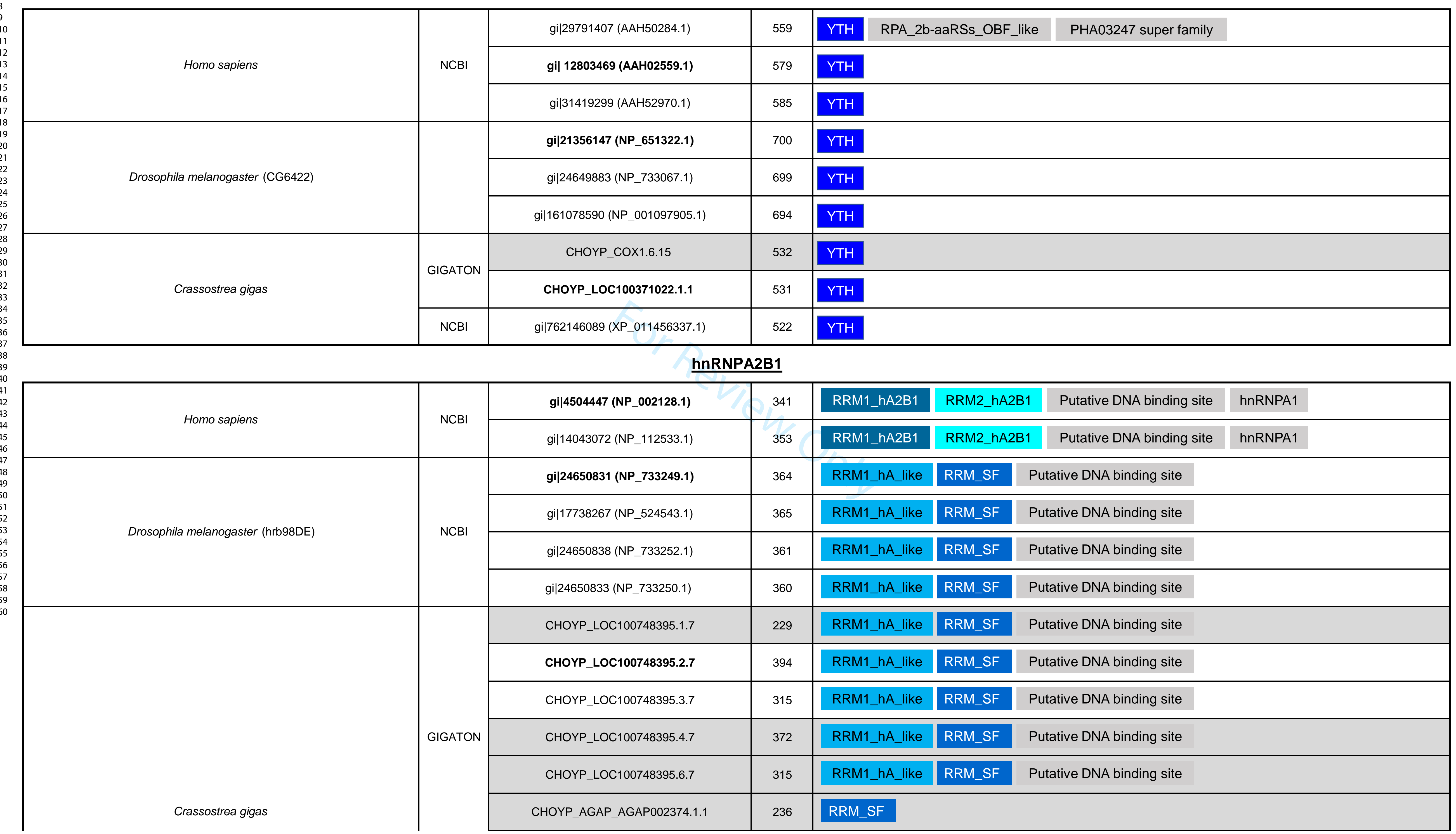


Drosophila melanogaster (IGF-II binding protein)

\begin{tabular}{|c|c|c|c|c|c|c|c|}
\hline \multirow{2}{*}{ NCBI } & gi|386764191 (NP_001245616.1) & 638 & $\mathrm{KH}-\mathrm{I}$ & $\mathrm{KH}-1$ & \multicolumn{3}{|l|}{ RRM2_VICKZ } \\
\hline & gi|281360685 (NP_001162717.1) & 580 & $\mathrm{KH}-\mathrm{I}$ & $\mathrm{KH}-1$ & & & \\
\hline GIGATON & CHOYP_LOC100114171.1.1 & 607 & $\mathrm{KH}-\mathrm{I}$ & $\mathrm{KH}-1$ & PCBP_like_KH & RRM1_VICKZ & RRM_SF super family \\
\hline \multirow[t]{2}{*}{ NCBI } & gi|762079093 (XP_011412008.1) & 607 & $\mathrm{KH}-\mathrm{I}$ & $\mathrm{KH}-1$ & PCBP_like_KH & RRM1_VICKZ & RRM_SF super family \\
\hline & gi|762079095 (XP_011412017.1) & 590 & $\mathrm{KH}-\mathrm{I}$ & $\mathrm{KH}-1$ & PCBP_like_KH & RRM1_VICKZ & RRM_SF super family \\
\hline
\end{tabular}

elF3a

\begin{tabular}{|c|c|c|c|c|c|c|c|c|c|}
\hline Homo sapiens & $\mathrm{NCBI}$ & gi|4503509(NP_003741.1) & 1382 & PINT & Smc supe & amily & U2AF_Ig super family & dnaA super family & Rho SF \\
\hline \multirow{2}{*}{ Drosophila melanogaster (IGF-II binding protein) } & \multirow{2}{*}{ NCBI } & gi|665393171 (NP_730838.3) & 1140 & PINT & DUF5401 & \multicolumn{2}{|c|}{ Rho SF } & & \\
\hline & & gi|24643988 (NP_649470.2) & 1140 & PINT & DUF5401 & Rho & & & \\
\hline \multirow{5}{*}{ Crassostrea gigas } & \multirow{3}{*}{ GIGATON } & CHOYP_BRAFLDRAFT_75590.1.1 & 155 & & & & & & \\
\hline & & CHOYP_UBP47.2.2 & 1253 & PAM & DUF5401 & & & & \\
\hline & & CHOYP_MROH1.1.1 & 1046 & PAM & DUF5401 & & & & \\
\hline & \multirow{2}{*}{$\mathrm{NCBI}$} & gi|762160635 (XP_011418535.1) & 759 & PAM & DUF5401 & & & & \\
\hline & & gi|762122193 (XP_011444042.1) & 1252 & PAM & DUF5401 & & & & \\
\hline
\end{tabular}




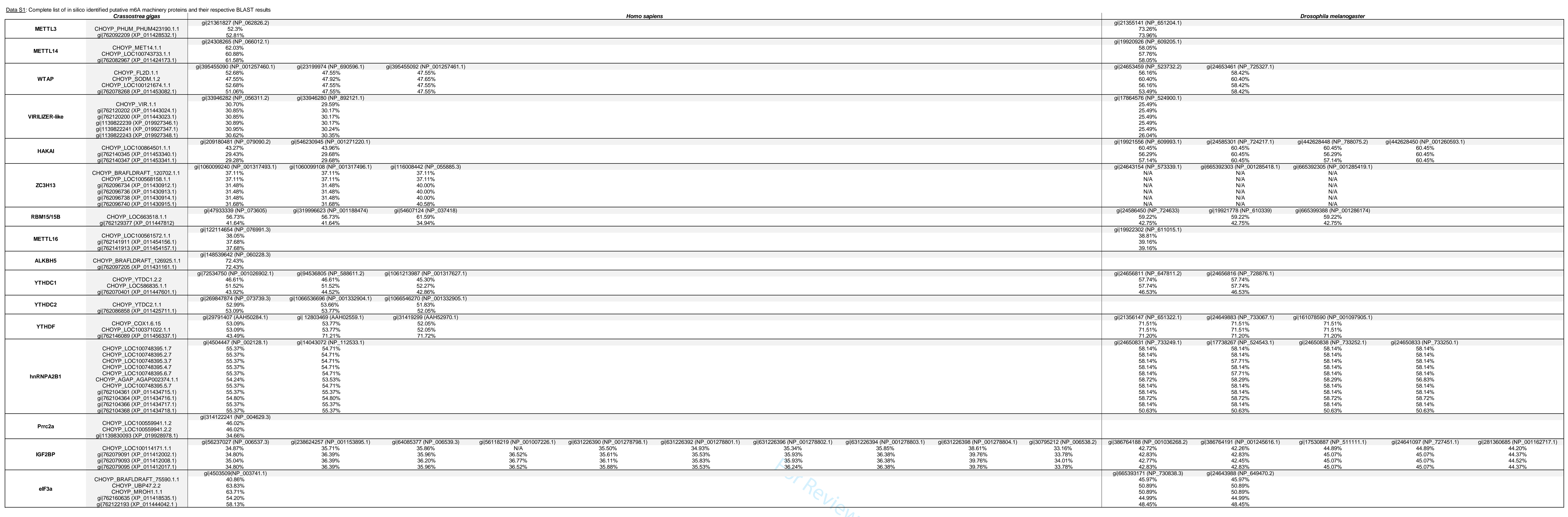


Data S2: Identified proteins by RNA pull down coupled with mass spectrometry with m6A or A-oligo, in nuclear or cytosolic protein extracts Proteins identified in nuclear extracts

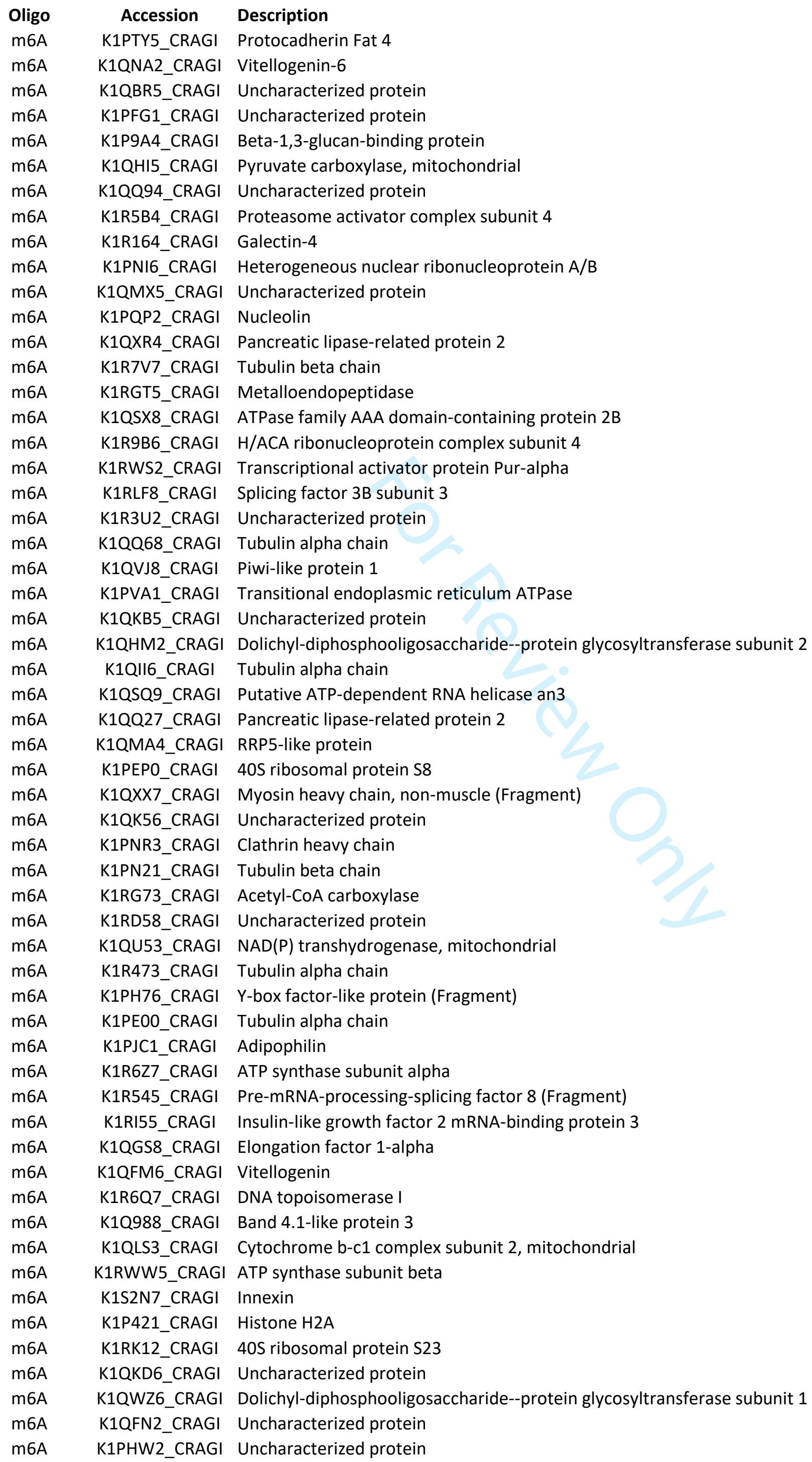




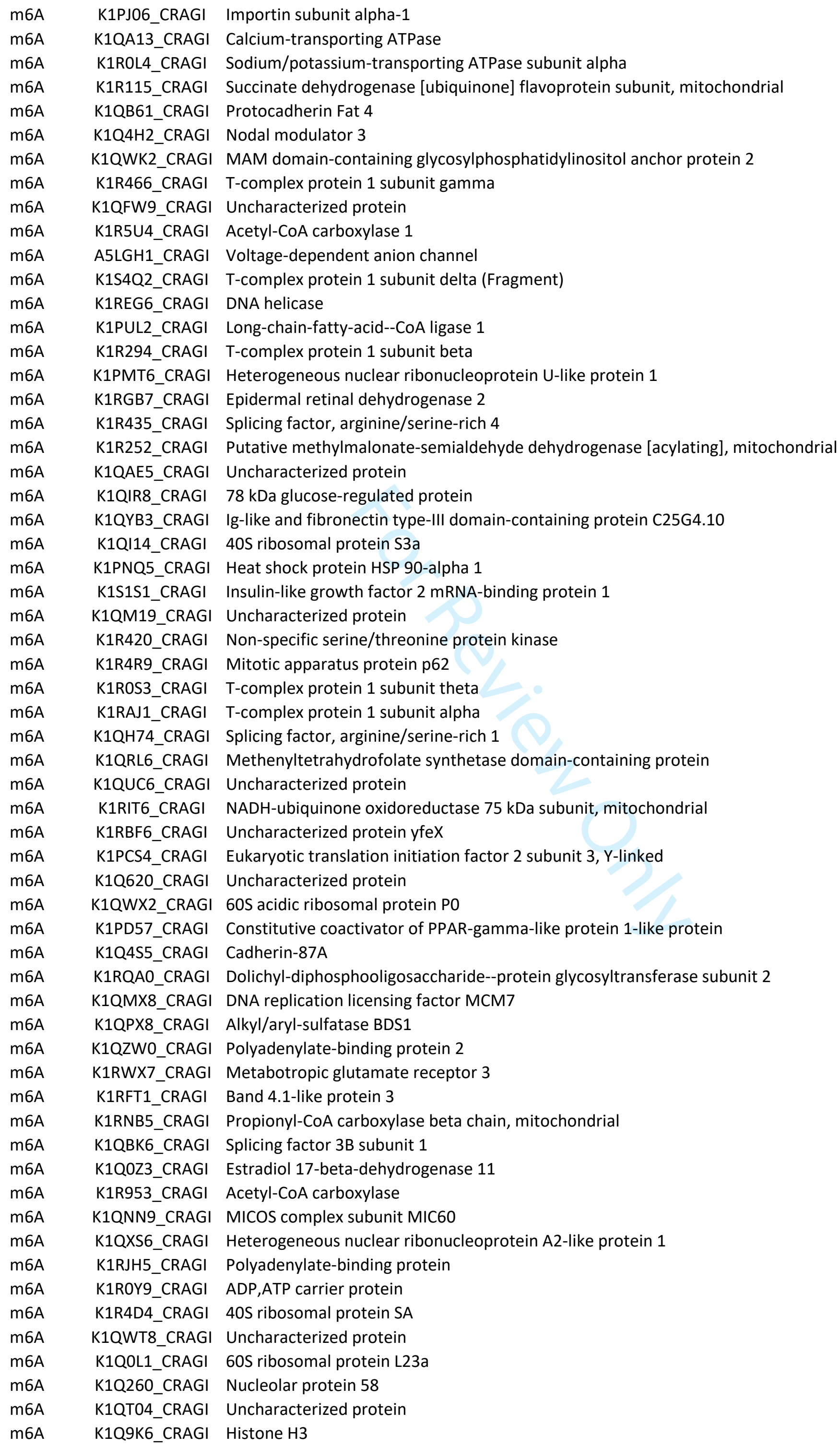


m6A K1QT21_CRAGI Putative ATP-dependent RNA helicase DDX5

m6A K1QBNO_CRAGI Methylcrotonoyl-CoA carboxylase beta chain, mitochondrial

m6A K1PLY1_CRAGI DNA polymerase

m6A K1QBH0_CRAGI Uncharacterized protein

m6A K1Q923_CRAGI Putative ATP-dependent RNA helicase DDX4

m6A K1QG58_CRAGI Actin

m6A K1QQB6_CRAGI 40S ribosomal protein S14

m6A K1QDX9_CRAGI Ribosome biogenesis protein BMS1-like protein

m6A K1QF01_CRAGI 40S ribosomal protein S4

$m 6 A$

$m 6 A$

m6A

$m 6 A$

m6A

$m 6 A$

$m 6 A$

$m 6 A$

$m 6 A$

$m 6 A$

m6A

$m 6 A$

$m 6 A$

$m 6 A$

$m 6 A$

$m 6 A$

$m 6 A$

$m 6 A$

$m 6 A$

$m 6 A$

$m 6 A$

$m 6 A$

$m 6 A$

m6A

$m 6 A$

$m 6 A$

$m 6 A$

$m 6 A$

$m 6 A$

m6A

$m 6 A$

$m 6 A$

$m 6 A$

$m 6 A$

$m 6 A$

$m 6 A$

m6A

$m 6 A$

$m 6 A$

$m 6 A$

$m 6 A$

$m 6 A$

m6A

$m 6 A$

$m 6 A$

$m 6 A$

$m 6 A$

$m 6 A$

$m 6 A$

$m 6 A$

$\mathrm{m} 6 \mathrm{~A}$

K1RLC5_CRAGI T-complex protein 1 subunit epsilon

K1QY12_CRAGI Dynamin-1-like protein

K1ROW4_CRAGI Signal recognition particle subunit SRP72

K1QX26_CRAGI Endoplasmin

K1QHS8_CRAGI Ribonucleoside-diphosphate reductase

K1QQ05_CRAGI Insulin-like growth factor-binding protein complex acid labile chain

K1QFP5_CRAGI NADH dehydrogenase [ubiquinone] flavoprotein 1, mitochondrial

K1QP17_CRAGI Caprin-1

K1R7A2_CRAGI Uncharacterized protein

K1R4L8_CRAGI Electron transfer flavoprotein-ubiquinone oxidoreductase, mitochondrial

K1R591_CRAGI Inter-alpha-trypsin inhibitor heavy chain H4

K1R7I9_CRAGI Heterogeneous nuclear ribonucleoprotein $Q$

K1QBW8_CRAGI Uncharacterized protein

K1RSZ6_CRAGI 40S ribosomal protein S7

K1QDZ5_CRAGI Cytochrome c1, heme protein, mitochondrial

K1PGW7_CRAGI Transmembrane protein 2

K1QMB9_CRAGI Eukaryotic translation initiation factor 3 subunit A

K1RNZ6_CRAGI Eukaryotic translation initiation factor 3 subunit D

K1Q9W5_CRAGI T-complex protein 1 subunit eta

K1Q404_CRAGI DNA topoisomerase 2

K1R7J6_CRAGI Putative sodium/potassium-transporting ATPase subunit beta-2

K1P8W6_CRAGI 60S ribosomal protein L4

K1RSA6_CRAGI Methylcrotonoyl-CoA carboxylase subunit alpha, mitochondrial

K1RW85_CRAGI Adenosylhomocysteinase

K1PS27_CRAGI DNA helicase

K1RH18_CRAGI Sarcalumenin

K1Q5H6_CRAGI FACT complex subunit SSRP1

K1PH66_CRAGI Fibrinolytic enzyme, isozyme C

K1PF10_CRAGI PAN2-PAN3 deadenylation complex catalytic subunit PAN2

K1Q358_CRAGI 60S acidic ribosomal protein P2

K1PXH5_CRAGI Putative saccharopine dehydrogenase

K1Q8SO_CRAGI Nucleolar complex protein 3 homolog

K1QYB6_CRAGI Delta-1-pyrroline-5-carboxylate synthetase

K1PV79_CRAGI Importin subunit alpha

K1PV49_CRAGI RuvB-like helicase

K1PRL4_CRAGI 60S ribosomal protein L38 (Fragment)

K1QL67_CRAGI 60S ribosomal protein L7a

K1PAY7_CRAGI Propionyl-CoA carboxylase alpha chain, mitochondrial

K1R6L5_CRAGI NADH-cytochrome b5 reductase

K1R1B1_CRAGI $35 \mathrm{kDa} S R$ repressor protein

K1QHQ6_CRAGI Acyl-CoA dehydrogenase family member 9, mitochondrial

K1QZU8_CRAGI Calcium-transporting ATPase

K1RN77_CRAGI Nuclear autoantigenic sperm protein

K1PZ23_CRAGI DnaJ-like protein subfamily C member 3

K1R005_CRAGI Filamin-C (Fragment)

K1RA35_CRAGI Splicing factor, arginine/serine-rich 7

K1R2V1_CRAGI Importin subunit beta-1

K1QAH9_CRAGI H/ACA ribonucleoprotein complex subunit

K1QET2_CRAGI Coatomer subunit alpha

K1RAB9_CRAGI Epoxide hydrolase 4

K1QGK2_CRAGI Coatomer subunit beta 


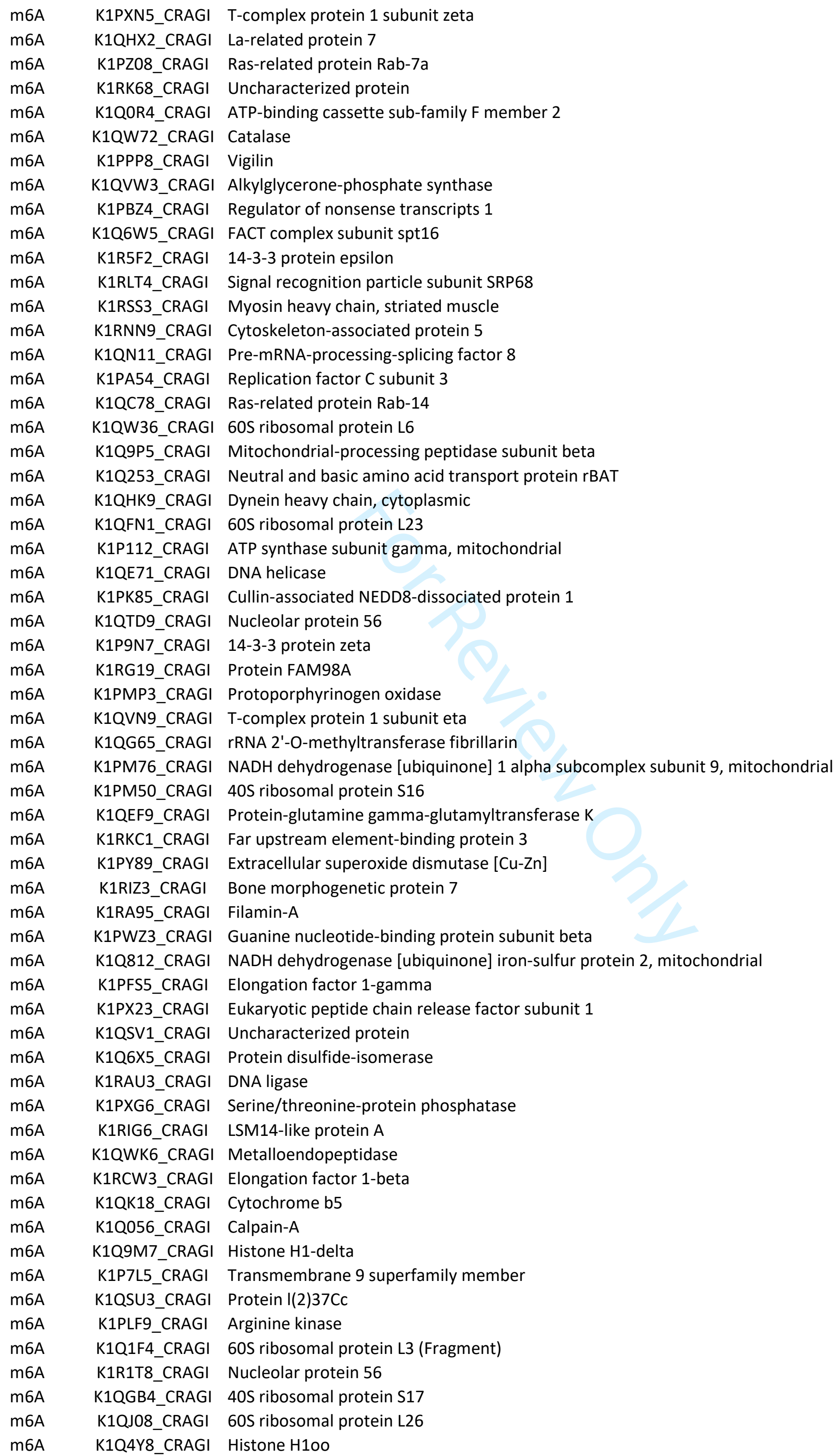


K1PKF5_CRAGI Protein-glutamine gamma-glutamyltransferase 4

$\mathrm{m} 6 \mathrm{~A}$ K1QYT5_CRAGI Phosphate carrier protein, mitochondrial

$m 6 A$

$m 6 A$ 
m6A

m6A

$\mathrm{m} 6 \mathrm{~A}$

m6A

$\mathrm{m} 6 \mathrm{~A}$

$m 6 A$

m6A

m6A

$\mathrm{m} 6 \mathrm{~A}$

$m 6 A$

m6A

m6A

m6A

$\mathrm{m} 6 \mathrm{~A}$

$\mathrm{m} 6 \mathrm{~A}$

$m 6 A$

m6A

m6A

m6A

$\mathrm{m} 6 \mathrm{~A}$

m6A

$\mathrm{m} 6 \mathrm{~A}$

m6A

m6A

m6A

$\mathrm{m} 6 \mathrm{~A}$

m6A

$\mathrm{m} 6 \mathrm{~A}$

m6A

m6A

m6A

$\mathrm{m} 6 \mathrm{~A}$

m6A

$\mathrm{m} 6 \mathrm{~A}$

m6A

m6A

m6A

m6A

$\mathrm{m} 6 \mathrm{~A}$

m6A

$\mathrm{m} 6 \mathrm{~A}$

$m 6 A$

m6A

m6A

$m 6 A$

m6A

$\mathrm{m} 6 \mathrm{~A}$

m6A

m6A

m6A

$m 6 A$

$\mathrm{m} 6 \mathrm{~A}$

$\mathrm{m} 6 \mathrm{~A}$

$m 6 A$

$\mathrm{m} 6 \mathrm{~A}$

m6A

m6A

$\mathrm{m} 6 \mathrm{~A}$

$\mathrm{m} 6 \mathrm{~A}$

$\mathrm{m} 6 \mathrm{~A}$

K1RG28_CRAGI Kinase $\mathrm{C}$ and casein kinase substrate in neurons protein 2

K1QKV1_CRAGI Cytochrome b-c1 complex subunit 6

K1P9S7_CRAGI Brix domain-containing protein 2

K1QN79_CRAGI 40S ribosomal protein S11

K1QEJO_CRAGI Ras GTPase-activating protein-binding protein 2

K1S1X3_CRAGI SWI/SNF-related matrix-associated actin-dependent regulator of chromatin subfamily A member 5

K1R9T2_CRAGI Eukaryotic translation initiation factor 3 subunit B

K1QED7_CRAGI Replication protein A subunit

K1QQK5_CRAGI Metabotropic glutamate receptor 2

K1RN97_CRAGI Hemagglutinin/amebocyte aggregation factor

K1PJS7_CRAGI Poly [ADP-ribose] polymerase

K1R6F5_CRAGI Putative ATP-dependent RNA helicase DDX23

K1R8R6_CRAGI Fructose-bisphosphate aldolase

K1QY85_CRAGI Transport protein Sec31A

K1QF31_CRAGI Serine/threonine-protein kinase PLK

K1Q5J7_CRAGI Uncharacterized protein

K1QPF0_CRAGI Uncharacterized protein

K1P6Y1_CRAGI Uncharacterized protein

K1QJM1_CRAGI 60S ribosomal protein L30

K1PXD4_CRAGI Putative ATP-dependent RNA helicase DDX6

K1PH31_CRAGI Protein arginine N-methyltransferase 1

K1PAM6_CRAGI Uncharacterized protein

K1RFU6_CRAGI Proteasome activator complex subunit 3

K1Q324_CRAGI Heterogeneous nuclear ribonucleoprotein $\mathrm{K}$

K1QRG9_CRAGI Uncharacterized protein

K1S6H7_CRAGI Vacuolar protein sorting-associated protein 13C

K1QE94_CRAGI Alpha-galactosidase

K1Q7Q2_CRAGI CCAAT/enhancer-binding protein zeta

K1Q7G8_CRAGI Fatty acid synthase

K1QXH3_CRAGI Translational activator GCN1

K1P8G1_CRAGI Heterogeneous nuclear ribonucleoprotein $\mathrm{H}$

K1QKQ8_CRAGI THO complex subunit 4-A

K1RA63_CRAGI Transmembrane protein 2

K1QAA2_CRAGI Uncharacterized protein

K1PLA7_CRAGI Eukaryotic initiation factor 4A-II (Fragment)

K1QIV3_CRAGI Uncharacterized protein

K1RAH2_CRAGI Superoxide dismutase [Cu-Zn]

K1QXA9_CRAGI Sortilin-related receptor

K1QSD9_CRAGI Uncharacterized protein

K1Q3W3_CRAGI NADH dehydrogenase [ubiquinone] iron-sulfur protein 3, mitochondrial

K1R3T3_CRAGI Transcription factor BTF3

K1QMH5_CRAGI Small nuclear ribonucleoprotein Sm D1

K1R1R9_CRAGI Pre-mRNA-processing factor 6

K1PM66_CRAGI 60S ribosomal protein L12

K1Q3W9_CRAGI FAS-associated factor 2-B

K1P9D0_CRAGI Stress-70 protein, mitochondrial

K1R4F7_CRAGI Ras-related protein Rab-6B

K1QGP7_CRAGI Uncharacterized protein

K1REY2_CRAGI Dysferlin

K1QSB2_CRAGI 26S protease regulatory subunit 6B

K1RAU8_CRAGI Eukaryotic translation initiation factor 3 subunit $E$

K1QAB1_CRAGI AP-2 complex subunit alpha

K1RFU8_CRAGI High mobility group protein DSP1

K1QAA8_CRAGI CAAX prenyl protease 1-like protein

K1PXS8_CRAGI Calreticulin

K1RV41_CRAGI Guanine nucleotide-binding protein subunit beta-2-like 1

K1Q5Z6_CRAGI Eukaryotic translation initiation factor 2 subunit 2

K1QYQ9_CRAGI Uncharacterized protein

K1RCL2_CRAGI Mitochondrial import inner membrane translocase subunit Tim13-B

K1PI50_CRAGI 40S ribosomal protein S26 


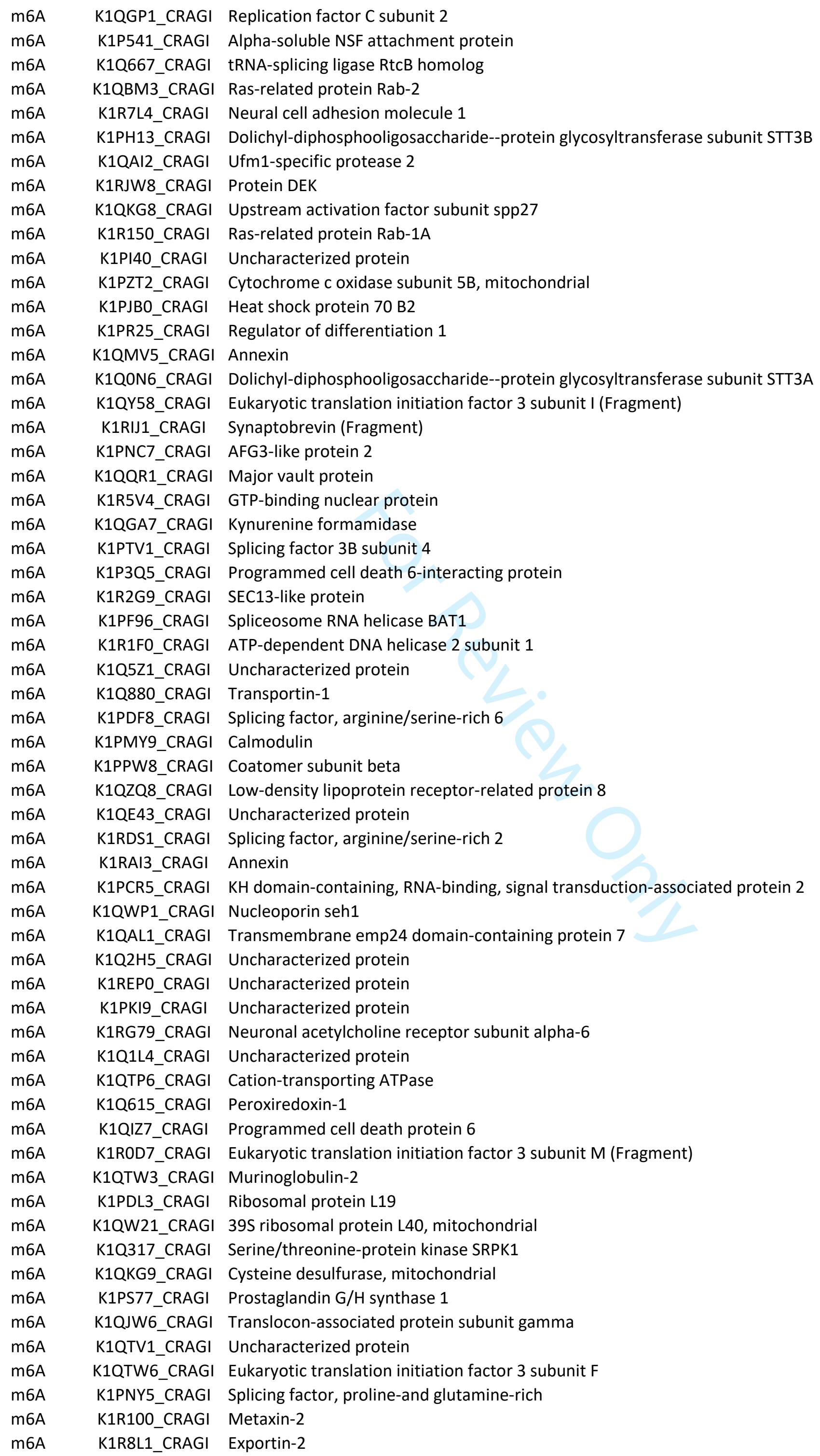


m6A

m6A

$\mathrm{m} 6 \mathrm{~A}$

$m 6 A$

$m 6 A$

$m 6 A$

$m 6 A$

$m 6 A$

$m 6 A$

$m 6 A$

$\mathrm{m} 6 \mathrm{~A}$

m6A

$m 6 A$

$m 6 A$

$m 6 A$

$m 6 A$

$m 6 A$

$m 6 A$

$m 6 A$

m6A

m6A

m6A

$m 6 A$

$m 6 A$

$m 6 A$

$m 6 A$

m6A

$m 6 A$

$m 6 A$

$\mathrm{m} 6 \mathrm{~A}$

$m 6 A$

$m 6 A$

$m 6 A$

$m 6 A$

$m 6 A$

$m 6 A$

$m 6 A$

$\mathrm{m} 6 \mathrm{~A}$

m6A

m6A

m6A

$m 6 A$

$m 6 A$

$m 6 A$

$m 6 A$

m6A

m6A

$m 6 A$

$m 6 A$

$m 6 A$

$m 6 A$

m6A

$m 6 A$

$m 6 A$

$m 6 A$

$m 6 A$

$m 6 A$

m6A

$m 6 A$

m6A
K1QZ64_CRAGI Nuclear pore complex protein Nup98-Nup96

K1QWZ8_CRAGI Catenin beta

K1QAT9_CRAGI ATP-dependent RNA helicase DDX1

K1P8Y9_CRAGI Cytochrome b-c1 complex subunit 7

K1PIC5_CRAGI Transmembrane protein 85

K1QMV7_CRAGI V-type proton ATPase subunit D

K1RC37_CRAGI Uncharacterized protein

K1PEY4_CRAGI 26S proteasome non-ATPase regulatory subunit 2

K1RG04_CRAGI ALK tyrosine kinase receptor

K1QG72_CRAGI Hemagglutinin/amebocyte aggregation factor

K1RK83_CRAGI Tyrosine-protein kinase BAZ1B

K1QMT1_CRAGI DnaJ-like protein subfamily B member 4

K1P8I1_CRAGI Pleckstrin-like protein domain-containing family F member 2 (Fragment)

K1R3I6_CRAGI Nucleolar complex protein 2-like protein (Fragment)

K1QDB9_CRAGI Transport protein Sec61 subunit alpha isoform 2 (Fragment)

K1QMJ8_CRAGI Transcription initiation factor IIA subunit 1

K1R5G4_CRAGI 60S ribosomal protein L31

K1R1W9_CRAGI Nicalin-1

K1QDA7_CRAGI Uracil phosphoribosyltransferase

K1QI02_CRAGI Vesicle-trafficking protein SEC22b

K1QFZ8_CRAGI Ceramide kinase-like protein

K1Q151_CRAGI 60S ribosomal protein L32

K1QNS4_CRAGI DnaJ-like protein subfamily $\mathrm{C}$ member 9

K1REQ4_CRAGI Cytochrome c oxidase subunit 6B

K1R4B8_CRAGI Plexin domain-containing protein 2

K1QC10_CRAGI GTP-binding protein 1

K1PJY2_CRAGI Inositol polyphosphate 1-phosphatase

K1R983_CRAGI Protein transport protein SEC23

K1Q5Y3_CRAGI Annexin

K1Q1N1_CRAGI Alpha-mannosidase

K1QNUO_CRAGI Non-specific serine/threonine protein kinase

K1R1Q8_CRAGI Ras-related protein Rab-5C

K1RH95_CRAGI Myosin-IIIB

K1QWE5_CRAGI Ras-related protein Rab-18-B

K1QCB0_CRAGI 40S ribosomal protein S5

K1Q0I8_CRAGI Putative splicing factor, arginine/serine-rich 7

K1QXF5_CRAGI Calcyphosin-like protein

K1R8C6_CRAGI 40S ribosomal protein S12

K1QFA9_CRAGI Low-density lipoprotein receptor-related protein 2

K1QYF5_CRAGI Apoptosis-inducing factor 1, mitochondrial

K1QA50_CRAGI V-type proton ATPase subunit $\mathrm{H}$

K1PY39_CRAGI Protocadherin Fat 4

K1Q330_CRAGI Dihydrolipoyl dehydrogenase

K1Q350_CRAGI Glyceraldehyde-3-phosphate dehydrogenase

K1Q6U7_CRAGI 78 kDa glucose-regulated protein

K1RBI9_CRAGI Small nuclear ribonucleoprotein Sm D2

K1POH0_CRAGI Aspartyl/asparaginyl beta-hydroxylase

K1QSR2_CRAGI Apoptosis inhibitor 5

K1RDV7_CRAGI Cell division control protein 2-like protein (Fragment)

K1PD30_CRAGI Putative histone-binding protein Caf1

K1P7K8_CRAGI Vesicle-fusing ATPase 1

K1PVZ3_CRAGI Cold shock domain-containing protein E1

K1RKZ5_CRAGI DNA damage-binding protein 1

K1R0Z4_CRAGI Uncharacterized protein

K1Q947_CRAGI Dynein light chain

K1PU46_CRAGI Lethal(2) giant larvae-like protein 1

K1Q8K9_CRAGI KRR1 small subunit processome component-like protein

K1PQZ3_CRAGI Armadillo repeat-containing protein 4

K1QL00_CRAGI Microsomal glutathione S-transferase 1

K1RDM2_CRAGI 60S ribosomal protein L18a 
m6A K1Q3V9_CRAGI Mitochondrial carnitine/acylcarnitine carrier protein

m6A K1QN55_CRAGI 60S acidic ribosomal protein P1

m6A K1R3G0_CRAGI Transformer-2-like protein beta

m6A K1PWM3_CRAGI MICOS complex subunit MIC13

m6A K1QKL8_CRAGI V-type proton ATPase subunit a

m6A K1S6T6_CRAGI UPF0480 protein C15orf24-like protein

m6A K1ROWO_CRAGI Ferritin

m6A K1PGK7_CRAGI Uncharacterized protein

m6A K1QY71_CRAGI Histone H2B

m6A K1QNT7_CRAGI Aldehyde dehydrogenase, mitochondrial

m6A K1RJ96_CRAGI Sphere organelles protein SPH-1

m6A K1RZE2_CRAGI Isocitrate dehydrogenase [NADP]

m6A K1PPV1_CRAGI Atlastin-2

m6A K1P9F1_CRAGI Insulin-like growth factor-binding protein complex acid labile chain

m6A K1QVUO_CRAGI Synaptojanin-2-binding protein

m6A K1QX44_CRAGI Ras-related protein Rab-11B

m6A K1QKU6_CRAGI mRNA export factor

m6A K1QDV6_CRAGI Protein argonaute-2

$m 6 A$

$m 6 A$

$m 6 A$

$m 6 A$

$m 6 A$

$m 6 A$

$m 6 A$

$m 6 A$

$m 6 A$

$m 6 A$

$m 6 A$

m6A

$m 6 A$

m6A

m6A

$m 6 A$

$m 6 A$

$m 6 A$

m6A

m6A

$m 6 A$

$m 6 A$

$m 6 A$

m6A

$m 6 A$

$m 6 A$

$m 6 A$

$m 6 A$

$m 6 A$

$m 6 A$

$m 6 A$

$m 6 A$

$m 6 A$

m6A

$m 6 A$

$m 6 A$

$m 6 A$

$m 6 A$

$m 6 A$

$m 6 A$

$m 6 A$

K1R5B9_CRAGI DNA-directed RNA polymerase, mitochondrial

K1RCT2_CRAGI Translocon-associated protein subunit delta

K1PKD4_CRAGI 40S ribosomal protein S30

K1PP50_CRAGI Golgi integral membrane protein 4

K1PG60_CRAGI 60S ribosomal protein L17

K1QWJ4_CRAGI Splicing factor $3 B$ subunit 5

K1RB91_CRAGI Neutral alpha-glucosidase AB

K1RD12_CRAGI Uncharacterized protein

K1PQE3_CRAGI RNA-binding protein Raly

K1Q2Y1_CRAGI 40S ribosomal protein S15

K1PQF1_CRAGI Neural cell adhesion molecule L1

K1QKJ0_CRAGI Aldehyde dehydrogenase family 3 member B1

K1PUQ5_CRAGI Histone H2B

K1Q2W7_CRAGI Uncharacterized protein

K1Q412_CRAGI Uncharacterized protein

K1RNH1_CRAGI 60S ribosomal protein L18 (Fragment)

K1QNT4_CRAGI Anoctamin

K1P8B7_CRAGI Ubiquitin-conjugating enzyme E2-17 kDa (Fragment)

K1Q1D7_CRAGI Putative rRNA-processing protein EBP2

K1PY30_CRAGI Septin-2

K1Q1R1_CRAGI Exostosin-3

K1RHP3_CRAGI Proliferation-associated protein 2G4

K1PZI3_CRAGI SWI/SNF complex subunit SMARCC2

K1QT97_CRAGI N(G),N(G)-dimethylarginine dimethylaminohydrolase 1

K1QQQ5_CRAGI Replication factor $\mathrm{C}$ subunit 5

K1PA61_CRAGI Actin-like protein 6A

K1PNLO_CRAGI Microtubule-associated protein futsch

K1QI28_CRAGI V-type proton ATPase subunit B

K1PYL5_CRAGI Uncharacterized protein

K1PJ65_CRAGI Dual specificity mitogen-activated protein kinase kinase 7

K1QMD8_CRAGI Proteasome subunit alpha type

K1Q2L4_CRAGI Transmembrane emp24 domain-containing protein 9

K1Q8C1_CRAGI Putative RNA-binding protein Luc7-like 2

K1PS71_CRAGI Uncharacterized protein

K10900_CRAGI Galectin

K1RKR8_CRAGI Pumilio-like protein 2

K1RKE5_CRAGI IQ and AAA domain-containing protein 1

K1QRL4_CRAGI Importin-5

K1PGNO_CRAGI Fatty-acid amide hydrolase 2

K1RD83_CRAGI Serine hydroxymethyltransferase

K1RFA3_CRAGI Lamin Dm0

$\mathrm{m6A}$

K1QAG7_CRAGI Phosphatidylinositide phosphatase SAC1 
m6A K1PJP7_CRAGI Surfeit locus protein 4

m6A K1PG07_CRAGI Lupus La-like protein

m6A K1QVSO_CRAGI Ras-like GTP-binding protein Rho1

m6A K1PWC3_CRAGI Tetratricopeptide repeat protein 35

m6A K1QZK9_CRAGI Uncharacterized protein

m6A K1QAG9_CRAGI Ferritin

m6A K1QHW8_CRAGI Ferritin

m6A K1PZF2_CRAGI Exportin-7

m6A K1RCF4_CRAGI Translocon-associated protein subunit alpha

m6A K1QVIO_CRAGI Isocitrate dehydrogenase [NAD] subunit, mitochondrial

m6A K1PX47_CRAGI Ubiquitin carboxyl-terminal hydrolase

m6A K1P8G6_CRAGI Vesicular integral-membrane protein VIP36

m6A K1PNZ8_CRAGI Ribosomal protein L37

m6A K1Q373_CRAGI Splicing factor, arginine/serine-rich 7

m6A K1R0U6_CRAGI Uncharacterized protein

m6A K1QAV0_CRAGI Guanine nucleotide-binding protein $G(Q)$ subunit alpha

m6A K1R8Y1_CRAGI Obg-like ATPase 1

m6A K1QBY6_CRAGI Transmembrane protein Tmp21

m6A K1QZ58_CRAGI Splicing factor U2AF 26 kDa subunit

m6A K1RAE9_CRAGI ADP-ribosylation factor-like protein 8A

m6A K1RCW5_CRAGI Eukaryotic translation initiation factor 4 gamma 3

m6A K1PZ89_CRAGI Mannosyl-oligosaccharide glucosidase

m6A K1PBG6_CRAGI Uncharacterized protein

m6A K1QPS1_CRAGI Poly [ADP-ribose] polymerase

m6A K1R1C5_CRAGI Signal recognition particle receptor subunit beta

m6A K1PVG0_CRAGI Long-chain fatty acid transport protein 4

m6A K1QXA1_CRAGI Retinol dehydrogenase 12

m6A K1R481_CRAGI Epimerase family protein SDR39U1

$m 6 A$

$m 6 A$

$m 6 A$

$m 6 A$

$m 6 A$

$m 6 A$

$m 6 A$

$m 6 A$

$m 6 A$

m6A

$\mathrm{m} 6 \mathrm{~A}$

$m 6 A$

$m 6 A$

$m 6 A$

$m 6 A$

m6A

$m 6 A$

$m 6 A$

$m 6 A$

$m 6 A$

$m 6 A$

$m 6 A$

$m 6 A$

$m 6 A$ K1QVP6_CRAGI Developmentally-regulated GTP-binding protein 1

K1PWB7_CRAGI Uncharacterized protein

K1PNQ1_CRAGI Ankyrin repeat domain-containing protein 5

K1Q8C5_CRAGI Putative ATP-dependent RNA helicase DDX47

K1PR38_CRAGI TAR DNA-binding protein 43

K1P7Q6_CRAGI 40S ribosomal protein S19

K1RFD2_CRAGI Adenylate kinase

K1PQJ9_CRAGI ATP synthase subunit delta, mitochondrial

K1Q4U7_CRAGI AP-3 complex subunit delta-1

K1QM06_CRAGI Prohibitin

K1QUW5_CRAGI U2 snRNP auxiliary factor large subunit

K1PD36_CRAGI Ubiquitin

K1PBL2_CRAGI Eukaryotic initiation factor 4A-III

K1R3V8_CRAGI COP9 signalosome complex subunit 4

K1PII4_CRAGI YTH domain-containing protein 1

K1PZLO_CRAGI B-box type zinc finger protein ncl-1

K1REW8_CRAGI Ribosomal protein L15

K1R9V5_CRAGI Tetraspanin

K1QPX1_CRAGI ATPase family AAA domain-containing protein 3

K1QHI2_CRAGI Heterogeneous nuclear ribonucleoprotein L

K1QZ95_CRAGI Nuclear pore complex protein

K1R401_CRAGI Spectrin alpha chain

K1PSA1_CRAGI Transmembrane 9 superfamily member

K1Q486_CRAGI Uncharacterized protein

$m 6 A$

$m 6 A$

$m 6 A$

$m 6 A$

$m 6 A$

$m 6 A$

$m 6 A$ K1PYA0_CRAGI Cytoplasmic dynein 2 heavy chain 1

K1QLC6_CRAGI JmjC domain-containing protein 8

K1RDG4_CRAGI DNA helicase

K1PQYO_CRAGI Protein quiver

K1QTD5_CRAGI Low-density lipoprotein receptor-related protein 12

K1PSP7_CRAGI Uncharacterized protein

K1QAL3_CRAGI RNA-binding protein 28

$\mathrm{m} 6 \mathrm{~A}$

K1QND2_CRAGI Septin-2 
K1RMM6_CRAGI Centromere protein J

$m 6 A$ K1R1K6_CRAGI Heat shock protein beta-1

$m 6 A$

$m 6 A$ 
m6A

m6A

$\mathrm{m} 6 \mathrm{~A}$

m6A

$\mathrm{m} 6 \mathrm{~A}$

$m 6 A$

m6A

m6A

$\mathrm{m} 6 \mathrm{~A}$

$m 6 A$

m6A

m6A

m6A

$\mathrm{m} 6 \mathrm{~A}$

$\mathrm{m} 6 \mathrm{~A}$

$m 6 A$

m6A

m6A

m6A

$\mathrm{m} 6 \mathrm{~A}$

m6A

$\mathrm{m} 6 \mathrm{~A}$

m6A

m6A

m6A

$\mathrm{m} 6 \mathrm{~A}$

m6A

$\mathrm{m} 6 \mathrm{~A}$

m6A

m6A

m6A

$\mathrm{m} 6 \mathrm{~A}$

m6A

$\mathrm{m} 6 \mathrm{~A}$

m6A

m6A

m6A

m6A

$\mathrm{m} 6 \mathrm{~A}$

m6A

$\mathrm{m} 6 \mathrm{~A}$

m6A

m6A

m6A

$\mathrm{m} 6 \mathrm{~A}$

m6A

$\mathrm{m} 6 \mathrm{~A}$

m6A

m6A

m6A

$m 6 A$

$\mathrm{m} 6 \mathrm{~A}$

$\mathrm{m} 6 \mathrm{~A}$

$m 6 A$

$\mathrm{m} 6 \mathrm{~A}$

m6A

m6A

$\mathrm{m} 6 \mathrm{~A}$

$\mathrm{m} 6 \mathrm{~A}$

$\mathrm{m} 6 \mathrm{~A}$
K1RZM3_CRAGI Cartilage acidic protein 1

K1R065_CRAGI Golgi membrane protein 1

K1RD19_CRAGI RNA-binding protein 4

K1R969_CRAGI Uncharacterized protein

K1RE19_CRAGI V-type proton ATPase subunit S1

K1QGW5_CRAGI WD repeat and SOF domain-containing protein 1

K1QKI1_CRAGI Tudor domain-containing protein 1

K1PSH2_CRAGI 28S ribosomal protein S12, mitochondrial

K1QMT2_CRAGI Signal peptidase complex catalytic subunit SEC11

K1QDI0_CRAGI Transmembrane protein 49

K1Q8T3_CRAGI Importin subunit alpha

K1Q525_CRAGI Mechanosensory protein 2 (Fragment)

K1Q5G6_CRAGI $60 \mathrm{kDa}$ heat shock protein, mitochondrial

K1QHFO_CRAGI 40S ribosomal protein S27

K1Q7X3_CRAGI Pre-mRNA-splicing factor SYF1

K1RRH1_CRAGI Chromodomain-helicase-DNA-binding protein Mi-2-like protein

K1Q435_CRAGI Eukaryotic translation initiation factor 2 subunit 1

K1RNS1_CRAGI NADH dehydrogenase [ubiquinone] 1 alpha subcomplex subunit 8

K1QGF9_CRAGI Rootletin

K1QJ36_CRAGI Muscle, skeletal receptor tyrosine protein kinase

K1RNU5_CRAGI Pre-mRNA-splicing factor RBM22

K1R916_CRAGI Structural maintenance of chromosomes protein

K1RUC9_CRAGI Uncharacterized protein

K1QR54_CRAGI Zinc finger RNA-binding protein

K1P9Q2_CRAGI Signal peptidase complex subunit 3

K1RTR1_CRAGI ATP-citrate synthase

K1Q050_CRAGI Centrin-3

K1QPA5_CRAGI Uncharacterized protein C16orf61-like protein

K1PSY2_CRAGI Fragile $X$ mental retardation syndrome-related protein 1

K1R7G0_CRAGI Chromobox-like protein 5

K1QFG2_CRAGI Telomere-associated protein RIF1

K1QYV5_CRAGI Cytoplasmic polyadenylation element-binding protein 1-B

K1R1I2_CRAGI Cation-independent mannose-6-phosphate receptor

K1R255_CRAGI Heterogeneous nuclear ribonucleoprotein L

K1RB07_CRAGI 60S ribosomal protein L27a

K1RYF2_CRAGI Enoyl-CoA hydratase domain-containing protein 3, mitochondrial

K1RJ53_CRAGI Tetratricopeptide repeat protein 12

K1QW73_CRAGI Glycoprotein 3-alpha-L-fucosyltransferase A

K1RBC9_CRAGI Transketolase-like protein 2

K1QJ46_CRAGI Putative methylcrotonoyl-CoA carboxylase beta chain, mitochondrial

K1Q9V2_CRAGI Antigen KI-67

K1PWQ2_CRAGI $60 \mathrm{kDa}$ neurofilament protein

K1QGF1_CRAGI Splicing factor $3 B$ subunit 2

K1QTEO_CRAGI Epidermal retinal dehydrogenase 2

K1PPQ1_CRAGI 14-3-3 protein gamma

K1Q7A7_CRAGI Putative tyrosinase-like protein tyr-3

K1QHA2_CRAGI Spectrin beta chain, brain 4

K1Q6U0_CRAGI Coatomer subunit zeta-1

K1QU16_CRAGI Protein polybromo-1

K1P7W5_CRAGI Histone H1-delta

K1QBL6_CRAGI Tudor domain-containing protein 1

K1QVS1_CRAGI ER membrane protein complex subunit 3

K1Q1L9_CRAGI Interferon-induced protein 44-like protein

K1Q109_CRAGI Neurexin-4

K1PJN7_CRAGI PC3-like endoprotease variant A

K1RAH1_CRAGI Uncharacterized protein

K1R472_CRAGI Synaptobrevin-like protein YKT6

K1QMY9_CRAGI Uncharacterized protein

K1QBT8_CRAGI Uncharacterized protein

K1Q1R2_CRAGI Caprin-2 
m6A K1R8V1_CRAGI Puratrophin-1

m6A K1PUF0_CRAGI G-protein coupled receptor moody

m6A K1Q4R2_CRAGI Zinc finger protein 26

$m 6 A$

$m 6 A$

A

K1QXP9_CRAGI Uncharacterized protein

K1P6M6_CRAGI Cerebellin-1

K1QNA2_CRAGI Vitellogenin-6

K1PTY5_CRAGI Protocadherin Fat 4

K1QBR5_CRAGI Uncharacterized protein

K1PFG1_CRAGI Uncharacterized protein

K1P9A4_CRAGI Beta-1,3-glucan-binding protein

K1QHI5_CRAGI Pyruvate carboxylase, mitochondrial

K1R5B4_CRAGI Proteasome activator complex subunit 4

K1QQ94_CRAGI Uncharacterized protein

K1QXR4_CRAGI Pancreatic lipase-related protein 2

K1RWS2_CRAGI Transcriptional activator protein Pur-alpha

K1PNI6_CRAGI Heterogeneous nuclear ribonucleoprotein A/B

K1R3U2_CRAGI Uncharacterized protein

K1R7V7_CRAGI Tubulin beta chain

K1QMX5_CRAGI Uncharacterized protein

K1R9B6_CRAGI H/ACA ribonucleoprotein complex subunit 4

K1QQ68_CRAGI Tubulin alpha chain

K1PQP2_CRAGI Nucleolin

K1RLF8_CRAGI Splicing factor 3B subunit 3

K1R164_CRAGI Galectin-4

K1QVJ8_CRAGI Piwi-like protein 1

K1RGT5_CRAGI Metalloendopeptidase

K1PH76_CRAGI Y-box factor-like protein (Fragment)

K1QII6_CRAGI Tubulin alpha chain

K1QSX8_CRAGI ATPase family AAA domain-containing protein 2B

K1QK56_CRAGI Uncharacterized protein

K1QKB5_CRAGI Uncharacterized protein

K1PE00_CRAGI Tubulin alpha chain

K1QQ27_CRAGI Pancreatic lipase-related protein 2

K1PVA1_CRAGI Transitional endoplasmic reticulum ATPase

K1PEPO_CRAGI 40S ribosomal protein $\mathrm{S8}$

K1QXX7_CRAGI Myosin heavy chain, non-muscle (Fragment)

K1RK12_CRAGI 40S ribosomal protein S23

K1QSQ9_CRAGI Putative ATP-dependent RNA helicase an3

K1PNR3_CRAGI Clathrin heavy chain

K1QMA4_CRAGI RRP5-like protein

K1QHM2_CRAGI Dolichyl-diphosphooligosaccharide--protein glycosyltransferase subunit 2

K1QU53_CRAGI NAD(P) transhydrogenase, mitochondrial

K1PJC1_CRAGI Adipophilin

K1RG73_CRAGI Acetyl-CoA carboxylase

K1QFM6_CRAGI Vitellogenin

K1R6Q7_CRAGI DNA topoisomerase I

K1R677_CRAGI ATP synthase subunit alpha

K1QGS8_CRAGI Elongation factor 1-alpha

K1QWZ6_CRAGI Dolichyl-diphosphooligosaccharide--protein glycosyltransferase subunit 1

K1RD58_CRAGI Uncharacterized protein

K1QLS3_CRAGI Cytochrome b-c1 complex subunit 2, mitochondrial

K1S1S1_CRAGI Insulin-like growth factor 2 mRNA-binding protein 1

K1ROL4_CRAGI Sodium/potassium-transporting ATPase subunit alpha

K1RWW5_CRAGI ATP synthase subunit beta

K1QA13_CRAGI Calcium-transporting ATPase

K1QFN2_CRAGI Uncharacterized protein

K1R545_CRAGI Pre-mRNA-processing-splicing factor 8 (Fragment)

K1R252_CRAGI Putative methylmalonate-semialdehyde dehydrogenase [acylating], mitochondrial

K1PMT6_CRAGI Heterogeneous nuclear ribonucleoprotein U-like protein 1

K1RGB7_CRAGI Epidermal retinal dehydrogenase 2 
K1R466_CRAGI T-complex protein 1 subunit gamma

K1R294_CRAGI T-complex protein 1 subunit beta

K1RIT6_CRAGI NADH-ubiquinone oxidoreductase $75 \mathrm{kDa}$ subunit, mitochondrial

K1QIR8_CRAGI $78 \mathrm{kDa}$ glucose-regulated protein

K1RI55_CRAGI Insulin-like growth factor 2 mRNA-binding protein 3

K1QH74_CRAGI Splicing factor, arginine/serine-rich 1

K1S2N7_CRAGI Innexin

K1R435_CRAGI Splicing factor, arginine/serine-rich 4

K1R5U4_CRAGI Acetyl-CoA carboxylase 1

K1QBK6_CRAGI Splicing factor 3B subunit 1

K1Q988_CRAGI Band 4.1-like protein 3

K1R420_CRAGI Non-specific serine/threonine protein kinase

A5LGH1_CRAGI Voltage-dependent anion channel

K1PHW2_CRAGI Uncharacterized protein

K1REG6_CRAGI DNA helicase

K1QAE5_CRAGI Uncharacterized protein

K1QWT8_CRAGI Uncharacterized protein

K1QRL6_CRAGI Methenyltetrahydrofolate synthetase domain-containing protein

K1QYB3_CRAGI Ig-like and fibronectin type-III domain-containing protein C25G4.10

K1QKD6_CRAGI Uncharacterized protein

K1R115_CRAGI Succinate dehydrogenase [ubiquinone] flavoprotein subunit, mitochondrial

K1S4Q2_CRAGI T-complex protein 1 subunit delta (Fragment)

K1QWK2_CRAGI MAM domain-containing glycosylphosphatidylinositol anchor protein 2

K1ROS3_CRAGI T-complex protein 1 subunit theta

K1QFW9_CRAGI Uncharacterized protein

K1Q0Z3_CRAGI Estradiol 17-beta-dehydrogenase 11

K1PNQ5_CRAGI Heat shock protein HSP 90-alpha 1

K1RBF6_CRAGI Uncharacterized protein yfeX

K1R4D4_CRAGI 40S ribosomal protein SA

K1QI14_CRAGI 40S ribosomal protein S3a

K1PUL2_CRAGI Long-chain-fatty-acid--CoA ligase 1

K1RFT1_CRAGI Band 4.1-like protein 3

K1PJ06_CRAGI Importin subunit alpha-1

K1QT21_CRAGI Putative ATP-dependent RNA helicase DDX5

K1QM19_CRAGI Uncharacterized protein

K1QXS6_CRAGI Heterogeneous nuclear ribonucleoprotein A2-like protein 1

K1QMX8_CRAGI DNA replication licensing factor MCM7

K1PD57_CRAGI Constitutive coactivator of PPAR-gamma-like protein 1-like protein

K1R953_CRAGI Acetyl-CoA carboxylase

K1RJH5_CRAGI Polyadenylate-binding protein

K1RSZ6_CRAGI 40S ribosomal protein S7

K1R7A2_CRAGI Uncharacterized protein

K1QUC6_CRAGI Uncharacterized protein

K1OWX2_CRAGI 60S acidic ribosomal protein P0

K1RNB5_CRAGI Propionyl-CoA carboxylase beta chain, mitochondrial

K1PCS4_CRAGI Eukaryotic translation initiation factor 2 subunit 3, Y-linked

K1Q923_CRAGI Putative ATP-dependent RNA helicase DDX4

K1QPX8_CRAGI Alkyl/aryl-sulfatase BDS1

K1R4R9_CRAGI Mitotic apparatus protein p62

K1RAJ1_CRAGI T-complex protein 1 subunit alpha

K1Q0L1_CRAGI 60S ribosomal protein L23a

K10620_CRAGI Uncharacterized protein

K1QG58_CRAGI Actin

K1Q4H2_CRAGI Nodal modulator 3

K1Q260_CRAGI Nucleolar protein 58

K1QF01_CRAGI 40S ribosomal protein S4

K1PUM2_CRAGI Histone H2A

K1QNN9_CRAGI MICOS complex subunit MIC60

K1RQA0_CRAGI Dolichyl-diphosphooligosaccharide--protein glycosyltransferase subunit 2

K1QZW0_CRAGI Polyadenylate-binding protein 2 
K1QBNO_CRAGI Methylcrotonoyl-CoA carboxylase beta chain, mitochondrial 
K1PM76_CRAGI NADH dehydrogenase [ubiquinone] 1 alpha subcomplex subunit 9, mitochondrial K1PRL4_CRAGI 60S ribosomal protein L38 (Fragment)

K1RW85_CRAGI Adenosylhomocysteinase

K1PAY7_CRAGI Propionyl-CoA carboxylase alpha chain, mitochondrial

K1PZ08_CRAGI Ras-related protein Rab-7a

K1QY12_CRAGI Dynamin-1-like protein

K1QFN1_CRAGI 60S ribosomal protein L23

K1RDW8_CRAGI Golgi apparatus protein 1

K1RSS3_CRAGI Myosin heavy chain, striated muscle

K1QGK2_CRAGI Coatomer subunit beta

K1PV79_CRAGI Importin subunit alpha

K1QN79_CRAGI 40S ribosomal protein S11

K1PV49_CRAGI RuvB-like helicase

K1QG65_CRAGI rRNA 2'-O-methyltransferase fibrillarin

K1PK85_CRAGI Cullin-associated NEDD8-dissociated protein 1

K1QVN9_CRAGI T-complex protein 1 subunit eta

K1QGB4_CRAGI 40S ribosomal protein S17

K1QK18_CRAGI Cytochrome b5

K1QVW3_CRAGI Alkylglycerone-phosphate synthase

K1QN11_CRAGI Pre-mRNA-processing-splicing factor 8

K1RJS5_CRAGI Uncharacterized protein

K1Q6W5_CRAGI FACT complex subunit spt16

K1QQB6_CRAGI 40S ribosomal protein S14

K1PKF5_CRAGI Protein-glutamine gamma-glutamyltransferase 4

K1PH66_CRAGI Fibrinolytic enzyme, isozyme C

K1PY89_CRAGI Extracellular superoxide dismutase [Cu-Zn]

K1QUK3_CRAGI Putative ATP-dependent RNA helicase DDX41

K1R2V1_CRAGI Importin subunit beta-1

K1PV86_CRAGI Phosphoglycerate mutase family member 5

K1QJ08_CRAGI 60S ribosomal protein L26

K1QLU6_CRAGI Poly [ADP-ribose] polymerase

K1QDN1_CRAGI Heat shock protein $75 \mathrm{kDa}$, mitochondrial (Fragment)

K1QPP2_CRAGI Elongation factor Tu, mitochondrial

K1R834_CRAGI 60S ribosomal protein L9

K1R005_CRAGI Filamin-C (Fragment)

K1QET2_CRAGI Coatomer subunit alpha

K1RKC1_CRAGI Far upstream element-binding protein 3

K1RG19_CRAGI Protein FAM98A

K1Q056_CRAGI Calpain-A

K1QKJO_CRAGI Aldehyde dehydrogenase family 3 member B1

K1QDZ5_CRAGI Cytochrome c1, heme protein, mitochondrial

K1PPP8_CRAGI Vigilin

K1RHB2_CRAGI Nucleolar RNA helicase 2

K1PH31_CRAGI Protein arginine N-methyltransferase 1

K106V6_CRAGI Replication factor C subunit 4

K1PI50_CRAGI 40S ribosomal protein S26

K1PX23_CRAGI Eukaryotic peptide chain release factor subunit 1

K1QFZ8_CRAGI Ceramide kinase-like protein

K1S2S8_CRAGI Signal recognition particle 54 kDa protein

K1R1T8_CRAGI Nucleolar protein 56

K1QRZ3_CRAGI 40S ribosomal protein S13

K1PMP3_CRAGI Protoporphyrinogen oxidase

K1P9N7_CRAGI 14-3-3 protein zeta

K1Q0R4_CRAGI ATP-binding cassette sub-family F member 2

K1QWC3_CRAGI 40S ribosomal protein S3

K1Q812_CRAGI NADH dehydrogenase [ubiquinone] iron-sulfur protein 2, mitochondrial

K1P5V7_CRAGI Eukaryotic translation initiation factor 3 subunit $\mathrm{C}$

K1R2NO_CRAGI Histone H4

K1QLK8_CRAGI GTP-binding protein SAR1b

K1QHX2_CRAGI La-related protein 7 
A K1S6V7_CRAGI Serine/threonine-protein phosphatase 2A $65 \mathrm{kDa}$ regulatory subunit A alpha isoform

A K1Q3W9_CRAGI FAS-associated factor 2-B

A K1QG72_CRAGI Hemagglutinin/amebocyte aggregation factor

A

K1QHQ6_CRAGI Acyl-CoA dehydrogenase family member 9, mitochondrial

K1QFR2_CRAGI Calnexin

K1S1X3_CRAGI SWI/SNF-related matrix-associated actin-dependent regulator of chromatin subfamily A member 5

K1PWZ3_CRAGI Guanine nucleotide-binding protein subunit beta

K1OW41_CRAGI Leucine-zipper-like transcriptional regulator 1

K1RK68_CRAGI Uncharacterized protein

K1RA95_CRAGI Filamin-A

K1QMV5_CRAGI Annexin

K1QW72_CRAGI Catalase

K1QXQ8_CRAGI DNA helicase

K1P7L5_CRAGI Transmembrane 9 superfamily member

K1P8G1_CRAGI Heterogeneous nuclear ribonucleoprotein $\mathrm{H}$

K1PZ23_CRAGI DnaJ-like protein subfamily $\mathrm{C}$ member 3

K1RIZ3_CRAGI Bone morphogenetic protein 7

K1RNN9_CRAGI Cytoskeleton-associated protein 5

K1R6L5_CRAGI NADH-cytochrome b5 reductase

K1R5F2_CRAGI 14-3-3 protein epsilon

K1P9D0_CRAGI Stress-70 protein, mitochondrial

K1RGJ7_CRAGI Neogenin

K1PZP6_CRAGI Coatomer subunit gamma

K1RJ97_CRAGI Multifunctional protein ADE2

K1R6F5_CRAGI Putative ATP-dependent RNA helicase DDX23

K1PS84_CRAGI Alpha-crystallin B chain

K1P9S7_CRAGI Brix domain-containing protein 2

K1PI40_CRAGI Uncharacterized protein

K1QAI2_CRAGI Ufm1-specific protease 2

K1REP0_CRAGI Uncharacterized protein

K1QJM1_CRAGI 60S ribosomal protein L30

K1S3G2 CRAGI HMGB1

K1PXD4_CRAGI Putative ATP-dependent RNA helicase DDX6

K1RJJ7_CRAGI Histone H5

K1Q3W3_CRAGI NADH dehydrogenase [ubiquinone] iron-sulfur protein 3, mitochondrial

K1RJW8_CRAGI Protein DEK

K1RN97_CRAGI Hemagglutinin/amebocyte aggregation factor

K1QW36_CRAGI 60S ribosomal protein L6

K1RA63_CRAGI Transmembrane protein 2

K1R9T2_CRAGI Eukaryotic translation initiation factor 3 subunit B

K1PM66_CRAGI 60S ribosomal protein L12

K1Q273_CRAGI 60S ribosomal protein L14

K1PXG6_CRAGI Serine/threonine-protein phosphatase

K1QPC6_CRAGI Nucleolar complex protein 2-like protein

K1RCW3_CRAGI Elongation factor 1-beta

K1Q324_CRAGI Heterogeneous nuclear ribonucleoprotein $\mathrm{K}$

K1PLA7_CRAGI Eukaryotic initiation factor 4A-II (Fragment)

K1RBI9_CRAGI Small nuclear ribonucleoprotein Sm D2

K1RCL2_CRAGI Mitochondrial import inner membrane translocase subunit Tim13-B

K1QKV1_CRAGI Cytochrome b-c1 complex subunit 6

K1QVU0_CRAGI Synaptojanin-2-binding protein

K1QRG9_CRAGI Uncharacterized protein

K1PZ70_CRAGI NADH dehydrogenase [ubiquinone] iron-sulfur protein 6, mitochondrial

K1Q350_CRAGI Glyceraldehyde-3-phosphate dehydrogenase

K1PXU6_CRAGI 60S ribosomal protein L24

K1QZQ8_CRAGI Low-density lipoprotein receptor-related protein 8

K1RUM2_CRAGI Uncharacterized protein

K1REY2_CRAGI Dysferlin

K1Q6X5_CRAGI Protein disulfide-isomerase

K1QWK6_CRAGI Metalloendopeptidase 
K1QDH9_CRAGI Myosin-11

K1QQR1_CRAGI Major vault protein

K1RAH2_CRAGI Superoxide dismutase [Cu-Zn]

K1PH13_CRAGI Dolichyl-diphosphooligosaccharide--protein glycosyltransferase subunit STT3B

K1PY73_CRAGI Basic leucine zipper and W2 domain-containing protein 1

K1Q7T5_CRAGI Protein disulfide-isomerase

K1PFS5_CRAGI Elongation factor 1-gamma

K1PW39_CRAGI Glycerol-3-phosphate dehydrogenase, mitochondrial

K1R1C5_CRAGI Signal recognition particle receptor subunit beta

K1Q1F4_CRAGI 60S ribosomal protein L3 (Fragment)

K1QNS4_CRAGI DnaJ-like protein subfamily C member 9

K1QY85_CRAGI Transport protein Sec31A

K1QWP1_CRAGI Nucleoporin seh1

K1RAU3_CRAGI DNA ligase

K1R5W3_CRAGI Uncharacterized protein

K1QF31_CRAGI Serine/threonine-protein kinase PLK

K1Q667_CRAGI tRNA-splicing ligase RtcB homolog

K1QRM1_CRAGI Nuclear pore protein

K1R790_CRAGI Retinol dehydrogenase 13

K1ROM2_CRAGI Uncharacterized protein

K1QNT7_CRAGI Aldehyde dehydrogenase, mitochondrial

K1QIV3_CRAGI Uncharacterized protein

K1QR48_CRAGI Calcium-binding mitochondrial carrier protein SCaMC-2

K1R4F7_CRAGI Ras-related protein Rab-6B

K1PIC5_CRAGI Transmembrane protein 85

K1RKZ5_CRAGI DNA damage-binding protein 1

K1QW21_CRAGI 39S ribosomal protein L40, mitochondrial

K1PB87_CRAGI Uncharacterized protein

K1R150_CRAGI Ras-related protein Rab-1A

K1PVZ3_CRAGI Cold shock domain-containing protein E1

K1QSD9_CRAGI Uncharacterized protein

K1PPW8_CRAGI Coatomer subunit beta

K1QKG9_CRAGI Cysteine desulfurase, mitochondrial

K1RK83_CRAGI Tyrosine-protein kinase BAZ1B

K1QE94_CRAGI Alpha-galactosidase

K1RIJ1_CRAGI Synaptobrevin (Fragment)

K1PJB0_CRAGI Heat shock protein 70 B2

K1R6S5_CRAGI 40S ribosomal protein S9

K1PAM6_CRAGI Uncharacterized protein

K1QY71_CRAGI Histone H2B

K1P6Y1_CRAGI Uncharacterized protein

K1PNY5_CRAGI Splicing factor, proline-and glutamine-rich

K1PDL3_CRAGI Ribosomal protein L19

K1RDG4_CRAGI DNA helicase

K1RV41_CRAGI Guanine nucleotide-binding protein subunit beta-2-like 1

K1QMH5_CRAGI Small nuclear ribonucleoprotein Sm D1

K1R4Z3_CRAGI Malate dehydrogenase, mitochondrial

K1R3T3_CRAGI Transcription factor BTF3

K1QAB1_CRAGI AP-2 complex subunit alpha

K1QSU3_CRAGI Protein I(2)37Cc

K1PEY4_CRAGI 26S proteasome non-ATPase regulatory subunit 2

K1PU46_CRAGI Lethal(2) giant larvae-like protein 1

K1Q0N6_CRAGI Dolichyl-diphosphooligosaccharide--protein glycosyltransferase subunit STT3A

K1QGP1_CRAGI Replication factor $C$ subunit 2

K1QDV6_CRAGI Protein argonaute-2

K1S6H7_CRAGI Vacuolar protein sorting-associated protein 13C

K1PF10_CRAGI PAN2-PAN3 deadenylation complex catalytic subunit PAN2

K1Q1L4_CRAGI Uncharacterized protein

K1PWC3_CRAGI Tetratricopeptide repeat protein 35

K1QKL8_CRAGI V-type proton ATPase subunit a 
K1QT61_CRAGI NADH dehydrogenase [ubiquinone] flavoprotein 2, mitochondrial (Fragment) 


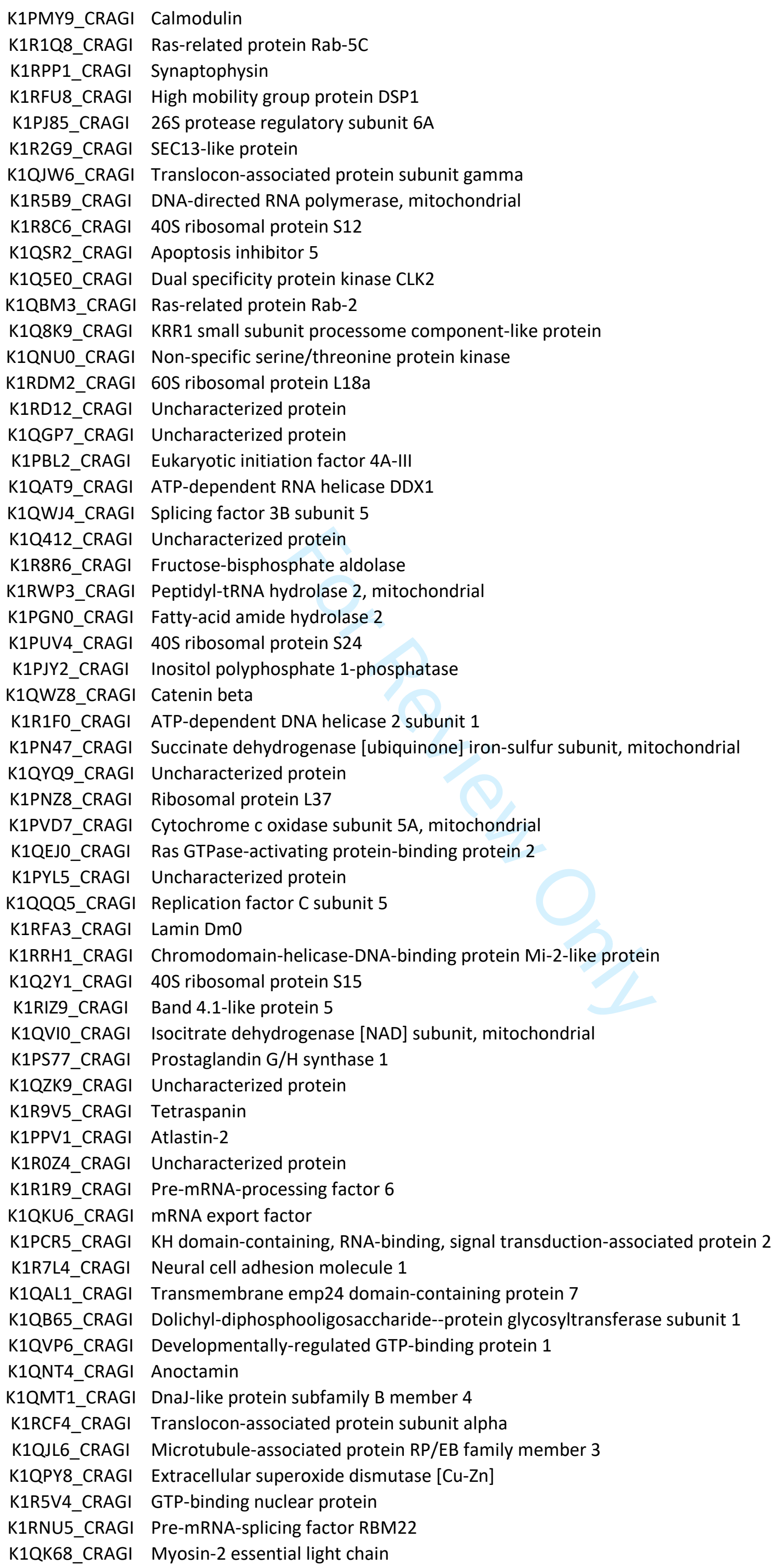


K1QED7_CRAGI Replication protein A subunit 
K1RJ91_CRAGI Ubiquitin-associated protein 2 
K1QQB4_CRAGI Long-chain-fatty-acid--CoA ligase 1

A K1QYM4_CRAGI D-beta-hydroxybutyrate dehydrogenase, mitochondrial

A K1P2G0_CRAGI Strawberry notch-like protein 1

A K1QCT0_CRAGI Sideroflexin

A K1QFG2_CRAGI Telomere-associated protein RIF1

A K1Q5J7_CRAGI Uncharacterized protein

A K1QKA9_CRAGI Piwi-like protein 2

A K1P7Q6_CRAGI 40S ribosomal protein S19

A K1QYV5_CRAGI Cytoplasmic polyadenylation element-binding protein 1-B

A K1QG84_CRAGI THO complex subunit 2

A K1R7G0_CRAGI Chromobox-like protein 5

A K1QHX4_CRAGI Uncharacterized protein

A K1QBY6_CRAGI Transmembrane protein Tmp21

A K1PKK7_CRAGI AP-2 complex subunit mu-1

A K1P9V5_CRAGI General transcription factor IIF subunit 1

A K1Q9V2_CRAGI Antigen KI-67

A K1PNU2_CRAGI Histone-arginine methyltransferase CARM1

A K1Q109_CRAGI Neurexin-4

A K1P9Q2_CRAGI Signal peptidase complex subunit 3

A K1QCNO_CRAGI Signal recognition particle $9 \mathrm{kDa}$ protein

A K1Q7E4_CRAGI Ubiquitin-conjugating enzyme E2 N

A K1Q5G6_CRAGI $60 \mathrm{kDa}$ heat shock protein, mitochondrial

A K1RUW0_CRAGI E3 SUMO-protein ligase RanBP2

A K1RB91_CRAGI Neutral alpha-glucosidase AB

A K1QGF1_CRAGI Splicing factor 3B subunit 2

A K1Q525_CRAGI Mechanosensory protein 2 (Fragment)

A K1RDB3_CRAGI F-box/WD repeat-containing protein $1 \mathrm{~A}$

A K1QI28_CRAGI V-type proton ATPase subunit B

A K1R4JO_CRAGI MAGUK p55 subfamily member 2

A K1Q9T7_CRAGI Afadin-and alpha-actinin-binding protein

A K1RNH6_CRAGI Toll-like receptor 3

A K1PZCO_CRAGI Structural maintenance of chromosomes protein

A K1PT69_CRAGI Uncharacterized protein

A K1RE67_CRAGI Methylated-DNA--protein-cysteine methyltransferase

A K1QCX5_CRAGI Cyclic AMP-dependent transcription factor ATF-2

A K1QBT8_CRAGI Uncharacterized protein

A K1RFF1_CRAGI Uncharacterized protein

A K1RS40_CRAGI Uncharacterized protein

A K1R8V1_CRAGI Puratrophin-1 
Data S2: Identified proteins by RNA pull down coupled with mass spectrometry with m6A or A-oligo, in nuclear or cytosolic protein extracts Proteins identified in cytosolic extracts

\begin{tabular}{|c|c|c|}
\hline Oligo & Accession & Description \\
\hline $\mathrm{m} 6 \mathrm{~A}$ & K1QNA2_CRAGI & Vitellogenin-6 \\
\hline $\mathrm{m} 6 \mathrm{~A}$ & K1QVJ8_CRAGI & Piwi-like protein 1 \\
\hline m6A & K1QQ94_CRAGI & Uncharacterized protein \\
\hline $\mathrm{m} 6 \mathrm{~A}$ & K1QHK9_CRAGI & Dynein heavy chain, cytoplasmic \\
\hline $\mathrm{m} 6 \mathrm{~A}$ & K1QQ68_CRAGI & Tubulin alpha chain \\
\hline $\mathrm{m} 6 \mathrm{~A}$ & K1RLF8_CRAGI & Splicing factor 3B subunit 3 \\
\hline $\mathrm{m} 6 \mathrm{~A}$ & K1R473_CRAGI & Tubulin alpha chain \\
\hline $\mathrm{m} 6 \mathrm{~A}$ & K1QII6_CRAGI & Tubulin alpha chain \\
\hline $\mathrm{m} 6 \mathrm{~A}$ & K1PNR3_CRAGI & Clathrin heavy chain \\
\hline $\mathrm{m} 6 \mathrm{~A}$ & K1R7V7_CRAGI & Tubulin beta chain \\
\hline $\mathrm{m} 6 \mathrm{~A}$ & K1PNI6_CRAGI & Heterogeneous nuclear ribonucleoprotein A/B \\
\hline $\mathrm{m} 6 \mathrm{~A}$ & K1QMX5_CRAGI & Uncharacterized protein \\
\hline $\mathrm{m} 6 \mathrm{~A}$ & K1QHI5_CRAGI & Pyruvate carboxylase, mitochondrial \\
\hline $\mathrm{m} 6 \mathrm{~A}$ & K1PE00_CRAGI & Tubulin alpha chain \\
\hline $\mathrm{m} 6 \mathrm{~A}$ & K1R294_CRAGI & T-complex protein 1 subunit beta \\
\hline $\mathrm{m} 6 \mathrm{~A}$ & K1S4Q2_CRAGI & T-complex protein 1 subunit delta (Fragment) \\
\hline $\mathrm{m} 6 \mathrm{~A}$ & K1PQP2_CRAGI & Nucleolin \\
\hline $\mathrm{m} 6 \mathrm{~A}$ & K1R466_CRAGI & T-complex protein 1 subunit gamma \\
\hline $\mathrm{m} 6 \mathrm{~A}$ & K1PN21_CRAGI & Tubulin beta chain \\
\hline $\mathrm{m} 6 \mathrm{~A}$ & K1R164_CRAGI & Galectin-4 \\
\hline $\mathrm{m} 6 \mathrm{~A}$ & K1S2N7_CRAGI & Innexin \\
\hline $\mathrm{m} 6 \mathrm{~A}$ & K1R6Z7_CRAGI & ATP synthase subunit alpha \\
\hline $\mathrm{m} 6 \mathrm{~A}$ & K1R5B4_CRAGI & Proteasome activator complex subunit 4 \\
\hline $\mathrm{m} 6 \mathrm{~A}$ & K1PVA1_CRAGI & Transitional endoplasmic reticulum ATPase \\
\hline $\mathrm{m} 6 \mathrm{~A}$ & K1QFW9_CRAGI & Uncharacterized protein \\
\hline $\mathrm{m} 6 \mathrm{~A}$ & K1ROS3_CRAGI & T-complex protein 1 subunit theta \\
\hline $\mathrm{m} 6 \mathrm{~A}$ & K1QMA4_CRAGI & RRP5-like protein \\
\hline $\mathrm{m} 6 \mathrm{~A}$ & K1R3U2_CRAGI & Uncharacterized protein \\
\hline $\mathrm{m} 6 \mathrm{~A}$ & K1Q9W5_CRAGI & T-complex protein 1 subunit eta \\
\hline $\mathrm{m} 6 \mathrm{~A}$ & K1QBK6_CRAGI & Splicing factor 3B subunit 1 \\
\hline $\mathrm{m} 6 \mathrm{~A}$ & K1R545_CRAGI & Pre-mRNA-processing-splicing factor 8 (Fragment) \\
\hline $\mathrm{m} 6 \mathrm{~A}$ & K1RAJ1_CRAGI & T-complex protein 1 subunit alpha \\
\hline $\mathrm{m} 6 \mathrm{~A}$ & K1RWS2_CRAGI & Transcriptional activator protein Pur-alpha \\
\hline $\mathrm{m} 6 \mathrm{~A}$ & K1Q350_CRAGI & Glyceraldehyde-3-phosphate dehydrogenase \\
\hline $\mathrm{m} 6 \mathrm{~A}$ & K1RGT5_CRAGI & Metalloendopeptidase \\
\hline $\mathrm{m} 6 \mathrm{~A}$ & K1PJ85_CRAGI & $26 \mathrm{~S}$ protease regulatory subunit $6 \mathrm{~A}$ \\
\hline $\mathrm{m} 6 \mathrm{~A}$ & K1S6V7_CRAGI & Serine/threonine-protein phosphatase $2 \mathrm{~A} 65 \mathrm{kDa}$ regulatory subunit $\mathrm{A}$ alpha isoform \\
\hline $\mathrm{m} 6 \mathrm{~A}$ & K1S1S1_CRAGI & Insulin-like growth factor 2 mRNA-binding protein 1 \\
\hline $\mathrm{m} 6 \mathrm{~A}$ & K1RZE2_CRAGI & Isocitrate dehydrogenase [NADP] \\
\hline $\mathrm{m} 6 \mathrm{~A}$ & K1PNQ5_CRAGI & Heat shock protein HSP 90-alpha 1 \\
\hline $\mathrm{m} 6 \mathrm{~A}$ & K1R866_CRAGI & Puromycin-sensitive aminopeptidase \\
\hline $\mathrm{m} 6 \mathrm{~A}$ & K1P9D0_CRAGI & Stress-70 protein, mitochondrial \\
\hline $\mathrm{m} 6 \mathrm{~A}$ & K1QXX7_CRAGI & Myosin heavy chain, non-muscle (Fragment) \\
\hline $\mathrm{m} 6 \mathrm{~A}$ & K1RG73_CRAGI & Acetyl-CoA carboxylase \\
\hline $\mathrm{m} 6 \mathrm{~A}$ & K1R420_CRAGI & Non-specific serine/threonine protein kinase \\
\hline $\mathrm{m} 6 \mathrm{~A}$ & K1PXN5_CRAGI & T-complex protein 1 subunit zeta \\
\hline $\mathrm{m} 6 \mathrm{~A}$ & K1QGS8_CRAGI & Elongation factor 1-alpha \\
\hline $\mathrm{m} 6 \mathrm{~A}$ & K1RLC5_CRAGI & T-complex protein 1 subunit epsilon \\
\hline $\mathrm{m} 6 \mathrm{~A}$ & K1R6Q7_CRAGI & DNA topoisomerase I \\
\hline $\mathrm{m} 6 \mathrm{~A}$ & K1RW85_CRAGI & Adenosylhomocysteinase \\
\hline $\mathrm{m} 6 \mathrm{~A}$ & K1QSX8_CRAGI & ATPase family AAA domain-containing protein $2 B$ \\
\hline $\mathrm{m} 6 \mathrm{~A}$ & K1R4Z3_CRAGI & Malate dehydrogenase, mitochondrial \\
\hline $\mathrm{m} 6 \mathrm{~A}$ & K1PEY4_CRAGI & 265 proteasome non-ATPase regulatory subunit 2 \\
\hline $\mathrm{m} 6 \mathrm{~A}$ & K1RI55_CRAGI & Insulin-like growth factor 2 mRNA-binding protein 3 \\
\hline $\mathrm{m} 6 \mathrm{~A}$ & K1PK85_CRAGI & Cullin-associated NEDD8-dissociated protein 1 \\
\hline $\mathrm{m} 6 \mathrm{~A}$ & K1R9B6_CRAGI & H/ACA ribonucleoprotein complex subunit 4 \\
\hline $\mathrm{m} 6 \mathrm{~A}$ & K1R252_CRAGI & Putative methylmalonate-semialdehyde dehydrogenase [acylating], mitoch \\
\hline
\end{tabular}


K1RK12_CRAGI K1QVN9_CRAGI K1PLF9_CRAGI Q8TA69_CRAGI K1QG58_CRAGI K1QSB2 CRAGI K1R401_CRAGI K1Q1I2_CRAGI K1Q4I9_CRAGI K1RJH5_CRAGI K1RWD4_CRAGI K1QI14_CRAGI K1RWW5_CRAGI K1QET2_CRAGI K1QVS3_CRAGI K1QSQ9_CRAGI K1Q923_CRAGI K1QXR4_CRAGI K1R512_CRAGI K1R8L1_CRAGI K1PAG1_CRAGI K1Q988_CRAGI K1PJ06_CRAGI K1QWX2_CRAGI K1PH76 CRAGI K1PW06_CRAGI K1RNB5_CRAGI K1QWT8_CRAGI K1QNW9_CRAGI K1QCC1_CRAGI K1QBNO_CRAGI K1Q3S7_CRAGI K1PMT6_CRAGI K1Q9Z6_CRAGI K1PH66_CRAGI K1R1M7_CRAGI K1Q7G8_CRAGI K1QEA6_CRAGI K1QRL4_CRAGI K1RFT1_CRAGI K1QR72_CRAGI K1R5R4_CRAGI K1QLK6_CRAGI K1R5U4_CRAGI K1QXS6_CRAGI K1R953_CRAGI K1PCS4_CRAGI K1QIR8_CRAGI K1RSA6_CRAGI K1R2V1_CRAGI K1QZWO_CRAGI K1R4R9_CRAGI K1QWK2_CRAGI K1R2D6_CRAGI K1QB04_CRAGI K1RH70_CRAGI K1QGK2_CRAGI K1QUE6_CRAGI K1R7I9_CRAGI K1PND7_CRAGI
40 S ribosomal protein $\mathrm{S} 23$

T-complex protein 1 subunit eta

Arginine kinase

Actin 2

Actin

265 protease regulatory subunit $6 B$

Spectrin alpha chain

26S protease regulatory subunit 7

D-3-phosphoglycerate dehydrogenase (Fragment)

Polyadenylate-binding protein

Actin, cytoplasmic

40 S ribosomal protein S3a

ATP synthase subunit beta

Coatomer subunit alpha

Thimet oligopeptidase

Putative ATP-dependent RNA helicase an3

Putative ATP-dependent RNA helicase DDX4

Pancreatic lipase-related protein 2

Uncharacterized protein

Exportin-2

Dynein beta chain, ciliary

Band 4.1-like protein 3

Importin subunit alpha-1

$60 S$ acidic ribosomal protein $\mathrm{PO}$

Y-box factor-like protein (Fragment)

Filamin-C

Propionyl-CoA carboxylase beta chain, mitochondrial

Uncharacterized protein

Bifunctional aminoacyl-tRNA synthetase

Phosphoglycerate kinase

Methylcrotonoyl-CoA carboxylase beta chain, mitochondrial

Cytosolic carboxypeptidase 1

Heterogeneous nuclear ribonucleoprotein U-like protein 1

$26 \mathrm{~S}$ proteasome non-ATPase regulatory subunit 7

Fibrinolytic enzyme, isozyme $C$

Ubiquitin-like modifier-activating enzyme 1

Fatty acid synthase

Phosphoenolpyruvate carboxykinase [GTP]

Importin-5

Band 4.1-like protein 3

Dipeptidyl peptidase 3

Dynein heavy chain 10 , axonemal

E3 ubiquitin-protein ligase HUWE1

Acetyl-CoA carboxylase 1

Heterogeneous nuclear ribonucleoprotein A2-like protein 1

Acetyl-CoA carboxylase

Eukaryotic translation initiation factor 2 subunit 3, Y-linked

$78 \mathrm{kDa}$ glucose-regulated protein

Methylcrotonoyl-CoA carboxylase subunit alpha, mitochondrial

Importin subunit beta-1

Polyadenylate-binding protein 2

Mitotic apparatus protein $\mathrm{p} 62$

MAM domain-containing glycosylphosphatidylinositol anchor protein 2

Plastin-3

265 proteasome non-ATPase regulatory subunit 3

6-phosphogluconate dehydrogenase, decarboxylating

Coatomer subunit beta

26S proteasome non-ATPase regulatory subunit 6

Heterogeneous nuclear ribonucleoprotein $Q$

Fatty acid synthase 
$\mathrm{m} 6 \mathrm{~A}$

$m 6 A$

$\mathrm{m} 6 \mathrm{~A}$

$\mathrm{m} 6 \mathrm{~A}$

$m 6 A$

$\mathrm{m} 6 \mathrm{~A}$

$10 \mathrm{~m} 6 \mathrm{~A}$

$11 \mathrm{~m} 6 \mathrm{~A}$

$12 \mathrm{~m} 6 \mathrm{~A}$

$13 \mathrm{~m} 6 \mathrm{~A}$

$15 \mathrm{~m} 6 \mathrm{~A}$

$16 \mathrm{~m} 6 \mathrm{~A}$

$17 \mathrm{~m} 6 \mathrm{~A}$

$18 \mathrm{~m} 6 \mathrm{~A}$

$19 \mathrm{~m} 6 \mathrm{~A}$

$21 \mathrm{~m} 6 \mathrm{~A}$

$22 \mathrm{~m} 6 \mathrm{~A}$

$23 \mathrm{~m} 6 \mathrm{~A}$

$24 \mathrm{~m} 6 \mathrm{~A}$

m6A

$7 \mathrm{~m} 6 \mathrm{~A}$

$28 \mathrm{~m} 6 \mathrm{~A}$

$29 \mathrm{~m} 6 \mathrm{~A}$

$30 \mathrm{~m} 6 \mathrm{~A}$

$31 \mathrm{~m} 6 \mathrm{~A}$

$32 \mathrm{~m} 6 \mathrm{~A}$

$34 \mathrm{~m} 6 \mathrm{~A}$

$35 \mathrm{~m} 6 \mathrm{~A}$

$36 \mathrm{~m} 6 \mathrm{~A}$

$37 \mathrm{~m} 6 \mathrm{~A}$

$39 \mathrm{~m} 6 \mathrm{~A}$

$40 \mathrm{~m} 6 \mathrm{~A}$

$41 \mathrm{~m} 6 \mathrm{~A}$

$42 \mathrm{~m} 6 \mathrm{~A}$

$43 \mathrm{~m} 6 \mathrm{~A}$

$45 \mathrm{~m} 6 \mathrm{~A}$

$46 \mathrm{~m} 6 \mathrm{~A}$

$47 \mathrm{~m} 6 \mathrm{~A}$

$48 \mathrm{~m} 6 \mathrm{~A}$

$49 \mathrm{~m} 6 \mathrm{~A}$

$51 \mathrm{~m} 6 \mathrm{~A}$

$52 \mathrm{~m} 6 \mathrm{~A}$

$53 \mathrm{~m} 6 \mathrm{~A}$

$54 \mathrm{~m} 6 \mathrm{~A}$

$55 \mathrm{~m} 6 \mathrm{~A}$

$56 \mathrm{~m} 6 \mathrm{~A}$

$58 \mathrm{~m} 6 \mathrm{~A}$

$59 \mathrm{~m} 6 \mathrm{~A}$

$60 \mathrm{~m} 6 \mathrm{~A}$

$m 6 A$

$m 6 A$

$m 6 A$

$m 6 A$

$m 6 A$

$m 6 A$

$m 6 A$

$m 6 A$

$m 6 A$

$m 6 A$

m6A
K1QI28_CRAGI V-type proton ATPase subunit B

K1Q2H5_CRAGI Uncharacterized protein

K1QLT5_CRAGI 26S protease regulatory subunit 4

K1R4I2_CRAGI 26S proteasome non-ATPase regulatory subunit 3

K1QQR1_CRAGI Major vault protein

K1RAU3_CRAGI DNA ligase

K1PFG1_CRAGI Uncharacterized protein

K1RBC9_CRAGI Transketolase-like protein 2

K1QT21_CRAGI Putative ATP-dependent RNA helicase DDX5

K1PKK7_CRAGI AP-2 complex subunit mu-1

K1Q358_CRAGI 60S acidic ribosomal protein P2

K1PS71_CRAGI Uncharacterized protein

K1QHA__CRAGI Spectrin beta chain, brain 4

K1REG6_CRAGI DNA helicase

A7M7T7_CRAGI Non-selenium glutathione peroxidase

K1QHX2_CRAGI La-related protein 7

K1RJ97_CRAGI Multifunctional protein ADE2

K1RNZ6_CRAGI Eukaryotic translation initiation factor 3 subunit D

K1PAY7_CRAGI Propionyl-CoA carboxylase alpha chain, mitochondrial

K1QQ27_CRAGI Pancreatic lipase-related protein 2

K1Q9K6_CRAGI Histone H3

K1R083_CRAGI Aspartate aminotransferase, mitochondrial

K1PEP0_CRAGI 40S ribosomal protein S8

K1PU26_CRAGI Malate dehydrogenase (Fragment)

K1QF01_CRAGI 40S ribosomal protein S4

K1QDN1_CRAGI Heat shock protein $75 \mathrm{kDa}$, mitochondrial (Fragment)

K1QBHO_CRAGI Uncharacterized protein

K1Q9V3_CRAGI V-type proton ATPase catalytic subunit A

K1PJC1_CRAGI Adipophilin

K1Q330_CRAGI Dihydrolipoyl dehydrogenase

K1S3Y1_CRAGI 2-amino-3-ketobutyrate coenzyme A ligase, mitochondrial (Fragment)

K1R2Q9_CRAGI Aspartate aminotransferase

K1QEF2_CRAGI ADP-ribosylation factor-like protein 15

K1PVH5_CRAGI Centromere/kinetochore protein zw10-like protein

K1PG07_CRAGI Lupus La-like protein

K1QMX8_CRAGI DNA replication licensing factor MCM7

K1P7K8_CRAGI Vesicle-fusing ATPase 1

K1QQL6_CRAGI Leucyl-tRNA synthetase, cytoplasmic

K1PY89_CRAGI Extracellular superoxide dismutase [Cu-Zn]

K1QKA9_CRAGI Piwi-like protein 2

K1QHI6_CRAGI Dynein heavy chain 5, axonemal

K1QBF7_CRAGI Hypoxia up-regulated protein 1

K1RTR1_CRAGI ATP-citrate synthase

K1PZF2_CRAGI Exportin-7

K1PPP8_CRAGI Vigilin

K1RN77_CRAGI Nuclear autoantigenic sperm protein

K1PV49_CRAGI RuvB-like helicase

K1QXQ8_CRAGI DNA helicase

K1P2G0_CRAGI Strawberry notch-like protein 1

K1QRQ2_CRAGI Glutamate dehydrogenase 1, mitochondrial

K1QHS8_CRAGI Ribonucleoside-diphosphate reductase

K1QX26_CRAGI Endoplasmin

K1QGB4_CRAGI 40S ribosomal protein S17

K1RJJ7_CRAGI Histone H5

K1QY85_CRAGI Transport protein Sec31A

K1Q6W3_CRAGI Talin-1

K1R3V8_CRAGI COP9 signalosome complex subunit 4

K1OY12_CRAGI Dynamin-1-like protein

K1PYAO_CRAGI Cytoplasmic dynein 2 heavy chain 1

K1PF10_CRAGI PAN2-PAN3 deadenylation complex catalytic subunit PAN2 
K1PNP4_CRAGI K1QMB9_CRAGI K1QC10_CRAGI K1QK56_CRAGI K1PJP9_CRAGI K1PUL2_CRAGI K1Q7Q2_CRAGI K1QQK1_CRAGI K1R3T3_CRAGI K1PK93_CRAGI K1PF96_CRAGI K1PM50_CRAGI K1PX47_CRAGI K1QMV7_CRAGI K1RALO_CRAGI K1P9N7_CRAGI K1QBR5_CRAGI K1PVWO_CRAGI K1PY73_CRAGI K1QBL6_CRAGI K1Q9M7_CRAGI K1S151_CRAGI K1RM80_CRAGI K1R115_CRAGI K1R5D5_CRAGI K1QSR2_CRAGI K1P5D4_CRAGI K1PE57_CRAGI K1P8I1_CRAGI K1Q5G9_CRAGI K1PVZ3_CRAGI K1R4D4_CRAGI K1QXH3_CRAGI K1PI02_CRAGI K1P3Q5_CRAGI K1PKF5_CRAGI K1QFZ8_CRAGI K1PJF4_CRAGI K1PV79_CRAGI K1QMD3_CRAGI K1RDV7_CRAGI K1P8W6_CRAGI K1P112_CRAGI K1R5F2 CRAGI K1QBW8_CRAGI K1PZP6_CRAGI K1PAR4_CRAGI K1QRZ3_CRAGI K1QQB6_CRAGI K1QE71_CRAGI K1RJM8_CRAGI K1RK33_CRAGI K1PPW8_CRAGI K1QRK9_CRAGI K1Q273_CRAGI K1PLY1_CRAGI K1PYR4_CRAGI K1QPC6_CRAGI K1QP17_CRAGI K1R2NO_CRAGI
265 proteasome non-ATPase regulatory subunit 11

Eukaryotic translation initiation factor 3 subunit $A$

GTP-binding protein 1

Uncharacterized protein

26S proteasome non-ATPase regulatory subunit 1

Long-chain-fatty-acid--CoA ligase 1

CCAAT/enhancer-binding protein zeta

26S proteasome non-ATPase regulatory subunit 12

Transcription factor BTF3

GDP-L-fucose synthetase

Spliceosome RNA helicase BAT1

$40 S$ ribosomal protein S16

Ubiquitin carboxyl-terminal hydrolase

V-type proton ATPase subunit D

Aspartate aminotransferase, cytoplasmic

14-3-3 protein zeta

Uncharacterized protein

S-adenosylmethionine synthase

Basic leucine zipper and W2 domain-containing protein 1

Tudor domain-containing protein 1

Histone H1-delta

Rab GDP dissociation inhibitor

Citrate synthase

Succinate dehydrogenase [ubiquinone] flavoprotein subunit, mitochondrial

U3 small nucleolar RNA-associated protein 6-like protein

Apoptosis inhibitor 5

Cysteine synthase

Severin

Pleckstrin-like protein domain-containing family F member 2 (Fragment)

SUMO-activating enzyme subunit 2

Cold shock domain-containing protein E1

40 S ribosomal protein SA

Translational activator GCN1

Talin-1

Programmed cell death 6-interacting protein

Protein-glutamine gamma-glutamyltransferase 4

Ceramide kinase-like protein

Isoleucyl-tRNA synthetase, cytoplasmic

Importin subunit alpha

Glycerol-3-phosphate dehydrogenase [NAD(+)]

Cell division control protein 2-like protein (Fragment)

$60 S$ ribosomal protein $L 4$

ATP synthase subunit gamma, mitochondrial

14-3-3 protein epsilon

Uncharacterized protein

Coatomer subunit gamma

Unc-45-like protein A

40 S ribosomal protein $\mathrm{S} 13$

$40 \mathrm{~S}$ ribosomal protein S14

DNA helicase

SAGA-associated factor 11 homolog

Exportin-1

Coatomer subunit beta

Succinyl-CoA ligase [GDP-forming] subunit beta, mitochondrial

$60 \mathrm{~S}$ ribosomal protein $\mathrm{L} 14$

DNA polymerase

26S proteasome non-ATPase regulatory subunit 1

Nucleolar complex protein 2-like protein

Caprin-1

Histone $\mathrm{H} 4$ 
K1Q5G6_CRAGI K1RIG6 CRAGI K1QY71_CRAGI K1QAB1_CRAGI K1QAF3_CRAGI K1QI97_CRAGI K1PD57_CRAGI K1Q0L1_CRAGI K1RGB7_CRAGI K1ROY9_CRAGI K1QXF5_CRAGI K1PA54_CRAGI K1PS27_CRAGI K1R8C6_CRAGI K1Q880_CRAGI K1PXD4_CRAGI K1P421_CRAGI K1RLO0_CRAGI K1PI50 CRAGI K1RCW5_CRAGI K1ROW4_CRAGI K1QN11_CRAGI K1R8R6_CRAGI K1QVE8_CRAGI K1R5B9 CRAGI K1QA50_CRAGI K1Q9J5_CRAGI K1R3V0_CRAGI K1PFK8_CRAGI K1PSNO_CRAGI K1QL67_CRAGI K1QE32_CRAGI K1QQ16_CRAGI K1QN79_CRAG K1P8B7_CRAGI K1RHB2_CRAGI K1QWC3_CRAGI K1Q4E1_CRAGI K1Q6F7_CRAGI K1R3I6_CRAGI K1PFS5 CRAGI K1PBZ4_CRAGI K1RV41_CRAGI K1QKV1_CRAGI K1S2Y0_CRAGI K1QKK5_CRAGI K1Q8SO CRAGI K1QWK6_CRAGI K1PH31_CRAGI K1R834_CRAGI K1RDG4_CRAGI K1R591_CRAGI K1Q9P5_CRAGI K1QLS3_CRAGI K1QNT7_CRAGI K1QDX9_CRAGI K1S6G3 CRAGI K1R8S7_CRAGI K1QFN1_CRAGI K1Q5Z6_CRAGI
$60 \mathrm{kDa}$ heat shock protein, mitochondrial LSM14-like protein A Histone $\mathrm{H} 2 \mathrm{~B}$

AP-2 complex subunit alpha

Alanine aminotransferase 2

Adenylyl cyclase-associated protein

Constitutive coactivator of PPAR-gamma-like protein 1-like protein $60 S$ ribosomal protein $\mathrm{L} 23 \mathrm{a}$

Epidermal retinal dehydrogenase 2

ADP,ATP carrier protein

Calcyphosin-like protein

Replication factor $\mathrm{C}$ subunit 3

DNA helicase

40 S ribosomal protein S12

Transportin-1

Putative ATP-dependent RNA helicase DDX6

Histone $\mathrm{H} 2 \mathrm{~A}$

Proteasome-associated protein ECM29-like protein

40 S ribosomal protein S26

Eukaryotic translation initiation factor 4 gamma 3

Signal recognition particle subunit SRP72

Pre-mRNA-processing-splicing factor 8

Fructose-bisphosphate aldolase

Phosphoacetylglucosamine mutase

DNA-directed RNA polymerase, mitochondrial

V-type proton ATPase subunit $\mathrm{H}$

Importin-4

CAD protein

Uncharacterized protein

Pre-mRNA-processing factor 40 -like protein A

$60 \mathrm{~S}$ ribosomal protein $\mathrm{L7a}$

Very long-chain specific acyl-CoA dehydrogenase, mitochondrial

AP complex subunit beta

40 S ribosomal protein S11

Ubiquitin-conjugating enzyme E2-17 kDa (Fragment)

Nucleolar RNA helicase 2

$40 \mathrm{~S}$ ribosomal protein S3

$\mathrm{N}$-acetyl-D-glucosamine kinase

V-type proton ATPase subunit C

Nucleolar complex protein 2-like protein (Fragment)

Elongation factor 1-gamma

Regulator of nonsense transcripts 1

Guanine nucleotide-binding protein subunit beta-2-like 1

Cytochrome b-c1 complex subunit 6

Uncharacterized protein

Vacuolar protein sorting-associated protein 4B

Nucleolar complex protein 3 homolog

Metalloendopeptidase

Protein arginine $\mathrm{N}$-methyltransferase 1

$60 S$ ribosomal protein $L 9$

DNA helicase

Inter-alpha-trypsin inhibitor heavy chain $\mathrm{H} 4$

Mitochondrial-processing peptidase subunit beta

Cytochrome b-c1 complex subunit 2, mitochondrial

Aldehyde dehydrogenase, mitochondrial

Ribosome biogenesis protein BMS1-like protein

Ubiquitin-like modifier-activating enzyme 1

Phospholipase A-2-activating protein

605 ribosomal protein $\mathrm{L} 23$

Eukaryotic translation initiation factor 2 subunit 2 
K1R6C2_CRAGI K1Q0R4_CRAGI K1P5V7_CRAGI K1PGW7_CRAGI K1RKC1_CRAGI K1QHY1_CRAGI K1QLK8_CRAGI K1QRG9_CRAGI K1QRW4_CRAGI K1QKI1_CRAGI K1QRM1_CRAGI K1RBZ5_CRAGI K1RLT4_CRAGI K1R7N6_CRAGI K1P5F7_CRAGI K1RCW3_CRAGI K1R2H9_CRAGI K1Q1K8_CRAGI K1QTD9_CRAGI K1QBW6_CRAGI K1QFR9_CRAGI K1P9S7_CRAGI K1QEK7_CRAGI K1PAM6_CRAG K1S3G2 CRAGI K1QI11_CRAGI K1QF31_CRAGI K1QDA7_CRAGI K1QKN4_CRAGI K1RNH1_CRAGI K1QK11_CRAGI K1QED7_CRAGI K1PB82_CRAGI K1PPQ1_CRAGI K1R8T6_CRAGI K1Q7E4_CRAGI K1RSZ6_CRAGI K1Q1S3_CRAGI K1QH70_CRAGI K1QZI3_CRAGI K1Q4Z4_CRAGI K1Q5H6_CRAGI K1PKL8_CRAGI K1QUC6 CRAGI K1QPP2_CRAGI K1QMH5_CRAGI K1PZD9_CRAGI K1PBU0_CRAGI K1QYB6_CRAGI K1PMP3_CRAGI K1Q2E0_CRAGI K1QEF9_CRAGI K1QGE4_CRAGI K1Q6V6_CRAGI K1QYT7_CRAGI K1PWP4_CRAGI K1PWD9_CRAGI K1QAH9_CRAGI K1PS13_CRAGI K1QJ33_CRAGI
Peroxisomal 3,2-trans-enoyl-CoA isomerase

ATP-binding cassette sub-family $\mathrm{F}$ member 2

Eukaryotic translation initiation factor 3 subunit $C$

Transmembrane protein 2

Far upstream element-binding protein 3

Eosinophil peroxidase

GTP-binding protein SAR1b

Uncharacterized protein

Coronin

Tudor domain-containing protein 1

Nuclear pore protein

Ran GTPase-activating protein 1

Signal recognition particle subunit SRP68

Eukaryotic translation initiation factor 6

Metastasis-associated protein MTA1

Elongation factor 1-beta

WD repeat-containing protein 35

Elongation factor 1-beta

Nucleolar protein 56

Tudor domain-containing protein 1

Spectrin beta chain

Brix domain-containing protein 2

Ubiquitin carboxyl-terminal hydrolase

Uncharacterized protein

HMGB1

Pyruvate dehydrogenase E1 component subunit alpha type II, mitochondrial Serine/threonine-protein kinase PLK

Uracil phosphoribosyltransferase

Dynein heavy chain 6, axonemal

605 ribosomal protein L18 (Fragment)

Dynein heavy chain 7, axonemal

Replication protein A subunit

Electron transfer flavoprotein subunit beta

14-3-3 protein gamma

Cullin-1

Ubiquitin-conjugating enzyme E2 N

40S ribosomal protein $\mathrm{S7}$

Myosin-VI

Leucine-rich repeat-containing protein 40

Myosin-le

Bifunctional purine biosynthesis protein PURH

FACT complex subunit SSRP1

Serine/threonine-protein phosphatase $2 A 56 \mathrm{kDa}$ regulatory subunit alpha isoform

Uncharacterized protein

Elongation factor Tu, mitochondrial

Small nuclear ribonucleoprotein Sm D1

26S proteasome non-ATPase regulatory subunit 11

L-fucose kinase

Delta-1-pyrroline-5-carboxylate synthetase

Protoporphyrinogen oxidase

AP-1 complex subunit mu-1

Protein-glutamine gamma-glutamyltransferase $\mathrm{K}$

Proteasome endopeptidase complex (Fragment)

Replication factor $\mathrm{C}$ subunit 4

COP9 signalosome complex subunit 7a

Phenylalanyl-tRNA synthetase alpha chain

Uncharacterized protein

H/ACA ribonucleoprotein complex subunit

Coatomer subunit beta (Fragment)

Aminoacyl tRNA synthetase complex-interacting multifunctional protein 2 
K1QRL6_CRAGI K1PU46_CRAGI K1R7J6_CRAGI K1QYV6_CRAGI K1R6E9_CRAGI K1P7L9_CRAGI K1PIB7_CRAGI K1PX23_CRAGI K1QDV6_CRAGI K1R5G4_CRAGI K1R9T2_CRAGI K1PW99_CRAGI K1R1F0_CRAGI K1Q260 CRAGI K1QFS4_CRAGI K1QLZ1_CRAGI K1Q6X5_CRAGI K1PJB0_CRAGI K1Q8K2_CRAGI K1PKF6_CRAGI K1QGL9_CRAGI K1RGJ7_CRAGI K1PUJ1_CRAGI K1Q811_CRAGI K1QWZO_CRAGI K1PRL4_CRAGI K1Q9I1_CRAGI K1QVRO CRAGI K1QK68_CRAGI K1QMH2_CRAGI K1PD36_CRAGI K1Q4V0_CRAGI K1QBT2 CRAGI K1PXU6_CRAGI K1Q329_CRAGI K1QDH9_CRAGI K1QW36_CRAGI K1Q4Y8_CRAGI K1PM66_CRAGI K1Q4U7_CRAGI K1QPY8_CRAGI K1QIP0_CRAGI K1QW72_CRAGI K1QMD8_CRAGI K1PZCO_CRAGI K1RBI9_CRAGI K1QCQ5_CRAGI K1ROL4_CRAGI K1QKG9_CRAGI K1PPK1_CRAGI K1PUQ5_CRAGI K1RFU6_CRAGI K1Q615_CRAGI K1RIT6_CRAGI K1PQZ3_CRAGI K1QW41_CRAGI K1PNS2_CRAGI K1QQP1_CRAGI K1QQC1_CRAGI K1P6F0_CRAGI
Methenyltetrahydrofolate synthetase domain-containing protein

Lethal(2) giant larvae-like protein 1

Putative sodium/potassium-transporting ATPase subunit beta-2

NMDA receptor-regulated protein 1

Dihydrolipoamide acetyltransferase component of pyruvate dehydrogenase complex Nucleolar GTP-binding protein 1

Phenylalanyl-tRNA synthetase beta chain

Eukaryotic peptide chain release factor subunit 1

Protein argonaute-2

60 S ribosomal protein $\mathrm{L} 31$

Eukaryotic translation initiation factor 3 subunit $B$

Protein OSCP1

ATP-dependent DNA helicase 2 subunit 1

Nucleolar protein 58

Actin-related protein 2

Actin-related protein 3

Protein disulfide-isomerase

Heat shock protein 70 B2

Importin subunit alpha

265 proteasome non-ATPase regulatory subunit 13

Mannose-1-phosphate guanyltransferase beta

Neogenin

Radixin

Alpha-centractin

Tetratricopeptide repeat protein 38

605 ribosomal protein L38 (Fragment)

TRAF2 and NCK-interacting protein kinase

26S proteasome non-ATPase regulatory subunit 8

Myosin-2 essential light chain

DNA polymerase

Ubiquitin

Myosin-VIla

Proteasome subunit beta

605 ribosomal protein $\mathrm{L} 24$

Pyruvate dehydrogenase E1 component subunit beta, mitochondrial

Myosin-11

$60 S$ ribosomal protein $\mathrm{L} 6$

Histone $\mathrm{H} 10 \mathrm{O}$

$60 \mathrm{~S}$ ribosomal protein $\mathrm{L} 12$

AP-3 complex subunit delta-1

Extracellular superoxide dismutase [Cu-Zn]

$26 \mathrm{~S}$ proteasome non-ATPase regulatory subunit 5

Catalase

Proteasome subunit alpha type

Structural maintenance of chromosomes protein

Small nuclear ribonucleoprotein Sm D2

Succinate--CoA ligase [ADP-forming] subunit beta, mitochondrial

Sodium/potassium-transporting ATPase subunit alpha

Cysteine desulfurase, mitochondrial

Actin-related protein 2/3 complex subunit 4

Histone $\mathrm{H} 2 \mathrm{~B}$

Proteasome activator complex subunit 3

Peroxiredoxin-1

NADH-ubiquinone oxidoreductase $75 \mathrm{kDa}$ subunit, mitochondrial

Armadillo repeat-containing protein 4

Leucine-zipper-like transcriptional regulator 1

$33 \mathrm{kDa}$ inner dynein arm light chain, axonemal

Programmed cell death protein 4

Dynein light chain roadblock

HEAT repeat-containing protein 2 
K1QHM2_CRAGI K1QY58_CRAGI K1PLA7_CRAGI K1R818_CRAGI K1R2L7_CRAGI K1QSD9_CRAGI K1R008_CRAGI K1QBL3_CRAGI K1R6S5_CRAGI K1QNS4_CRAGI K1Q7X3_CRAGI K1QG65_CRAGI K1QU53_CRAGI K1RU04_CRAGI K1RAH6_CRAGI K1PTV1_CRAGI K1PCR5_CRAGI K1QYH6_CRAGI K1QH74_CRAGI K1PX83_CRAGI K1QJF7_CRAGI K1PNXO_CRAGI K1Q1L4_CRAGI K1PH10_CRAGI K1QCL6_CRAGI K1Q1Q9_CRAGI K1QVP6_CRAGI K1QNUO_CRAGI K1Q6U0_CRAGI K1S058_CRAGI K1R488_CRAGI K1Q4G7_CRAGI K1PDL3_CRAGI K1PBL2_CRAGI K1QE83_CRAGI K1R1Q8_CRAGI K1ROP8_CRAGI K1QJ46_CRAGI K1QG70_CRAGI K1RBF6_CRAGI K1RZM3_CRAGI K1R5V4_CRAGI K1QZX9_CRAGI K1Q6U7 CRAGI K1R195_CRAGI K1Q317_CRAGI K1QJE9_CRAGI K1PD30_CRAGI K1QJM1_CRAGI K1RHP3_CRAGI K1PMJ9_CRAGI K1RAU8_CRAGI K1RIS2_CRAGI K1PLM3_CRAGI K1PWU5_CRAGI K1QFFO_CRAGI K1P6C4_CRAGI K1RG19_CRAGI K1QCBO_CRAGI K1PCH8_CRAGI
Dolichyl-diphosphooligosaccharide--protein glycosyltransferase subunit 2 Eukaryotic translation initiation factor 3 subunit I (Fragment) Eukaryotic initiation factor 4A-II (Fragment)

Acetyltransferase component of pyruvate dehydrogenase complex

Glutaminyl-tRNA synthetase (Fragment)

Uncharacterized protein

Proteasome subunit alpha type

Putative phosphoglycerate mutase $40 S$ ribosomal protein 59

DnaJ-like protein subfamily $\mathrm{C}$ member 9

Pre-mRNA-splicing factor SYF1

rRNA 2'-O-methyltransferase fibrillarin

$\mathrm{NAD}(\mathrm{P})$ transhydrogenase, mitochondrial

Actin, cytoplasmic

Ubiquitin-conjugating enzyme E2-17 kDa

Splicing factor $3 \mathrm{~B}$ subunit 4

$\mathrm{KH}$ domain-containing, RNA-binding, signal transduction-associated protein 2

COP9 signalosome complex subunit 3

Splicing factor, arginine/serine-rich 1

Dynein heavy chain 5 , axonemal

Coronin

Methionyl-tRNA synthetase, cytoplasmic

Uncharacterized protein

Polyadenylate-binding protein-interacting protein 1

Proteasomal ubiquitin receptor ADRM1

Alpha-aminoadipic semialdehyde synthase, mitochondrial

Developmentally-regulated GTP-binding protein 1

Non-specific serine/threonine protein kinase

Coatomer subunit zeta-1

Transcription factor RFX3

Actin-related protein $2 / 3$ complex subunit

Tubulin gamma chain

Ribosomal protein L19

Eukaryotic initiation factor $4 \mathrm{~A}-\mathrm{III}$

CCR4-NOT transcription complex subunit 1

Ras-related protein Rab-5C

CTP synthase

Putative methylcrotonoyl-CoA carboxylase beta chain, mitochondrial

Katanin p60 ATPase-containing subunit A1

Uncharacterized protein yfeX

Cartilage acidic protein 1

GTP-binding nuclear protein

Uncharacterized protein

$78 \mathrm{kDa}$ glucose-regulated protein

Protein DJ-1

Serine/threonine-protein kinase SRPK1

Uncharacterized protein

Putative histone-binding protein Caf1

$60 S$ ribosomal protein $\mathrm{L} 30$

Proliferation-associated protein 2G4

Cleavage stimulation factor $77 \mathrm{kDa}$ subunit

Eukaryotic translation initiation factor 3 subunit $\mathrm{E}$

3-oxoacyl-[acyl-carrier-protein] reductase

Hydroxyacyl-coenzyme A dehydrogenase, mitochondrial

Cytosolic carboxypeptidase 1

Vacuolar protein sorting-associated protein 35 (Fragment)

Poly [ADP-ribose] polymerase

Protein FAM98A

$40 S$ ribosomal protein 55

Nucleoporin p54 
$\mathrm{m} 6 \mathrm{~A}$

$m 6 A$

$m 6 A$

$m 6 A$

$m 6 A$

$\mathrm{m} 6 \mathrm{~A}$

$10 \mathrm{~m} 6 \mathrm{~A}$

$11 \mathrm{~m} 6 \mathrm{~A}$

$12 \mathrm{~m} 6 \mathrm{~A}$

$36 A$

$5 \mathrm{~m} 6 \mathrm{~A}$

$16 \mathrm{~m} 6 \mathrm{~A}$

$17 \mathrm{~m} 6 \mathrm{~A}$

$18 \mathrm{~m} 6 \mathrm{~A}$

$19 \mathrm{~m} 6 \mathrm{~A}$

$21 \mathrm{~m} 6 \mathrm{~A}$

$22 \mathrm{~m} 6 \mathrm{~A}$

$23 \mathrm{~m} 6 \mathrm{~A}$

$24 \mathrm{~m} 6 \mathrm{~A}$

${ }^{5} \mathrm{~m} 6 \mathrm{~A}$

$7 \mathrm{~m} 6 \mathrm{~A}$

$28 \mathrm{~m} 6 \mathrm{~A}$

$29 \mathrm{~m} 6 \mathrm{~A}$

$30 \mathrm{~m} 6 \mathrm{~A}$

$31 \mathrm{~m} 6 \mathrm{~A}$

$32 \mathrm{~m} 6 \mathrm{~A}$

$34 \mathrm{~m} 6 \mathrm{~A}$

$35 \mathrm{~m} 6 \mathrm{~A}$

$36 \mathrm{~m} 6 \mathrm{~A}$

$37 \mathrm{~m} 6 \mathrm{~A}$

$39 \mathrm{~m} 6 \mathrm{~A}$

$40 \mathrm{~m} 6 \mathrm{~A}$

$41 \mathrm{~m} 6 \mathrm{~A}$

$42 \mathrm{~m} 6 \mathrm{~A}$

$43 \mathrm{~m} 6 \mathrm{~A}$

$45 \mathrm{~m} 6 \mathrm{~A}$

$46 \mathrm{~m} 6 \mathrm{~A}$

$47 \mathrm{~m} 6 \mathrm{~A}$

$48 \mathrm{~m} 6 \mathrm{~A}$

$49 \mathrm{~m} 6 \mathrm{~A}$

$51 \mathrm{~m} 6 \mathrm{~A}$

$52 \mathrm{~m} 6 \mathrm{~A}$

$53 \mathrm{~m} 6 \mathrm{~A}$

$54 \mathrm{~m} 6 \mathrm{~A}$

$55 \mathrm{~m} 6 \mathrm{~A}$

$56 \mathrm{~m} 6 \mathrm{~A}$

$58 \mathrm{~m} 6 \mathrm{~A}$

$59 \mathrm{~m} 6 \mathrm{~A}$

$60 \mathrm{~m} 6 \mathrm{~A}$

$m 6 A$

$m 6 A$

$m 6 A$

$m 6 A$

$m 6 A$

$m 6 A$

$m 6 A$

$m 6 A$

m6A

$m 6 A$

m6A
K1Q2Y1_CRAGI 40S ribosomal protein S15

K1QGW4_CRAGI Density-regulated protein

K1R6H7_CRAGI Uncharacterized protein

K1R0D7_CRAGI Eukaryotic translation initiation factor 3 subunit M (Fragment)

K1PPI6_CRAGI Synaptobrevin-like protein YKT6

K1RMW3_CRAGI Protein kinase C

K1QV25_CRAGI Transcription elongation factor B polypeptide 2

K1QC27_CRAGI Hydroxysteroid dehydrogenase-like protein 2

K1RAT9_CRAGI Tubulin-specific chaperone D

K1QWJ4_CRAGI Splicing factor 3B subunit 5

K1PZ08_CRAGI Ras-related protein Rab-7a

K1QMQ1_CRAGI TBC1 domain family member 10B

K1R811_CRAGI Ribonucleoside-diphosphate reductase small chain

K1P8G1_CRAGI Heterogeneous nuclear ribonucleoprotein $\mathrm{H}$

K1R983_CRAGI Protein transport protein SEC23

K1QDI4_CRAGI Superoxide dismutase [Cu-Zn]

K1RDM2_CRAGI 60S ribosomal protein L18a

K1QYI9_CRAGI Arginyl-tRNA synthetase, cytoplasmic (Fragment)

K1QVSO_CRAGI Ras-like GTP-binding protein Rho1

K1PJS7_CRAGI Poly [ADP-ribose] polymerase

K1QRD0_CRAGI Cytoplasmic dynein 1 light intermediate chain 1

K1ROR7_CRAGI Putative ATP-dependent RNA helicase DHX36

K1Q1F1_CRAGI Serine/threonine-protein kinase 31

K1QI32_CRAGI Synaptotagmin-like protein 5

K1PMY9_CRAGI Calmodulin

K1PXG6_CRAGI Serine/threonine-protein phosphatase

K1QW61_CRAGI WD repeat-containing protein 19

K1P2B8_CRAGI GDP-mannose 4,6 dehydratase

K1QYT5_CRAGI Phosphate carrier protein, mitochondrial

K1RIZ9_CRAGI Band 4.1-like protein 5

K1QT97_CRAGI N(G),N(G)-dimethylarginine dimethylaminohydrolase 1

K1QKF8_CRAGI S-(hydroxymethyl)glutathione dehydrogenase

K1REJ2_CRAGI Lon protease homolog, mitochondrial

K1R1B1_CRAGI $35 \mathrm{kDa}$ SR repressor protein

K1PRK2_CRAGI Small glutamine-rich tetratricopeptide repeat-containing protein beta

K1QAT9_CRAGI ATP-dependent RNA helicase DDX1

K1PFV9_CRAGI 4-trimethylaminobutyraldehyde dehydrogenase

K1QLP5_CRAGI Coatomer subunit delta

K1PIH2_CRAGI V-type proton ATPase subunit E

K1RBU9_CRAGI Non-specific serine/threonine protein kinase

K1QGP1_CRAGI Replication factor $C$ subunit 2

K1PJ96_CRAGI Uncharacterized protein

K1QHHO_CRAGI Protein henna

K1ROWO_CRAGI Ferritin

K1Q6W5_CRAGI FACT complex subunit spt16

K1QEZ5_CRAGI MON2-like protein

K1RJW8_CRAGI Protein DEK

K1P752_CRAGI UPF0195 protein FAM96B

K1RP91_CRAGI Putative RNA exonuclease NEF-sp

K1QSZ6_CRAGI Uncharacterized protein

K1RD83_CRAGI Serine hydroxymethyltransferase

K1R5W3_CRAGI Uncharacterized protein

K1S211_CRAGI Poly(A) RNA polymerase gld-2-like protein A

K1QTW6_CRAGI Eukaryotic translation initiation factor 3 subunit $F$

K1QEJO_CRAGI Ras GTPase-activating protein-binding protein 2

K1R1R9_CRAGI Pre-mRNA-processing factor 6

K1QJL2_CRAGI CCR4-NOT transcription complex subunit 10

K1PUV4_CRAGI 40S ribosomal protein S24

K1RH58_CRAGI Alpha-actinin, sarcomeric

K1PQI4_CRAGI Enolase-phosphatase E1 
K1R7D7_CRAGI

K1PS84_CRAGI

K1QQVO_CRAGI

K1QPJ9_CRAGI

K1OZX3_CRAGI

K1R517_CRAGI

K1RJS5_CRAGI

K1S309_CRAGI

K1PKD4_CRAGI

K1PGZO_CRAGI

K1REV3_CRAGI

K1QGF1_CRAGI

K1R8B2_CRAGI

K1PR25_CRAGI

K1PZ23_CRAGI

K1PLG1_CRAGI

K1PNY5_CRAGI

K1RG79_CRAGI

K1PRB6_CRAGI

K1PTR3_CRAGI

K1Q1F4_CRAGI

Q70MT4_CRAGI

K1Q662_CRAGI

K1R2G9_CRAGI

K1PRV7_CRAGI

K1QWZ6_CRAGI

K1R9S5_CRAGI

K1QUKO_CRAGI

K1PTE3_CRAGI

K1Q6M6_CRAGI

K1QZN3_CRAGI

K1PB94_CRAGI

K1RNN9_CRAGI

K1PZLO_CRAGI

K1RKZ5_CRAGI

K1R138_CRAGI

K1Q9D7_CRAGI

K1R6F1_CRAGI

K1QKQ5_CRAGI

K1PDC6_CRAGI

A5LGH1_CRAGI

K1PF60_CRAGI

K1R924_CRAGI

K1RTQ6_CRAGI

K1Q888_CRAGI

K1R255_CRAGI

K1QIZ7_CRAGI

K1QI48_CRAGI

K1PWB9_CRAGI

K1QZ84_CRAGI

K1PJY4_CRAGI

K1PBCO_CRAGI

K1PRD5_CRAGI

K1QXH7_CRAGI

K1Q719_CRAGI

K1QV87_CRAGI

K1PBH3_CRAGI

K1R4M7_CRAGI

K1R3A0_CRAGI

K1QQQ5_CRAGI
Poly(A)-specific ribonuclease PARN

Alpha-crystallin B chain

Histone H1.2

Serine/threonine-protein phosphatase $2 \mathrm{~A} 55 \mathrm{kDa}$ regulatory subunit B

Vacuolar protein sorting-associated protein VTA1-like protein

Superkiller viralicidic activity 2-like 2

Uncharacterized protein

MAK16-like protein (Fragment)

$40 \mathrm{~S}$ ribosomal protein $\mathrm{S} 30$

Thyroid adenoma-associated protein

DNA polymerase delta subunit 2

Splicing factor $3 B$ subunit 2

Isovaleryl-CoA dehydrogenase, mitochondrial

Regulator of differentiation 1

DnaJ-like protein subfamily $\mathrm{C}$ member 3

Putative ribosomal RNA methyltransferase NOP2

Splicing factor, proline-and glutamine-rich

Neuronal acetylcholine receptor subunit alpha- 6

Apolipoprotein D

Oxysterol-binding protein

60S ribosomal protein L3 (Fragment)

$40 \mathrm{~S}$ ribosomal protein $\mathrm{S} 10$

Actin-interacting protein 1

SEC13-like protein

Profilin

Dolichyl-diphosphooligosaccharide--protein glycosyltransferase subunit 1

Cytosolic Fe-S cluster assembly factor NUBP2 homolog

NEDD8-activating enzyme E1 catalytic subunit

Uncharacterized protein

6-phosphofructokinase

Myosin-Id

ATP-binding cassette sub-family E member 1

Cytoskeleton-associated protein 5

B-box type zinc finger protein $\mathrm{ncl}-1$

DNA damage-binding protein 1

Nuclear pore glycoprotein p62

Sorting nexin-2

Proteasome subunit alpha type

$\mathrm{N}$-terminal acetyltransferase B complex subunit MDM20

Proteasome subunit beta

Voltage-dependent anion channel

3-ketoacyl-CoA thiolase, mitochondrial

RNA-binding protein 45

Fructose-bisphosphate aldolase

Translin

Heterogeneous nuclear ribonucleoprotein $\mathrm{L}$

Programmed cell death protein 6

Inositol hexakisphosphate and diphosphoinositol-pentakisphosphate kinase

EH domain-containing protein 1

Thioredoxin domain-containing protein 3-like protein

Calcium-binding protein 39

Non-neuronal cytoplasmic intermediate filament protein

Trifunctional purine biosynthetic protein adenosine-3

DNA replication licensing factor $\mathrm{mcm} 4-\mathrm{B}$

Serine/threonine-protein kinase OSR1

Catenin alpha-2

Dynein heavy chain 3, axonemal

Serine/threonine protein phosphatase $2 \mathrm{~A}$ regulatory subunit

Transcription initiation factor IIB

Replication factor $\mathrm{C}$ subunit 5 
K1RJ70_CRAGI Cytosolic non-specific dipeptidase

K1QNY7_CRAGI Transport protein Sec24C

K1R481_CRAGI

K1QRE1_CRAGI

K1RA63_CRAGI

K1QHTO CRAGI

K1PQA3_CRAGI

K1PII4_CRAGI

K1P8S5_CRAGI

K1QMT1_CRAGI

K1PN10_CRAGI

K1PCR9_CRAGI

K1PZI3_CRAGI

K1RIZ3_CRAGI

K1QMY1_CRAGI

K1R3W9_CRAGI

K1PLD4_CRAGI

K1QC78_CRAGI

K1PTV5_CRAGI

K1RGG1_CRAGI

K1R3R4_CRAGI

K1R266_CRAGI

K1QGC9_CRAGI

K1Q7T5_CRAGI

K1QKQ8_CRAGI

K1QR54_CRAGI

K1PEW1_CRAGI

K1PFL3_CRAGI

K1QC11_CRAGI

K1QQI3_CRAGI

K1R916_CRAGI

K1PF37_CRAGI

K1PJWO_CRAGI

K1PUX5_CRAGI

K1QB86_CRAGI

K1QWXO_CRAGI

K1QBM3_CRAGI

K1RG04_CRAGI

K1PXH5_CRAGI

K1Q407_CRAGI

K1PYK7_CRAGI

K1PZR3_CRAGI

K1RBJ3_CRAGI

K1Q324_CRAGI

K1PA61_CRAGI

K1PWS8_CRAGI

K1PL64_CRAGI

K1RB97_CRAGI

K1R6S7_CRAGI

K1RK83_CRAGI

K1QSA2_CRAGI

K1RFU8_CRAGI

K1QV46_CRAGI

K1R8W3_CRAGI

K1RFF7_CRAGI

K1R1T8_CRAGI

K1PNG7_CRAGI

K1PCVO_CRAGI

K1QVX4_CRAGI

K1P9V5_CRAGI

Epimerase family protein SDR39U1

Transmembrane protein 2

YTH domain-containing protein 1

Condensin complex subunit 3

Intron-binding protein aquarius

Bone morphogenetic protein 7

Dynein heavy chain 2, axonemal

Ras-related protein Rab-14

Programmed cell death protein 10

Retinal dehydrogenase 1

Acetyl-coenzyme A synthetase

Protein disulfide-isomerase

THO complex subunit 4-A

Zinc finger RNA-binding protein

Sorting nexin

Dihydropteridine reductase

AP-1 complex subunit gamma

Rab-like protein 5

Talin-1

Casein kinase II subunit alpha

Dynamin-1

Ras-related protein Rab-2

ALK tyrosine kinase receptor

Ras GTPase-activating protein 1

RNA-binding protein 39

Actin-like protein $6 \mathrm{~A}$

Poly(A) polymerase gamma

Kinetochore-associated protein 1

Tyrosine-protein kinase BAZ1B

High mobility group protein DSP1

Protein lethal(2)essential for life

Nucleolar protein 56

Sorting nexin-33

Severin

Glycogen synthase kinase-3 beta
COP9 signalosome complex subunit 6

Deoxyuridine 5'-triphosphate nucleotidohydrolase, mitochondrial

Pseudouridylate synthase 7-like protein

DnaJ-like protein subfamily B member 4

Proteasome endopeptidase complex

SWI/SNF complex subunit SMARCC2

Aconitate hydratase, mitochondrial

Replication protein A $14 \mathrm{kDa}$ subunit

Alanyl-tRNA synthetase, cytoplasmic

Cytosolic Fe-S cluster assembly factor NUBP1 homolog

Structural maintenance of chromosomes protein

Thioredoxin domain-containing protein 9

26S proteasome non-ATPase regulatory subunit 14

Putative saccharopine dehydrogenase

U2 small nuclear ribonucleoprotein A

DnaJ-like protein subfamily $\mathrm{C}$ member 13

Heterogeneous nuclear ribonucleoprotein $\mathrm{K}$

Mitotic spindle assembly checkpoint protein MAD2A

Mannose-1-phosphate guanyltransferase alpha-A

Short-chain specific acyl-CoA dehydrogenase, mitochondrial

Tetratricopeptide repeat protein 21B

S-phase kinase-associated protein 1

General transcription factor IIF subunit 1 
K1Q904_CRAGI K1REC3_CRAGI K1P137_CRAGI K1QBT8_CRAGI K1PZN1_CRAGI K1QVZ2 CRAGI K1REPO_CRAGI K1QHXO_CRAGI K1PVL5_CRAGI K1Q6Y2_CRAGI K1PMQ4_CRAGI K1PQR9_CRAGI K1R150_CRAGI K1PNU2_CRAGI K1PEX5_CRAGI K1PDFO_CRAGI K1QC22_CRAGI K1PUFO_CRAGI K1S422_CRAGI K1PI41_CRAGI K1RON8_CRAGI K1RXR4_CRAGI K1PXX6_CRAGI K1QXP9_CRAGI K1RJB4_CRAGI K1QNA2_CRAGI K1QHK9_CRAGI K1PNR3_CRAGI K1QVJ8_CRAGI K1R7V7_CRAGI K1QQ94_CRAGI K1RLF8_CRAGI K1QQ68_CRAGI K1S2N7_CRAGI K1R164_CRAGI K1QMX5_CRAGI K1QHI5_CRAGI K1PQP2_CRAGI K1PN21_CRAGI K1PAG1_CRAGI K1QII6 CRAGI K1R5B4_CRAGI K1QFW9_CRAGI K1R473_CRAGI K1PK85_CRAGI K1R294_CRAGI K1PE00_CRAGI K1PNI6_CRAGI K1PYA0_CRAGI K1R466_CRAGI K1S4Q2_CRAGI K1QMA4_CRAGI K1R5R4_CRAGI K1RZE2_CRAGI K1QGS8_CRAGI K1QXX7_CRAGI K1S6V7_CRAGI K1R866_CRAGI K1QBK6_CRAGI K1R3U2_CRAGI
PAN2-PAN3 deadenylation complex subunit PAN3

Exportin-5

Actin-related protein $2 / 3$ complex subunit 5

Uncharacterized protein

Calcium/calmodulin-dependent protein kinase type II delta chain

Uncharacterized protein

Uncharacterized protein

Double-stranded RNA-specific editase 1

tRNA 2'-phosphotransferase 1

Uncharacterized protein

Microtubule-associated serine/threonine-protein kinase-like protein

Squamous cell carcinoma antigen recognized by T-cells 3

Ras-related protein Rab-1A

Histone-arginine methyltransferase CARM1

Protein hu-li tai shao

Protein disulfide-isomerase A6

40 S ribosomal protein S19

G-protein coupled receptor moody

Katanin p80 WD40 repeat-containing subunit B1

Flap endonuclease 1

Flap endonuclease GEN-like protein 1

Arrestin domain-containing protein 3

Uncharacterized protein

Uncharacterized protein

Ubiquitin carboxyl-terminal hydrolase 1

Vitellogenin-6

Dynein heavy chain, cytoplasmic

Clathrin heavy chain

Piwi-like protein 1

Tubulin beta chain

Uncharacterized protein

Splicing factor 3B subunit 3

Tubulin alpha chain

Innexin

Galectin-4

Uncharacterized protein

Pyruvate carboxylase, mitochondrial

Nucleolin

Tubulin beta chain

Dynein beta chain, ciliary

Tubulin alpha chain

Proteasome activator complex subunit 4

Uncharacterized protein

Tubulin alpha chain

Cullin-associated NEDD8-dissociated protein 1

T-complex protein 1 subunit beta

Tubulin alpha chain

Heterogeneous nuclear ribonucleoprotein A/B

Cytoplasmic dynein 2 heavy chain 1

T-complex protein 1 subunit gamma

T-complex protein 1 subunit delta (Fragment)

RRP5-like protein

Dynein heavy chain 10, axonemal

Isocitrate dehydrogenase [NADP]

Elongation factor 1-alpha

Myosin heavy chain, non-muscle (Fragment)

Serine/threonine-protein phosphatase $2 \mathrm{~A} 65 \mathrm{kDa}$ regulatory subunit A alpha isoform

Puromycin-sensitive aminopeptidase

Splicing factor $3 B$ subunit 1

Uncharacterized protein 
K1QNW9_CRAGI K1R545_CRAGI K1R6Z7_CRAGI

K1R6Q7_CRAGI

K1ROS3_CRAGI

K1RAJ1_CRAGI

K1PNQ5_CRAGI

K1PVA1_CRAGI

K1QHI6_CRAGI

K1Q7G8_CRAGI

K1R401_CRAGI

K1PND7_CRAGI

K1RGT5_CRAGI

K1PLF9_CRAGI

K1QET2_CRAGI

K1QSB2_CRAGI

K1R9B6_CRAGI

K1R512_CRAGI

K1RK12_CRAGI

K1QQR1_CRAGI

K1R420_CRAGI

K1Q9W5_CRAGI

K1QSX8_CRAGI

K1Q350_CRAGI

K1PJ85_CRAGI

K1Q923_CRAGI

K1PJ06_CRAGI

K1RLC5_CRAGI

K1R278_CRAGI

K1R8L1_CRAGI

K1PEY4_CRAGI

K1RWS2_CRAGI

K1RG73_CRAGI

K1QLK6_CRAGI

K1PXN5_CRAGI

K1P9D0_CRAGI

K1QR72_CRAGI

K1R4Z3_CRAGI

K1Q988_CRAGI

K1QB04_CRAGI

K1QRL4_CRAGI

K1Q1I2_CRAGI

K1QXR4_CRAGI

K1RH70_CRAGI

K1PH66_CRAGI

K1PTY5_CRAGI

K1QI14_CRAGI

K1QBNO_CRAGI

K1QMD3_CRAGI

K1QVN9_CRAGI

K1RN77_CRAGI

K1QSQ9_CRAGI

K1RI55_CRAGI

K1S1S1_CRAGI

K1PH76_CRAGI

K1QWP8_CRAGI

K1R252_CRAGI

K1QEA6_CRAGI

K1RNB5_CRAGI

K1RJH5_CRAGI
Bifunctional aminoacyl-tRNA synthetase

Pre-mRNA-processing-splicing factor 8 (Fragment)

ATP synthase subunit alpha

DNA topoisomerase I

T-complex protein 1 subunit theta

T-complex protein 1 subunit alpha

Heat shock protein HSP 90-alpha 1

Transitional endoplasmic reticulum ATPase

Dynein heavy chain 5, axonemal

Fatty acid synthase

Spectrin alpha chain

Fatty acid synthase

Metalloendopeptidase

Arginine kinase

Coatomer subunit alpha

265 protease regulatory subunit $6 \mathrm{~B}$

H/ACA ribonucleoprotein complex subunit 4

Uncharacterized protein

40 S ribosomal protein S23

Major vault protein

Non-specific serine/threonine protein kinase

T-complex protein 1 subunit eta

ATPase family AAA domain-containing protein $2 B$

Glyceraldehyde-3-phosphate dehydrogenase

265 protease regulatory subunit $6 \mathrm{~A}$

Putative ATP-dependent RNA helicase DDX4

Importin subunit alpha-1

T-complex protein 1 subunit epsilon

Tubulin beta chain

Exportin-2

26S proteasome non-ATPase regulatory subunit 2

Transcriptional activator protein Pur-alpha

Acetyl-CoA carboxylase

E3 ubiquitin-protein ligase HUWE1

T-complex protein 1 subunit zeta

Stress-70 protein, mitochondrial

Dipeptidyl peptidase 3

Malate dehydrogenase, mitochondrial

Band 4.1-like protein 3

$26 \mathrm{~S}$ proteasome non-ATPase regulatory subunit 3

Importin-5

265 protease regulatory subunit 7

Pancreatic lipase-related protein 2

6-phosphogluconate dehydrogenase, decarboxylating

Fibrinolytic enzyme, isozyme $\mathrm{C}$

Protocadherin Fat 4

$40 \mathrm{~S}$ ribosomal protein $\mathrm{S3a}$

Methylcrotonoyl-CoA carboxylase beta chain, mitochondrial

Glycerol-3-phosphate dehydrogenase [NAD(+)]

T-complex protein 1 subunit eta

Nuclear autoantigenic sperm protein

Putative ATP-dependent RNA helicase an3

Insulin-like growth factor 2 mRNA-binding protein 3

Insulin-like growth factor 2 mRNA-binding protein 1

Y-box factor-like protein (Fragment)

Actin-2

Putative methylmalonate-semialdehyde dehydrogenase [acylating], mitochondrial

Phosphoenolpyruvate carboxykinase [GTP]

Propionyl-CoA carboxylase beta chain, mitochondrial

Polyadenylate-binding protein 
K1PLY1_CRAGI K1R5U4_CRAGI K1PF10_CRAGI K1QBR5_CRAGI K1QVS3_CRAGI K1RFT1_CRAGI K1R2V1_CRAGI K1RW85_CRAGI K1QWT8_CRAGI K1PFG1_CRAGI K1QWX2_CRAGI K1R1M7_CRAGI

K1QK11_CRAGI K1RWW5_CRAGI K1RJ97_CRAGI K1RWD4_CRAGI K1R3V0_CRAGI K1QHA2_CRAGI K1REG6_CRAGI K1R4I2_CRAGI K1RTR1_CRAGI K1QGK2_CRAGI K1Q9Z6_CRAGI K1QQL6_CRAGI K1Q330_CRAGI K1QUE6_CRAGI K1QY12_CRAGI K1Q3S7_CRAGI K1RSZ6_CRAGI K1PJF4_CRAGI K1Q9V3_CRAGI K1RBC9_CRAGI K1PPP8_CRAGI K1PX47_CRAGI K1QX26_CRAGI K1PZP6_CRAGI K1QE71_CRAGI K1QBHO_CRAGI K1QCC1_CRAGI K1PJP9_CRAGI K1QIR8_CRAGI K1Q4I9_CRAGI K1RNZ6_CRAGI K1R3V8_CRAGI K1PUL2_CRAGI K1QHX2_CRAGI K1QDN1_CRAGI K1PZF2_CRAGI K1PMT6_CRAGI K1RCW5_CRAGI K1R7I9_CRAGI K1QYB6_CRAGI K1P3Q5_CRAGI K1Q2H5_CRAGI K1QBF7_CRAGI K1PW06_CRAGI K1QHS8_CRAGI K1RL00_CRAGI K1QQ16_CRAGI K1R4R9_CRAGI
DNA polymerase

Acetyl-CoA carboxylase 1

PAN2-PAN3 deadenylation complex catalytic subunit PAN2

Uncharacterized protein

Thimet oligopeptidase

Band 4.1-like protein 3

Importin subunit beta-1

Adenosylhomocysteinase

Uncharacterized protein

Uncharacterized protein

$60 \mathrm{~S}$ acidic ribosomal protein $\mathrm{PO}$

Ubiquitin-like modifier-activating enzyme 1

Dynein heavy chain 7, axonemal

ATP synthase subunit beta

Multifunctional protein ADE2

Actin, cytoplasmic

CAD protein

Spectrin beta chain, brain 4

DNA helicase

26S proteasome non-ATPase regulatory subunit 3

ATP-citrate synthase

Coatomer subunit beta

26S proteasome non-ATPase regulatory subunit 7

Leucyl-tRNA synthetase, cytoplasmic

Dihydrolipoyl dehydrogenase

26S proteasome non-ATPase regulatory subunit 6

Dynamin-1-like protein

Cytosolic carboxypeptidase 1

$40 S$ ribosomal protein $\mathrm{S7}$

Isoleucyl-tRNA synthetase, cytoplasmic

V-type proton ATPase catalytic subunit A

Transketolase-like protein 2

Vigilin

Ubiquitin carboxyl-terminal hydrolase

Endoplasmin

Coatomer subunit gamma

DNA helicase

Uncharacterized protein

Phosphoglycerate kinase

$26 \mathrm{~S}$ proteasome non-ATPase regulatory subunit 1

$78 \mathrm{kDa}$ glucose-regulated protein

D-3-phosphoglycerate dehydrogenase (Fragment)

Eukaryotic translation initiation factor 3 subunit D

COP9 signalosome complex subunit 4

Long-chain-fatty-acid--CoA ligase 1

La-related protein 7

Heat shock protein $75 \mathrm{kDa}$, mitochondrial (Fragment)

Exportin-7

Heterogeneous nuclear ribonucleoprotein U-like protein 1

Eukaryotic translation initiation factor 4 gamma 3

Heterogeneous nuclear ribonucleoprotein $Q$

Delta-1-pyrroline-5-carboxylate synthetase

Programmed cell death 6-interacting protein

Uncharacterized protein

Hypoxia up-regulated protein 1

Filamin-C

Ribonucleoside-diphosphate reductase

Proteasome-associated protein ECM29-like protein

AP complex subunit beta

Mitotic apparatus protein $\mathrm{p} 62$ 
K1QXH3_CRAGI K1P5D4_CRAGI K1RM80_CRAGI K1PVH5_CRAGI

K1QQ27_CRAGI K1QMX8 CRAGI K1QK56_CRAGI K1QMB9_CRAGI K1ROW4_CRAGI K1QLT5_CRAGI K1QSR2_CRAGI K1QKA9_CRAGI K1RJM8_CRAGI K1QQB6_CRAGI K1PE57_CRAGI K1PKK7_CRAGI K1QXS6_CRAGI K1R5F2_CRAGI K1Q4VO_CRAGI K1QA50_CRAGI K1QWK2_CRAGI K1PV49_CRAGI K1QAB1_CRAGI K1RK33_CRAGI K1PCS4_CRAGI K1RSA6_CRAGI K1PI02_CRAGI K1PNP4_CRAGI K1RALO_CRAGI K1QXQ8_CRAGI K1QI28_CRAGI K1Q9K6_CRAGI K1S151_CRAGI K1P2G0_CRAGI K1QI97_CRAGI K1QBW6_CRAGI K1PEPO_CRAGI

K1QG84_CRAGI K1PUM2_CRAGI K1PU26_CRAGI A7M7T7_CRAGI K1PWW9_CRAGI K1QF01_CRAGI K1QZWO_CRAGI K1RAU3_CRAGI K1PVWO_CRAGI K1QBL6_CRAGI K1QE32_CRAGI K1PY73_CRAGI K1S2YO_CRAGI K1QEF2_CRAGI K1PV79_CRAGI K1R083_CRAGI K1QMH2_CRAGI K1QL67_CRAGI K1QDV6_CRAGI K1QU53_CRAGI K1RIZ9_CRAGI K1R2Q9_CRAGI K1Q4E1_CRAGI
Translational activator GCN1

Cysteine synthase

Citrate synthase

Centromere/kinetochore protein $\mathrm{zw} 10$-like protein

Pancreatic lipase-related protein 2

DNA replication licensing factor MCM7

Uncharacterized protein

Eukaryotic translation initiation factor 3 subunit $A$

Signal recognition particle subunit SRP72

265 protease regulatory subunit 4

Apoptosis inhibitor 5

Piwi-like protein 2

SAGA-associated factor 11 homolog

40 S ribosomal protein S14

Severin

AP-2 complex subunit mu-1

Heterogeneous nuclear ribonucleoprotein A2-like protein 1

14-3-3 protein epsilon

Myosin-VIla

V-type proton ATPase subunit $\mathrm{H}$

MAM domain-containing glycosylphosphatidylinositol anchor protein 2

RuvB-like helicase

AP-2 complex subunit alpha

Exportin-1

Eukaryotic translation initiation factor 2 subunit 3, Y-linked

Methylcrotonoyl-CoA carboxylase subunit alpha, mitochondrial

Talin-1

26S proteasome non-ATPase regulatory subunit 11

Aspartate aminotransferase, cytoplasmic

DNA helicase

V-type proton ATPase subunit B

Histone H3

Rab GDP dissociation inhibitor

Strawberry notch-like protein 1

Adenylyl cyclase-associated protein

Tudor domain-containing protein 1

$40 S$ ribosomal protein $\mathrm{S} 8$

THO complex subunit 2

Histone $\mathrm{H} 2 \mathrm{~A}$

Malate dehydrogenase (Fragment)

Non-selenium glutathione peroxidase

265 proteasome non-ATPase regulatory subunit 3

$40 S$ ribosomal protein $\mathrm{S} 4$

Polyadenylate-binding protein 2

DNA ligase

S-adenosylmethionine synthase

Tudor domain-containing protein 1

Very long-chain specific acyl-CoA dehydrogenase, mitochondrial

Basic leucine zipper and W2 domain-containing protein 1

Uncharacterized protein

ADP-ribosylation factor-like protein 15

Importin subunit alpha

Aspartate aminotransferase, mitochondrial

DNA polymerase

$60 \mathrm{~S}$ ribosomal protein $\mathrm{L7a}$

Protein argonaute-2

$\mathrm{NAD}(\mathrm{P})$ transhydrogenase, mitochondrial

Band 4.1-like protein 5

Aspartate aminotransferase

$\mathrm{N}$-acetyl-D-glucosamine kinase 
K1R916_CRAGI K1R2NO_CRAGI K1P7K8_CRAGI K1PJC1_CRAGI K1QVRO_CRAGI K1Q6X5_CRAGI K1QGB4_CRAGI K1QT21_CRAGI K1Q7Q2_CRAGI K1Q6W3_CRAGI K1R4D4_CRAGI K1QH70_CRAGI K1Q880_CRAGI K1PS71_CRAGI K1PAY7_CRAGI K1QPP2_CRAGI K1PX23_CRAGI K1QRG9_CRAGI K1PIB7_CRAGI K1R115_CRAGI K1PF96_CRAGI K1QFN1_CRAGI K1ROD7_CRAGI K1PK93_CRAGI K1R2D6 CRAGI K1Q358_CRAGI K1QMV7_CRAGI K1R953_CRAGI K1PPQ1_CRAGI K1QYV6_CRAGI K1PH31_CRAGI K1RDV7_CRAGI K1PBZ4_CRAGI K1PD57_CRAGI K1PVZ3_CRAGI K1PLA7_CRAGI K1Q1S3_CRAGI K1QY85_CRAGI K1QH74_CRAGI K1RB97_CRAGI K1REC3_CRAGI K1R3T3_CRAGI K1Q9J5_CRAGI K1Q0R4_CRAGI K1QD40_CRAGI K1R5B9 CRAGI K1PD30_CRAGI K1QRW4_CRAGI K1RDG4_CRAGI K1QHY1_CRAGI K1QLS3_CRAGI K1Q5G9_CRAGI K1QED7_CRAGI K1S3Y1_CRAGI K1PGW7_CRAGI K1R7N6_CRAGI K1QRL6_CRAGI K1PN10_CRAGI K1QNT7_CRAGI K1QLZ1_CRAGI
Structural maintenance of chromosomes protein Histone $\mathrm{H} 4$

Vesicle-fusing ATPase 1

Adipophilin

26S proteasome non-ATPase regulatory subunit 8

Protein disulfide-isomerase

40 S ribosomal protein S17

Putative ATP-dependent RNA helicase DDX5

CCAAT/enhancer-binding protein zeta

Talin-1

40 S ribosomal protein SA

Leucine-rich repeat-containing protein 40

Transportin-1

Uncharacterized protein

Propionyl-CoA carboxylase alpha chain, mitochondrial

Elongation factor Tu, mitochondrial

Eukaryotic peptide chain release factor subunit 1

Uncharacterized protein

Phenylalanyl-tRNA synthetase beta chain

Succinate dehydrogenase [ubiquinone] flavoprotein subunit, mitochondrial Spliceosome RNA helicase BAT1

60 S ribosomal protein $\mathrm{L} 23$

Eukaryotic translation initiation factor 3 subunit M (Fragment)

GDP-L-fucose synthetase

Plastin-3

605 acidic ribosomal protein P2

V-type proton ATPase subunit $D$

Acetyl-CoA carboxylase

14-3-3 protein gamma

NMDA receptor-regulated protein 1

Protein arginine $\mathrm{N}$-methyltransferase 1

Cell division control protein 2-like protein (Fragment)

Regulator of nonsense transcripts 1

Constitutive coactivator of PPAR-gamma-like protein 1-like protein

Cold shock domain-containing protein E1

Eukaryotic initiation factor 4A-II (Fragment)

Myosin-VI

Transport protein Sec31A

Splicing factor, arginine/serine-rich 1

Kinetochore-associated protein 1

Exportin-5

Transcription factor BTF3

Importin-4

ATP-binding cassette sub-family $\mathrm{F}$ member 2

Importin-7

DNA-directed RNA polymerase, mitochondrial

Putative histone-binding protein Caf1

Coronin

DNA helicase

Eosinophil peroxidase

Cytochrome b-c1 complex subunit 2, mitochondrial

SUMO-activating enzyme subunit 2

Replication protein A subunit

2-amino-3-ketobutyrate coenzyme A ligase, mitochondrial (Fragment)

Transmembrane protein 2

Eukaryotic translation initiation factor 6

Methenyltetrahydrofolate synthetase domain-containing protein

Intron-binding protein aquarius

Aldehyde dehydrogenase, mitochondrial

Actin-related protein 3 
K1R9T2_CRAGI

K1PS27_CRAGI

K1Q5G6_CRAGI

K1QRM1_CRAGI

K1QGC9_CRAGI

K1RLT4_CRAGI

K1PAR4_CRAGI

K1QVE8_CRAGI

K1Q4Z4_CRAGI

K1P8W6_CRAGI

K1QQK1_CRAGI

K1RIT6_CRAGI

K1R2L7_CRAGI

K1QRQ2 CRAGI

K1RKZ5_CRAGI

K1QC10_CRAGI

K1PGZO_CRAGI

K1QUKO_CRAGI

K1QQP1_CRAGI

K1PM50 CRAGI

K1PJS7_CRAGI

K1QX37_CRAGI

K1QCA7_CRAGI

K10811_CRAGI

K1QRZ3_CRAGI

K1QG70_CRAGI

K1QW36_CRAGI

K1R8S7_CRAGI

K1P9N7_CRAGI

K1PG07_CRAGI

K1QFZ8_CRAGI

K1Q1Q9_CRAGI

K1PX83 CRAGI

K1PCV0_CRAGI

K1QP17_CRAGI

K1PS13_CRAGI

K1Q273_CRAGI

K1PBUO CRAGI

K1QVV5_CRAGI

K1P112_CRAGI

K1QKN4_CRAGI

K1P2B8_CRAGI

K1QC11_CRAGI

K1QPD6_CRAGI

K1QWZO_CRAG

K1QKF8_CRAGI

K1RD83_CRAGI

K1R1F0_CRAGI

K1QMD8_CRAGI

K1Q8SO_CRAGI

K1PI50_CRAGI

K1R8T6 CRAGI

K1P6F0_CRAGI

K1PXG6_CRAGI

K1QG65_CRAGI

K1R5W3_CRAGI

K1QB60_CRAGI

K1R5D5_CRAGI

K1REJ2_CRAGI

K1PLD4_CRAGI
Eukaryotic translation initiation factor 3 subunit B

DNA helicase

$60 \mathrm{kDa}$ heat shock protein, mitochondrial

Nuclear pore protein

Acetyl-coenzyme A synthetase

Signal recognition particle subunit SRP68

Unc-45-like protein A

Phosphoacetylglucosamine mutase

Bifunctional purine biosynthesis protein PURH

$60 S$ ribosomal protein $L 4$

$26 \mathrm{~S}$ proteasome non-ATPase regulatory subunit 12

NADH-ubiquinone oxidoreductase $75 \mathrm{kDa}$ subunit, mitochondrial

Glutaminyl-tRNA synthetase (Fragment)

Glutamate dehydrogenase 1, mitochondrial

DNA damage-binding protein 1

GTP-binding protein 1

Thyroid adenoma-associated protein

NEDD8-activating enzyme E1 catalytic subunit

Programmed cell death protein 4

$40 S$ ribosomal protein S16

Poly [ADP-ribose] polymerase

Enolase

Valyl-tRNA synthetase

Alpha-centractin

$40 \mathrm{~S}$ ribosomal protein $\mathrm{S} 13$

Katanin p60 ATPase-containing subunit A1

60S ribosomal protein $L 6$

Phospholipase A-2-activating protein

14-3-3 protein zeta

Lupus La-like protein

Ceramide kinase-like protein

Alpha-aminoadipic semialdehyde synthase, mitochondrial

Dynein heavy chain 5 , axonemal

Severin

Caprin-1

Coatomer subunit beta (Fragment)

$60 S$ ribosomal protein L14

L-fucose kinase

Periostin

ATP synthase subunit gamma, mitochondrial

Dynein heavy chain 6 , axonemal

GDP-mannose 4,6 dehydratase

AP-1 complex subunit gamma

Ubiquitin conjugation factor E4 B

Tetratricopeptide repeat protein 38

S-(hydroxymethyl)glutathione dehydrogenase

Serine hydroxymethyltransferase

ATP-dependent DNA helicase 2 subunit 1

Proteasome subunit alpha type

Nucleolar complex protein 3 homolog

40 S ribosomal protein S26

Cullin-1

HEAT repeat-containing protein 2

Serine/threonine-protein phosphatase

rRNA 2'-O-methyltransferase fibrillarin

Uncharacterized protein

Uncharacterized protein

U3 small nucleolar RNA-associated protein 6-like protein

Lon protease homolog, mitochondrial

Dynein heavy chain 2, axonemal 
K1QPC6_CRAGI K1PQZ3_CRAGI K1Q6F7_CRAGI K1RPF7_CRAGI K1QHQ6_CRAGI K1PFS5 CRAGI K1PPW8_CRAGI K1QGE4 CRAGI K1QDX9_CRAGI K1Q8K2_CRAGI K1QTW6_CRAGI K1QBW8_CRAGI K1QT97_CRAGI K1QWK6_CRAGI K1QQ93_CRAGI K1PWD9_CRAGI K1R6S5_CRAGI K1QBL3_CRAGI K1RH58_CRAGI K1R5V4_CRAGI K1P8I1_CRAGI K1PA54_CRAGI K1QYI9_CRAGI K1PVV6_CRAGI K1RV41_CRAGI K1PMP3_CRAGI K1PJ96_CRAGI K1RG19_CRAGI K1QIPO_CRAGI K1QXF5_CRAGI K1Q6W5_CRAGI K1QRK9_CRAGI K1R983 CRAGI K1P5V7_CRAGI K1RCW3_CRAGI K1R8R6_CRAGI K1QPY8_CRAGI K1PCQ2_CRAGI K1Q7T5_CRAGI K1PLM3_CRAGI K1RAT9_CRAGI K1QKK5_CRAGI K1QJL6_CRAGI K1QB86_CRAGI K1QN11_CRAGI K1QHHO_CRAGI K1QVP6_CRAGI K1PQI4_CRAGI K1R3I6_CRAGI K1QJF7_CRAGI K1PKF5_CRAGI K1R266_CRAGI K1Q3F9_CRAGI K1QSZ6_CRAGI K1P8B7_CRAGI K1QLK8_CRAGI K1QF31_CRAGI K1RKC1_CRAGI K1PHE1_CRAGI K1Q0L1_CRAGI
Nucleolar complex protein 2-like protein

Armadillo repeat-containing protein 4

V-type proton ATPase subunit C

$60 S$ ribosomal protein $L 5$

Acyl-CoA dehydrogenase family member 9 , mitochondrial

Elongation factor 1-gamma

Coatomer subunit beta

Proteasome endopeptidase complex (Fragment)

Ribosome biogenesis protein BMS1-like protein

Importin subunit alpha

Eukaryotic translation initiation factor 3 subunit $F$

Uncharacterized protein

$N(G), N(G)$-dimethylarginine dimethylaminohydrolase 1

Metalloendopeptidase

Adenosine kinase 1

Uncharacterized protein

$40 S$ ribosomal protein 59

Putative phosphoglycerate mutase

Alpha-actinin, sarcomeric

GTP-binding nuclear protein

Pleckstrin-like protein domain-containing family $\mathrm{F}$ member 2 (Fragment)

Replication factor $\mathrm{C}$ subunit 3

Arginyl-tRNA synthetase, cytoplasmic (Fragment)

Putative aminopeptidase W07G4.4

Guanine nucleotide-binding protein subunit beta-2-like 1

Protoporphyrinogen oxidase

Uncharacterized protein

Protein FAM98A

26S proteasome non-ATPase regulatory subunit 5

Calcyphosin-like protein

FACT complex subunit spt16

Succinyl-CoA ligase [GDP-forming] subunit beta, mitochondrial

Protein transport protein SEC23

Eukaryotic translation initiation factor 3 subunit $C$

Elongation factor 1-beta

Fructose-bisphosphate aldolase

Extracellular superoxide dismutase [Cu-Zn]

E3 ubiquitin-protein ligase UBR4

Protein disulfide-isomerase

Hydroxyacyl-coenzyme A dehydrogenase, mitochondrial

Tubulin-specific chaperone D

Vacuolar protein sorting-associated protein 4B

Microtubule-associated protein RP/EB family member 3

Dynamin-1

Pre-mRNA-processing-splicing factor 8

Protein henna

Developmentally-regulated GTP-binding protein 1

Enolase-phosphatase E1

Nucleolar complex protein 2-like protein (Fragment)

Coronin

Protein-glutamine gamma-glutamyltransferase 4

Retinal dehydrogenase 1

Armadillo repeat-containing protein 8

Uncharacterized protein

Ubiquitin-conjugating enzyme E2-17 kDa (Fragment)

GTP-binding protein SAR1b

Serine/threonine-protein kinase PLK

Far upstream element-binding protein 3

Putative ubiquitin carboxyl-terminal hydrolase FAF-X

60 S ribosomal protein L23a 
K1R008_CRAGI K1QBG8_CRAGI K1R8B2_CRAGI

K1RNN9_CRAGI

K1QYG7_CRAGI

K1PFK8 CRAGI

K1PRD5_CRAGI K1PBH3_CRAGI

K1QVKO_CRAGI

K1PAM6_CRAGI

K1Q948_CRAGI

K1RGG1_CRAGI

K1Q9P5_CRAGI

K1QTE3 CRAGI

K1PZ08_CRAGI

K1RGJ7_CRAGI

K1RK68_CRAGI

K1QEF9_CRAGI

K1RHB2 CRAGI

K1QAF3_CRAGI

K1PB94_CRAGI

K1R488_CRAGI

K1QC65_CRAGI

K1PCR9_CRAGI

K1RFU6 CRAGI

K1R9R5_CRAGI

K1PRQ5_CRAGI

K1Q1L4_CRAGI

K1Q982_CRAGI

K1PKF6_CRAGI

K1QBT2_CRAGI

K1P5Z3_CRAGI

K1P7L9_CRAGI

K1Q9M7_CRAGI

K1PS84_CRAGI

K1R6C2_CRAGI

K1PZCO_CRAGI

K1PMJ9_CRAGI

K1R4M7_CRAGI

K1S3G2_CRAGI

K1PB82_CRAGI

K1PWP4_CRAGI

K1QNS4_CRAGI

K1Q7E4_CRAGI

K1R6F1_CRAGI

K1Q667_CRAGI

K1QWC3_CRAGI

K1RAH6_CRAGI

K1RIM7_CRAGI

K1PXS8_CRAGI

K1RIG6_CRAGI

K1R168_CRAGI

K1R591_CRAGI

K1QKI1_CRAGI

K1RNB6_CRAGI

K1ROY9_CRAGI

K1QE83_CRAGI

K1QFR9_CRAGI

K1RAP8_CRAGI

K1PK49_CRAGI
Proteasome subunit alpha type

Proteasome subunit beta type-4

Isovaleryl-CoA dehydrogenase, mitochondrial

Cytoskeleton-associated protein 5

Glucosamine--fructose-6-phosphate aminotransferase [isomerizing] 1

Uncharacterized protein

Trifunctional purine biosynthetic protein adenosine-3

Dynein heavy chain 3, axonemal

Transaldolase

Uncharacterized protein

Alpha-1,4 glucan phosphorylase

Alanyl-tRNA synthetase, cytoplasmic

Mitochondrial-processing peptidase subunit beta

ATP-binding cassette sub-family F member 1

Ras-related protein Rab-7a

Neogenin

Uncharacterized protein

Protein-glutamine gamma-glutamyltransferase $\mathrm{K}$

Nucleolar RNA helicase 2

Alanine aminotransferase 2

ATP-binding cassette sub-family E member 1

Actin-related protein $2 / 3$ complex subunit

DNA polymerase alpha subunit $B$

Proteasome endopeptidase complex

Proteasome activator complex subunit 3

Proteasome subunit alpha type

Ubiquitin-like modifier-activating enzyme 1

Uncharacterized protein

Malignant fibrous histiocytoma-amplified sequence 1

26S proteasome non-ATPase regulatory subunit 13

Proteasome subunit beta

Lysosomal aspartic protease

Nucleolar GTP-binding protein 1

Histone H1-delta

Alpha-crystallin B chain

Peroxisomal 3,2-trans-enoyl-CoA isomerase

Structural maintenance of chromosomes protein

Cleavage stimulation factor $77 \mathrm{kDa}$ subunit

Serine/threonine protein phosphatase $2 \mathrm{~A}$ regulatory subunit

HMGB1

Electron transfer flavoprotein subunit beta

Phenylalanyl-tRNA synthetase alpha chain

DnaJ-like protein subfamily $\mathrm{C}$ member 9

Ubiquitin-conjugating enzyme E2 N

Proteasome subunit alpha type

tRNA-splicing ligase RtcB homolog

40 S ribosomal protein S3

Ubiquitin-conjugating enzyme E2-17 kDa

Methionine aminopeptidase 2

Calreticulin

LSM14-like protein A

Dynein heavy chain 2 , axonemal

Inter-alpha-trypsin inhibitor heavy chain $\mathrm{H} 4$

Tudor domain-containing protein 1

Alpha-aminoadipic semialdehyde dehydrogenase

ADP,ATP carrier protein

CCR4-NOT transcription complex subunit 1

Spectrin beta chain

Malic enzyme

Myosin-Ic 
K1QAH9_CRAGI K1PYR4_CRAGI K1R8C6_CRAGI K1PY89_CRAGI K1Q662_CRAGI K1Q4G7 CRAGI K1R472_CRAGI K1PS69_CRAGI K1QDU9_CRAGI K1PFU5_CRAGI K1QKG8_CRAGI K1ROP8_CRAGI K1QZX9_CRAGI K1QTD9_CRAGI K1PIP8_CRAGI K1RBF6_CRAGI K1PW99_CRAGI K1PWB9_CRAGI K1PU46_CRAGI K1QYH6_CRAGI K1Q6I1_CRAGI K1PF60_CRAGI K1PQD4_CRAGI K1PSNO_CRAGI K1R834_CRAGI K1RBU9_CRAGI K1QHM2_CRAGI K1QW73_CRAGI K1Q7X3_CRAGI K1PUJ1_CRAGI K1R8I8_CRAGI K1PRL4_CRAGI K1Q0G7_CRAGI K1PBN1_CRAGI K1QJ33_CRAGI A5LGH1_CRAGI K1PUV4_CRAGI K1QJE9_CRAGI K1R005_CRAGI K1RGB7_CRAGI K1PPJ6_CRAGI K1PEW1_CRAGI K1QDH9_CRAGI K1QPJ9_CRAGI K1R9S5_CRAGI K1PTV1_CRAGI K1Q5H6_CRAGI K1RN05_CRAGI K1PDE4_CRAGI K1Q9G3_CRAGI K1R2H9_CRAGI K1PA61_CRAGI K1QQT2_CRAGI K1PJG8_CRAGI K1QJM1_CRAGI K1QK68_CRAGI K1R517_CRAGI K1Q6V6_CRAGI K1Q888_CRAGI K1QQC1_CRAGI
H/ACA ribonucleoprotein complex subunit 26S proteasome non-ATPase regulatory subunit 1 40 S ribosomal protein $\mathrm{S} 12$

Extracellular superoxide dismutase [Cu-Zn]

Actin-interacting protein 1

Tubulin gamma chain

Synaptobrevin-like protein YKT6 Importin-9

3-phosphoinositide-dependent protein kinase 1

Ubiquitin-conjugating enzyme E2 C

Upstream activation factor subunit spp27

CTP synthase

Uncharacterized protein

Nucleolar protein 56

Proteasome subunit beta

Uncharacterized protein yfeX

Protein OSCP1

EH domain-containing protein 1

Lethal(2) giant larvae-like protein 1

COP9 signalosome complex subunit 3

Ubiquitin-conjugating enzyme E2 L3

3-ketoacyl-CoA thiolase, mitochondrial

Phosphoglucomutase-1

Pre-mRNA-processing factor 40 -like protein A

605 ribosomal protein $\mathrm{L} 9$

Non-specific serine/threonine protein kinase

Dolichyl-diphosphooligosaccharide--protein glycosyltransferase subunit 2

Glycoprotein 3-alpha-L-fucosyltransferase A

Pre-mRNA-splicing factor SYF1

Radixin

Acetyltransferase component of pyruvate dehydrogenase complex

60 ribosomal protein L38 (Fragment)

Developmentally-regulated GTP-binding protein 2

Phospholipase

Aminoacyl tRNA synthetase complex-interacting multifunctional protein 2

Voltage-dependent anion channel

40 S ribosomal protein S24

Uncharacterized protein

Filamin-C (Fragment)

Epidermal retinal dehydrogenase 2

Nicotinamide phosphoribosyltransferase

Sorting nexin

Myosin-11

Serine/threonine-protein phosphatase $2 \mathrm{~A} 55 \mathrm{kDa}$ regulatory subunit B

Cytosolic Fe-S cluster assembly factor NUBP2 homolog

Splicing factor 3B subunit 4

FACT complex subunit SSRP1

Transportin-3

Protein arginine $\mathrm{N}$-methyltransferase

Isocitrate dehydrogenase [NAD] subunit, mitochondrial

WD repeat-containing protein 35

Actin-like protein 6A

Uncharacterized protein $\mathrm{y} 4 \mathrm{xO}$

Timeless-like protein

60 S ribosomal protein $\mathrm{L} 30$

Myosin-2 essential light chain

Superkiller viralicidic activity 2-like 2

Replication factor $\mathrm{C}$ subunit 4

Translin

Dynein light chain roadblock 
K1Q1F4_CRAGI K1Q2E0_CRAGI K1Q155_CRAGI

K1R3M4_CRAGI

K1PML4_CRAGI

K1QEK7_CRAGI

K1QDI4_CRAGI

K1Q1Z3_CRAGI

K1Q4X8_CRAGI

K1P5F7_CRAGI

K1R7J6_CRAGI

K1QNY7_CRAGI

K1QKQ5_CRAGI

K1PH10_CRAGI

K1Q329_CRAGI

K1QI08_CRAGI

K1QV87_CRAGI

K1PXD4_CRAGI

K1QCQ5_CRAGI

K1QCL6_CRAGI

K1PFV9_CRAGI

K1PTR3_CRAGI

K1R1T8_CRAGI

K1QUC6_CRAGI

K1QCMO_CRAGI

K1QNZ3_CRAGI

K1QKG9_CRAGI

K1RUWO_CRAGI

K1QPZ1_CRAGI

K1QHTO_CRAGI

K1Q5I4_CRAGI

K1PLW6_CRAGI

K1PWU5_CRAGI

K1P9S7_CRAGI

K1Q260_CRAGI

K1PKL8_CRAGI

K1S1X3_CRAGI

K1Q3F4_CRAGI

K1P7J8_CRAGI

K1QXR6_CRAGI

K1Q4Q8_CRAGI

K1RA63_CRAGI

K1Q8T3_CRAGI

K1QMT1_CRAGI

K1RBZ5_CRAGI

K1PST9_CRAGI

K1QWJ4_CRAGI

K1QYT7_CRAGI

K1R7D7_CRAGI

K1QZI3_CRAGI

K1PNXO_CRAGI

K1Q324_CRAGI

K1QY71_CRAGI

K1QDA7_CRAGI

K1RAU8_CRAGI

K1QRDO_CRAGI

K1Q719_CRAGI

K1RJJ7_CRAGI

K1P8Y3_CRAGI

K1QMY1_CRAGI
60S ribosomal protein L3 (Fragment)

AP-1 complex subunit mu-1

THO complex subunit 1

Ubiquitin-like modifier-activating enzyme 1

Pre-mRNA-processing factor 39

Ubiquitin carboxyl-terminal hydrolase

Superoxide dismutase [Cu-Zn]

Seryl-tRNA synthetase, cytoplasmic

DNA mismatch repair protein Msh2

Metastasis-associated protein MTA1

Putative sodium/potassium-transporting ATPase subunit beta- 2

Transport protein Sec24C

$\mathrm{N}$-terminal acetyltransferase B complex subunit MDM20

Polyadenylate-binding protein-interacting protein 1

Pyruvate dehydrogenase E1 component subunit beta, mitochondrial

Ribose-phosphate pyrophosphokinase 1

Catenin alpha-2

Putative ATP-dependent RNA helicase DDX6

Succinate--CoA ligase [ADP-forming] subunit beta, mitochondrial

Proteasomal ubiquitin receptor ADRM1

4-trimethylaminobutyraldehyde dehydrogenase

Oxysterol-binding protein

Nucleolar protein 56

Uncharacterized protein

Rho GDP-dissociation inhibitor 1

Serine/threonine-protein phosphatase

Cysteine desulfurase, mitochondrial

E3 SUMO-protein ligase RanBP2

Actin-related protein 2/3 complex subunit 3

Deoxyuridine 5'-triphosphate nucleotidohydrolase, mitochondrial

COP9 signalosome complex subunit 2

Bifunctional purine biosynthesis protein PURH

Cytosolic carboxypeptidase 1

Brix domain-containing protein 2

Nucleolar protein 58

Serine/threonine-protein phosphatase $2 \mathrm{~A} 56 \mathrm{kDa}$ regulatory subunit alpha isoform

SWI/SNF-related matrix-associated actin-dependent regulator of chromatin subfamily A member 5

Inorganic pyrophosphatase

6-phosphofructokinase

Protein farnesyltransferase/geranylgeranyltransferase type-1 subunit alpha

Pyruvate dehydrogenase E1 component subunit alpha, somatic form, mitochondrial

Transmembrane protein 2

Importin subunit alpha

DnaJ-like protein subfamily B member 4

Ran GTPase-activating protein 1

Brefeldin A-inhibited guanine nucleotide-exchange protein 1

Splicing factor $3 \mathrm{~B}$ subunit 5

COP9 signalosome complex subunit 7a

Poly(A)-specific ribonuclease PARN

Myosin-le

Methionyl-tRNA synthetase, cytoplasmic

Heterogeneous nuclear ribonucleoprotein $\mathrm{K}$

Histone $\mathrm{H} 2 \mathrm{~B}$

Uracil phosphoribosyltransferase

Eukaryotic translation initiation factor 3 subunit $\mathrm{E}$

Cytoplasmic dynein 1 light intermediate chain 1

Serine/threonine-protein kinase OSR1

Histone $\mathrm{H} 5$

Sulfotransferase $1 \mathrm{C} 4$

Aconitate hydratase, mitochondrial 
K1RBI9_CRAGI K1QEJO_CRAGI K1Q5Z6_CRAGI K1RGS1_CRAGI K1R195_CRAGI K1R8Y1_CRAGI K1RRH1_CRAGI K1PM66_CRAGI K1PKQ3_CRAGI K1QIB2_CRAGI K1PSN4_CRAGI K1PT09_CRAGI K1SOI4_CRAGI K1Q9I1_CRAGI K1R5G4_CRAGI K1R7F6_CRAGI K1QGP1_CRAGI K1Q4S7_CRAGI K1RTQ6_CRAGI K1QN79_CRAGI K1R6E9_CRAGI K1PXU6_CRAGI K1PVAO_CRAGI K1QSZ4_CRAGI K1RNH1_CRAGI K1PIH2_CRAGI K1QG08_CRAGI K1RVR1_CRAGI K1Q9D7_CRAGI K1PDC6_CRAGI K1R1E2_CRAGI K1PCR5_CRAGI K1P8S5_CRAGI K1PCH8_CRAGI K1QY58_CRAGI K1Q947_CRAGI K1Q615_CRAGI K1QC78_CRAGI K1QET6_CRAGI K1PG48_CRAGI K1R9P5_CRAGI K1PGV8_CRAGI K1PRV7_CRAGI K1QIZ7_CRAGI K1Q4U7_CRAGI K1QGL9_CRAGI K1PBL2_CRAGI K1R3A0_CRAGI K1P7Q2_CRAGI K1PNU2_CRAGI K1PWP8_CRAGI K1QV46_CRAGI K1QKQ9_CRAGI K1PR47_CRAGI K1S058_CRAGI K1QEG3_CRAGI K1R481_CRAGI K1QBF3_CRAGI K1PUX5_CRAGI K1QK98_CRAGI
Small nuclear ribonucleoprotein Sm D2

Ras GTPase-activating protein-binding protein 2

Eukaryotic translation initiation factor 2 subunit 2

WD repeat-containing protein 19

Protein DJ-1

Obg-like ATPase 1

Chromodomain-helicase-DNA-binding protein Mi-2-like protein 60 S ribosomal protein $\mathrm{L} 12$

Uncharacterized protein

Mitogen-activated protein kinase

Tetratricopeptide repeat protein $39 \mathrm{C}$

Uncharacterized protein

Methylthioribose-1-phosphate isomerase

TRAF2 and NCK-interacting protein kinase

$60 \mathrm{~S}$ ribosomal protein $\mathrm{L} 31$

Cystathionine gamma-lyase

Replication factor $\mathrm{C}$ subunit 2

Calreticulin

Fructose-bisphosphate aldolase

40 S ribosomal protein $\mathrm{S} 11$

Dihydrolipoamide acetyltransferase component of pyruvate dehydrogenase complex 605 ribosomal protein $\mathrm{L} 24$

Cullin-5

Serine--pyruvate aminotransferase

$60 S$ ribosomal protein L18 (Fragment)

V-type proton ATPase subunit E

Phosphatidylinositol-binding clathrin assembly protein LAP

Telomerase protein component 1

Sorting nexin-2

Proteasome subunit beta

Arp2/3 complex $34 \mathrm{kDa}$ subunit

$\mathrm{KH}$ domain-containing, RNA-binding, signal transduction-associated protein 2

Condensin complex subunit 3

Nucleoporin p54

Eukaryotic translation initiation factor 3 subunit I (Fragment)

Dynein light chain

Peroxiredoxin-1

Ras-related protein Rab-14

Neurobeachin

Dynein-1-beta heavy chain, flagellar inner arm 11 complex

Mitochondrial import receptor subunit TOM70

Nucleoprotein TPR

Profilin

Programmed cell death protein 6

AP-3 complex subunit delta-1

Mannose-1-phosphate guanyltransferase beta

Eukaryotic initiation factor $4 \mathrm{~A}-\mathrm{III}$

Transcription initiation factor IIB

Elongation factor 1-gamma

Histone-arginine methyltransferase CARM1

Echinoderm microtubule-associated protein-like 1

Tetratricopeptide repeat protein 21B

Dynein heavy chain 7, axonemal

Eukaryotic translation initiation factor $2 \mathrm{~A}$

Transcription factor RFX3

Heat shock $70 \mathrm{kDa}$ protein 12B

Epimerase family protein SDR39U1

Trpc4-associated protein

Casein kinase II subunit alpha

IST1-like protein 
K1RDV2_CRAGI K1PDL3_CRAGI K1S2S8_CRAGI

K1QZ11_CRAGI

K1QU47_CRAGI

K1QXF9_CRAGI

K1PL64_CRAGI

K1RQJ6_CRAGI

K1QLP5_CRAGI

K1PJB0_CRAGI

K1Q404_CRAGI

K1QJA7_CRAGI

K1RP91_CRAGI

K1PZD9 CRAGI

K1QI32_CRAGI

K1RK83_CRAGI

K1QQG2_CRAGI

K1PUQ5_CRAGI

K1QW72_CRAGI

K1R2U8 CRAGI

K1PY30_CRAGI

K1Q8C5_CRAGI

K1QNP9_CRAGI

K1PDFO_CRAGI

K1R1R9 CRAGI

K1Q3G8_CRAGI

K1QBH4_CRAGI

K1PEMO_CRAGI

K1QD23_CRAGI

K1RJ96_CRAGI

K1R1B1_CRAGI

K1QCB0_CRAGI

K1RGZ8_CRAGI

K1Q107_CRAGI

K1QYM1_CRAGI

K1QYT5_CRAGI

K1QJT3_CRAGI

K1QAU8_CRAGI

K1RG28 CRAGI

K1R2S4_CRAGI

K1Q4Y8_CRAGI

K1PYQ1_CRAGI

K1RWE5_CRAGI

K1QJL2 CRAGI

K1P6C4_CRAGI

K1PNLO CRAGI

K1QSA2_CRAGI

K1QU30_CRAGI

K1Q317_CRAGI

K1RGE2_CRAGI

K1RIB1_CRAGI

K1ROWO_CRAGI

K1P8T5_CRAGI

K1QQD8_CRAGI

K1QMH5_CRAGI

K1QS22_CRAGI

K1QHP8_CRAGI

K1PXM3_CRAGI

K1QF45_CRAGI

K1QC27_CRAGI
Myotrophin-like protein

Ribosomal protein L19

Signal recognition particle 54 kDa protein

Geranylgeranyl transferase type-2 subunit alpha

Dual oxidase 2

Acyl-protein thioesterase 2

Poly(A) polymerase gamma

Enhancer of mRNA-decapping protein 4

Coatomer subunit delta

Heat shock protein 70 B2

DNA topoisomerase 2

Histone chaperone asf1-B

Putative RNA exonuclease NEF-sp

26S proteasome non-ATPase regulatory subunit 11

Synaptotagmin-like protein 5

Tyrosine-protein kinase BAZ1B

ATP-dependent RNA helicase DHX8

Histone H2B

Catalase

Universal stress protein A-like protein

Septin-2

Putative ATP-dependent RNA helicase DDX47

Putative deoxyribose-phosphate aldolase

Protein disulfide-isomerase $A 6$

Pre-mRNA-processing factor 6

Chaperone activity of bc1 complex-like, mitochondrial

ATP-dependent RNA helicase DDX42

Ubiquitin-like modifier-activating enzyme 5

Acetyl-CoA acetyltransferase $B$, mitochondrial

Sphere organelles protein SPH-1

$35 \mathrm{kDa}$ SR repressor protein

$40 \mathrm{~S}$ ribosomal protein $\mathrm{S} 5$

Wings apart-like protein

Histidine triad nucleotide-binding protein 1

Thymidylate synthase

Phosphate carrier protein, mitochondrial

COP9 signalosome complex subunit 1

Peptidyl-prolyl cis-trans isomerase $\mathrm{E}$

Kinase $C$ and casein kinase substrate in neurons protein 2

NEDD8-activating enzyme E1 regulatory subunit (Fragment)

Histone $\mathrm{H} 100$

Protein phosphatase 1 regulatory subunit 7

Thioredoxin-like protein 1

CCR4-NOT transcription complex subunit 10

Poly [ADP-ribose] polymerase

Microtubule-associated protein futsch

Short-chain specific acyl-CoA dehydrogenase, mitochondrial

MON2-like protein

Serine/threonine-protein kinase SRPK1

Prostaglandin reductase 1

Arginyl-tRNA synthetase, cytoplasmic

Ferritin

Glycerol-3-phosphate dehydrogenase [NAD(+)]

Putative ATP-dependent RNA helicase DDX43

Small nuclear ribonucleoprotein Sm D1

UPF0160 protein MYG1, mitochondrial (Fragment)

Uncharacterized protein

Chromatin assembly factor 1 subunit $A$

Alpha-tocopherol transfer-like protein

Hydroxysteroid dehydrogenase-like protein 2 
Q70MT4_CRAGI K1PQB4_CRAGI K1PZI3_CRAGI K1PNS2_CRAGI K1RG36_CRAGI K1QMQ0_CRAGI K1QD80_CRAGI K1ROM2_CRAGI K1QKI4_CRAGI K1PPH6_CRAGI K1QBE2_CRAGI K1RHP3_CRAGI K1PZU1_CRAGI K1RMW3_CRAGI K1R1Q8_CRAGI K1PPK1_CRAGI K1R8Y9_CRAGI K1QW41_CRAGI K1Q1G2_CRAGI K1RA79_CRAGI K1RZM3_CRAGI K1QD81_CRAGI K1PMY9_CRAGI K1RU04_CRAGI K1QND2 CRAGI K1PR25_CRAGI K1QV25_CRAGI K1RJ70_CRAGI K1R751_CRAGI K1QDKO_CRAGI K1PLV6_CRAGI K1QWN2_CRAGI K1RRP7_CRAGI K1R6H7_CRAGI K1REPO_CRAGI K1ROL4_CRAGI K1ROV5_CRAGI K1R2N1_CRAGI K1PRB6_CRAGI K1QMF1_CRAGI K1R5E7_CRAGI K1PMIO_CRAGI K1QZN3_CRAGI K1SON3_CRAGI K1RDM2_CRAGI K1ROR7_CRAGI K1QWXO_CRAGI K1PQA3_CRAGI K1Q7K0_CRAGI K1R7N8_CRAGI K1QCL7_CRAGI K1QQB3_CRAGI K1RFU8_CRAGI K1PJWO_CRAGI K1RBJ3_CRAGI K1PRV2_CRAGI K1R347_CRAGI K1S422_CRAGI K1QK18_CRAGI K1QJU3_CRAGI
$40 \mathrm{~S}$ ribosomal protein $\mathrm{S} 10$

Acyl-CoA dehydrogenase family member 10 SWI/SNF complex subunit SMARCC2

$33 \mathrm{kDa}$ inner dynein arm light chain, axonemal

Phosphoribosylformylglycinamidine synthase (Fragment)

Putative exonuclease mut-7-like protein

Protein quaking- $B$

Uncharacterized protein

Lysine--tRNA ligase

Kelch domain-containing protein $8 \mathrm{~B}$

Syntaxin-5

Proliferation-associated protein 2G4

Hsc70-interacting protein

Protein kinase $\mathrm{C}$

Ras-related protein Rab-5C

Actin-related protein $2 / 3$ complex subunit 4

Translin-associated protein $\mathrm{X}$

Leucine-zipper-like transcriptional regulator 1

Elongator complex protein 1

E3 ubiquitin-protein ligase HECTD1

Cartilage acidic protein 1

Ubiquitin conjugation factor $\mathrm{E} 4 \mathrm{~A}$

Calmodulin

Actin, cytoplasmic

Septin-2

Regulator of differentiation 1

Transcription elongation factor B polypeptide 2

Cytosolic non-specific dipeptidase

Nuclear pore complex protein Nup88

Engulfment and cell motility protein 2

F-actin-capping protein subunit alpha

Elongation factor 1-delta

Uncharacterized protein

Uncharacterized protein

Uncharacterized protein

Sodium/potassium-transporting ATPase subunit alpha Cell differentiation protein RCD1-like protein

Glutathione reductase

Apolipoprotein D

Isocitrate dehydrogenase [NAD] subunit gamma, mitochondrial

Cathepsin L

Charged multivesicular body protein $4 \mathrm{~b}$

Myosin-Id

Glutamate receptor-interacting protein 1

$60 S$ ribosomal protein L18a

Putative ATP-dependent RNA helicase DHX36

26S proteasome non-ATPase regulatory subunit 14

Pseudouridylate synthase 7-like protein

Putative serine carboxypeptidase CPVL

Proteasome endopeptidase complex

Uncharacterized protein

Glycyl-tRNA synthetase

High mobility group protein DSP1

Talin-1

DnaJ-like protein subfamily $\mathrm{C}$ member 13

Threonine synthase-like 1

Tetratricopeptide repeat protein 38

Katanin p80 WD40 repeat-containing subunit B1

Cytochrome b5

Cell division cycle protein 20-like protein 
K1QRM9_CRAGI K1R373_CRAGI K1RE81 CRAGI

K1QW21_CRAGI

K1PLG1_CRAGI

K1R712_CRAGI

K1Q1K8_CRAGI

K1PNK5_CRAGI

K1Q1F1 CRAGI

K1QFS4_CRAGI

K1PUK3_CRAGI

K1PI41_CRAGI

K1QU96_CRAGI

K1QFK8 CRAGI

K1R4Q3_CRAGI

K1QMS7_CRAGI

K1P8Q1_CRAGI

K1RXV8_CRAGI

K1PXH5 CRAGI

K1QWP1_CRAGI

K1RDF6_CRAGI

K1QYH5 CRAGI

K1S0J9_CRAGI

K1R247_CRAGI

K1QKZ6 CRAGI

K1QQ48_CRAGI

K1RIZ3_CRAGI

K1PVQ8_CRAGI

K1QMQ1_CRAGI

K1QFF0_CRAGI

K1Q435_CRAGI

K1QNZ7 CRAGI

K1QYI6 CRAGI

K1PFV4_CRAGI

K1QVV1_CRAGI

K1RT39_CRAGI

K1PNG7_CRAGI

K1PYK7_CRAGI

K1QCP3_CRAGI

K1QSV4_CRAGI

K1R811 CRAGI

K1R944_CRAGI

K1QS07_CRAGI

K1PZV3_CRAGI

K1QNU0_CRAGI

K1R3R4 CRAGI

K1RJS5_CRAGI

K1RNK8_CRAGI

K1RG79_CRAGI

K1QVF8_CRAGI

K1Q4C3 CRAGI

K1R7T0_CRAGI

K1QX22_CRAGI

K1RIS2_CRAGI

K1Q407_CRAGI

K1R9I0_CRAGI

K1Q0N9_CRAGI

K1PUE8_CRAGI

K1PSY2_CRAGI

K1RA35_CRAGI
Acidic leucine-rich nuclear phosphoprotein 32 family member A

ATP-binding cassette sub-family $\mathrm{F}$ member 3

Transport protein Sec24B

$39 S$ ribosomal protein L40, mitochondrial

Putative ribosomal RNA methyltransferase NOP2

Transforming growth factor-beta receptor-associated protein 1

Elongation factor 1-beta

Ras GTPase-activating-like protein IQGAP1

Serine/threonine-protein kinase 31

Actin-related protein 2

Armadillo repeat-containing protein 6

Flap endonuclease 1

Pre-rRNA-processing protein TSR1-like protein

Target of Myb protein 1

Spectrin beta chain, brain 1

Malonyl CoA-acyl carrier protein transacylase, mitochondrial

Putative methyltransferase TARBP1

PAT1-like protein 1

Putative saccharopine dehydrogenase

Nucleoporin seh1

Long-chain specific acyl-CoA dehydrogenase, mitochondrial

Ubiquitin carboxyl-terminal hydrolase 14

Uncharacterized protein

Condensin complex subunit 1

Inosine-5'-monophosphate dehydrogenase

Serine/threonine-protein kinase N2

Bone morphogenetic protein 7

Eukaryotic translation initiation factor 3 subunit $\mathrm{K}$

TBC1 domain family member 10B

Vacuolar protein sorting-associated protein 35 (Fragment)

Eukaryotic translation initiation factor 2 subunit 1

Ubiquilin-1

Cullin-3-B

Eukaryotic translation initiation factor $4 \mathrm{E}$

Ribose-5-phosphate isomerase

Glutaredoxin-3

Sorting nexin-33

RNA-binding protein 39

Crooked neck-like protein 1

RNA helicase

Ribonucleoside-diphosphate reductase small chain

Tetratricopeptide repeat protein 37

Proteasome subunit beta type-3

Guanine nucleotide-binding protein-like 3-like protein (Fragment)

Non-specific serine/threonine protein kinase

Cytosolic Fe-S cluster assembly factor NUBP1 homolog

Uncharacterized protein

Rho GTPase-activating protein 17

Neuronal acetylcholine receptor subunit alpha-6

Uncharacterized protein in QAH/OAS sulfhydrylase 3'region (Fragment)

Fumarylacetoacetase

GMP synthase [glutamine-hydrolyzing]

4-hydroxyphenylpyruvate dioxygenase

3-oxoacyl-[acyl-carrier-protein] reductase

Ras GTPase-activating protein 1

Myosin-VIIa

Uncharacterized protein

Serine/threonine-protein phosphatase 4 regulatory subunit 3

Fragile $X$ mental retardation syndrome-related protein 1

Splicing factor, arginine/serine-rich 7 
K1QW39_CRAGI Neurobeachin

K1QJI9_CRAGI Importin-13

K1R3M6_CRAGI Ubiquitin-conjugating enzyme E2-22 kDa

K1RCR8_CRAGI Carbonyl reductase [NADPH] 1

K1RJW8_CRAGI Protein DEK

K1R2G9_CRAGI SEC13-like protein

K1PLF8_CRAGI Diacylglycerol kinase

K1PWV7_CRAGI Uncharacterized protein

K1R3W9_CRAGI Replication protein A 14 kDa subunit

K1P8G1_CRAGI Heterogeneous nuclear ribonucleoprotein $\mathrm{H}$

K1R2S2_CRAGI Peptidylprolyl isomerase

K1PNY5_CRAGI Splicing factor, proline-and glutamine-rich

K1P7Q6 CRAGI 40S ribosomal protein S19

K1PZN1_CRAGI Calcium/calmodulin-dependent protein kinase type II delta chain

K1PBCO_CRAGI Non-neuronal cytoplasmic intermediate filament protein

K1QNN9_CRAGI MICOS complex subunit MIC60

K1QJ46_CRAGI Putative methylcrotonoyl-CoA carboxylase beta chain, mitochondrial

K1R2G7_CRAGI Ran-binding protein 3

K1RJG6_CRAGI Heterogeneous nuclear ribonucleoprotein 27C

K1QZ58_CRAGI Splicing factor U2AF 26 kDa subunit

K1QCU0_CRAGI Eukaryotic translation initiation factor 3 subunit $G$

K1PH25_CRAGI Methionyl-tRNA synthetase, cytoplasmic

K1RN97_CRAGI Hemagglutinin/amebocyte aggregation factor

K1Q6M6_CRAGI 6-phosphofructokinase

K1PPL6_CRAGI Malonyl-CoA decarboxylase, mitochondrial

K1R9Q4_CRAGI Uncharacterized protein

K1QPX8_CRAGI Alkyl/aryl-sulfatase BDS1

K1PJP2_CRAGI

K1RRZ9_CRAGI

K1S6R2_CRAGI

K1PJY4_CRAGI

K1Q1G9_CRAGI

K1RA95_CRAGI

K1Q865_CRAGI

K1RFQ4_CRAGI

K1QRD4_CRAGI

K1Q9Z4_CRAGI

K1QB76_CRAGI

K1Q2Y1_CRAGI

K1S3Q9_CRAGI

K1RAF8_CRAGI

K1QE44_CRAGI

K1PN44_CRAGI

K1PWR4_CRAGI

K1QDS1_CRAGI

K1R924_CRAGI

K1QWZ6_CRAGI

K1PSH2_CRAGI

K1QKL1_CRAGI

K1RCY7_CRAGI

K1Q6U7_CRAGI

K1R2E8_CRAGI

K1R4M1_CRAGI

K1RB91_CRAGI

K1Q056_CRAGI

K1REW8_CRAGI

K1QQQ5_CRAGI

K1QLC6_CRAGI

K1QFP5_CRAGI

Putative pre-mRNA-splicing factor ATP-dependent RNA helicase DHX15

MKI67 FHA domain-interacting nucleolar phosphoprotein-like protein

$\mathrm{N}$-acetyltransferase 11

Calcium-binding protein 39

Putative ATP-dependent RNA helicase DHX37

Filamin-A

Trafficking protein particle complex subunit 4

Tetratricopeptide repeat protein 27

S-formylglutathione hydrolase

Aldehyde dehydrogenase

Uncharacterized protein

40 S ribosomal protein S15

MAK16-like protein (Fragment)

Uncharacterized protein

UPF0663 transmembrane protein C17orf28

Casein kinase II subunit beta

Signal recognition particle receptor subunit alpha

3-hydroxyacyl-CoA dehydrogenase type-2

RNA-binding protein 45

Dolichyl-diphosphooligosaccharide--protein glycosyltransferase subunit 1

$28 \mathrm{~S}$ ribosomal protein S12, mitochondrial

DNA-directed RNA polymerases I, II, and III subunit RPABC3

Eukaryotic peptide chain release factor GTP-binding subunit ERF3B

78 kDa glucose-regulated protein

Prolyl endopeptidase

Intraflagellar transport protein 52-like protein

Neutral alpha-glucosidase $A B$

Calpain-A

Ribosomal protein L15

Replication factor $\mathrm{C}$ subunit 5

JmjC domain-containing protein 8

NADH dehydrogenase [ubiquinone] flavoprotein 1, mitochondrial

ATP-dependent DNA helicase II subunit 2 
K1PYW7_CRAGI K1QVD0_CRAGI K1QAT9_CRAGI K1R920_CRAGI K1QQG7_CRAGI K1ROT1_CRAGI K1PD36_CRAGI K1QHI2_CRAGI K1RED7_CRAGI K1QRE1_CRAGI K1QHS9_CRAGI K1R6Y8_CRAGI K1RC37_CRAGI K1PBG6 CRAGI K1R150_CRAGI K1QVSO_CRAGI K1R716_CRAGI K1Q113_CRAGI K1Q151_CRAGI K1QMY8_CRAGI K1PR93_CRAGI K1QZX3_CRAGI K1Q3W3_CRAGI K1RHA5_CRAGI K1RG61_CRAGI K1RSK5_CRAGI K1Q105_CRAGI K1QCS7_CRAGI K1PWRO_CRAGI K1RIAO_CRAGI K1RC43_CRAGI K1S185_CRAGI K1PFL3_CRAGI K1QIU2_CRAGI K1S6H7_CRAGI K1OMM4_CRAGI K1PEX5_CRAGI K1PUM5_CRAGI K1QE49_CRAGI K1QGF1_CRAGI K1P8Z2_CRAGI K1QFN2_CRAGI K1QI48_CRAGI K1PZ93_CRAGI K1QN99_CRAGI K1QXX2_CRAGI K1Q6UO_CRAGI K1P8F1_CRAGI K1RTD6_CRAGI K1RKE5_CRAGI K1QKD6_CRAGI K1QN55_CRAGI K1RGT9_CRAGI K1PZ23_CRAGI K1PCC8_CRAGI K1PKD4_CRAGI K1RXA0_CRAGI K1QAL3_CRAGI K106J3_CRAGI K1S049_CRAGI
CDK5 regulatory subunit-associated protein 3 Small nuclear ribonucleoprotein Sm D3 ATP-dependent RNA helicase DDX1 Eukaryotic translation initiation factor $1 \mathrm{~A}, \mathrm{X}$-chromosomal DNA-directed RNA polymerase subunit V-type proton ATPase subunit $\mathrm{G}$ Ubiquitin Heterogeneous nuclear ribonucleoprotein $\mathrm{L}$ Poly(RC)-binding protein 3 COP9 signalosome complex subunit 6 Tubulin polyglutamylase TTLL13 Uncharacterized protein Uncharacterized protein Uncharacterized protein Ras-related protein Rab-1A Ras-like GTP-binding protein Rho1 Putative isovaleryl-CoA dehydrogenase Ornithine aminotransferase 605 ribosomal protein $\mathrm{L} 32$ Dedicator of cytokinesis protein 9 3-hydroxyisobutyrate dehydrogenase Vacuolar protein sorting-associated protein VTA1-like protein NADH dehydrogenase [ubiquinone] iron-sulfur protein 3, mitochondrial Nucleoside diphosphate kinase Cytosolic carboxypeptidase 2 Kelch-like protein 6 Ferrochelatase Leucine-rich repeat-containing protein $16 \mathrm{~A}$ Protein SET Molybdopterin molybdenumtransferase U4/U6 small nuclear ribonucleoprotein Prp31 Counting factor associated protein D Dihydropteridine reductase Putative tRNA (cytidine(32)/guanosine(34)-2'-0)-methyltransferase Vacuolar protein sorting-associated protein $13 \mathrm{C}$ Leucine zipper transcription factor-like protein 1 Protein hu-li tai shao

Cytoplasmic aconitate hydratase DnaJ-like protein subfamily A member 1 Splicing factor $3 \mathrm{~B}$ subunit 2 Histidyl-tRNA synthetase, cytoplasmic Uncharacterized protein Inositol hexakisphosphate and diphosphoinositol-pentakisphosphate kinase Dihydropyrimidine dehydrogenase [NADP $(+)]$

Regulator of nonsense transcripts 2

Ubiquitin-conjugating enzyme E2 Q2

Coatomer subunit zeta-1

Uncharacterized protein

UDP-glucose:glycoprotein glucosyltransferase 1

IQ and AAA domain-containing protein 1

Uncharacterized protein 605 acidic ribosomal protein $\mathrm{P} 1$ $60 S$ ribosomal protein $\mathrm{L13a}$ DnaJ-like protein subfamily $\mathrm{C}$ member 3 Serine/threonine-protein kinase 25 $40 \mathrm{~S}$ ribosomal protein $\mathrm{S} 30$ cAMP-dependent protein kinase regulatory subunit RNA-binding protein 28 Eukaryotic translation initiation factor 2-alpha kinase 4 Putative RNA-binding protein 16 
K1RBT3_CRAGI K1QFS8_CRAGI K1QVF4_CRAGI K1PGD2_CRAGI K1QUT5_CRAGI K1QAGO CRAGI K1PHS4_CRAGI K1RMSO_CRAGI K1R604 CRAGI K1PQE3_CRAGI K1PXH6_CRAGI K1PM29_CRAGI K1QNK4_CRAGI K1PD41_CRAGI K1PTV5_CRAGI K1PV35_CRAGI K1Q4J3_CRAGI K1RJY3_CRAGI K1QM61_CRAGI K1PKI9_CRAGI K1QPB0_CRAGI K1PF70_CRAGI K1RFF7_CRAGI K1PG60_CRAGI K1Q189_CRAGI K1QBM3_CRAGI K1PNP9_CRAGI K1QIJ3 CRAGI K1QX44_CRAGI K1QLD7_CRAGI K1QUD7_CRAGI K1Q9Z5_CRAGI K1RLTO_CRAGI K1PG98_CRAGI K1QKQ8_CRAGI K1RB07_CRAGI K1PEZ6_CRAGI D7EZH1_CRAGI K1RJ53_CRAGI K1QQH9_CRAGI K1PL63_CRAGI K1PG17_CRAGI K1QQ99_CRAGI K1RG04_CRAGI K1PZP3_CRAGI K1QH68 CRAGI K1S4H5 CRAGI K1R4L8_CRAGI K1RFD2_CRAGI K1PB87_CRAGI K1PM74_CRAGI K1RR99_CRAGI K1QGQ5_CRAGI K1PBB1_CRAGI K1Q681_CRAGI K1PQR9_CRAGI K1QSV1_CRAGI K1QKY7_CRAGI K1QBJ7_CRAGI K1S5H7_CRAGI
ATP-dependent RNA helicase SUV3-like protein, mitochondrial Importin-9

Heterogeneous nuclear ribonucleoprotein L

Putative aminopeptidase NPEPL1

Amine oxidase

Serine-threonine kinase receptor-associated protein

Ribosome-binding protein 1

Translation initiation factor elF-2B subunit beta

DCC-interacting protein 13-alpha

RNA-binding protein Raly

Cullin-4A

Glucose-6-phosphate 1-dehydrogenase

3-oxoacyl-[acyl-carrier-protein] reductase

DNA primase

Programmed cell death protein 10

Kyphoscoliosis peptidase

Nuclear cap-binding protein subunit 1

TRS85-like protein

Uncharacterized protein

Uncharacterized protein

U3 small nucleolar RNA-associated protein 6-like protein

MON2-like protein (Fragment)

Protein lethal(2)essential for life

$60 S$ ribosomal protein $\mathrm{L} 17$

F-box/WD repeat-containing protein 9

Ras-related protein Rab-2

Bullous pemphigoid antigen 1, isoforms $1 / 2 / 3 / 4$

Nuclear pore complex protein Nup85

Ras-related protein Rab-11B

Kinetochore protein NDC80-like protein

Conserved oligomeric Golgi complex subunit 3 (Fragment)

Peptidyl-prolyl cis-trans isomerase

D-erythrulose reductase

rRNA-processing protein FCF1-like protein

THO complex subunit 4-A

$60 S$ ribosomal protein $L 27 a$

Kyphoscoliosis peptidase

Cystatin B-like protein

Tetratricopeptide repeat protein 12

DNA (Cytosine-5)-methyltransferase 1 (Fragment)

TBC1 domain family member 15

$60 S$ ribosomal protein $L 21$

Uncharacterized protein

ALK tyrosine kinase receptor

Conserved oligomeric Golgi complex subunit 2

Syntenin-1

Adenosylhomocysteinase

Electron transfer flavoprotein-ubiquinone oxidoreductase, mitochondrial

Adenylate kinase

Uncharacterized protein

DNA mismatch repair protein Msh6

Rho guanine nucleotide exchange factor 12

Superoxide dismutase

Stress-induced-phosphoprotein 1

Clustered mitochondria protein homolog

Squamous cell carcinoma antigen recognized by T-cells 3

Uncharacterized protein

Uncharacterized protein

Uncharacterized protein

Cell division cycle 5-related protein 
K1RHJ9_CRAGI K1R2Z2 CRAGI K1QHY6_CRAGI

K1Q1L1_CRAGI

K1R3Z4_CRAGI

K1P951_CRAGI

K1PKD7_CRAGI

K1QN54_CRAG

K1QYDO_CRAGI

K1QCY6_CRAGI

K1QZ29_CRAGI

K1R136_CRAGI

K1R969_CRAGI

K1R1E4_CRAGI

K1QVL1_CRAGI

K1QYD8_CRAGI

K1Q927_CRAGI

K1QAU3_CRAG

K1Q8P7_CRAGI

K1QZ64_CRAGI

K1PLR8_CRAGI

K1P752_CRAGI

K1QAY3_CRAGI

K1R669_CRAGI

K1PWS8_CRAGI

K1PK87_CRAGI

K1QKU6_CRAGI

K1QQVO_CRAGI

K1QR54_CRAGI

K1PE13_CRAGI

K1QUW5_CRAGI

K1PTH4_CRAGI

K1Q3C3_CRAGI

K1RE82_CRAGI

K1P486_CRAGI

K1R7A4_CRAGI

K1PEC8_CRAGI

K1RAR8_CRAGI

K1QZD2_CRAGI

K1QM54_CRAGI

K1Q904_CRAGI

K1P6N8_CRAGI

K1RBM7_CRAGI

K1PV92 CRAGI

K1PQU8_CRAGI

K1QUK4 CRAGI

K1QJ85_CRAGI

K1QJW3_CRAGI

K1QNW5_CRAGI

K1QZ84_CRAGI

K1QXH7_CRAGI

K1Q1L9_CRAGI

K1RGD5_CRAGI

K1Q3B4_CRAGI

K1P8Z1_CRAGI

K1PYA2_CRAGI

K1PZR3_CRAGI

K1QB69_CRAGI

K1PI78_CRAGI

K1RKK2_CRAGI
Suppressor of G2 allele of SKP1-like protein

Methyltransferase-like protein 13

Rap1 GTPase-GDP dissociation stimulator 1-A

Kinesin-associated protein 3

5'-3' exoribonuclease 1

Fanconi anemia group D2 protein

6-phosphogluconolactonase

Brain protein 16

UBX domain-containing protein 1

40 S ribosomal protein S28

Uncharacterized protein

Phosphatidylinositol transfer protein alpha isoform

Uncharacterized protein

Serine/threonine-protein kinase Chk2

Serine/threonine-protein phosphatase 4 regulatory subunit 4

Trans-1,2-dihydrobenzene-1,2-diol dehydrogenase

Neurofibromin

WD repeat-containing protein 63

Aspartyl aminopeptidase

Nuclear pore complex protein Nup98-Nup96

Chromosome transmission fidelity protein 18-like protein (Fragment)

UPF0195 protein FAM96B

Dipeptidyl-peptidase 1 (Fragment)

Uncharacterized protein

Mitotic spindle assembly checkpoint protein MAD2A

Putative E3 ubiquitin-protein ligase TRIP12

mRNA export factor

Histone H1.2

Zinc finger RNA-binding protein

Uncharacterized protein

U2 snRNP auxiliary factor large subunit

ADP-ribosylation factor

Lambda-crystallin-like protein

Uncharacterized protein

Heat shock $70 \mathrm{kDa}$ protein $12 \mathrm{~A}$

Peptidylprolyl isomerase

Actin-related protein 8

Protein FAM49B

Tudor domain-containing protein 7

Activator of $90 \mathrm{kDa}$ heat shock protein ATPase-like protein 1

PAN2-PAN3 deadenylation complex subunit PAN3

Ubiquitin carboxyl-terminal hydrolase 7

Ubiquitin-conjugating enzyme E2 variant 1

Hsp90 co-chaperone Cdc37

Sperm-associated antigen 6

Protein SET

Glutathione S-transferase A

Heat shock $70 \mathrm{kDa}$ protein 12B

MAK10-like protein

Thioredoxin domain-containing protein 3-like protein

DNA replication licensing factor $\mathrm{mcm} 4-\mathrm{B}$

Interferon-induced protein 44 -like protein

F-box only protein 36

DNA topoisomerase

Uncharacterized protein

Host cell factor

U2 small nuclear ribonucleoprotein A

Uncharacterized protein

Golgi-specific brefeldin A-resistance guanine nucleotide exchange factor 1

Phosphatidylinositol-4-phosphate 5-kinase type-1 alpha 
K1QLS5_CRAGI K1QFI3_CRAGI K1QKB1_CRAGI K1REU2_CRAGI K1QUK3_CRAGI K1QBT8_CRAGI K1QVX4_CRAGI K1PF20_CRAGI K1RFG1_CRAGI K1PCI8_CRAGI K1QS27_CRAGI K1RFF1_CRAGI K1Q4N9_CRAGI K1QJN8_CRAGI K1PXA0_CRAGI K1QA13_CRAGI K1OXY4_CRAGI K1PBW4_CRAGI K1PUFO_CRAGI K1QMY9_CRAGI K1QZ54_CRAGI K1QWU8_CRAGI K1Q3L1_CRAGI K1PGR2_CRAGI K1RXP9_CRAGI K1PIB2_CRAGI K1R4U3_CRAGI
Uncharacterized protein

Apoptosis-inducing factor 3

Tryptophanyl-tRNA synthetase, cytoplasmic

WD repeat and HMG-box DNA-binding protein 1

Putative ATP-dependent RNA helicase DDX41

Uncharacterized protein

Glycogen synthase kinase- 3 beta

Gamma-tubulin complex component

Lipoxygenase-like protein domain-containing protein 1

Cullin-2

UBX domain-containing protein 6

Uncharacterized protein

Uncharacterized protein

AP-3 complex subunit beta

Uncharacterized protein

Calcium-transporting ATPase

Kinase

Uncharacterized protein

G-protein coupled receptor moody

Uncharacterized protein

Coiled-coil domain-containing protein 39

Uncharacterized protein

Kielin/chordin-like protein

$\mathrm{G}$ patch domain-containing protein 1

Ventricular zone-expressed PH domain-containing-like protein 1

Uncharacterized protein

Uncharacterized protein 
Data S3: Complete list of GO terms of clustered genes of m6A interacting proteins ( $p$-value $<0,05)$

\begin{tabular}{|c|c|c|c|c|}
\hline Cluster & term_ID & description & $\log 10 p$-value & Class \\
\hline cluster1 & GO:0006172 & ADP biosynthetic process & $-2,848$ & Biological process \\
\hline cluster1 & GO:0006886 & intracellular protein transport & $-6,1176$ & Biological process \\
\hline cluster1 & GO:0015031 & protein transport & $-1,6944$ & Biological process \\
\hline cluster1 & GO:0006511 & ubiquitin-dependent protein catabolic process & $-1,8071$ & Biological process \\
\hline cluster1 & GO:0030833 & regulation of actin filament polymerization & $-2,5256$ & Biological process \\
\hline cluster1 & GO:0006563 & L-serine metabolic process & $-2,3716$ & Biological process \\
\hline cluster1 & GO:0006544 & glycine metabolic process & $-2,0706$ & Biological process \\
\hline cluster1 & GO:0016192 & vesicle-mediated transport & $-3,119$ & Biological process \\
\hline cluster1 & GO:0006429 & leucyl-tRNA aminoacylation & $-2,1763$ & Biological process \\
\hline cluster1 & GO:0006413 & translational initiation & $-1,3708$ & Biological process \\
\hline cluster1 & GO:0006122 & mitochondrial electron transport, ubiquinol to cytochrome c & $-1,9328$ & Biological process \\
\hline cluster1 & GO:0048280 & vesicle fusion with Golgi apparatus & $-2,3699$ & Biological process \\
\hline cluster1 & GO:0006888 & ER to Golgi vesicle-mediated transport & $-1,4737$ & Biological process \\
\hline cluster1 & GO:0030117 & membrane coat & $-3,0546$ & Cellular componen \\
\hline cluster1 & GO:0030127 & COPII vesicle coat & $-1,6994$ & Cellular componen \\
\hline cluster1 & GO:0030131 & clathrin adaptor complex & $-1,5595$ & Cellular componen \\
\hline cluster1 & GO:0005737 & cytoplasm & $-2,3551$ & Cellular componen \\
\hline cluster1 & GO:0031105 & septin complex & $-2,0349$ & Cellular componen \\
\hline cluster1 & GO:0005850 & eukaryotic translation initiation factor 2 complex & $-2,6924$ & Cellular componen \\
\hline cluster1 & GO:0005856 & cytoskeleton & $-1,6967$ & Cellular componen \\
\hline cluster1 & GO:0005750 & mitochondrial respiratory chain complex III & $-1,9328$ & Cellular componen \\
\hline cluster1 & GO:0000139 & Golgi membrane & $-1,4267$ & Cellular componen \\
\hline cluster1 & GO:0003743 & translation initiation factor activity & $-2,6564$ & Molecular function \\
\hline cluster1 & GO:0004372 & glycine hydroxymethyltransferase activity & $-2,3716$ & Molecular function \\
\hline cluster1 & GO:0005488 & binding & $-1,66$ & Molecular function \\
\hline cluster1 & GO:0008565 & protein transporter activity & $-2,7964$ & Molecular function \\
\hline cluster1 & GO:0004823 & leucine-tRNA ligase activity & $-2,1763$ & Molecular function \\
\hline cluster1 & GO:0008242 & omega peptidase activity & $-2,0158$ & Molecular function \\
\hline cluster1 & GO:0008536 & Ran GTPase binding & $-1,4396$ & Molecular function \\
\hline cluster1 & GO:0005525 & GTP binding & $-1,9855$ & Molecular function \\
\hline cluster1 & GO:0016813 & hydrolase activity, acting on carbon-nitrogen (but not peptide) bonds, in linear amidines & $-1,9675$ & Molecular function \\
\hline cluster1 & GO:0002161 & aminoacyl-tRNA editing activity & $-1,4387$ & Molecular function \\
\hline cluster1 & GO:0016776 & phosphotransferase activity, phosphate group as acceptor & $-2,0567$ & Molecular function \\
\hline cluster1 & GO:0005543 & phospholipid binding & $-1,3689$ & Molecular function \\
\hline cluster1 & GO:0004017 & adenylate kinase activity & $-2,2504$ & Molecular function \\
\hline cluster1 & GO:0019205 & nucleobase-containing compound kinase activity & $-1,9387$ & Molecular function \\
\hline cluster1 & GO:0019904 & protein domain specific binding & $-1,4245$ & Molecular function \\
\hline cluster1 & GO:0004843 & thiol-dependent ubiquitin-specific protease activity & $-1,6596$ & Molecular function \\
\hline cluster1 & GO:0003779 & actin binding & $-1,33$ & Molecular function \\
\hline cluster 2 & GO:0006376 & mRNA splice site selection & $-2,2802$ & Biological process \\
\hline cluster 2 & GO:0016192 & vesicle-mediated transport & $-1,9467$ & Biological process \\
\hline cluster 2 & GO:0006511 & ubiquitin-dependent protein catabolic process & $-1,895$ & Biological process \\
\hline cluster 2 & GO:0051603 & proteolysis involved in cellular protein catabolic process & $-1,4434$ & Biological process \\
\hline cluster 2 & GO:0006281 & DNA repair & $-1,946$ & Biological process \\
\hline cluster 2 & GO:0006164 & purine nucleotide biosynthetic process & $-1,9132$ & Biological process \\
\hline cluster 2 & GO:0006606 & protein import into nucleus & $-1,6687$ & Biological process \\
\hline cluster 2 & GO:0006367 & transcription initiation from RNA polymerase II promoter & $-1,8729$ & Biological process \\
\hline cluster 2 & GO:0045893 & positive regulation of transcription, DNA-templated & $-1,8902$ & Biological process \\
\hline cluster 2 & GO:0051276 & chromosome organization & $-1,9322$ & Biological process \\
\hline cluster 2 & GO:0005685 & U1 snRNP & $-2,0889$ & Cellular componen \\
\hline cluster 2 & GO:0005694 & chromosome & $-1,6569$ & Cellular componen \\
\hline cluster 2 & GO:0019773 & proteasome core complex, alpha-subunit complex & $-1,7608$ & Cellular componen \\
\hline cluster 2 & GO:0005839 & proteasome core complex & $-1,4434$ & Cellular componen \\
\hline cluster 2 & GO:0005643 & nuclear pore & $-1,5471$ & Cellular componen \\
\hline cluster 2 & GO:0003938 & IMP dehydrogenase activity & $-2,5964$ & Molecular function \\
\hline cluster 2 & GO:0005488 & binding & $-5,6024$ & Molecular function \\
\hline cluster 2 & GO:0008536 & Ran GTPase binding & $-3,3815$ & Molecular function \\
\hline cluster 2 & GO:0008565 & protein transporter activity & $-1,3099$ & Molecular function \\
\hline cluster 2 & GO:0017056 & structural constituent of nuclear pore & $-2,5981$ & Molecular function \\
\hline cluster 2 & GO:0016844 & strictosidine synthase activity & $-2,4472$ & Molecular function \\
\hline cluster 2 & GO:0042578 & phosphoric ester hydrolase activity & $-2,0068$ & Molecular function \\
\hline cluster 2 & GO:0008641 & small protein activating enzyme activity & $-1,8257$ & Molecular function \\
\hline cluster 2 & GO:0003729 & mRNA binding & $-1,9507$ & Molecular function \\
\hline cluster 2 & GO:0000166 & nucleotide binding & $-1,9175$ & Molecular function \\
\hline cluster 2 & GO:0030554 & adenyl nucleotide binding & $-1,4276$ & Molecular function \\
\hline cluster 2 & GO:0004175 & endopeptidase activity & $-1,4434$ & Molecular function \\
\hline cluster 2 & GO:0004298 & threonine-type endopeptidase activity & $-1,4434$ & Molecular function \\
\hline cluster 3 & GO:0006184 & (obsolete) GTP catabolic process & $-1,3497$ & Biological process \\
\hline cluster 3 & GO:0007156 & homophilic cell adhesion via plasma membrane adhesion molecules & $-1,6645$ & Biological process \\
\hline cluster 3 & GO:0008152 & metabolic process & $-1,9382$ & Biological process \\
\hline
\end{tabular}




\begin{tabular}{ll} 
cluster 3 & $\mathrm{GO}: 0015986$ \\
cluster 3 & $\mathrm{GO}: 0006096$ \\
cluster 3 & $\mathrm{GO}: 0051258$ \\
cluster 3 & $\mathrm{GO}: 0044262$ \\
cluster 3 & $\mathrm{GO}: 0006388$ \\
cluster 3 & $\mathrm{GO}: 0006879$ \\
cluster 3 & $\mathrm{GO}: 0007017$ \\
cluster 3 & $\mathrm{GO}: 0006412$ \\
cluster 3 & $\mathrm{GO}: 0006122$ \\
cluster 3 & $\mathrm{GO}: 0000276$ \\
cluster 3 & $\mathrm{GO}: 0005750$ \\
cluster 3 & $\mathrm{GO}: 0045261$ \\
cluster 3 & $\mathrm{GO}: 0005874$ \\
cluster 3 & $\mathrm{GO}: 0005882$ \\
cluster 3 & $\mathrm{GO}: 0043231$ \\
cluster 3 & $\mathrm{GO}: 0005852$ \\
cluster 3 & $\mathrm{GO}: 0005737$ \\
cluster 3 & $\mathrm{GO}: 0005840$ \\
cluster 3 & $\mathrm{GO}: 0043234$ \\
cluster 3 & $\mathrm{GO}: 0004739$ \\
cluster 3 & $\mathrm{GO}: 0016624$ \\
cluster 3 & $\mathrm{GO}: 0005200$ \\
cluster 3 & $\mathrm{GO}: 0005525$ \\
cluster 3 & $\mathrm{GO}: 0015078$ \\
cluster 3 & $\mathrm{GO}: 0046961$ \\
cluster 3 & $\mathrm{GO}: 0046933$ \\
cluster 3 & $\mathrm{GO}: 0004775$ \\
cluster 3 & $\mathrm{GO}: 0046912$ \\
cluster 3 & $\mathrm{GO}: 0016874$ \\
cluster 3 & $\mathrm{GO}: 0048037$ \\
cluster 3 & $\mathrm{GO}: 0008199$ \\
cluster 3 & $\mathrm{GO}: 0005544$ \\
cluster 3 & $\mathrm{GO}: 0003878$ \\
cluster 3 & $\mathrm{GO}: 0003735$ \\
& \\
\hline
\end{tabular}

ATP synthesis coupled proton transport $\quad-4,8627$ glycolytic process $-1,4156$ protein polymerization

cellular carbohydrate metabolic process

$-2,6757$

$-2,0966$

tRNA splicing, via endonucleolytic cleavage and ligation $\quad-1,523$

cellular iron ion homeostasis $\quad-1,4857$ microtubule-based process $-2,4915$ translation $-2,0331$

mitochondrial electron transport, ubiquinol to cytochrome c $\quad-2,0662$ mitochondrial proton-transporting ATP synthase complex, coupling factor $F(0) \quad-4,1068$ mitochondrial respiratory chain complex III $-2,0662$

proton-transporting ATP synthase complex, catalytic core F(1) $\quad-2,0025$ microtubule $-2,2282$ intermediate filament $\quad-1,9067$

intracellular membrane-bounded organelle eukaryotic translation initiation factor 3 complex cytoplasm ribosome protein complex

pyruvate dehydrogenase (acetyl-transferring) activity structural constituent of cytoskeleton

$$
\text { GTP binding }
$$

hydrogen ion transmembrane transporter activity

proton-transporting ATPase activity, rotational mechanism

proton-transporting ATP synthase activity, rotational mechanism succinate-CoA ligase (ADP-forming) activity

transferase activity, transferring acyl groups, acyl groups converted into alkyl on transfer

$$
\begin{aligned}
& \text { ligase activity } \\
& \text { cofactor binding } \\
& \text { ferric iron binding }
\end{aligned}
$$

calcium-dependent phospholipid binding

ATP citrate synthase activity

structural constituent of ribosome
Biological process Biological process Biological process Biological process Biological process Biological process Biological process Biological process Biological process Cellular component Cellular component Cellular component Cellular component Cellular component

Cellular component Cellular component

Cellular component Cellular component Cellular component Molecular function Molecular function

Molecular function Molecular function

Molecular function Molecular function Molecular function Molecular function Molecular function Molecular function Molecular function Molecular function Molecular function Molecular function Molecular function 
Table S1: Transitions used for each compound. A: first transition, B: second transition

\begin{tabular}{|l|l|l|l|l|l|l|}
\hline Nucleoside & $\begin{array}{l}\text { Retention } \\
\text { time }(\mathbf{m i n})\end{array}$ & $\begin{array}{l}\text { MRM } \\
\text { precursor }\end{array}$ & \multicolumn{2}{l|}{$\begin{array}{l}\text { MRM product } \\
(\mathbf{m} / \mathbf{z})\end{array}$} & \multicolumn{2}{l}{$\begin{array}{l}\text { Collision Energy } \\
(\mathbf{V})\end{array}$} \\
\cline { 4 - 8 } & & $(\mathbf{m} / \mathbf{z})$ & A & B & A & B \\
\hline $\mathbf{A}$ & 3.07 & 268.0 & 135.9 & 119.0 & -30 & -12 \\
\hline $\mathbf{m}^{6} \mathbf{A}$ & 2.12 & 282.0 & 150.1 & 123.1 & -17 & -46 \\
\hline
\end{tabular}


Table S2: Correspondence between development stages in our study, and the GigaTON database.

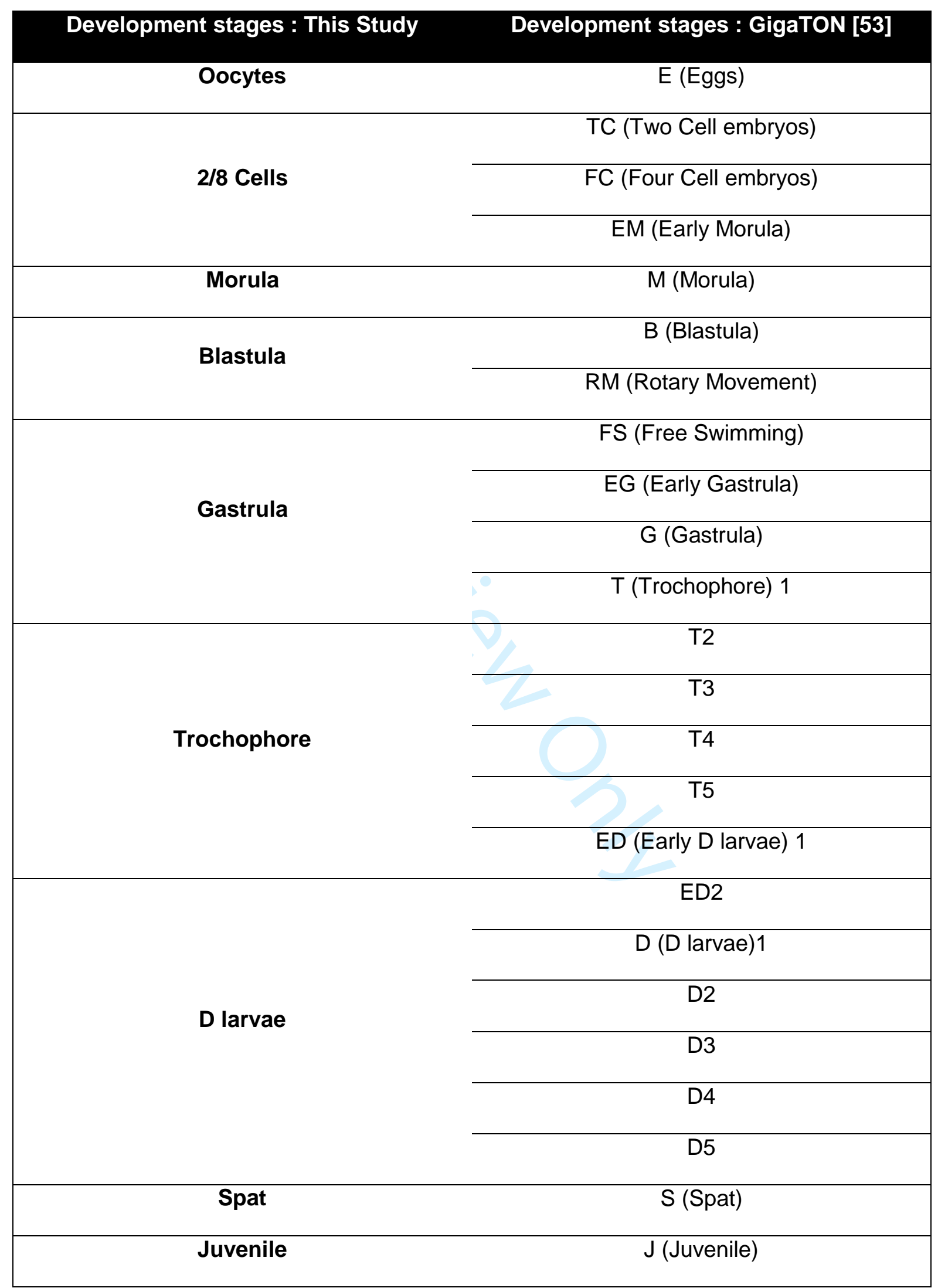

